Florida International University FIU Digital Commons

\title{
On Some Test Statistics for Testing the Population Skewness and Kurtosis: An Empirical Study
}

Yawen Guo

yguo013@fiu.edu

DOI: $10.25148 /$ etd.FIDC001189

Follow this and additional works at: https://digitalcommons.fiu.edu/etd

Part of the Statistical Methodology Commons, and the Statistical Theory Commons

\section{Recommended Citation}

Guo, Yawen, "On Some Test Statistics for Testing the Population Skewness and Kurtosis: An Empirical Study" (2016). FIU Electronic Theses and Dissertations. 3045.

https://digitalcommons.fiu.edu/etd/3045 


\section{FLORIDA INTERNATIONAL UNIVERSITY}

Miami, Florida

ON SOME TEST STATISTICS FOR TESTING THE POPULATION SKEWNESS

AND KURTOSIS: AN EMPIRICAL STUDY

A thesis submitted in partial fulfillment of the

requirements for the degree of

MASTER OF SCIENCE

in

STATISTICS

by

Yawen Guo

2016 
To: Dean Michael R. Heithaus

College of Arts, Sciences and Education

This thesis, written by Yawen Guo, and entitled On Some Test Statistics for Testing the Population Skewness and Kurtosis: An Empirical Study, having been approved in respect to style and intellectual content, is referred to you for judgment.

We have read this thesis and recommend that it be approved.

\section{Wensong $\mathrm{Wu}$}

Florence George

B.M. Golam Kibria, Major Professor

Date of Defense: August 26, 2016

The thesis of Yawen Guo is approved.

Dean Michael R. Heithaus

College of Arts, Sciences and Education

Andrés G. Gil

Vice President for Research and Economic Development and Dean of the University Graduate School

Florida International University, 2016 


\section{ACKNOWLEDGMENTS}

Foremost, I would first like to express my sincere gratitude to my major professor Dr B.M. Golam Kibria, for his encouragement, patient guidance, passionate participation and immense knowledge throughout the whole study. I couldn't finish my thesis without his great support.

Besides my major professor, I would also like to thank the rest of my thesis committee members: Dr Wensong $\mathrm{Wu}$ and Dr Florence George for their continuous encouragement and worthy advice. In addition, the courses throughout this program provide me with useful tools to do researches and I am sure it will be helpful for my future life.

Finally, I must express my very profound gratitude to my family and to my friend for providing me with unfailing support and continuous encouragement throughout my years of study and through the process of writing this thesis. This accomplishment would not have been possible without them. 
ABSTRACT OF THE THESIS

ON SOME TEST STATISTICS FOR TESTING THE POPULATION SKEWNESS

AND KURTOSIS: AN EMPIRICAL STUDY

by

Yawen Guo

Florida International University, 2016

Miami, Florida

Professor B.M. Golam Kibria, Major Professor

The purpose of this thesis is to propose some test statistics for testing the skewness and kurtosis parameters of a distribution, not limited to a normal distribution. Since a theoretical comparison is not possible, a simulation study has been conducted to compare the performance of the test statistics. We have compared both parametric methods (classical method with normality assumption) and non-parametric methods (bootstrap in Bias Corrected Standard Method, Efron's Percentile Method, Hall's Percentile Method and Bias Corrected Percentile Method). Our simulation results for testing the skewness parameter indicate that the power of the tests differs significantly across sample sizes, the choice of alternative hypotheses and methods we chose. For testing the kurtosis parameter, the simulation results suggested that the classical method performs well when the data are from both normal and beta distributions and bootstrap methods are useful for uniform distribution especially when the sample size is large. 


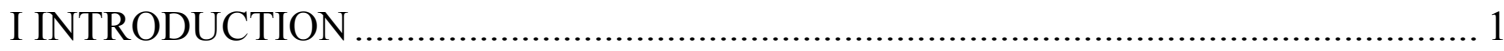

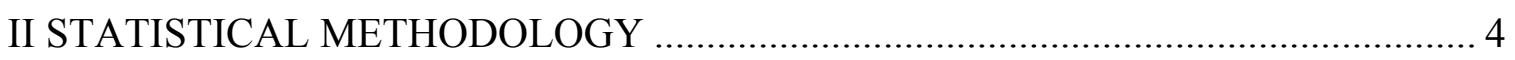

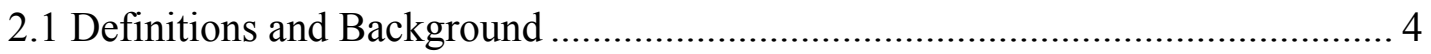

2.2 Testing Skewness (Parametric Approach) …………….................................... 5

2.3 Testing Kurtosis (Parametric Approach) ………................................................ 7

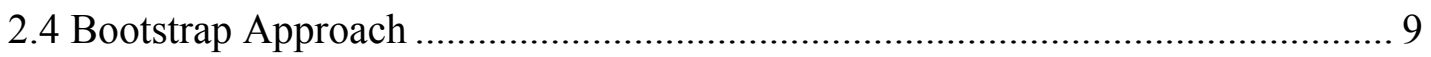

2.4.1 Bias-Corrected Standard Bootstrap Approach.......................................... 10

2.4.2 Efron's Percentile Bootstrap Approach ..................................................... 10

2.4.3 Hall's Percentile Bootstrap Approach ........................................................ 11

2.4.4 Bias-Corrected Percentile Bootstrap Approach ....................................... 12

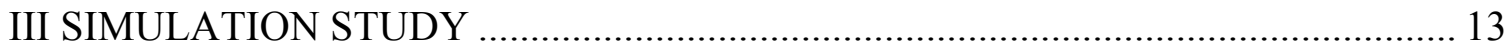

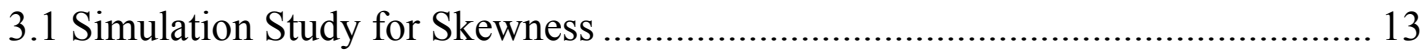

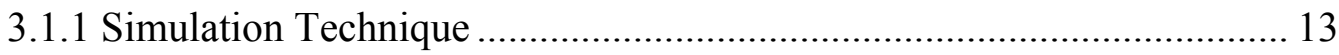

3.1.2 Performance for Normal distribution.................................................... 17

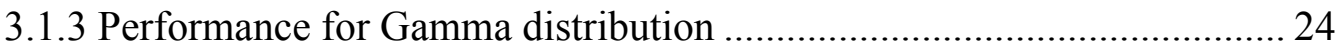

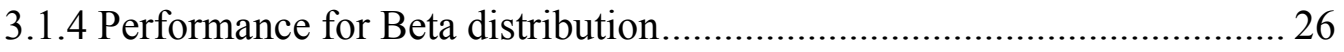

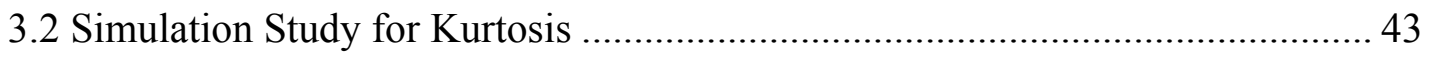

3.2.1 Simulation Technique ....................................................................... 43

3.2.2 Performance for Normal distribution......................................................... 46

3.2.3 Performance for Beta distribution.......................................................... 51

3.2.4 Performance for Uniform distribution ................................................. 57

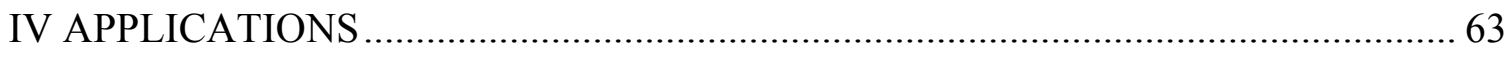

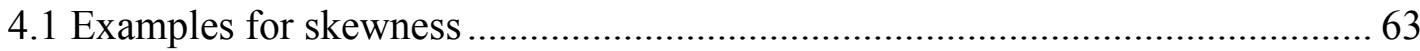

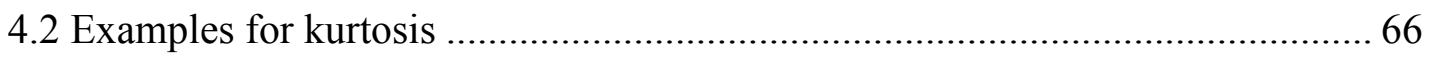

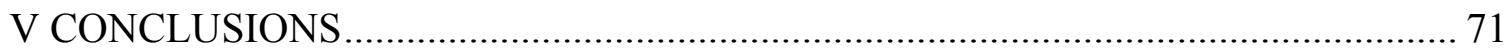

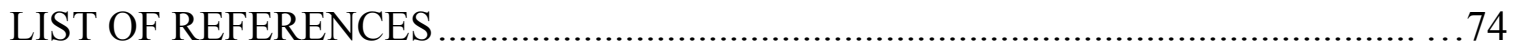

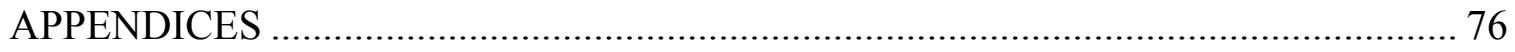




\section{LIST OF FIGURES}

FIGURE

PAGE

3.1.1.1 Probability density function of $\mathrm{N}(0,1)$ distribution............................................. 14

3.1.1.2 Probability density function of Gamma $(4,1)$ distribution.................................. 14

3.1.1.3 Probability density function of Gamma $(7.5,1)$ distribution................................. 15

3.1.1.4 Probability density function of Gamma $(10,1)$ distribution................................ 15

3.1.1.5 Probability density function of Beta $(1,0.35181)$ distribution .............................. 16

3.1.1.6 Probability density function of Beta $(1,0.15470)$ distribution ............................ 16

3.1.1 Empirical size of testing skewness $=0$ with different methods and sample size ...... 18

3.1.2 Power of testing skewness of $\mathrm{N}(0,1)$ in different methods when $\mathrm{n}=10 \ldots \ldots \ldots \ldots \ldots . . .19$

3.1.3 Power of testing skewness of $\mathrm{N}(0,1)$ in different methods when $\mathrm{n}=20 \ldots \ldots \ldots \ldots \ldots . . .19$

3.1.4 Power of testing skewness of $\mathrm{N}(0,1)$ in different methods when $\mathrm{n}=30 \ldots \ldots \ldots \ldots \ldots . .20$

3.1.5 Power of testing skewness of $\mathrm{N}(0,1)$ in different methods when $\mathrm{n}=50 \ldots \ldots \ldots \ldots \ldots . .20$

3.1.6 Power of testing skewness of $\mathrm{N}(0,1)$ in different methods when $\mathrm{n}=100 \ldots \ldots \ldots \ldots \ldots . .21$

3.1.7 Power of testing skewness of $\mathrm{N}(0,1)$ in different methods when $\mathrm{n}=300 \ldots \ldots \ldots \ldots . . .22$

3.1.8 Power of testing skewness of $\mathrm{N}(0,1)$ in different sample size with Classical

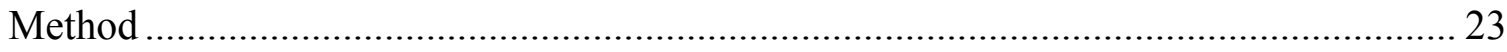

3.1.9 Power of testing skewness of $\mathrm{N}(0,1)$ in different sample size with Efron's

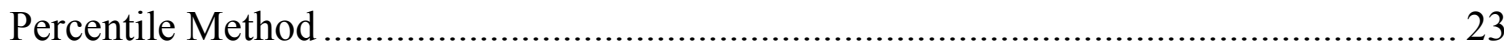

3.1.10 Empirical size of testing Gamma $(4,1)$ skewness $=1$ with different methods and

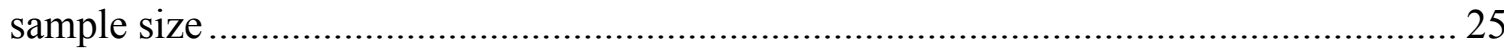


3.1.11 Empirical size of testing Gamma $(10,1)$ skewness $=0.63$ with different methods and sample size

3.1.12 Power of testing skewness of Gamma $(10,1)$ in different sample size with Classical Method. 26

3.1.13 Empirical size of testing skewness $=-1$ with different methods and sample size $\ldots 28$

3.1.14 Power of testing skewness of Beta $(1,0.35181)$ in different methods when $n=10$

3.1.15 Power of testing skewness of Beta $(1,0.35181)$ in different methods when $n=20$

3.1.16 Power of testing skewness of Beta $(1,0.35181)$ in different methods when $n=30$

3.1.17 Power of testing skewness of Beta $(1,0.35181)$ in different methods when $n=50$

3.1.18 Power of testing skewness of Beta $(1,0.35181)$ in different methods when

3.1.19 Power of testing skewness of Beta $(1,0.35181)$ in different methods when $\mathrm{n}=300$

3.1.20 Power of testing skewness of Beta $(1,0.35181)$ in different sample size with Classical Method.

3.1.21 Power of testing skewness of Beta $(1,0.35181)$ in different sample size with Bias Corrected Standard Method

3.1.22 Power of testing skewness of Beta $(1,0.35181)$ in different sample size with

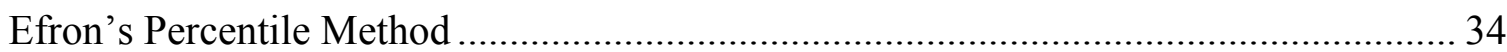

3.1.23 Power of testing skewness of Beta $(1,0.35181)$ in different sample size with Hall's Percentile Method 35

3.1.24 Power of testing skewness of Beta $(1,0.35181)$ in different sample size with Bias Corrected Percentile Method.... 
3.1.25 Empirical size of testing skewness $=-2$ with different methods and sample size $\ldots 37$

3.1.26 Power of testing skewness of Beta $(1,0.15470)$ in different methods when $n=10$

3.1.27 Power of testing skewness of Beta $(1,0.15470)$ in different methods when $n=20$

3.1.28 Power of testing skewness of Beta $(1,0.15470)$ in different methods when $n=30$

3.1.29 Power of testing skewness of Beta $(1,0.15470)$ in different methods when $n=50$

3.1.30 Power of testing skewness of Beta $(1,0.15470)$ in different methods when $\mathrm{n}=100$

3.1.31 Power of testing skewness of Beta $(1,0.15470)$ in different methods when $\mathrm{n}=300$.

3.1.32 Power of testing skewness of Beta $(1,0.15470)$ in different sample size with Efron's Percentile Method

3.1.33 Power of testing skewness of Beta $(1,0.15470)$ in different sample size with Bias Corrected Standard Method

3.1.34 Power of testing skewness of Beta $(1,0.15470)$ in different sample size with Hall's Percentile Method

3.1.35 Power of testing skewness of Beta $(1,0.15470)$ in different sample size with Bias Corrected Percentile Method.

3.2.1.1 Probability density function of $\mathrm{N}(0,1)$ distribution.

3.2.1.2 Probability density function of $\mathrm{N}(0,1)$ distribution. 45

3.2.1.3 Probability density function of $\mathrm{N}(0,1)$ distribution. 45

3.2.1 Empirical size of testing kurtosis $=0$ with different methods and sample size 46 
3.2.2 Power of testing kurtosis of $\mathrm{N}(0,1)$ in different methods when $\mathrm{n}=10$ 47

3.2.3 Power of testing kurtosis of $\mathrm{N}(0,1)$ in different methods when $\mathrm{n}=20$ 48

3.2.4 Power of testing kurtosis of $\mathrm{N}(0,1)$ in different methods when $\mathrm{n}=30$ 48

3.2.5 Power of testing kurtosis of $\mathrm{N}(0,1)$ in different methods when $\mathrm{n}=50$ 49

3.2.6 Power of testing kurtosis of $\mathrm{N}(0,1)$ in different methods when $\mathrm{n}=100$ 50

3.2.7 Power of testing kurtosis of $\mathrm{N}(0,1)$ in different methods when $\mathrm{n}=300$ 50

3.2.8 Power of testing kurtosis of $\mathrm{N}(0,1)$ in different sample size with Classical Method 51

3.2.9 Empirical size of testing kurtosis $=-0.12$ with different methods and sample size... 52

3.2.10 Power of testing kurtosis of Beta $(2,5)$ in different methods when $n=10 \ldots \ldots \ldots \ldots . .53$

3.2.11 Power of testing kurtosis of Beta $(2,5)$ in different methods when $n=20 \ldots \ldots \ldots \ldots . .53$

3.2.12 Power of testing kurtosis of Beta $(2,5)$ in different methods when $n=30$........... 54

3.2.13 Power of testing kurtosis of Beta $(2,5)$ in different methods when $n=50 \ldots \ldots \ldots \ldots . . .55$

3.2.14 Power of testing kurtosis of Beta $(2,5)$ in different methods when $n=100$ …..... 55

3.2.15 Power of testing kurtosis of Beta $(2,5)$ in different methods when $n=300$ …..... 56

3.2.16 Power of testing kurtosis of Beta $(2,5)$ in different sample size with Classical Method 57

3.2.17 Empirical size of testing kurtosis=-1.2 with different methods and sample size... 58

3.2.18 Power of testing kurtosis of Uniform $(0,1)$ in different methods when $n=10 \ldots \ldots .59$

3.2.19 Power of testing kurtosis of Uniform $(0,1)$ in different methods when $n=20 \ldots \ldots .60$

3.2.20 Power of testing kurtosis of Uniform $(0,1)$ in different methods when $n=30 \ldots \ldots . .61$ 
3.2.21 Power of testing kurtosis of Uniform $(0,1)$ in different methods when $n=50 \ldots \ldots .61$

3.2.22 Power of testing kurtosis of Uniform $(0,1)$ in different methods when $n=100 \ldots . .61$

3.2.23 Power of testing kurtosis of Uniform $(0,1)$ in different methods when $n=300 \ldots . .62$

3.2.24 Power of testing kurtosis of Uniform $(0,1)$ in different sample size with Bias

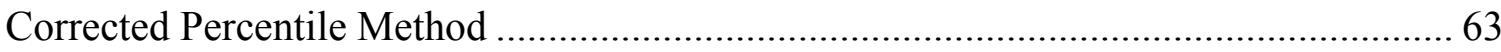

4.1.1 Normal Q-Q plot for SIDS data in Example 1 …………………............................. 64

4.1.2 Normal Q-Q plot for number of death data in Example 2 …………..................... 66

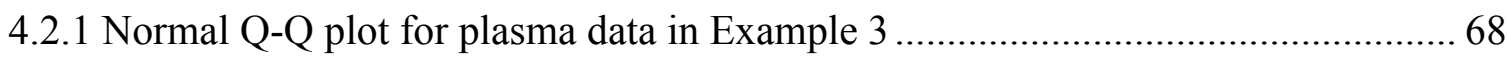

4.2.2 Normal Q-Q plot for cholesterol data in Example 4............................................ 70 


\section{CHAPTER I INTRODUCTION}

Shape parameters are useful in testing normality and robustness studies and widely used by researchers in many disciplines. Joanes and Gill (1998) suggested that skewness and kurtosis are popular as shape parameters and they could easily be estimated by using higher moments. Skewness is a measure of the symmetry of a distribution, and it could be either positive or negative. When the coefficient of skewness is equal to zero, it means that the distribution is symmetric. If the coefficient is positive, the tail on the right side is longer than the left side, and if the coefficient is negative, the tail on the left side is longer than the right side (Groeneveld and Meeden, 1984).

Kurtosis is another important estimator of the shape parameter, which is measuring the tailedness of a probability distribution. Balanda and MacGillivray (1988) concluded that kurtosis could be vaguely viewed as a location-free and scale-free movement of the probability from the tails to its center. It is the same as skewness that the main objective is to work as a descriptor of the shape, but it uses different ways to quantify and corresponding ways to estimate. In this thesis, we are using the standard measure of kurtosis, which is defined by Karl Pearson (1895), who uses the $4^{\text {th }}$ moment of the sample or population dataset to measure the heavy tails. It also should be mentioned that there is another version of Pearson's kurtosis, named excess kurtosis, which is the kurtosis value minus 3 . This version could be used to compare with a normal distribution. 
Perez-Meloand and Kibria (2016) considers several confidence intervals and proposed some bootstrap version of the existing interval estimators for estimating the skewness parameter of a distribution and compared them using a simulation study for a large sample size. In addition Ankarali (2009) mentioned that the distribution shape of the variable plays an important role in selecting appropriate test statistics among all criteria, in particular in small samples with a normal distribution. Another interesting result obtained from them is that skewness coefficient follows a normal distribution and the kurtosis coefficient follows a skewed distribution.

Since there are several studies that already have compared the confidence interval of the skewness and kurtosis parameters, the literature on the hypothesis testing of skewness and kurtosis parameters are limited. In this thesis, we will focus on hypothesis testing of skewness and kurtosis parameters and compare them in the sense of nominal size and empirical power of the test.

The comparison will be made on the basis of following characteristics:

- $\quad$ Different sample sizes

- $\quad$ Different proposed test statistics

- $\quad$ Different methods including parametric and non-parametric

The organization of the thesis is as follows. In Chapter II we review the previously proposed estimators and formulate the hypothesis testing for both a single parametric method and several non-parametric methods and their relative confidence interval. A 
simulation study on the nominal size and power of the tests of skewness and kurtosis are discussed in Chapter III. As an illustration, some examples for skewness and kurtosis have been considered in Chapter IV. Some concluding remarks are presented in Chapter V. 


\section{CHAPTER II \\ STATISTICAL METHODOLOGY}

In this chapter, we consider some parametric and non-parametric test statistics for testing the population skewness and kurtosis.

\subsection{Definitions and Background}

Skewness and kurtosis are viewed as major shape parameters for a probability distribution. The skewness of a random variable $\mathrm{X}$ is the moment coefficient of skewness. In probability theory and statistics, skewness is a measure of symmetry or asymmetry of the probability distribution. It could be represented by the third central moment and standard deviation as follows,

$$
\gamma_{1}=\frac{\mu_{3}}{\sigma^{3}}=E\left[\left(\frac{X-\mu}{\sigma}\right)^{3}\right]=\frac{E\left[(X-\mu)^{3}\right]}{\left(E\left[(X-\mu)^{2}\right]\right)^{\frac{3}{2}}},
$$

which $\gamma_{1}$ is the population skewness parameter, $\mu_{3}$ is the third central moment of the mean, $\mu$ is the mean, $\sigma$ is the standard deviation and $E$ is the expectation operator.

Kurtosis is a measure that considers the "tailedness" of a given probability distribution. The standard measure of kurtosis, originating by Karl Pearson, is similar to skewness which also employs the moment procedure, in this case the fourth moment of the data or population are used instead of the third moment as follows:

$$
\gamma_{2}=\frac{\mu_{4}}{\sigma^{4}}=E\left[\left(\frac{X-\mu}{\sigma}\right)^{4}\right]=\frac{E\left[(X-\mu)^{4}\right]}{\left(E\left[(X-\mu)^{2}\right]\right)^{2}},
$$

where $\gamma_{2}$ is the parameter of kurtosis for population, $\mu_{4}$ is the fourth central moment of the mean, $\mu$ is the mean, $\sigma$ is the standard deviation and $E$ is the expectation operator. 
However for different definitions of skewness and kurtosis, we have different ways to evaluate the performance. Let $X_{1}, X_{2}, \ldots, X_{n}$ be a iid random sample from a population with mean $\mu$ and standard deviation $\sigma$. The traditional definition of skewness and excess kurtosis, proposed by Cramer (1946), are defined respectively as follows:

$$
g_{1}=m_{3} / m_{2}^{3 / 2}
$$

and

$$
g_{2}=m_{4} / m_{2}^{2}-3,
$$

where the sample moments for variable $\mathrm{X}$ are defined as,

$$
m_{r}=\frac{1}{n} \sum\left(x_{i}-\bar{x}\right)^{r} .
$$

\subsection{Testing Skewness (Parametric Approach)}

Let $X_{1}, X_{2}, \ldots, X_{n}$ be a iid random sample from a population with mean $\mu$ and standard deviation $\sigma$. Following the work by Joanes and Gill (1998), the three most commonly used parametric estimators for skewness from traditional measures, which has been developed by SAS and MINITAB are provided below:

$$
\begin{aligned}
g_{1}=\frac{m_{3}}{m_{2}{ }^{3 / 2}}=\frac{\frac{1}{n} \sum_{i=1}^{n}\left(x_{i}-\bar{x}\right)^{3}}{\left[\frac{1}{n} \sum_{i=1}^{n}\left(x_{i}-\bar{x}\right)^{2}\right]^{3 / 2}} & =\frac{\frac{1}{n} \sum_{i=1}^{n}\left(x_{i}-\bar{x}\right)^{3}}{\left[\frac{1}{n} *(n-1) * s^{2}\right]^{3 / 2}}=\left(\frac{n}{n-1}\right)^{3 / 2} * \frac{1}{n} * \frac{\sum_{i=1}^{n}\left(x_{i}-\bar{x}\right)^{3}}{s^{3}}, \\
G_{1} & =\frac{\sqrt{n(n-1)}}{n-2} g_{1}, \\
b_{1} & =\left(\frac{n-1}{n}\right)^{3 / 2} g_{1} .
\end{aligned}
$$

It should be mentioned that for large sample sizes, the results do not make a huge differences, but for small sample sizes, the results among those three methods of 
estimators are sometimes significant at 0.05 level. Following Perez-Meloand and Kibria (2016), where they constructed confidence interval estimators for the skewness parameter of normal, right skewed and left skewed populations; we develop some test statistics for testing population skewness and kurtosis. Theoretically, one will reject the null hypothesis if the hypothesized parameter value in not included in the confidence interval.

For normal distribution, Fisher (1930) stated that $E\left(g_{1}\right)=0$ which is unbiased, and we could easily find that $E\left(G_{1}\right)=\frac{\sqrt{n(n-1)}}{n-2} E\left(g_{1}\right)=0$ and $E\left(b_{1}\right)=\left(\frac{n-1}{n}\right)^{\frac{3}{2}} E\left(g_{1}\right)=0$.

In this thesis, we perform a Z-test to make conclusions about the null hypothesis. As given by Cramer (1946), in normal samples the variance of the Fisher-Pearson coefficient of skewness $\left(g_{1}\right)$ is

$$
\operatorname{var}\left(g_{1}\right)=\frac{6(n-2)}{(n+1)(n+3)} .
$$

Then the variance of $G_{1}$ and $b_{1}$ are obtained as follows:

$$
\begin{gathered}
\operatorname{Var}\left(G_{1}\right)=\frac{n(n-1)}{(n-2)^{2}} \operatorname{Var}\left(g_{1}\right)=\frac{6 n(n-1)(n-2)}{(n+1)(n+3)(n-2)^{2}} \\
\operatorname{Var}\left(b_{1}\right)=\left(\frac{n-1}{n}\right)^{3} \operatorname{Var}\left(g_{1}\right)=\left(\frac{n-1}{n}\right)^{3} \frac{6(n-2)}{(n+1)(n+3)} .
\end{gathered}
$$

Following Joanes and Gill (1998) and Perez-Meloand and Kibria (2016), we attempt to develop Z-test statistic for testing the population skewness parameter. That means, we will test the following null and alternative hypothesis,

$$
\begin{aligned}
& H_{0}: \gamma_{1}=\gamma_{s} \\
& H_{0}: \gamma_{1} \neq \gamma_{s},
\end{aligned}
$$


and the test statistic using the three estimators $\left(g_{1}, G_{1}\right.$, and $\left.b_{1}\right)$ can be defined respectively as follows:

$$
\begin{gathered}
Z_{g 1}=\frac{g_{1}-\gamma_{s}}{\sqrt{\frac{6(n-2)}{(n+1)(n+3)}},} \\
Z_{G 1}=\frac{G_{1}-\gamma_{s}}{\sqrt{\frac{6(n-1)}{(n+1)(n+3)(n-2)}}}, \\
Z_{b 1}=\frac{b_{1}-\gamma_{s}}{\sqrt{\frac{6(n-2)}{(n+1)(n+3)}}\left(\frac{n-1}{n}\right)^{\frac{3}{2}}},
\end{gathered}
$$

where $g_{1}, G_{1}, b_{1}$ are previously defined in equation (2.4), $\mathrm{n}$ is the sample size, $\gamma_{s}$ is hypothesized value of skewness parameter. We will reject $H_{0}$ at $\alpha$ level of significance

if the test statistics $\left(Z_{g_{1}}, Z_{G_{1}}, Z_{b_{1}}\right)$ are greater than $Z_{\alpha / 2}$, where $Z_{\alpha / 2}$ is the upper $\frac{\alpha}{2}$ percentile of the standard normal distribution.

\subsection{Testing Kurtosis (Parametric Approach)}

As we introduced kurtosis in equation 2.2 and excess kurtosis is the kurtosis minus 3 , only one parameter will be discussed in this thesis and the parameter we are using is designed by excess kurtosis. For further discussion, we will refer excess kurtosis to kurtosis by itself. Let $X_{1}, X_{2}, \ldots, X_{n}$ be a iid random sample from a population with mean $\mu$ and standard deviation $\sigma$. On the basis of work by Joanes and Gill (1998), there are also three most commonly used parametric estimators for kurtosis: traditional measures, SAS and MINITAB, which are provided below. 


$$
\begin{gathered}
g_{2}=\frac{m_{4}}{m_{2}{ }^{2}}-3=\frac{\frac{1}{n} \sum_{i=1}^{n}\left(x_{i}-\bar{x}\right)^{4}}{\left[\frac{1}{n} \sum_{i=1}^{n}\left(x_{i}-\bar{x}\right)^{2}\right]^{2}}-3, \\
G_{2}=\frac{n-1}{(n-2)(n-3)}\left\{(n+1) g_{2}+6\right\}, \\
b_{2}=\left(\frac{n-1}{n}\right)^{2}\left(g_{2}+3\right)-3 .
\end{gathered}
$$

For normal distribution, Fisher (1930) stated that only $G_{2}$ is unbiased thus $E\left(G_{2}\right)=0$ while the other two estimators are biased, $E\left(g_{2}\right)=-\frac{6}{n+1}$ and $E\left(b_{2}\right)=$ $3 \frac{(n-1)^{3}}{n^{2}(n+1)}-3 \approx \frac{-12}{n+1}$.

As given by Cramer (1946), for normal population the variance of the kurtosis $\left(g_{2}\right)$ is

$$
\operatorname{var}\left(g_{2}\right)=\frac{24 n(n-2)(n-3)}{(n+1)^{2}(n+3)(n+5)}
$$

Then the variance of $G_{2}$ and $b_{2}$ are obtained below,

$$
\begin{gathered}
\operatorname{Var}\left(G_{2}\right)=\frac{(n-1)^{2}(n+1)^{2}}{(n-2)^{2}(n-3)^{2}} \operatorname{Var}\left(g_{2}\right)=\frac{24 n(n-1)^{2}}{(n-2)(n-3)(n+3)(n+5)} \\
\approx\left(1+\frac{10}{n}\right) \frac{24 n(n-2)(n-3)}{(n+1)^{2}(n+3)(n+5)} \\
\operatorname{Var}\left(b_{2}\right)=\left(\frac{n-1}{n}\right)^{4} \operatorname{Var}\left(g_{2}\right)=\left(\frac{n-1}{n}\right)^{4} \frac{24 n(n-2)(n-3)}{(n+1)^{2}(n+3)(n+5)} \approx\left(1-\frac{4}{n}\right) \frac{24 n(n-2)(n-3)}{(n+1)^{2}(n+3)(n+5)}
\end{gathered}
$$

Similar to skewness, the null and alternative hypothesis for testing the kurtosis parameter are generated as follows:

$$
\begin{aligned}
& H_{0}: \gamma_{2}=\gamma_{k} \\
& H_{0}: \gamma_{2} \neq \gamma_{k},
\end{aligned}
$$

and the test statistics based on the three estimators $\left(g_{2}, G_{2}\right.$ and $\left.b_{2}\right)$ are defined respectively as follows: 


$$
\begin{gathered}
Z_{g 2}=\frac{g_{2}+\frac{6}{n+1}-\gamma_{k}}{\sqrt{\frac{24 n(n-2)(n-3)}{(n+1)^{2}(n+3)(n+5)}}}, \\
Z_{G 2}=\frac{G_{2}-\gamma_{k}}{\sqrt{\frac{24 n(n-1)^{2}}{(n-2)(n-3)(n+3)(n+5)}}}, \\
Z_{b 2}=\frac{b_{2}-3 \frac{(n-1)^{3}}{n^{2}(n+1)}+3-\gamma_{k}}{\left(\frac{n-1}{n}\right)^{2} \sqrt{\frac{24 n(n-2)(n-3)}{(n+1)^{2}(n+3)(n+5)}}},
\end{gathered}
$$

where $g_{2}, G_{2}, b_{2}$ are previously defined as above, $\mathrm{n}$ is the sample size, $\gamma_{k}$ is the hypothesized kurtosis parameter. We will reject $H_{0}$ at $\alpha$ level of significance if the test statistics of $\left(Z_{g_{2}}, Z_{G_{2}}, Z_{b_{2}}\right)$ are greater than $Z_{\alpha / 2}$, where $Z_{\alpha / 2}$ is the upper $\frac{\alpha}{2}$ percentile of the standard normal distribution.

\subsection{Bootstrap Approach}

In this section, we will discuss the bootstrap techniques for testing the skewness and kurtosis parameters. The bootstrap approach can be applied in any population as it does not require any assumption about the distribution, and if the sample size is large enough, the process of bootstrap could be very accurate (Efron, 1979). Following Perez-Meloand and Kibria (2016) the bootstrap methods can be summarized as follows: Let $X^{(*)}=X_{1}^{(*)}, X_{2}^{(*)}, \ldots, X_{n}^{(*)}$, where the $\mathrm{i}^{\text {th }}$ sample is denoted $X^{(i)}$ for $\mathrm{i}=1,2, \ldots, \mathrm{B}$, where B is the number of bootstrap samples. Parametric method requires normality assumption, however, in reality, most of the data do not follow a normal distribution. 


\subsubsection{Bias-Corrected Standard Bootstrap Approach}

Let $\hat{\theta}$ be a point estimator of $\theta$ (skewness and kurtosis parameter), then the bias-corrected standard bootstrap confidence interval for $\theta$ proposed by Perez-Meloand and Kibria (2016) as shown below,

$$
\widehat{\theta}-\operatorname{Bias}(\hat{\theta}) \pm Z_{\alpha / 2} \widehat{\sigma_{B}}
$$

where $\widehat{\sigma_{B}}=\sqrt{\frac{1}{B-1} \sum_{i=1}^{B}\left(\theta_{i}^{*}-\bar{\theta}\right)^{2}}$ is the bootstrap standard deviation, $\bar{\theta}=\frac{1}{B} \sum_{i=1}^{B} \theta_{i}^{*}$ is the bootstrap mean and $\operatorname{Bias}(\hat{\theta})=\bar{\theta}-\hat{\theta}$ is the estimated bias. Now we attempt to develop a Z-test statistic for testing the hypothesis of population skewness or kurtosis. In this regard, the null and alternative hypothesis are defined below:

$$
\begin{aligned}
& H_{0}: \theta=\theta_{0} \\
& H_{0}: \theta \neq \theta_{0},
\end{aligned}
$$

Then the test statistic for testing the alternative hypothesis can be written as follows:

$$
Z_{\theta_{0}}=\frac{\widehat{\theta}-\operatorname{Bias}(\hat{\theta})-\theta_{0}}{\widehat{\sigma_{B}}},
$$

where $\operatorname{Bias}(\hat{\theta}), \bar{\theta}$ are previously defined as above, B is the number of bootstrap samples, $\theta$ is population skewness or kurtosis parameter. We will reject $H_{0}$ at $\alpha$ level of significance if the test statistic $Z_{\theta_{0}}$ is greater than $Z_{\alpha / 2}$, where $Z_{\alpha / 2}$ is the upper $\frac{\alpha}{2}$ percentile of the standard normal distribution.

\subsubsection{Efron's Percentile Bootstrap Approach}


Comparing with bias-corrected standard bootstrap approach, Efron's Percentile method is much simpler to consider the confidence since the confidence interval will depend on value of upper $\alpha / 2$ level of bootstrap samples and lower $\alpha / 2$ level of bootstrap samples (Efron,1987). Firstly we order the sample skewness or kurtosis of each bootstrap sample as follows:

$$
\theta_{(1)}^{*} \leq \theta_{(2)}^{*} \leq \theta_{(3)}^{*} \leq \cdots \leq \theta_{(B)}^{*} .
$$

Following Efron's (1987), the confidence interval will be given by

$$
L=\theta_{\left[\left(\frac{\alpha}{2}\right) * B\right]}^{*} \text { and } U=\theta_{\left[\left(1-\frac{\alpha}{2}\right) * B\right]}^{*} .
$$

And we will reject the null hypothesis $H_{0}: \theta=\theta_{0}$ against alternative hypothesis $H_{a}: \theta \neq \theta_{0}$ if

$$
L>\theta_{0} \text { or } U<\theta_{0} .
$$

\subsubsection{Hall's Percentile Bootstrap Approach}

This is also a non-parametric approach proposed by Hall (1992), which does not require the standard deviation. In Hall's method, he ordered the errors of the estimator instead of estimator itself. The errors are ordered as follows:

$$
\varepsilon_{(1)}^{*} \leq \varepsilon_{(2)}^{*} \leq \varepsilon_{(3)}^{*} \leq \cdots \leq \varepsilon_{(B)}^{*},
$$

where $\varepsilon_{i}^{*}=\theta_{i}^{*}-\theta$. The confidence interval could be obtained in the similar manner as previous Efron's Percentile approach and it is presented below:

$$
L=\theta-\varepsilon_{\left[\left(1-\frac{\alpha}{2}\right) * B\right]}^{*} \text { and } U=\theta-\varepsilon_{\left[\left(\frac{\alpha}{2}\right) * B\right]}^{*} .
$$

Following Hall (1992), the confidence interval could be simplified as: 


$$
L=2 \theta-\theta_{\left[\left(1-\frac{\alpha}{2}\right) * B\right]}^{*} \text { and } U=2 \theta-\theta_{\left[\left(\frac{\alpha}{2}\right) * B\right]}^{*}
$$

And we will reject the null hypothesis: $H_{0}: \theta=\theta_{0}$ against alternative hypothesis $H_{a}: \theta \neq \theta_{0}$ if

$$
L>\theta_{0} \text { or } U<\theta_{0}
$$

\subsubsection{Bias-Corrected Percentile Bootstrap Approach}

This method was introduced by Efron (1987) and the first step is we have to find the proportion of times that $\theta_{i}^{*}$ greater than $\theta$, that is,

$$
P=\frac{\#\left(\theta_{i}^{*}>\theta\right)}{B}
$$

and then find $Z_{0}$ in order to make $\phi\left(Z_{0}\right)=1-P$, where $\phi$ is the cumulative distribution function of standard normal random variable. $Z_{0}$ will be used as the estimator instead of $\theta$ in the following confidence interval,

$$
L=\theta_{\left[\phi\left(2 Z_{0}-Z_{1-\alpha / 2}\right) * B\right]}^{*} \text { and } U=\theta_{\left[\phi\left(2 Z_{0}+Z_{1-\alpha / 2}\right) * B\right]}^{*}
$$

And we will reject the null hypothesis $H_{0}: \theta=\theta_{0}$ against alternative hypothesis $H_{a}: \theta \neq \theta_{0}$ if

$$
L>\theta_{0} \text { or } U<\theta_{0}
$$

Thomas and Joseph (1998) claimed that bias-corrected percentile bootstrap performed better than bias-corrected standard bootstrap and other percentile bootstrap approaches; we will employ the simulation study to examine this statement. 


\section{CHAPTER III}

\section{SIMULATION STUDY}

In this chapter, we will compare the performance of the proposed test statistics. We conducted a simulation study using through R Version 3.2.1 to compare the performance of the test statistics in the sense of nominal size and empirical power of the test.

\subsection{Simulation Study for Skewness}

\subsubsection{Simulation Technique}

Even though the proposed test statistics are mainly developed for testing data from a normal (or symmetric) population, we will try to see the performance of this tests when the data are from a skewed distribution. The flow chart of our simulation study is pointed below:

(1) Sample size, $\mathrm{n}=10,20,30,50,100$ and 300 .

(2) 3000 simulation replications are used for each case, 1000 bootstrap samples for each simulation replication.

(3) The normal, right skewed and left skewed distribution are generated below and the probability density function of each distribution are located thereafter:

a) Normal distribution with mean 0 and SD 1

b) Gamma distribution with shape parameter 4, 7.5 and 10 and scale parameter 1

c) Beta distribution with alpha parameters 1 and beta parameters 0.35181 and 0.15470 respectively. 


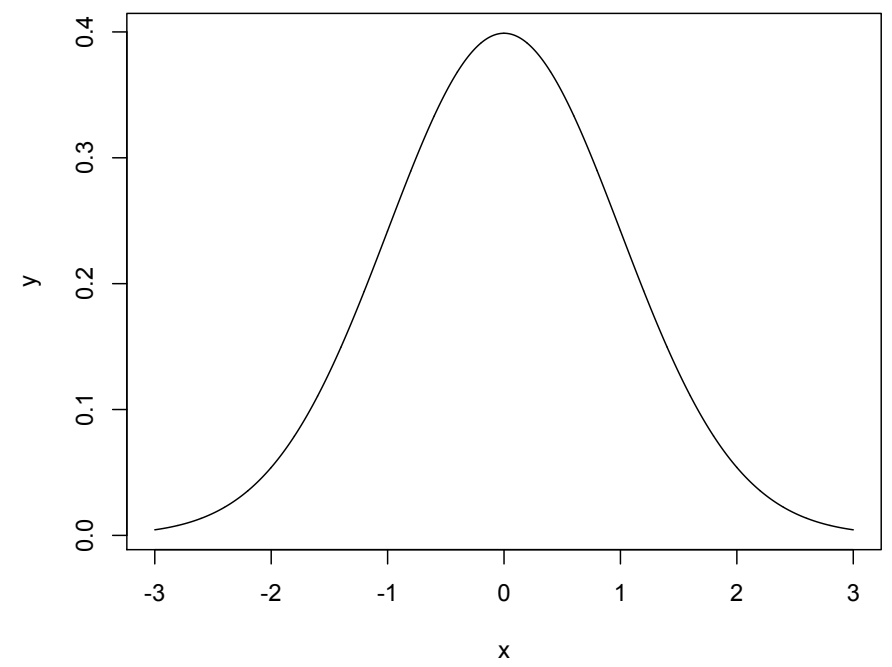

Figure 3.1.1.1 Probability density function of $\mathrm{N}(0,1)$ distribution

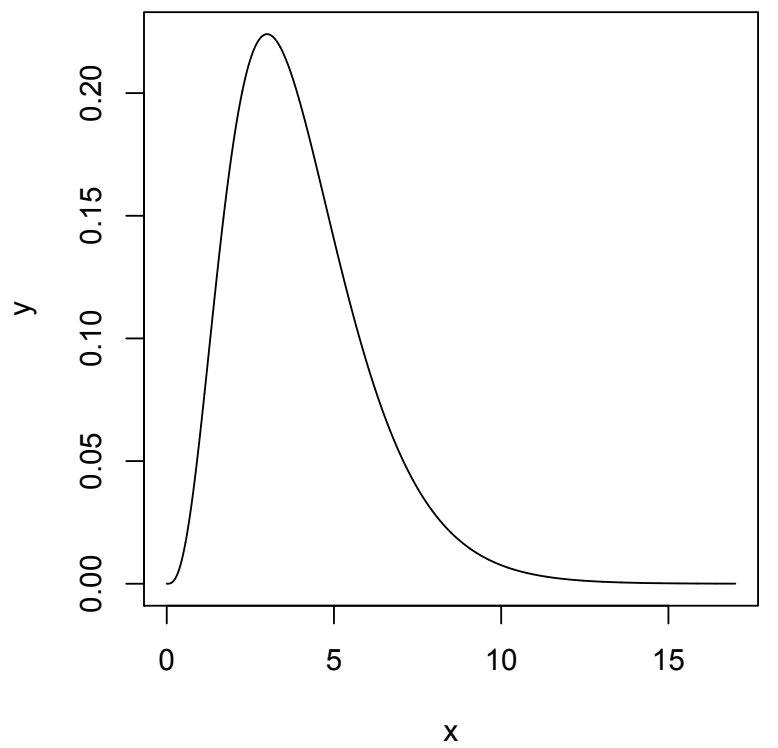

Figure 3.1.1.2 Probability density function of Gamma $(4,1)$ distribution 


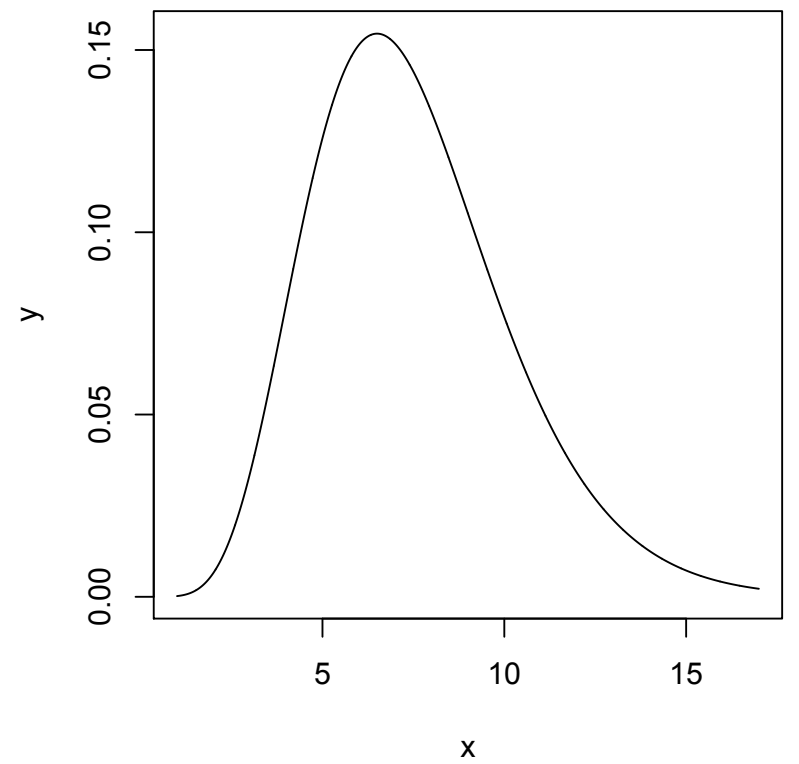

Figure 3.1.1.3 Probability density function of Gamma $(7.5,1)$ distribution

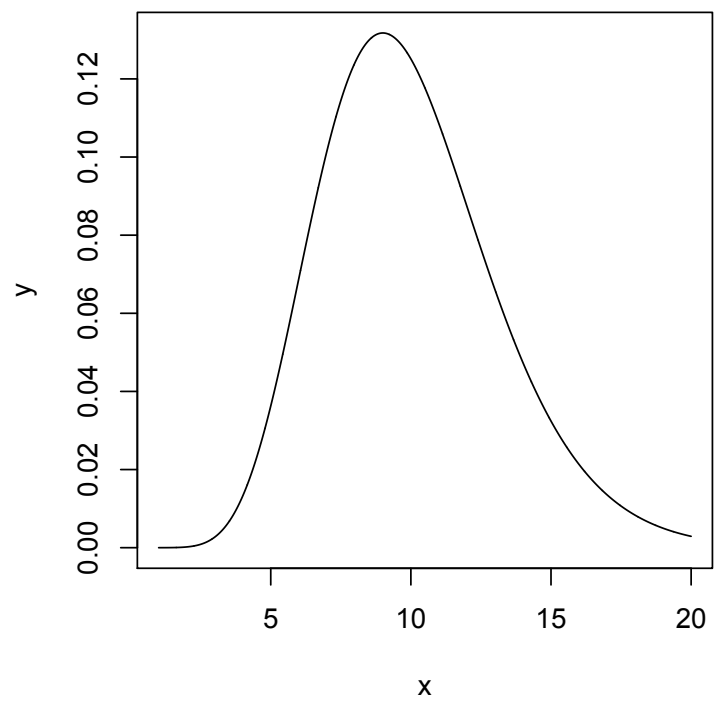

Figure 3.1.1.4 Probability density function of Gamma (10,1) distribution 


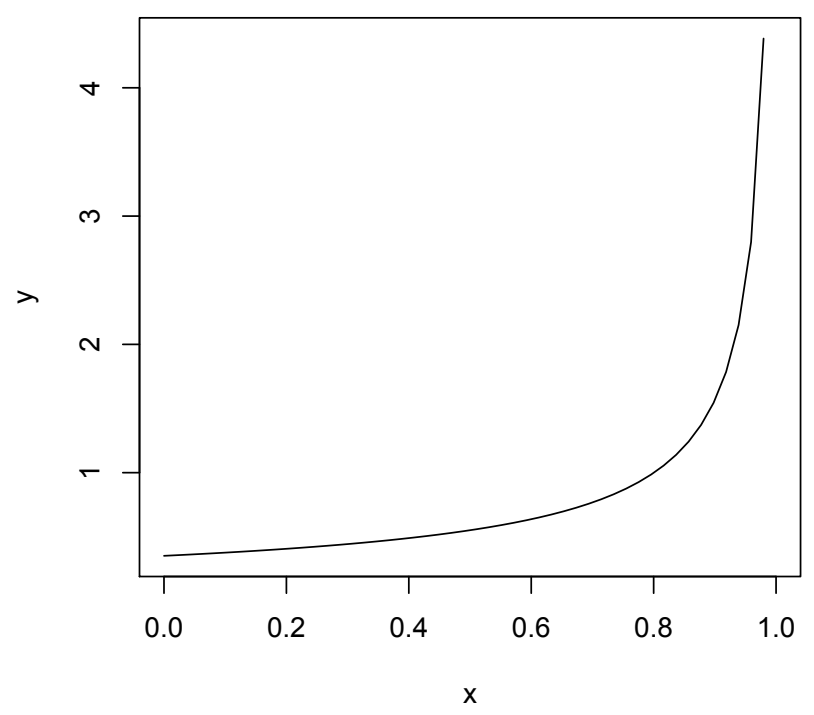

Figure 3.1.1.5 Probability density function of Beta $(1,0.35181)$ distribution

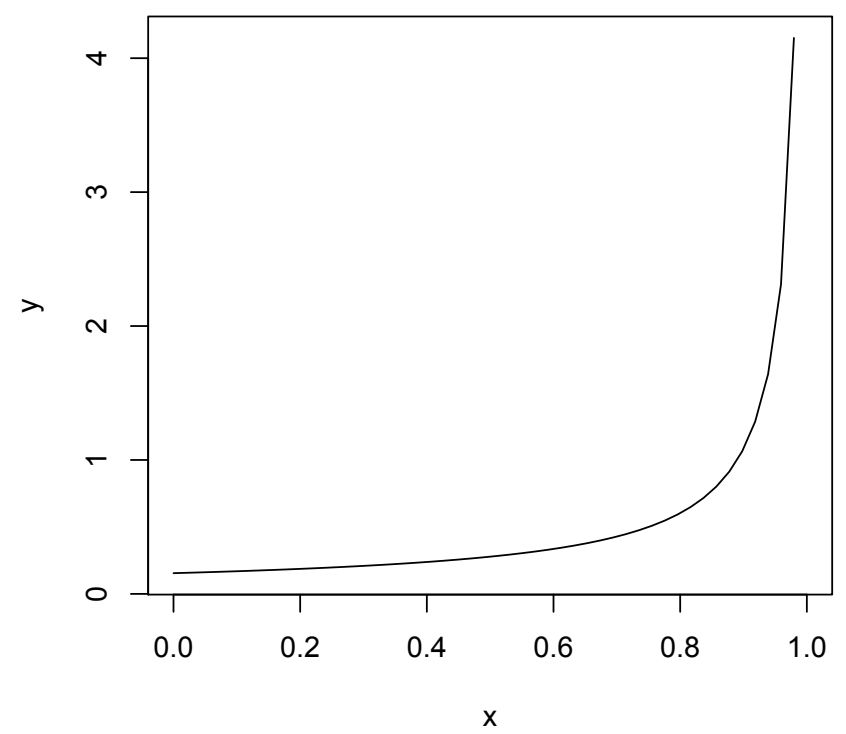

Figure 3.1.1.6 Probability density function of Beta $(1,0.15470)$ distribution 


\subsubsection{Performance for Normal distribution}

It is well known that the normal distribution is symmetric and the skewness for normal distribution equals 0 . Under this assumption and at alpha $=0.05$ level of significance, we are expecting to get the power $=0.05$ from the simulation dataset. Figure 3.1.1 shows the empirical size of the test when we are testing whether the skewness equals 0. It appears from Figure 3.1.1 that the classical method performs the best among all methods in the sense of attaining nominal size of 0.05 for different sample sizes. It differs only when sample size is small, that is when $n=10$. Among four types of bootstrap methods, only Efron's Percentile method attained the nominal size of 0.05 . For the Bias Corrected Standard Method, Hall's Percentile Method and Bias Corrected Percentile Method, the empirical nominal size is beyond 0.1 when the sample size is less than 100 . However, they attained nominal size 0.05 when the sample size is 300 . In this case bootstrap methods cannot provide better results than the classical method, despite the limit of sample size and complex bootstrap method to test the skewness for normal distribution. It should be mentioned that for power test, we deleted the unqualified statistics using a 0.05 nominal size and all good test statistics will be demonstrated in the graph. 


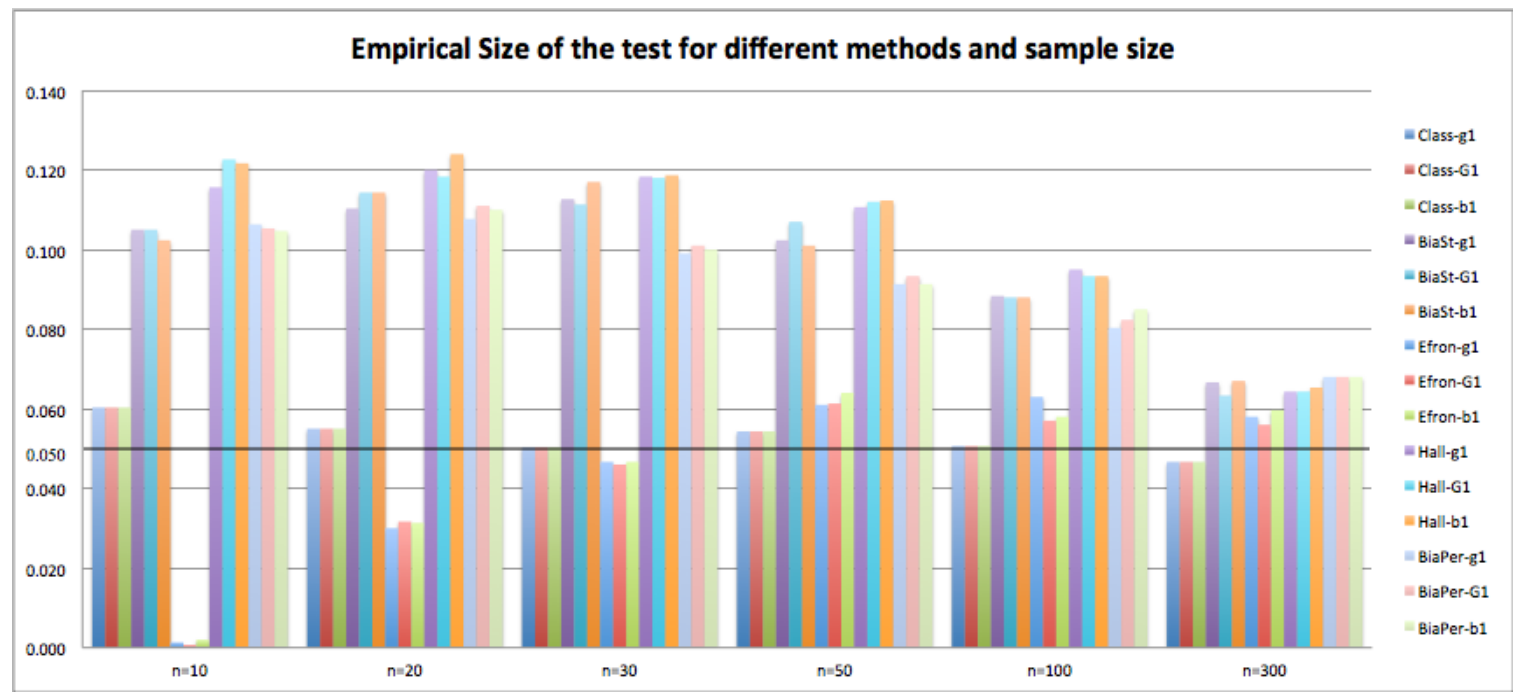

Figure 3.1.1 Empirical size of testing skewness=0 with different methods and sample size

Figures 3.1.2 to 3.1.7 show the empirical power against different hypothesized values for all proposed test statistics with different sample sizes: $\mathrm{n}=10,20,30,50,100$ and 300. The $\mathrm{X}$-axis represents different hypothesized values and $\mathrm{Y}$-axis is the empirical power. We would expect to have the empirical power close to 1 when increasing the hypothesized value from 0 to a larger value. From these six figures it appears that empirical powers are close to 1 when skewness equals to 2 or less than 2 .

From Figures 3.1.2 to 3.1.7, we can also see that for small sample sizes and near the null hypothesis or for large sample sizes and for high skewness, the power of the tests do not vary greatly. However, for small sample size with moderate departure from null hypothesis, the power of the tests varies among the test statistics. Among all test statistics using the proposed estimators we examined, the classical method is more powerful when the sample size is small (say 10) while for sample size greater than 10, Efron's Percentile 
Method shows absolute advantage other than classical method. Overall, the power approaches 1 when the alternative hypothesis is testing for skewness $=2$.

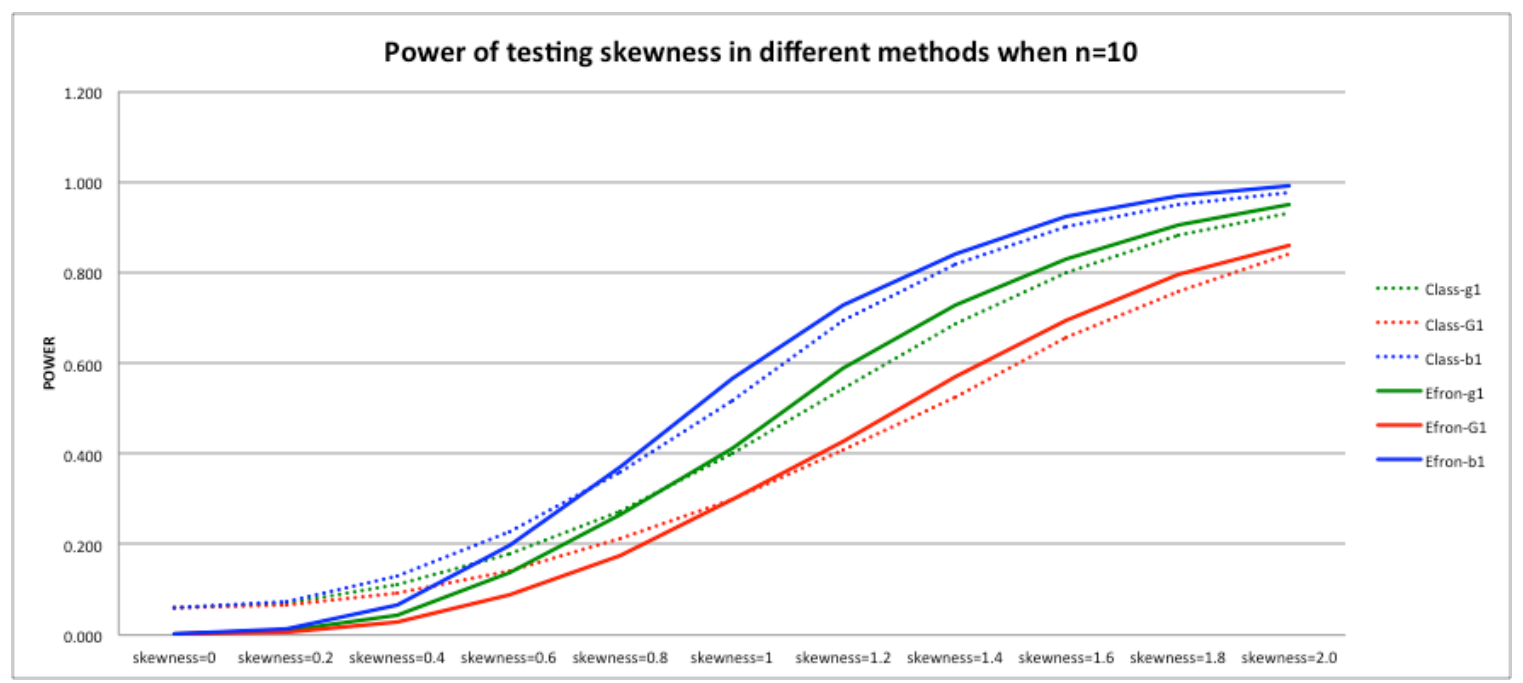

Figure 3.1.2 Power of testing skewness of $\mathrm{N}(0,1)$ in different methods when $\mathrm{n}=10$

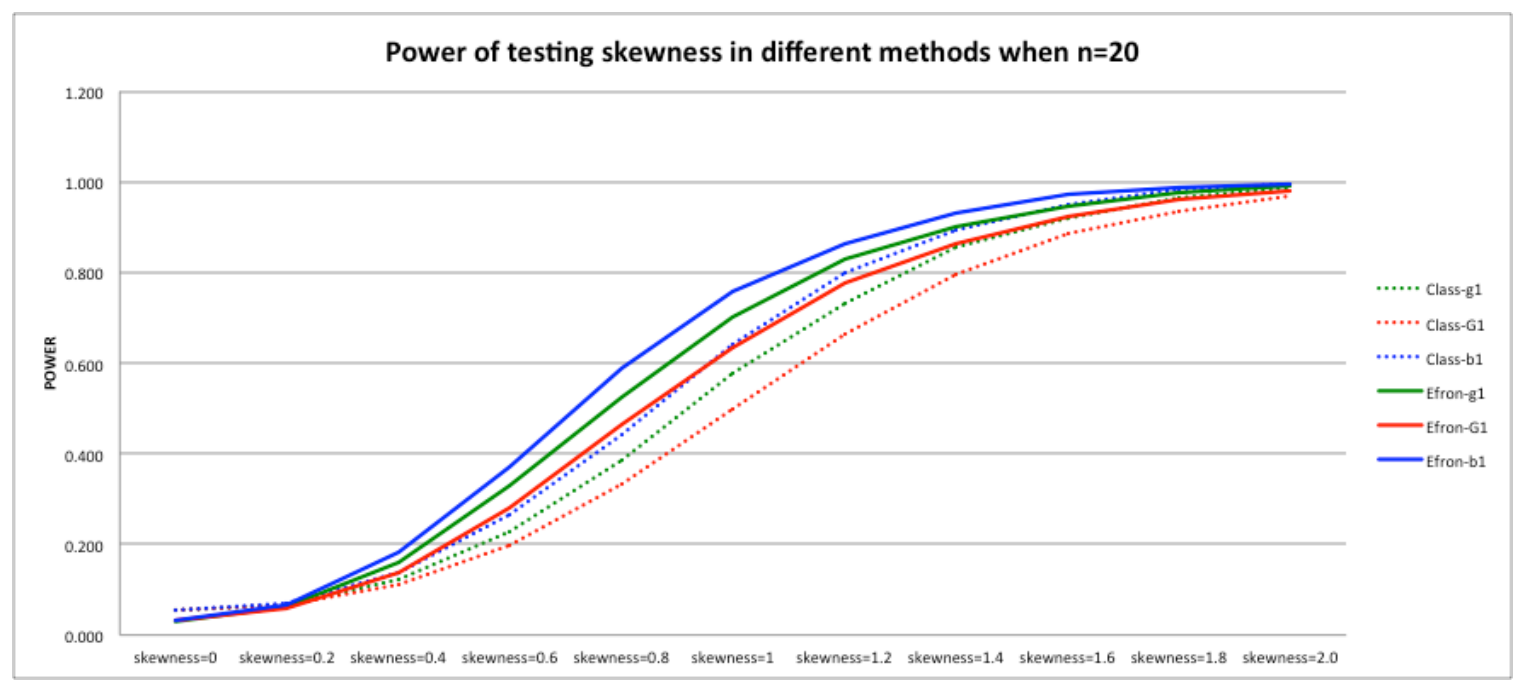

Figure 3.1.3 Power of testing skewness of $\mathrm{N}(0,1)$ in different methods when $\mathrm{n}=20$

Both the classical and Efron's Percentile methods show acceptable results. By changing the alternative hypothesis, the Efron's Percentile is getting close to other bootstrap methods and apparently away from the classical method. The power increases 
slightly to 1 when skewness $=1.6$ and 1.2 respectively for $n=30$ and 50 .

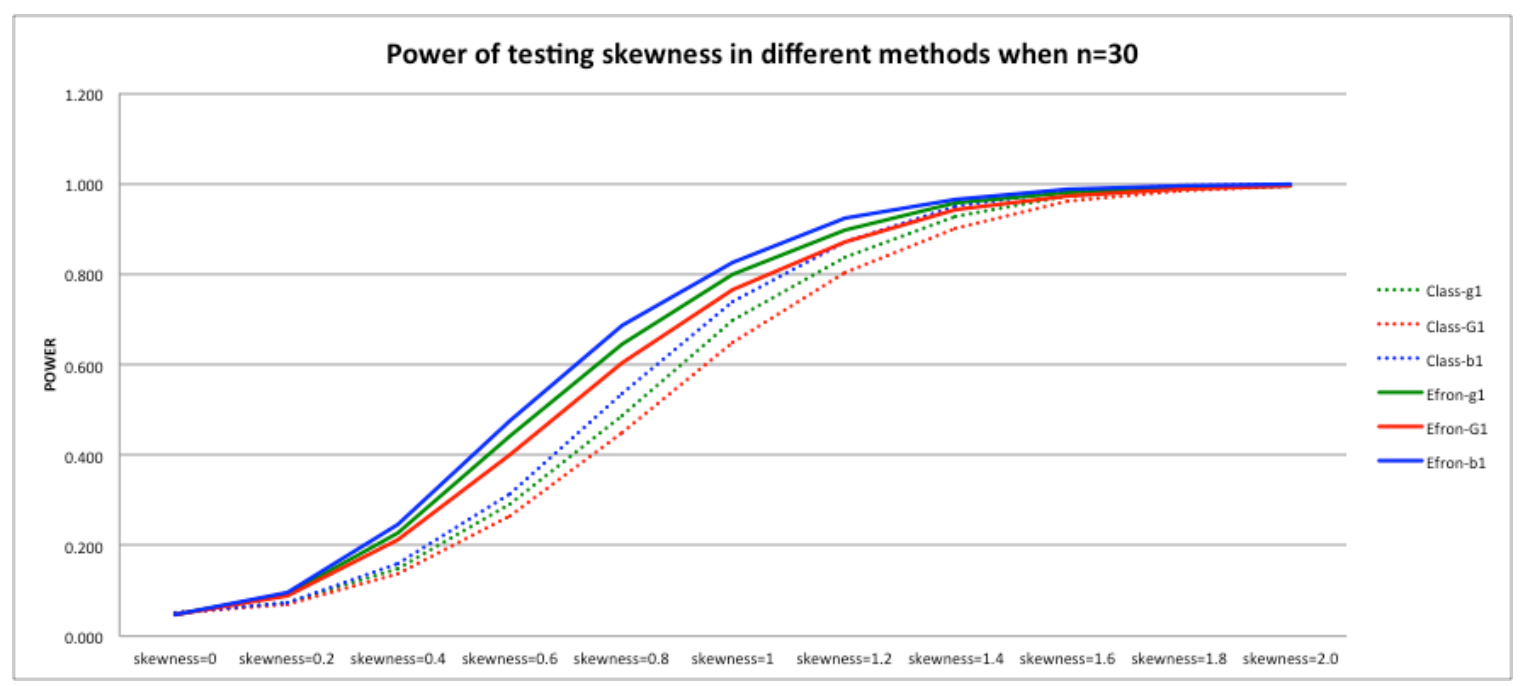

Figure 3.1.4 Power of testing skewness of $\mathrm{N}(0,1)$ in different methods when $\mathrm{n}=30$

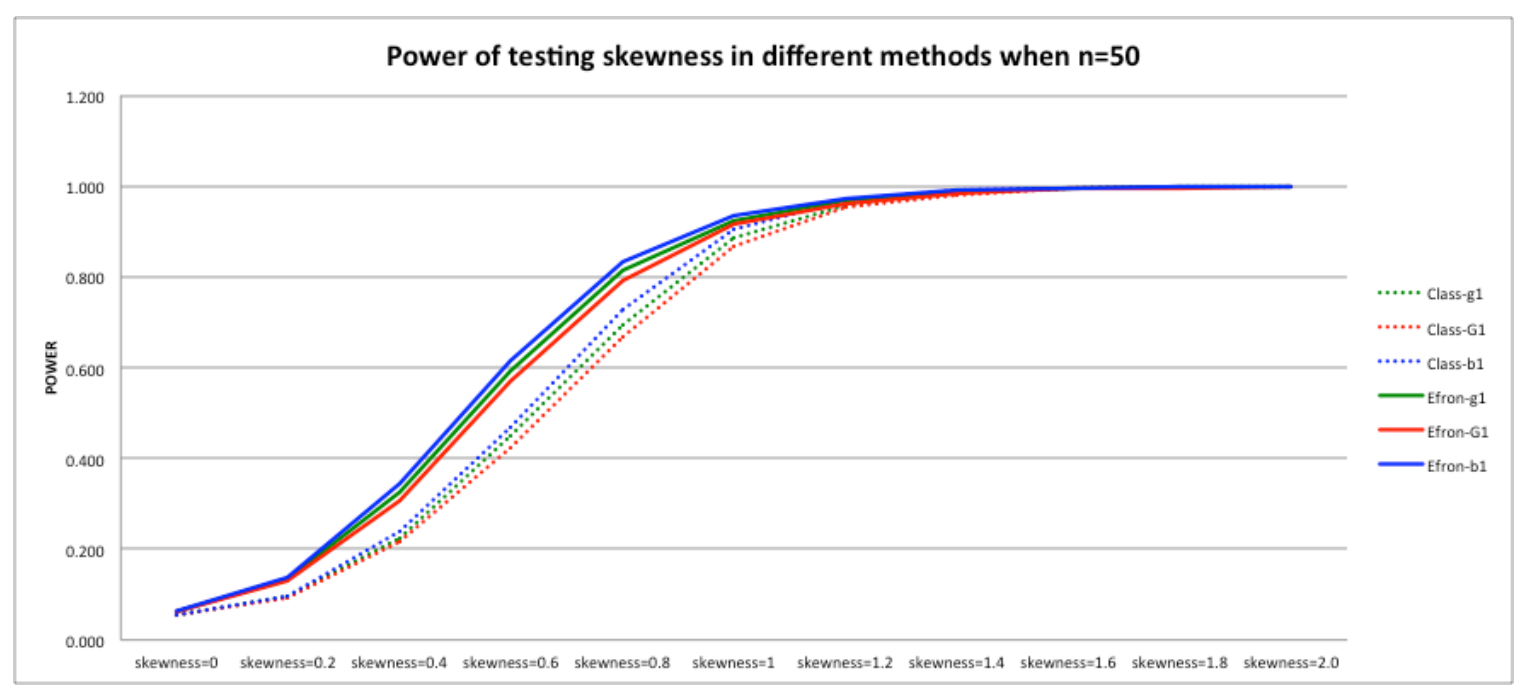

Figure 3.1.5 Power of testing skewness of $\mathrm{N}(0,1)$ in different methods when $\mathrm{n}=50$

When we consider the larger sample size, say 100 , the classical method is less powerful than the bootstrap methods when we are testing skewness $=0.2,0.4$ or 0.6 . The power increases sharply to 0.9 for all methods when skewness $=0.8$ and it goes up steadily to 1 from that point on. When the sample size goes up to 300 , the power rises by an order 
of magnitude from 0.05 to 0.7 when the skewness shifts from 0 to 0.4 , and thereafter, it increases gradually until 1 when skewness $=0.6$. Thus, it may be concluded that the classical method shows a little less power than Efron's Percentile method for moderate departure from null value, and when the sample size is large enough, there is no significant difference among bootstrap methods. However, it is noted that when the classical and Efron's Percentile methods attain a nominal size 0.05 , other proposed bootstrap methods, from data in a normal population, are not useful.

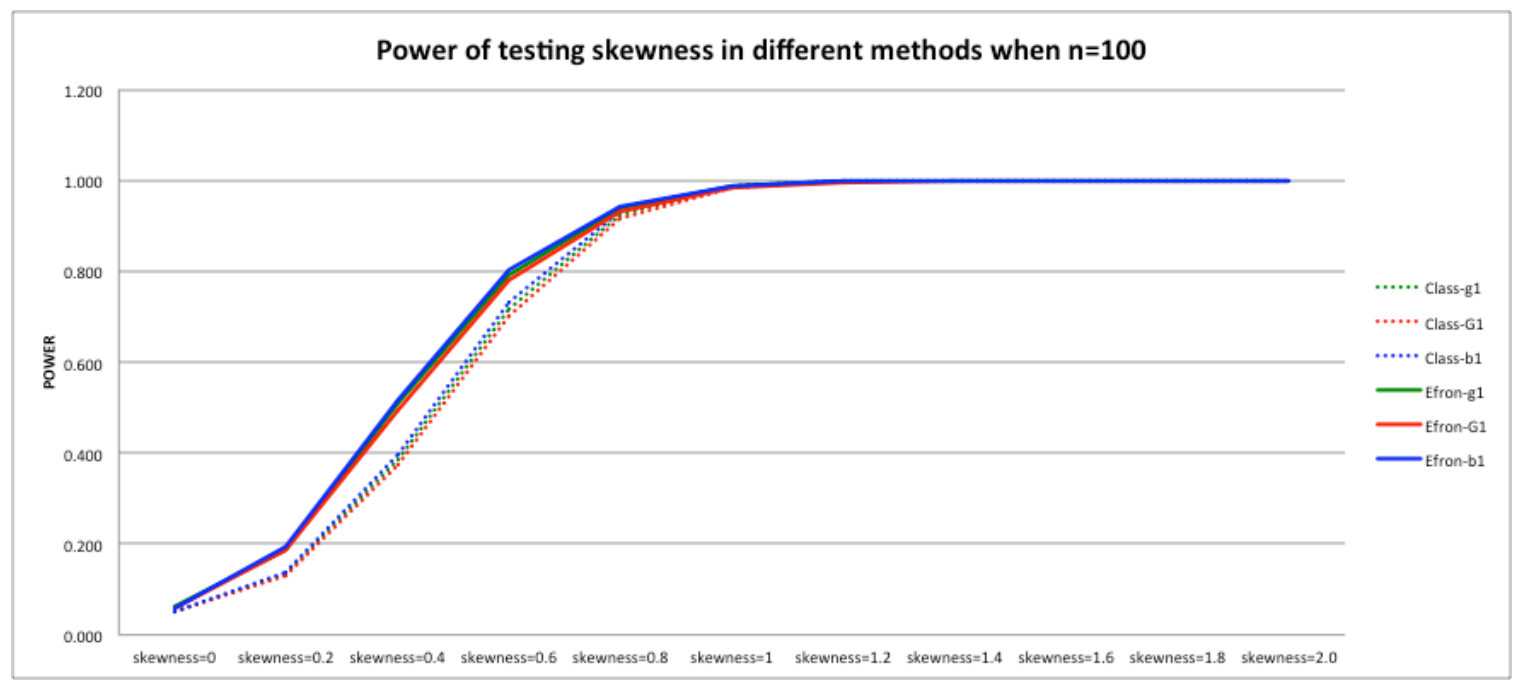

Figure 3.1.6 Power of testing skewness of $\mathrm{N}(0,1)$ in different methods when $\mathrm{n}=100$ 


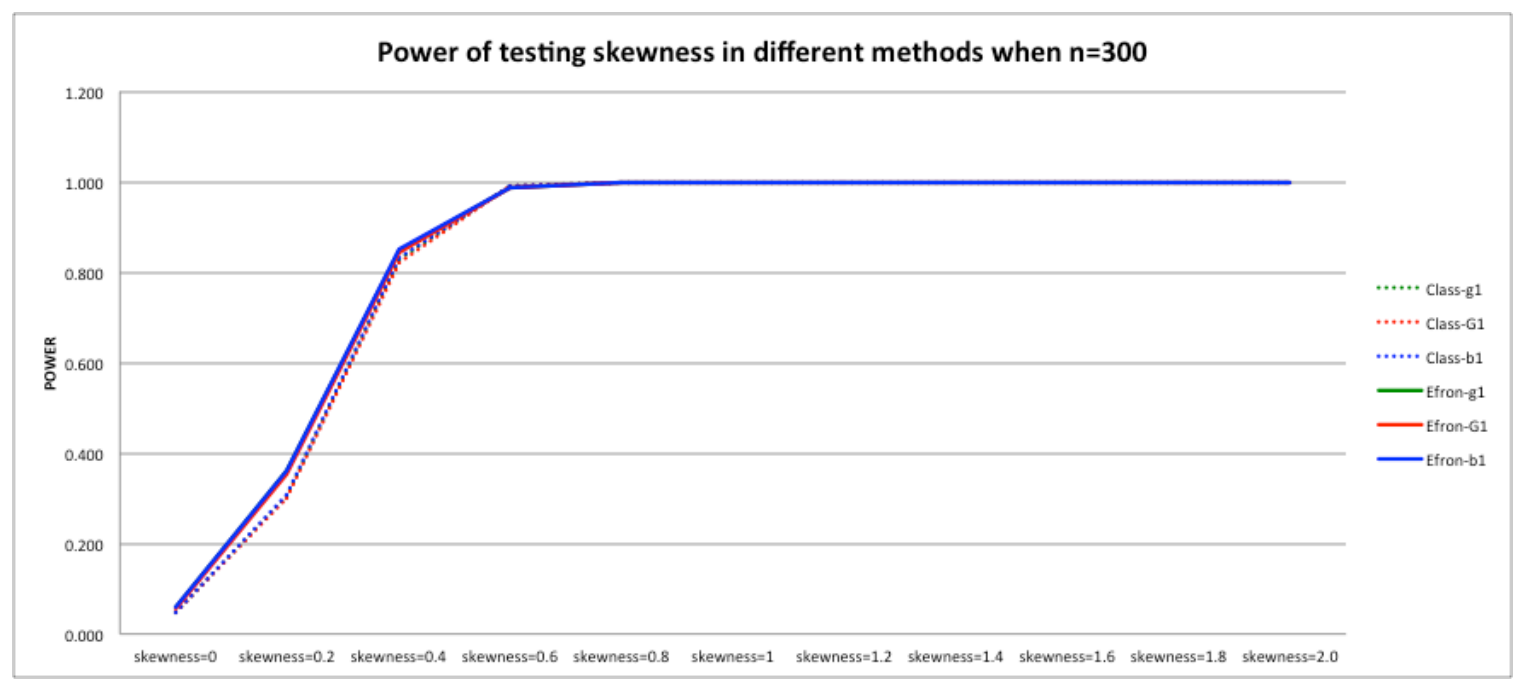

Figure 3.1.7 Power of testing skewness of $\mathrm{N}(0,1)$ in different methods when $\mathrm{n}=300$

We analyzed the performance of test statistics using sample size with different methods separately. Figure 3.1.8 and 3.1.9 illustrates the power of testing skewness in different sample size with classical method and Efron's Percentile Method only as other methods failed to perform. Those two figures indicate that if the sample size is large enough, there seems no obvious difference among those three test statistics. The difference is only visible when the sample size is small, say $n=10$. Within each test statistic using those three estimators, increasing the sample size could improve the power of test for both classical and Efron's Percentile Method. Moreover, we find that the test statistic based on $G_{1}$ has the smallest power while the test statistic of estimator $b_{1}$ has the highest power within each sample size. 


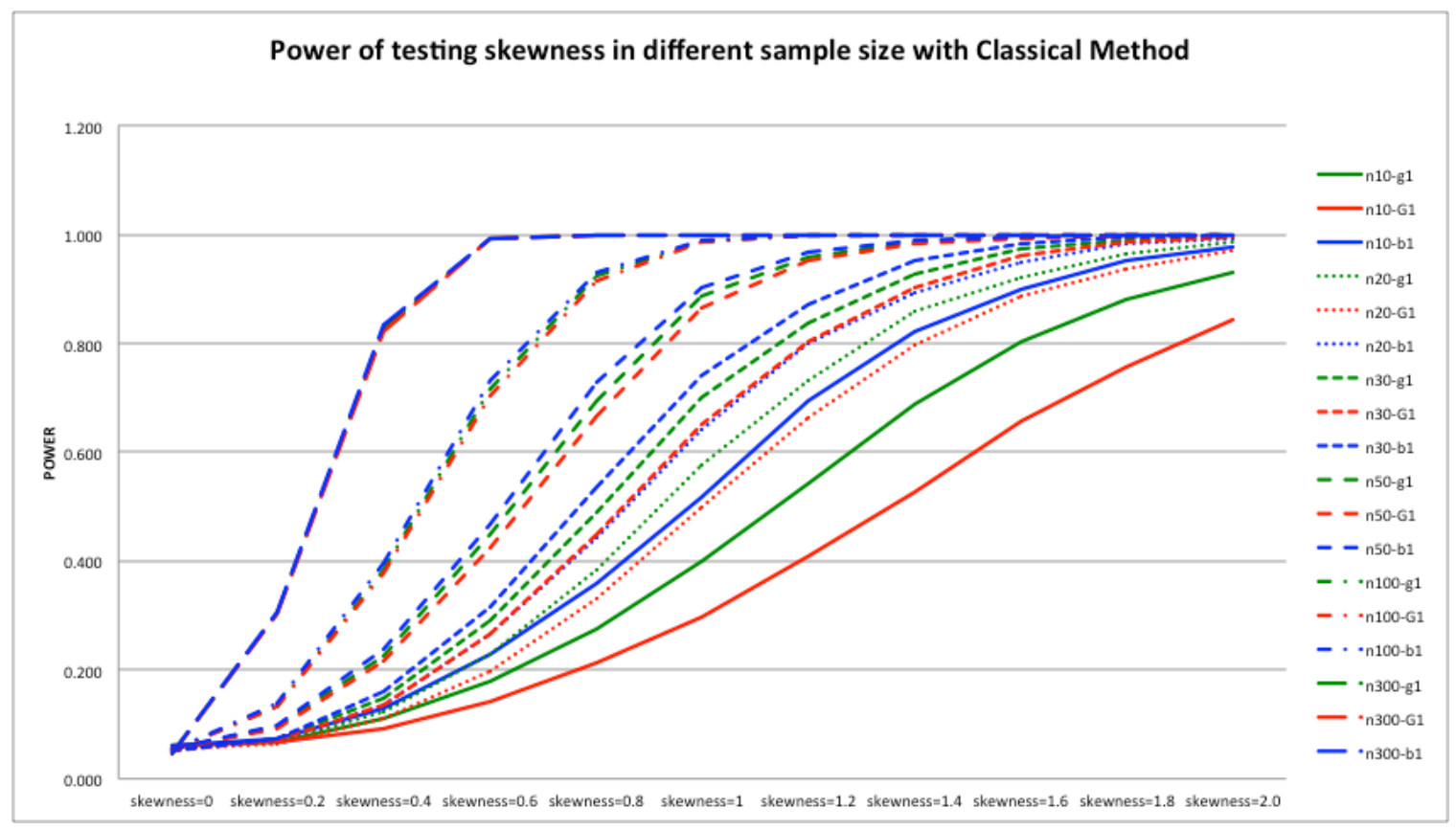

Figure 3.1.8 Power of testing skewness of $\mathrm{N}(0,1)$ in different sample size with Classical Method

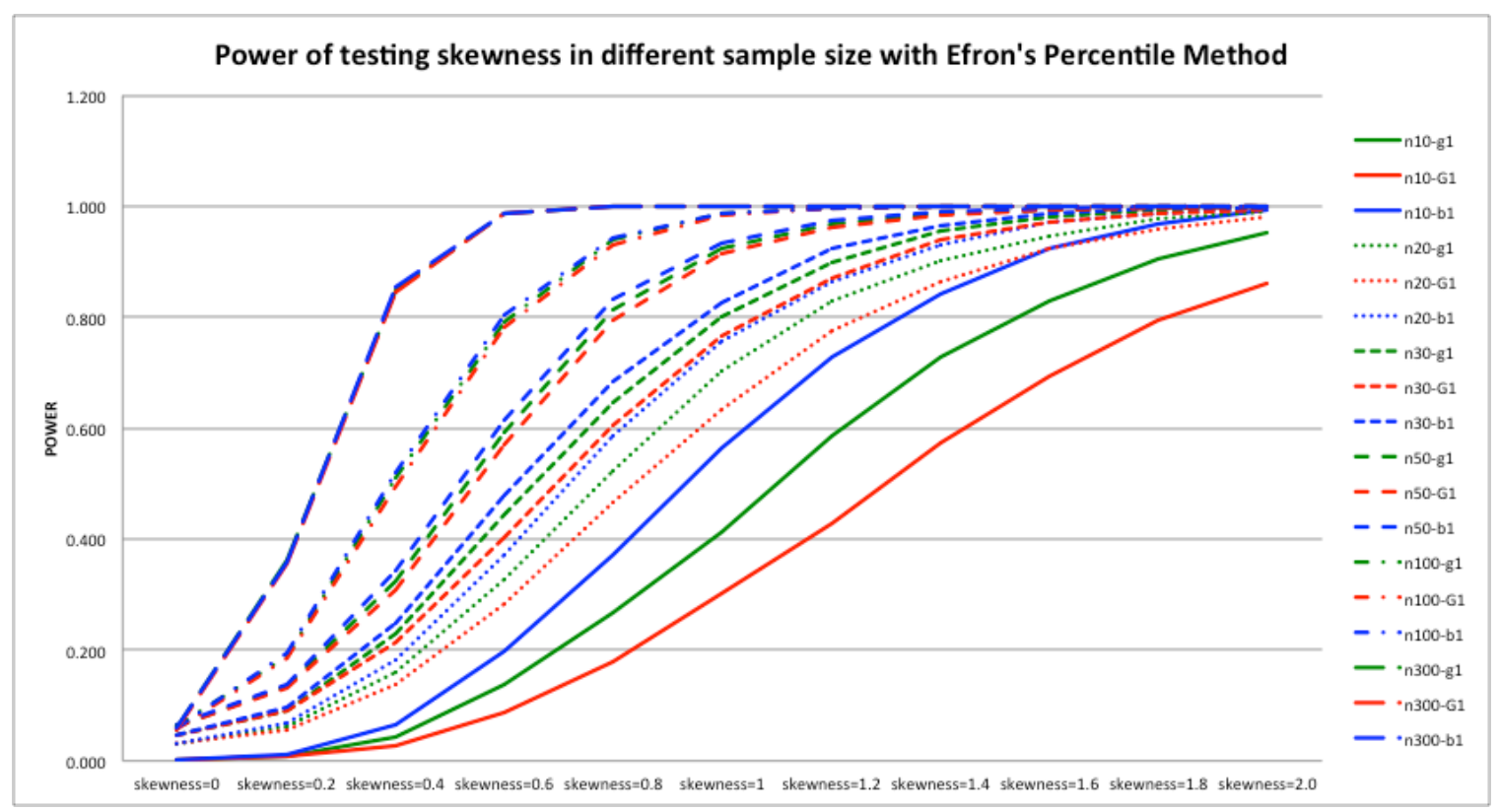

Figure 3.1.9 Power of testing skewness of $\mathrm{N}(0,1)$ in different sample size with Efron's Percentile Method 


\subsubsection{Performance for Gamma distribution}

Even though the parametric methods are developed for testing the skewness parameter of normal distribution, we made an attempt to apply this method along with bootstrap methods to other asymmetric distributions, which will be discussed in the next section.

The skewness of the gamma distribution depends on the scale parameter only. For instance, the skewness of Gamma $(k, p)$ is $\frac{2}{\sqrt{k}}$. At alpha $=0.05$ level of significance, we are expecting the nominal size 0.05 from the simulation data when we are testing the skewness equal to $\frac{2}{\sqrt{k}}$. Figures 3.1.10 and 3.1.11 illustrate the empirical sizes for testing the skewness $=1$ of Gamma $(4,1)$ and skewness $=0.63$ of Gamma $(10,1)$ respectively. Unfortunately, the results are not acceptable for both parametric and bootstrap methods for Gamma $(4,1)$, while the results are closer to 0.05 for Gamma $(10,1)$. For small sample size $\mathrm{n}=10$, as Efron's Percentile method is under 0.05 limit, it can be chosen as a good test statistic. By increasing $\mathrm{k}$, the shape of gamma distribution became closer to the bell-shaped "normal" distribution, which allowed us to find a nominal size closer to 0.05 . We consider the following gamma distribution in simulations: Gamma $(4,1)$, Gamma $(7.5,1)$ and Gamma $(10,1)$ and the full results could be found in the Appendix A2 to A4. Following Figures 3.1.10 and 3.1.11, we find that the nominal size is much closer to 0.05 from Gamma $(10,1)$ than from Gamma $(4,1)$. Because of the imperfect results, we can organize a graph to see the trend of changes of power as a reference but not encourage 
using these results as conclusive. The classical method is selected from all five methods as the relatively best result, which shows the trend of power changes from above 0.05 to 1 in Gamma $(10,1)$. In Figure 3.1.12, we can find the test statistic based on estimator $G_{1}$ is less powerful for a small sample size, say $\mathrm{n}=10$ or 20 when other conditions are the same. When sample size increases to 100 in the simulation, we can easily find test statistic of $G_{1}$ has lower power while that of $b_{1}$ has higher power. By increasing the sample size to 300 two results were gathered: the power increases sharply to 1 at skewness $=2$ and stays at 1 thereafter, and there is no apparent difference among the test statistics based on these three estimators. In the contrast, when the sample size is small, say $n=10$, the power rises gradually to 1 at skewness $=3$. In this thesis, we will not discuss more about the results deeply but they are provided in Appendix A2 to A4 as a reference.

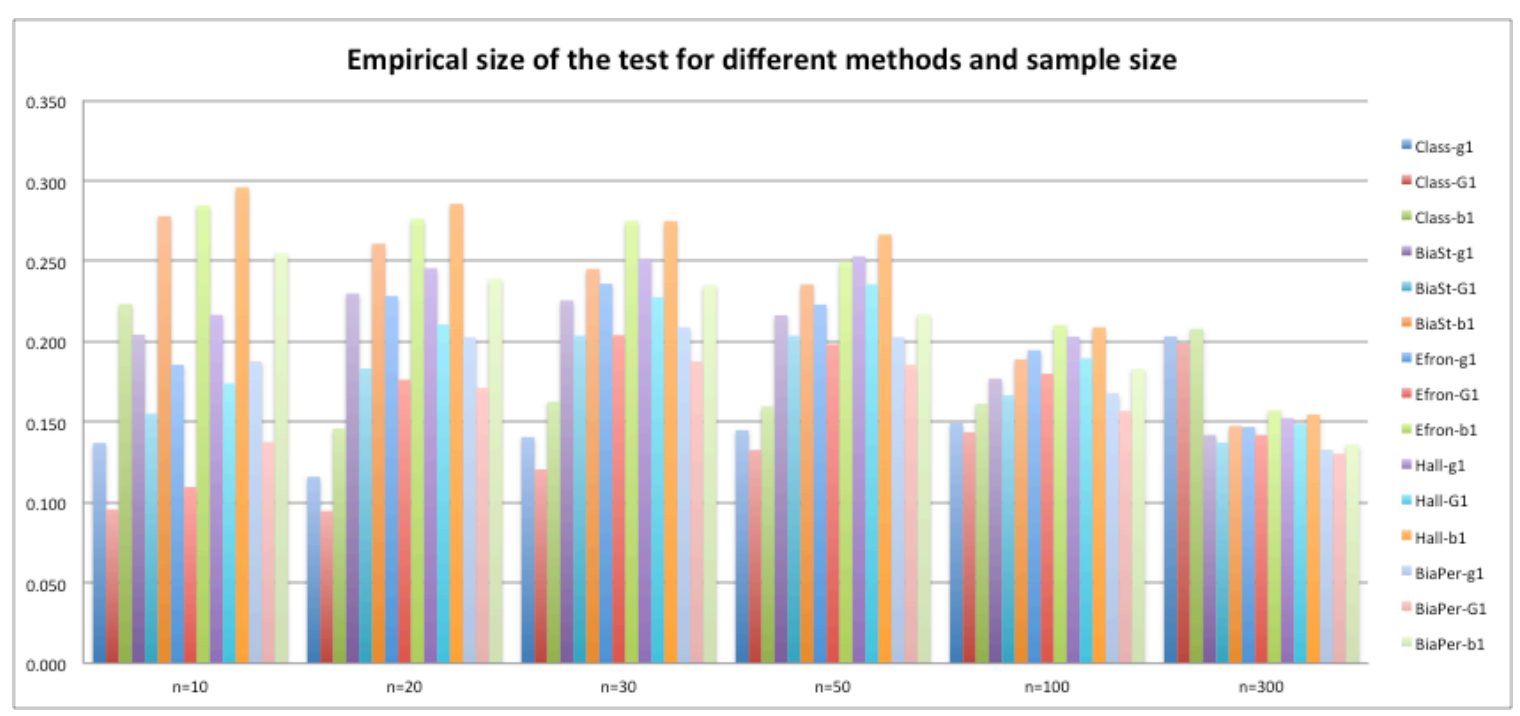

Figure 3.1.10 Empirical size of testing Gamma $(4,1)$ skewness=1 with different methods and sample size 


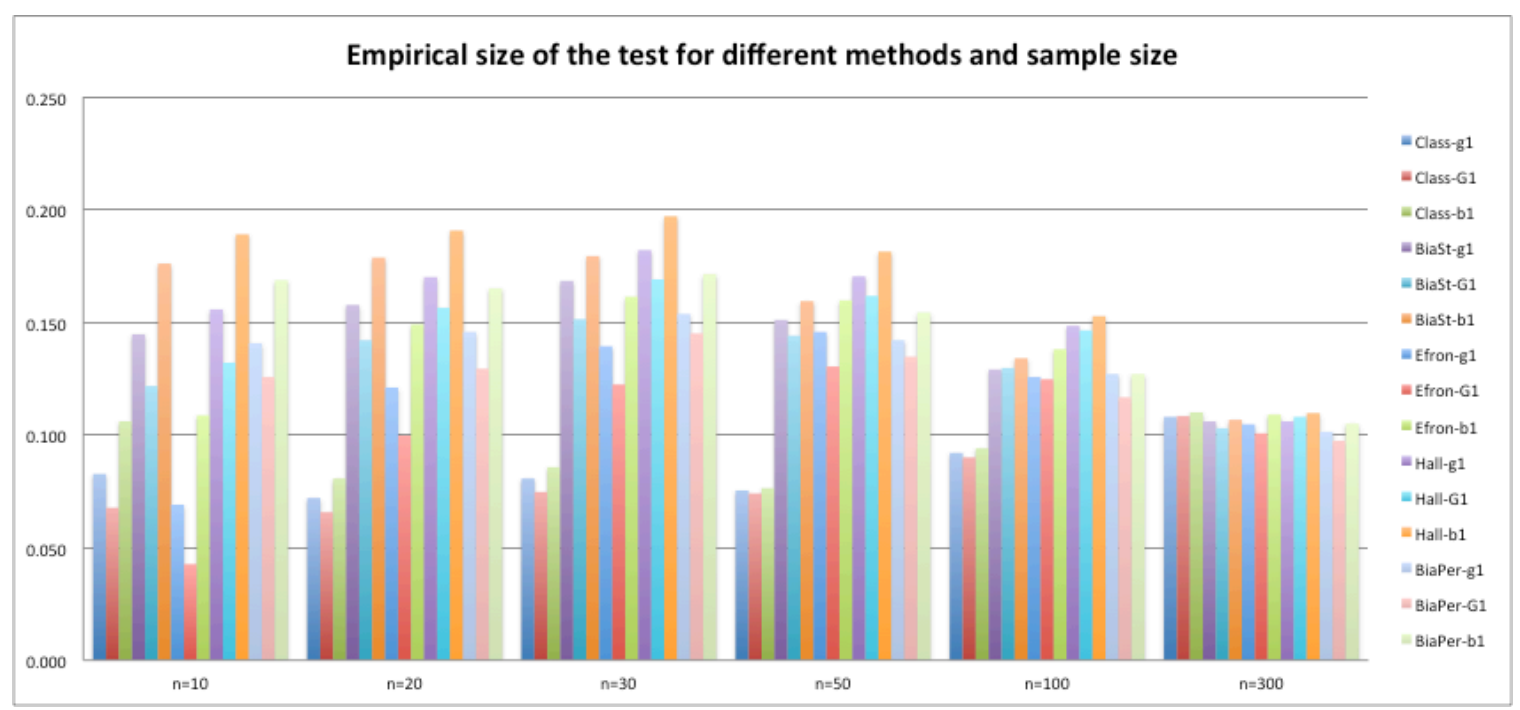

Figure 3.1.11 Empirical size of testing Gamma $(10,1)$ skewness=0.63 with different methods and sample size

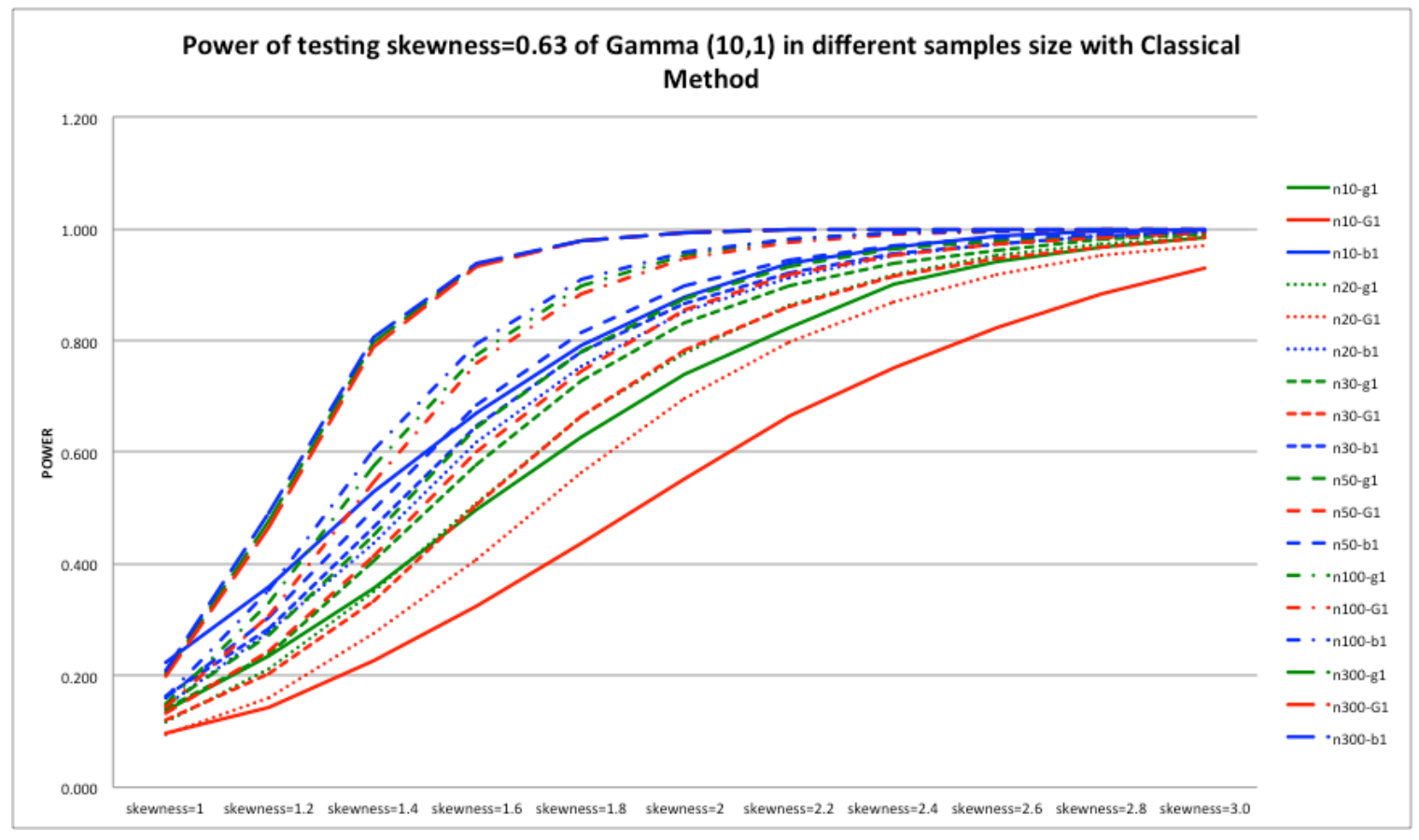

Figure 3.1.12 Power of testing skewness of Gamma $(10,1)$ in different sample size with Classical Method

\subsubsection{Performance for Beta distribution}

Besides gamma distribution, we also make an attempt to test beta distribution using the same proposed estimators defined for normal distribution. Comparing with the results 
from gamma distribution, the beta distribution results are more convincible. The skewness of beta distribution Beta $(a, b)$ can be calculated by $\frac{2(b-a) * \sqrt{a+b+1}}{(a+b+2) \sqrt{a * b}}$. For the beta distribution, we used Beta $(1,0.35181)$ with skewness $=-1$ and Beta $(1,0.15470)$ with skewness $=-2$. Under alpha $=0.05$ level of significance, we are expecting to get empirical nominal size 0.05 from the simulation data when we are testing whether the skewness equal to $\frac{2(b-a) * \sqrt{a+b+1}}{(a+b+2) \sqrt{a * b}}$.

Firstly we start with the simulation of Beta $(1,0.35181)$ and Figure 3.1 .13 shows the results when we are testing whether the skewness equals to -1 with respect to the $\mathrm{X}$-axis represents the different sample size and Y-axis stands for empirical power. When the sample size is small, especially $n=10$, the performance among the test statistics using the three proposed estimators differs a lot, only $g_{1}$ and $G_{1}$ from Classical Method and Efron's Percentile Method could make it or others are more than 0.05. By increasing the sample size to 20 and 50 , the difference is not that significant as $n=10$, all results could be acceptable except $b_{1}$ from Bias Corrected Standard Method and Hall's Percentile Method. And Bias Corrected Percentile Method is the most accurate method to do the hypothesized test when $n=20$. When sample size is 30 , the test statistic calculated with the estimator $b_{1}$ from Hall's Percentile Method and $G_{1}$ from Bias Corrected Percentile Method are not acceptable. While the sample size is large enough, such as $n=100$ and 300 , the results from all testing are as good as what we expected. Especially when samples size is 300 , all methods provide nominal size of approximating 0.05 except classical 
method. Therefore, we may conclude that the larger the sample size is, the more accurate the bootstrap method is. The classical method is difficult to show any advantages if we employ the large sample size from non-normal distribution.

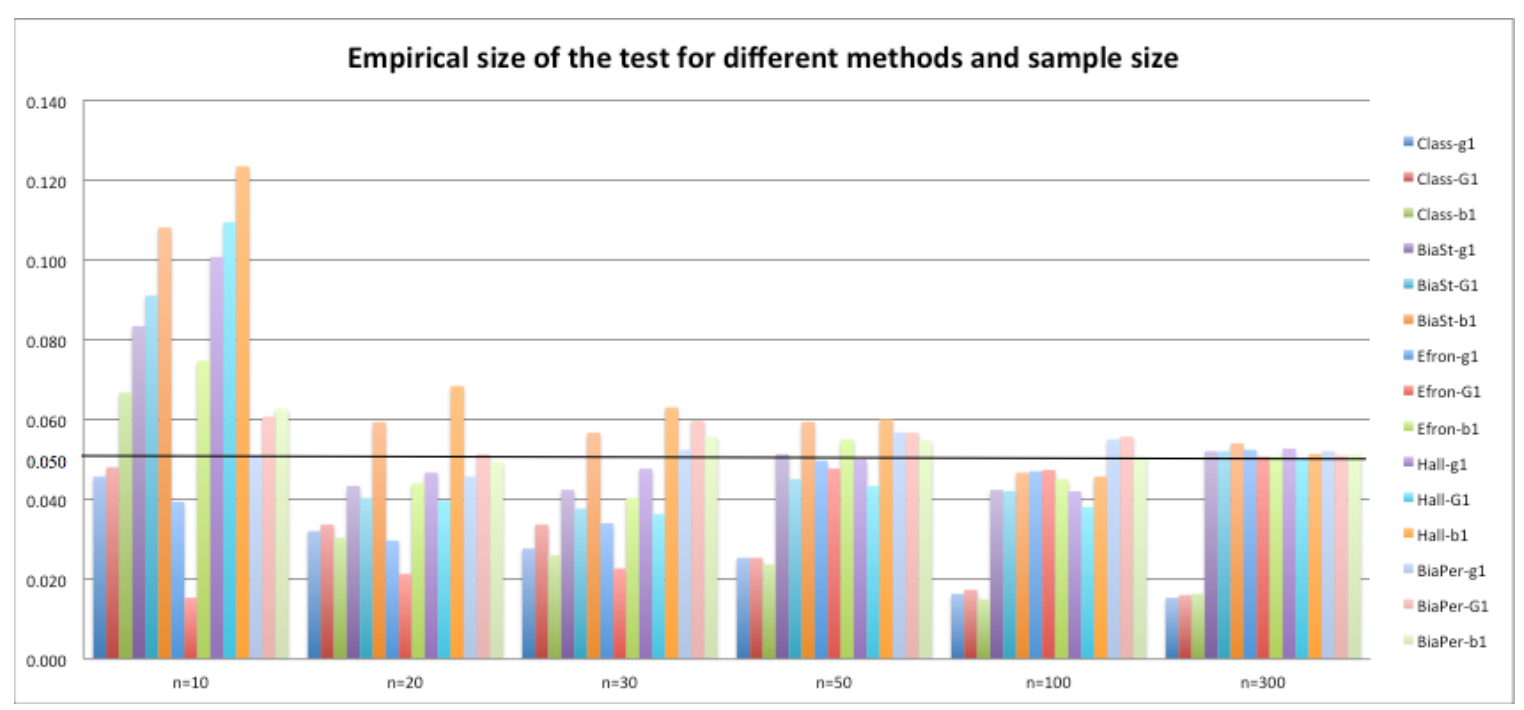

Figure 3.1.13 Empirical size of testing skewness=-1 with different methods and sample size

Figure 3.1.14 to 3.1 .19 are discussing the empirical power against different hypothesized values for all proposed test statistics with different sample sizes: $\mathrm{n}=10,20$, $30,50,100$ and 300 . When the sample size is small, only the classical method and the Bias Percentile Method are acceptable and Figure 3.1.14 shows the power for those two methods. The power increases steadily to 1 when testing skewness greater than 1 . The test statistic based on estimator $g_{1}$ is stable no matter how the other two test statistics change on power. If the alternative hypothesis value is less than 0 , the performance of test statistic based on estimator $G_{1}$ shows more power than that on $b_{1}$ while the test statistic based on estimator $b_{1}$ provides higher power than that on $G_{1}$ if alternative 
hypothesis value is greater than 0 .

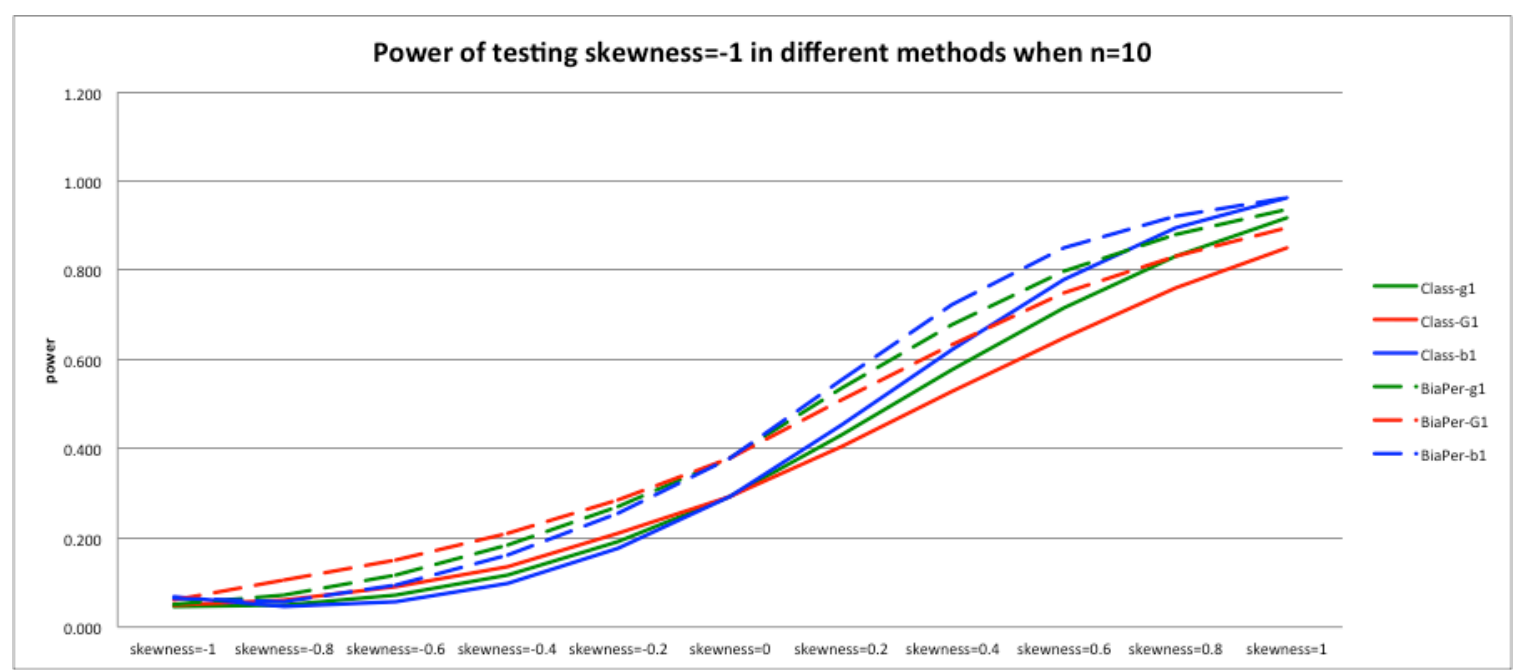

Figure 3.1.14 Power of testing skewness of Beta $(1,0.35181)$ in different methods when $n=10$

For sample size $=20,30,50$, the Bias Corrected Percentile Method provides more power than other methods. Consider testing skewness equal to -0.4 or below, when $n=20$, we could not confirm that classical tests or bootstrap method are powerful but after -0.4 , Efron's Percentile Method shows good power and Hall's Percentile Method provides least power under same condition. The results for $n=30$ are quite same as $n=20$, the only difference is Hall's Percentile Method gives the least power but after -0.2, classical method works as least powerful. When $n=50$, the classical method is less powerful than other methods. When the sample size is large enough to 100 and 300 , there is no obvious difference among bootstrap methods but apparent difference between bootstrap methods and classical method, which provides lower power under same condition. 


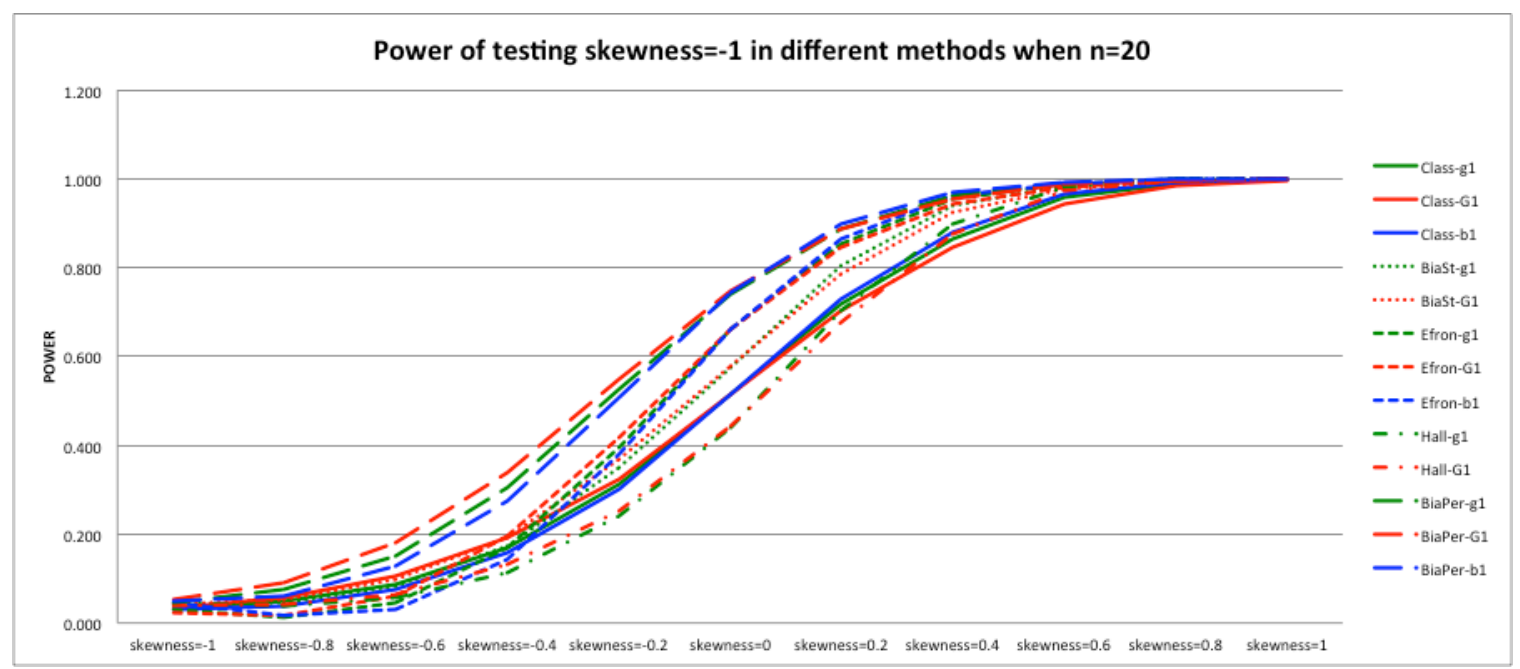

Figure 3.1.15 Power of testing skewness of Beta $(1,0.35181)$ in different methods when $n=20$

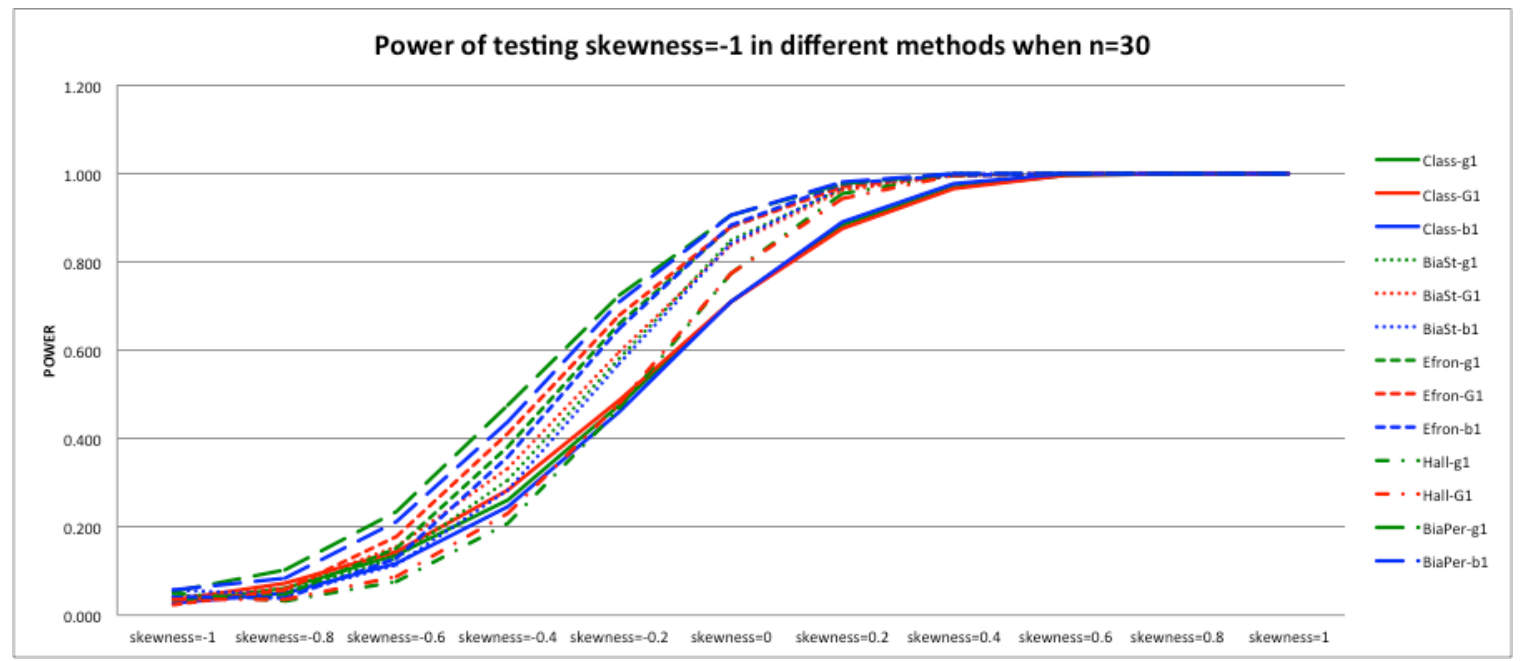

Figure 3.1.16 Power of testing skewness of Beta $(1,0.35181)$ in different methods when $n=30$ 


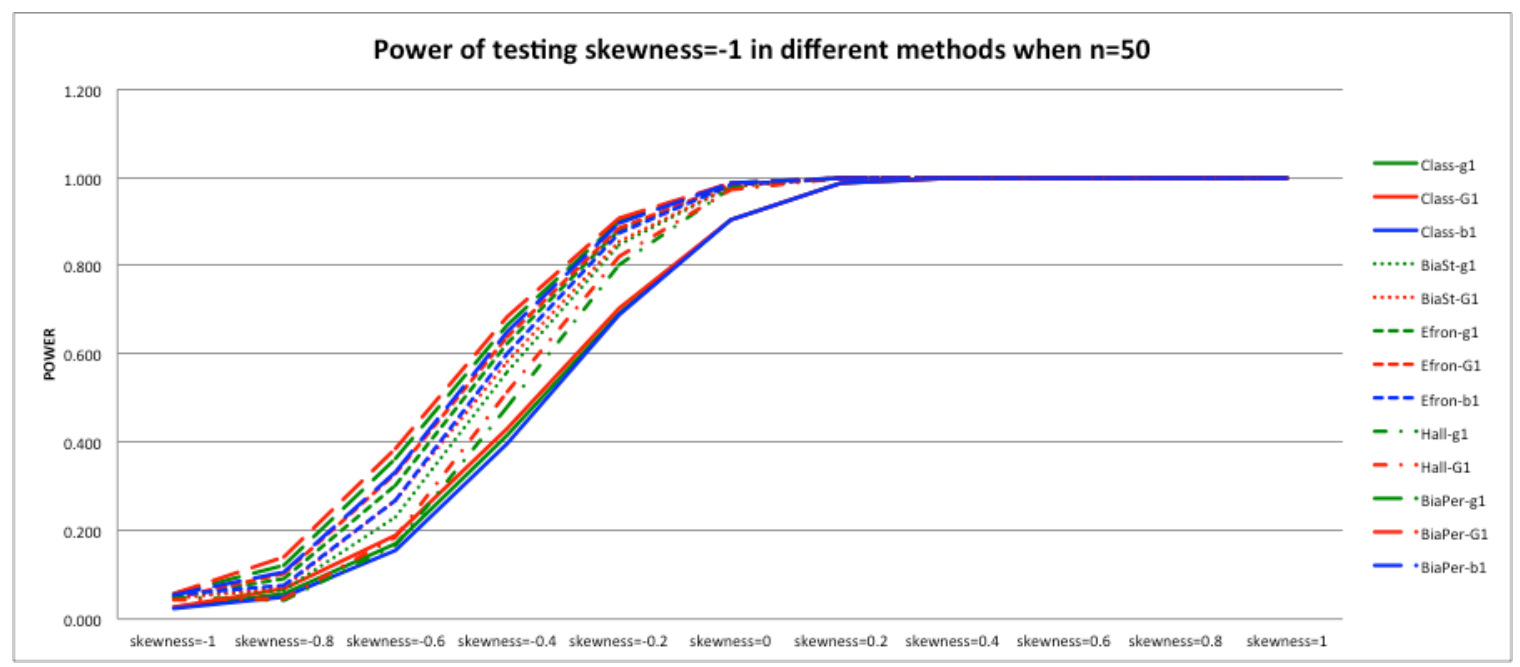

Figure 3.1.17 Power of testing skewness of Beta $(1,0.35181)$ in different methods when $n=50$

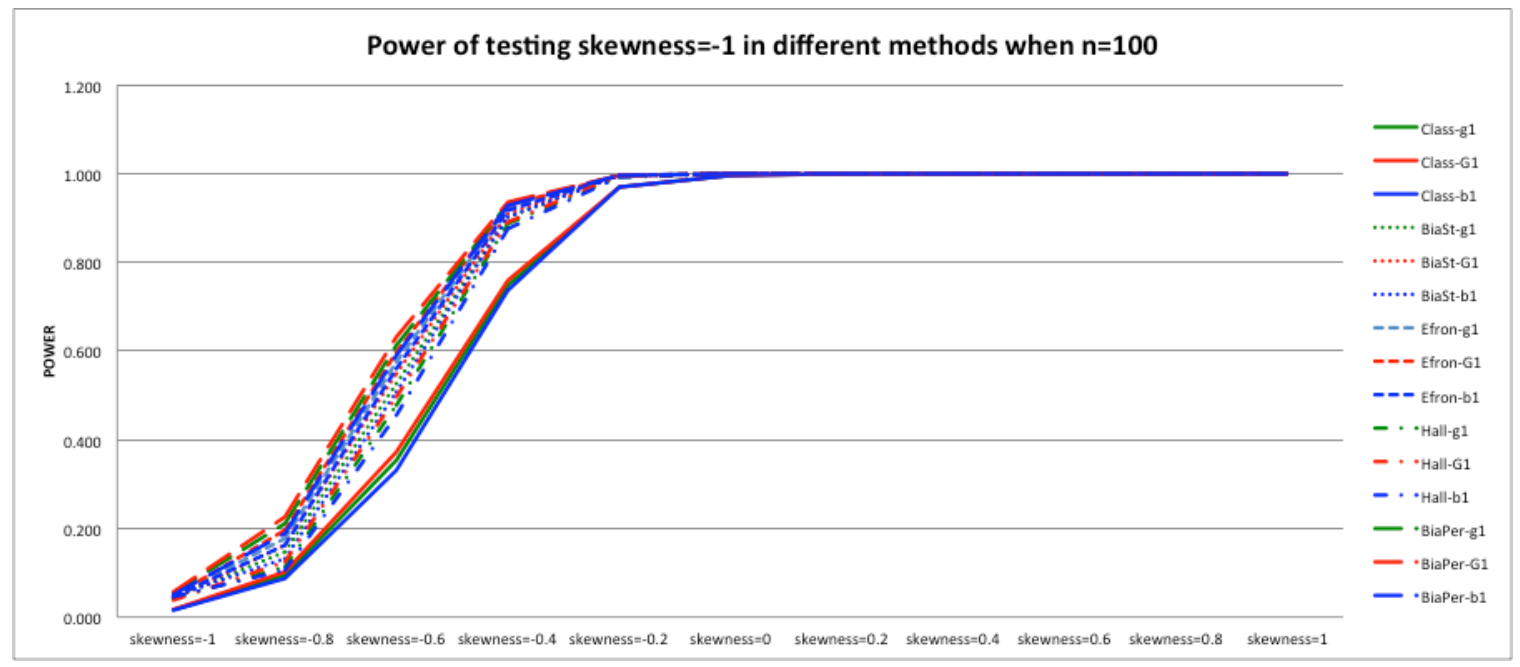

Figure 3.1.18 Power of testing skewness of Beta $(1,0.35181)$ in different methods when $n=100$ 


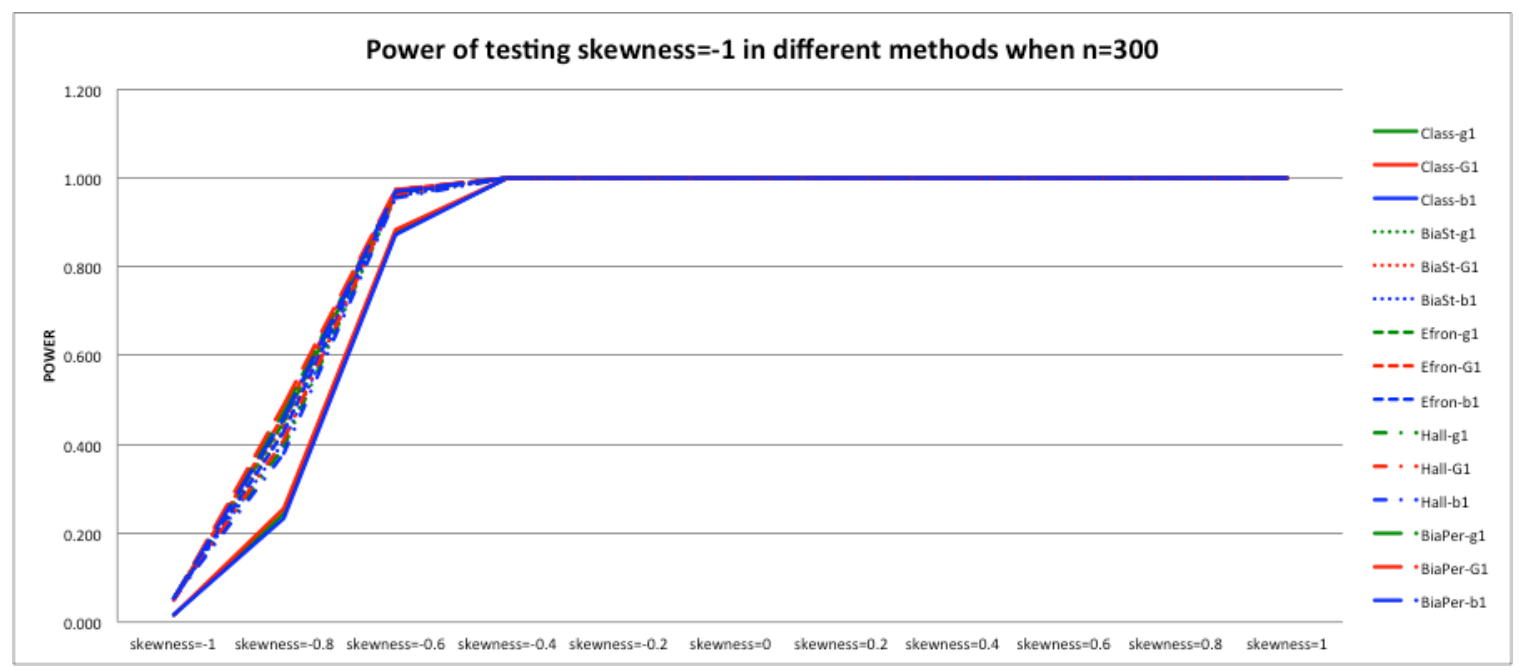

Figure 3.1.19 Power of testing skewness of Beta $(1,0.35181)$ in different methods when $n=300$

We considered power changes with different sample size for each method respectively shown in Figure 3.1.20 to 3.1.24. Among all five methods show that with increase of the sample size, the power rises sharply to 1 . When $n=300$, the power to 1 when skewness $=-0.4$. For a smaller sample size of 100 , the power increase to 1 at skewness $=0$ for classical method, while other methods provides early arrival at skewness $=-0.2$. When sample size is 50 , the methods do not make big difference about gradual increase to 1 . If the sample size is small, such as 10 , the power rises slowly to 1 and the performance of classical method is not consistent. When we are testing skewness equal to 0 or less, the test statistic derived from the estimator $b_{1}$ shows lower power while on $G_{1}$ provides higher power. However, the performance of these two test statistics exchanges when we are testing skewness greater than 0 . For large sample size 100 and 300, the performance of different methods or test statistics are getting closer and 
no apparent differences could be viewed. Figure 3.1.23 illustrates the power changes for the test statistics based on those three proposed estimators. From the classical method with different sample size and when $n=20,30,50$, we could get a result that the test statistic using the estimator $G_{1}$ performs better than the other two test statistics, and that on $b_{1}$ is the least powerful estimator. However, with increase about the testing skewness, they eventually perform as one line and the performance will be similar when we are testing skewness $=1$ or greater than 1 .

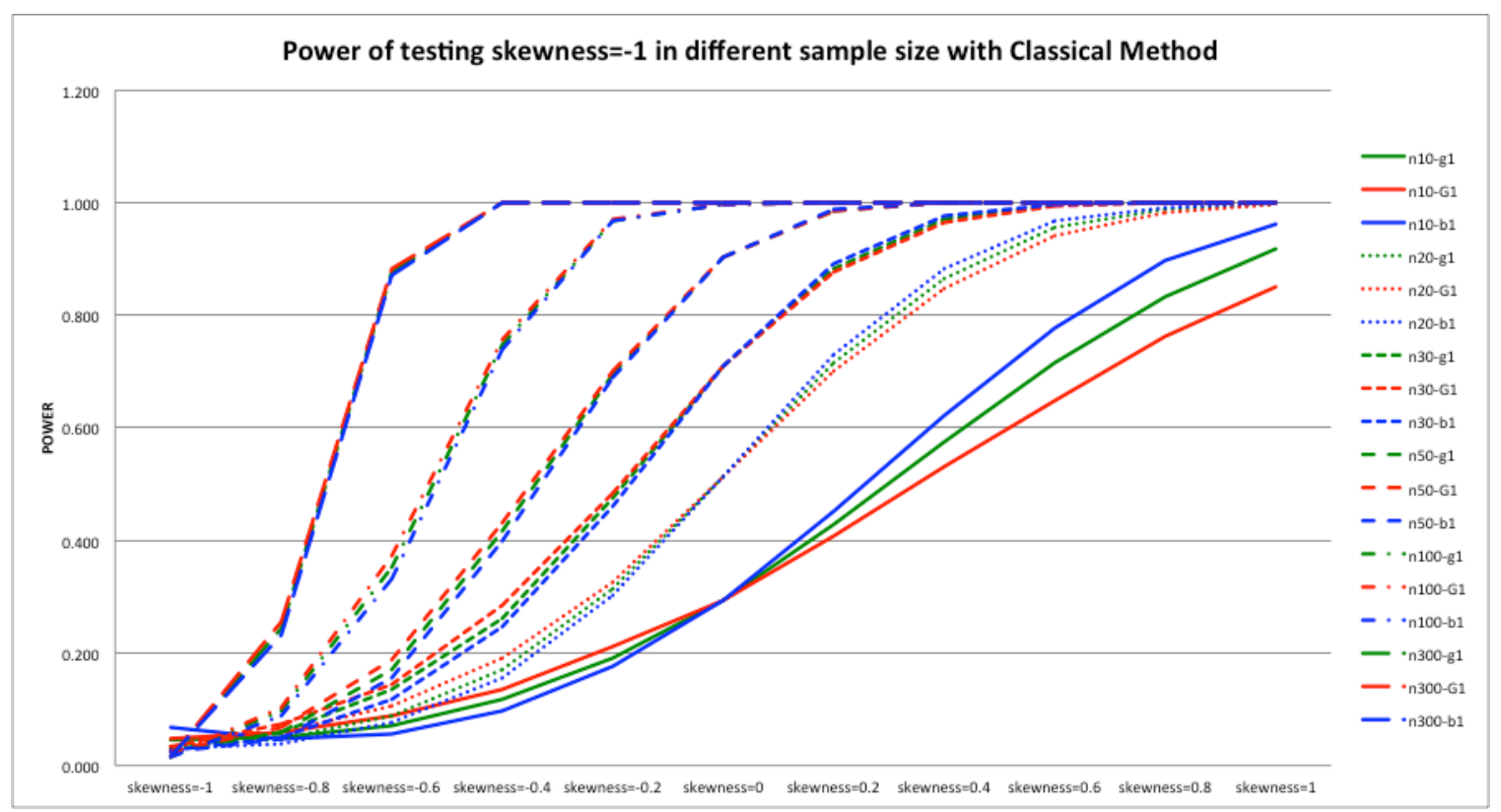

Figure 3.1.20 Power of testing skewness of Beta $(1,0.35181)$ in different sample size with Classical Method 


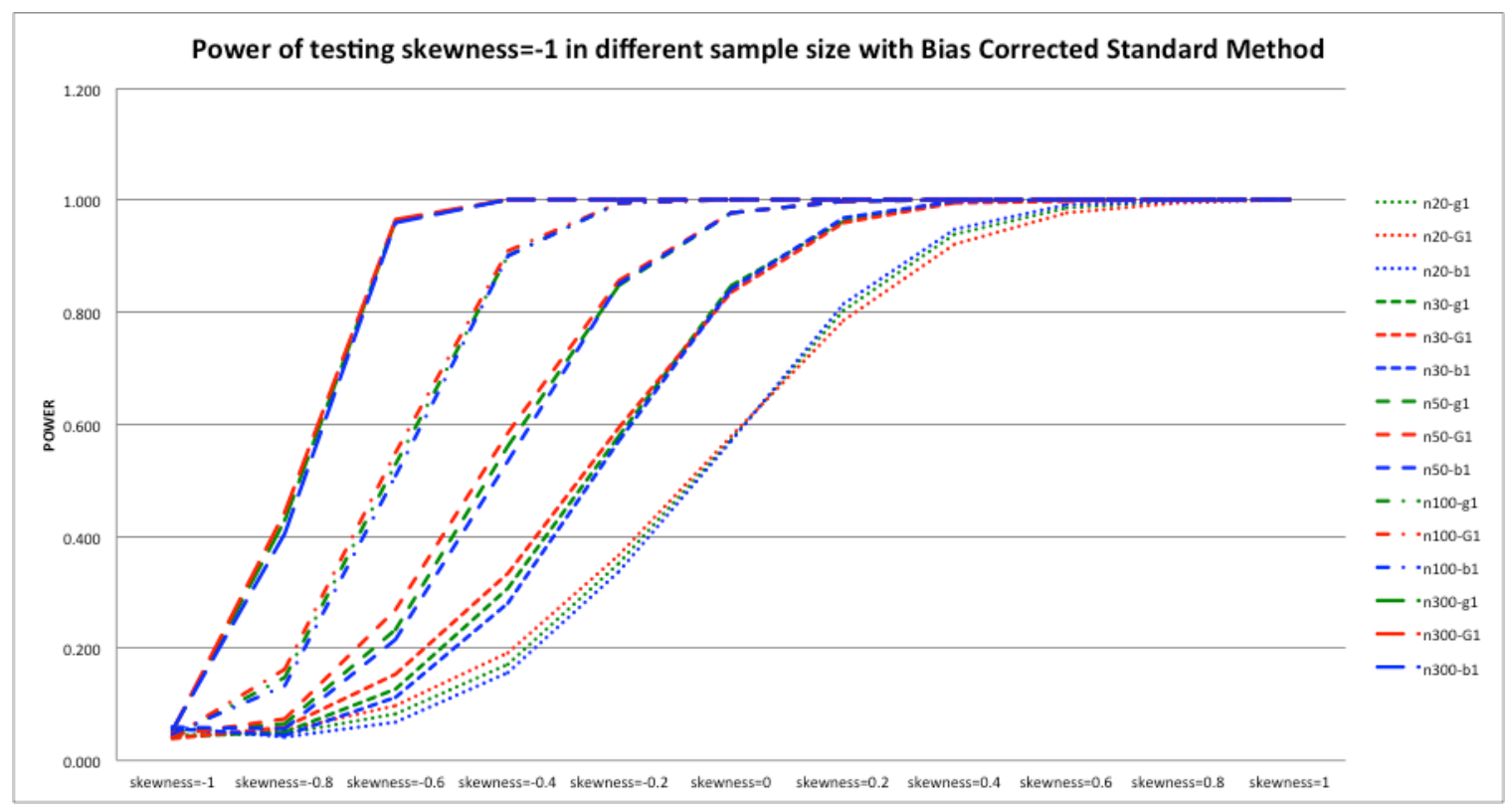

Figure 3.1.21 Power of testing skewness of Beta $(1,0.35181)$ in different sample size with Bias Corrected Standard Method

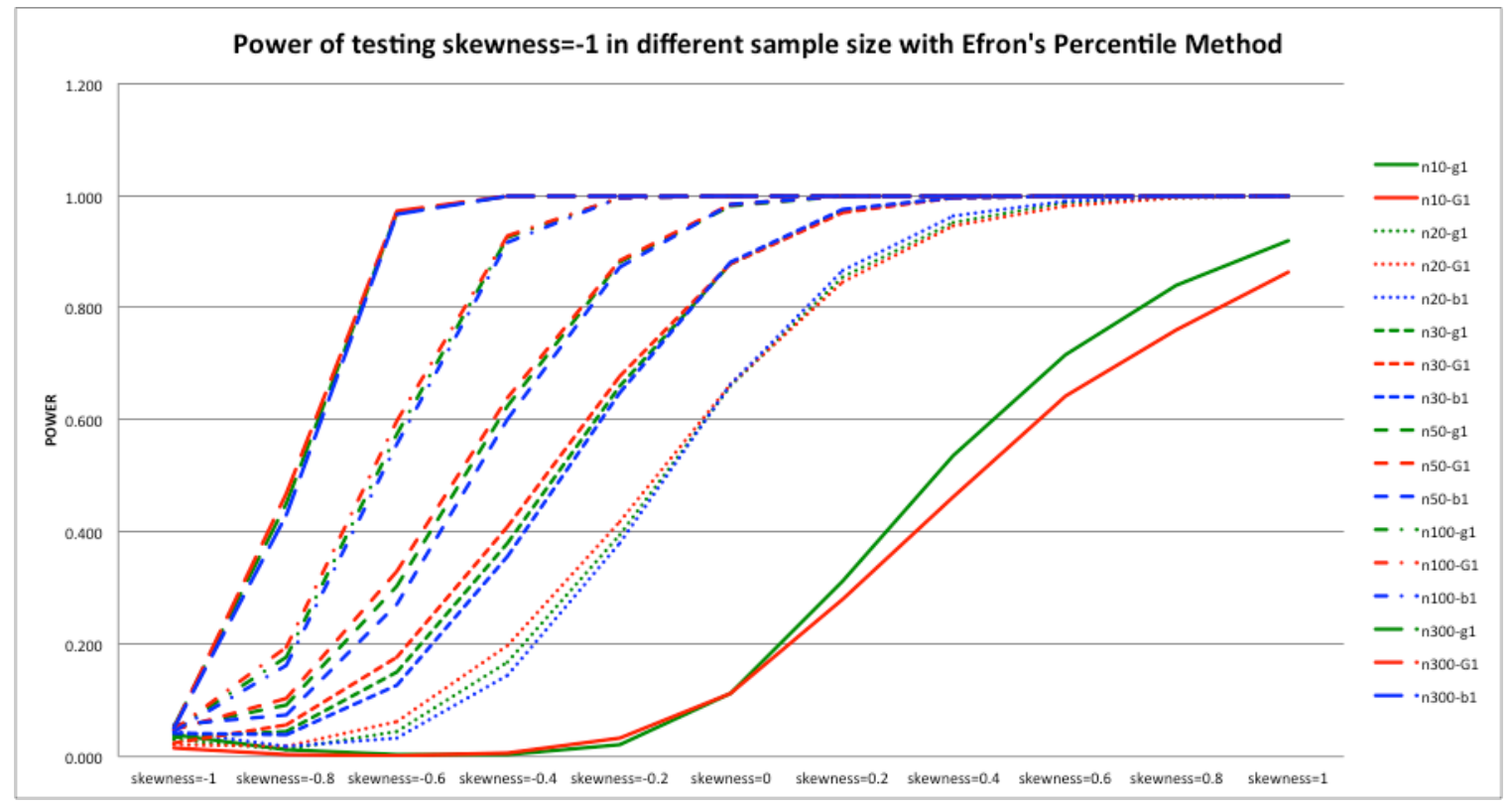

Figure 3.1.22 Power of testing skewness of Beta $(1,0.35181)$ in different sample size with Efron's Percentile Method 


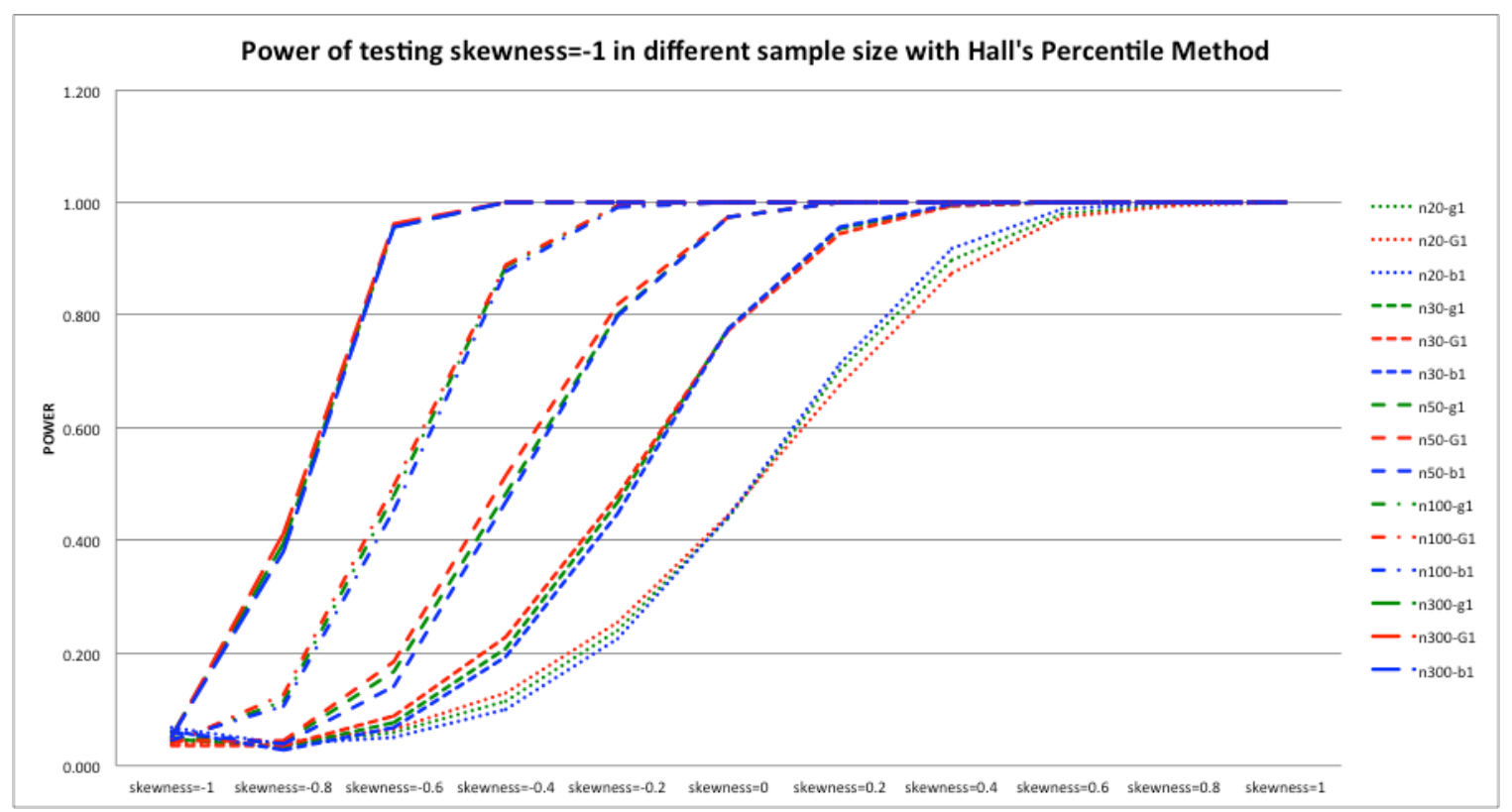

Figure 3.1.23 Power of testing skewness of Beta $(1,0.35181)$ in different sample size with Hall's Percentile Method

From Figure 3.1.24, we observe that the power changes of moderate departure from null hypothesized value to a large value. We may conclude that when Bias Corrected Percentile Method is used with a Beta distribution, the power goes up rapidly to 1 for large sample size when testing skewness $=-0.2$ and -0.4 for $n=100$ and 300 respectively. Even though sample size is not that large, only little difference can be observed among three test statistics. However for sample size 10, the performance of the test statistics based on the three estimators is not stable, that will be depending on the testing hypothesized value. 


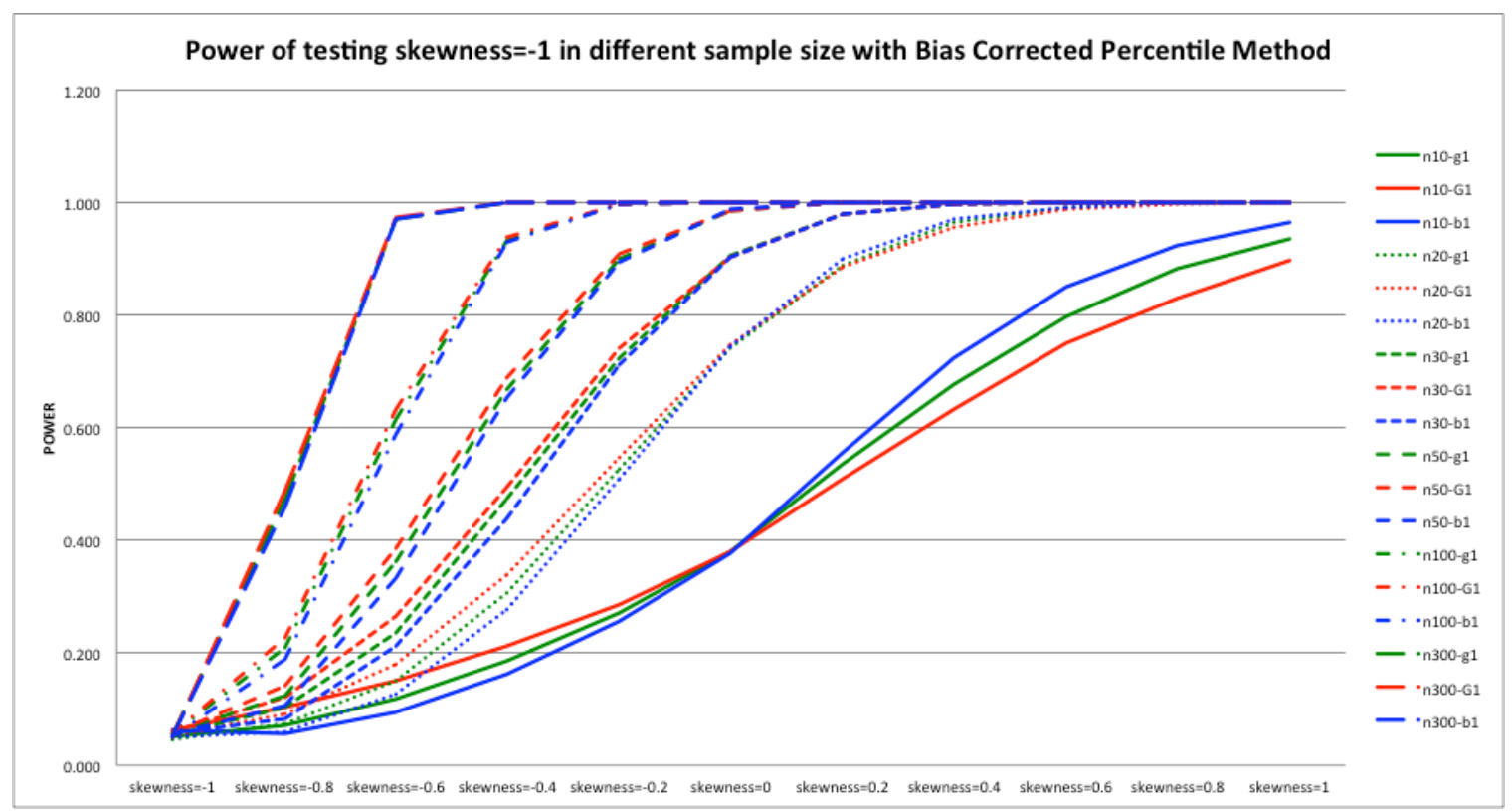

Figure 3.1.24 Power of testing skewness of Beta $(1,0.35181)$ in different sample size with Bias Corrected Percentile Method

Below Figure 3.1.25 displays the results when we are testing whether the skewness $=-2$ or not for Beta $(1,0.15470)$, the $\mathrm{X}$-axis represents the different sample size and Y-axis stands for empirical power, all three proposed test statistics using the estimators are analyzed as what we did for Beta $(1,0.35181)$. When the sample size is small, especially $n=10$, we are not able to confirm which method or estimator performs better, only the test statistic based on $G_{1}$ from Bias Corrected Percentile Method, Classical Method and Efron's Percentile Method can make it or others are more than 0.05. With the increase of sample size to 20 , only results of test statistics based on estimator $g_{1}$ and $G_{1}$ from Efron's Percentile Method could be acceptable. Comparing to a sample size of 20, we have to add the test statistics based on Efron's $b_{1}$ estimator to test the power when $n=30$. For sample size 50 , even though the results among three test statistics 
of $g_{1}, G_{1}$ and $b_{1}$ from Bias Corrected Percentile Method are a little beyond what we need, we still keep them, as we would like to compare it with large sample size 300 . The test performance based on estimator $g_{1}, G_{1}$ and $b_{1}$ from Efron's Percentile Method could meet the requirement. While the sample size is large enough, such as $n=100$ and 300 , the results from most of the estimators are good as what we expected. Especially when samples size is 300 , all methods provide power about 0.05 except Classical Method. Thus we may conclude that the bootstrap method will be more accurate with increase of the sample size and Classical method is not use for Beta $(1,0.15470)$ except small sample size 10 .

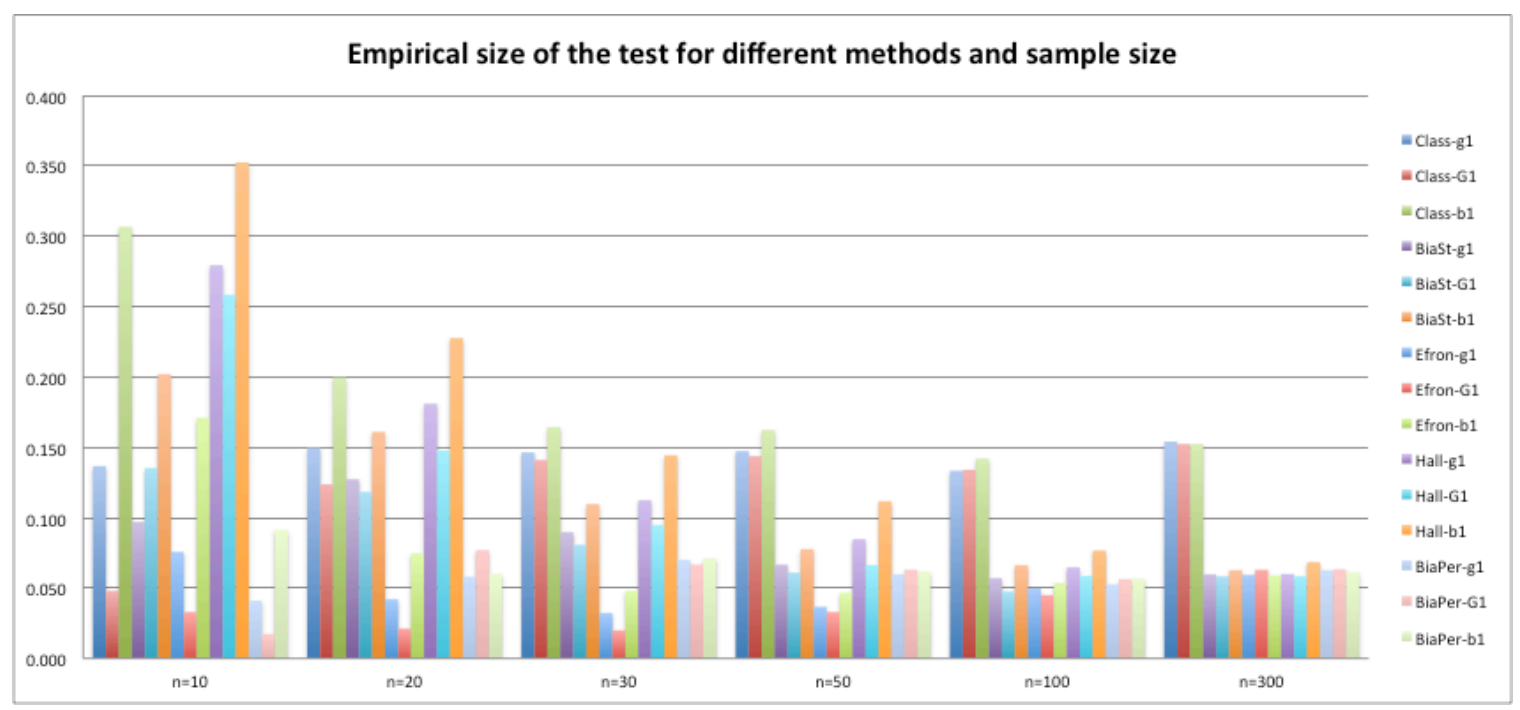

Figure 3.1.25 Empirical size of testing skewness $=-2$ with different methods and sample size

When sample size equals to 10, we only have below four lines from Figure 3.1.26 acceptable due to limitation of critical value, however, the test statistics based on Efron's $G_{1}$ could not be acceptable since the power doesn't go up until testing skewness $=-0.4$. 
We are expecting a rise with each increase in testing skewness but failed in testing the skewness based on this estimator. All other three test statistics show gradual increase about the power but we do not see a power 1 in this graph, when we test skewness $=1$, power could be near 1 .

From Figure 3.1.27 and 3.1.28, we get a gentle increase in power to 1 at skewness $=-0.2$ and skewness $=0$ respectively. And under same situation, the test statistic based on $G_{1}$ provides higher power than that based on $g_{1}$. However there is still some drawback in $n=20$ and 30 which is at the beginning we increase the skewness, we catch a constant or even decrease power other than gradually increase as a whole.

When $\mathrm{n}=50$, as we expected, Figure 3.1.29 shows the power reached 1 when skewness $=-0.6$. The test statistic based on the estimator $G_{1}$ in Efron's Percentile Method provides a higher power while on b1 in Efron's Percentile Method shows lower power.

By increasing sample size to 100 , the results from Figure 3.1.30 seems more reasonable than small sample size, the power rises slightly to 1 at skewness $=-0.6$. However in this sample size, the peak and weak power changed to $G_{1}$ in Bias Corrected Percentile Method and Hall's Percentile Method respectively.

When the sample size is large enough, $\mathrm{n}=300$, the power rises to 1 rapidly at skewness $=-1.2$ and most of the lines are overlapping thus it is not easy to identify which measurement performs best. 


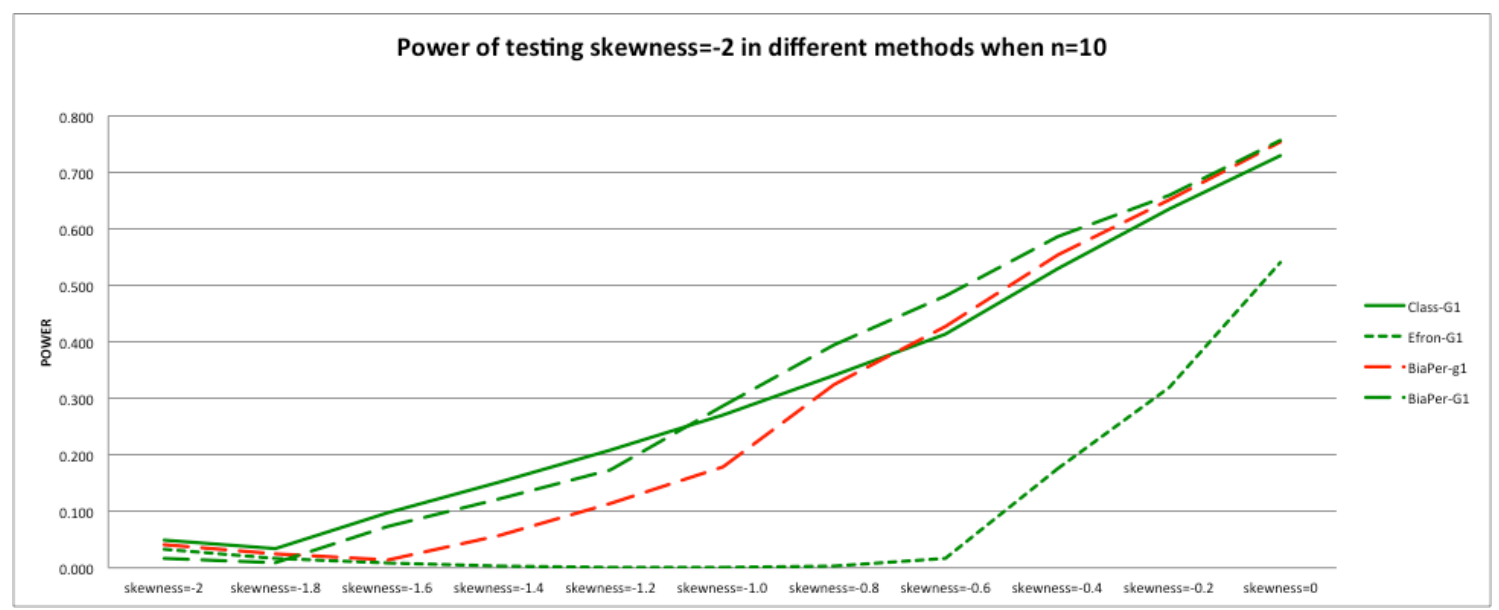

Figure 3.1.26 Power of testing skewness of Beta $(1,0.15470)$ in different methods when $n=10$

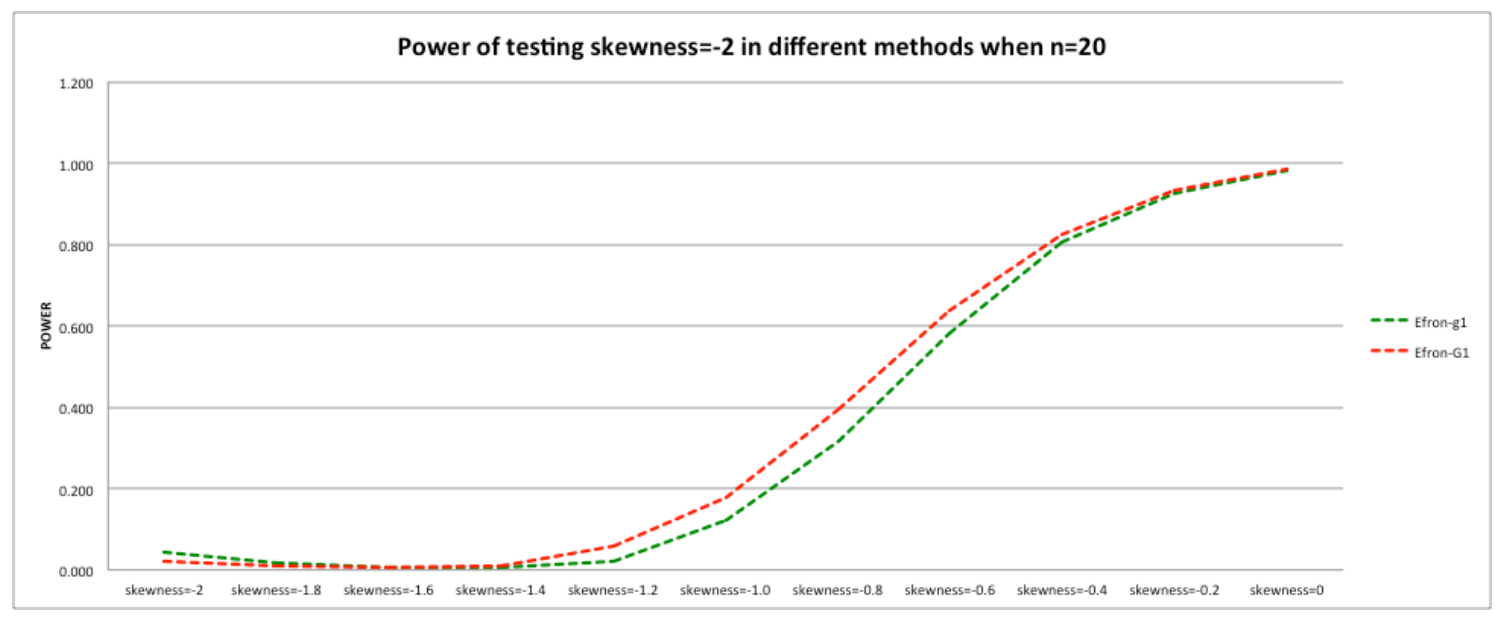

Figure 3.1.27 Power of testing skewness of Beta $(1,0.15470)$ in different methods when $n=20$

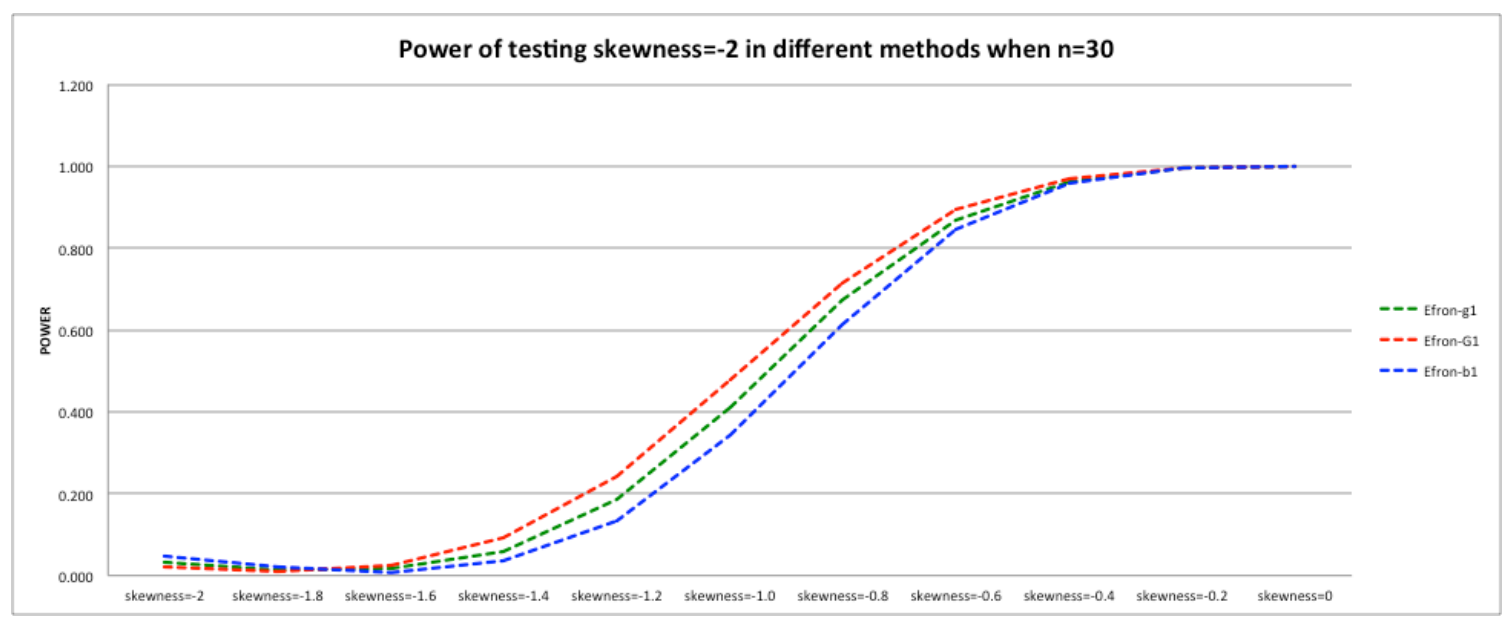

Figure 3.1.28 Power of testing skewness of Beta $(1,0.15470)$ in different methods when $n=30$ 


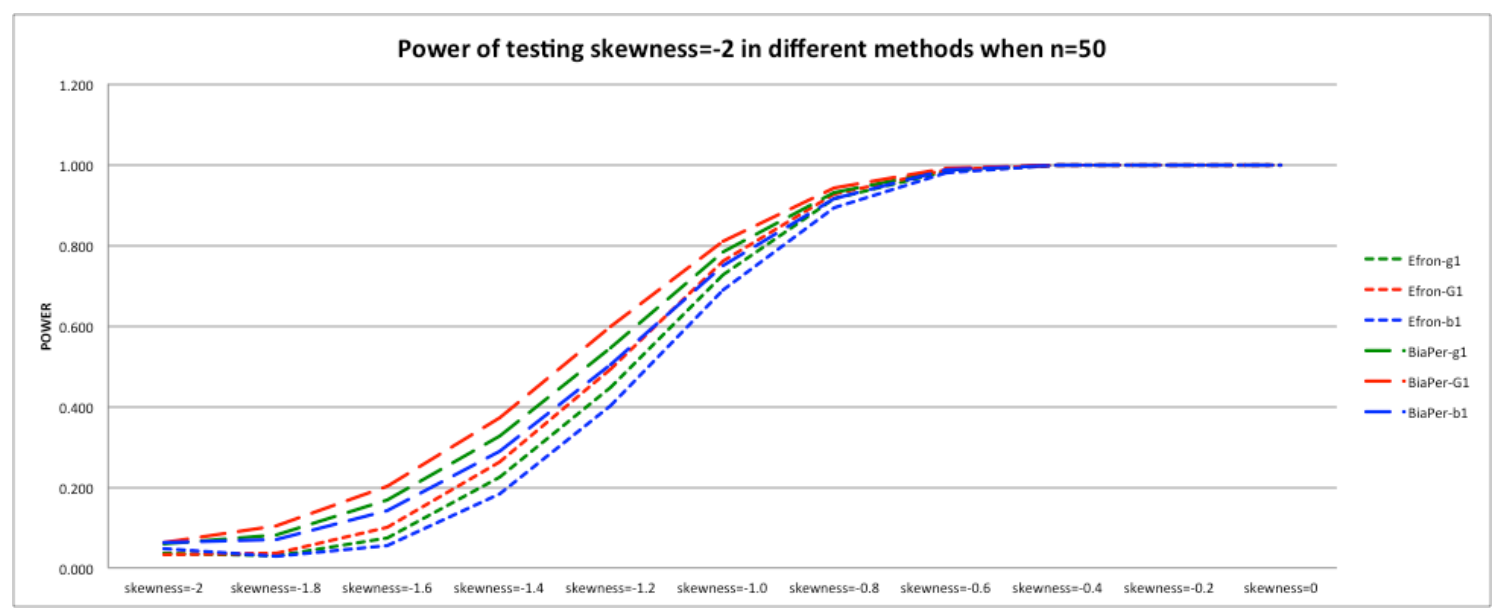

Figure 3.1.29 Power of testing skewness of Beta $(1,0.15470)$ in different methods when $n=50$

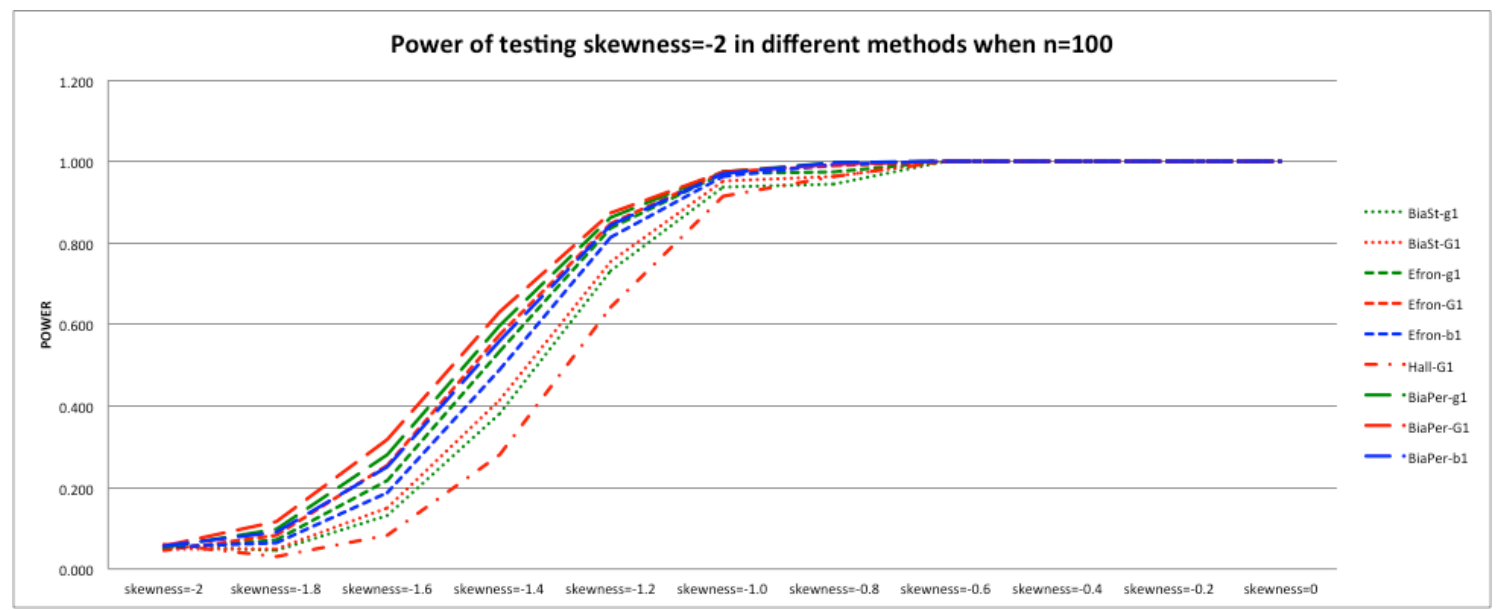

Figure 3.1.30 Power of testing skewness of Beta $(1,0.15470)$ in different methods when $n=100$

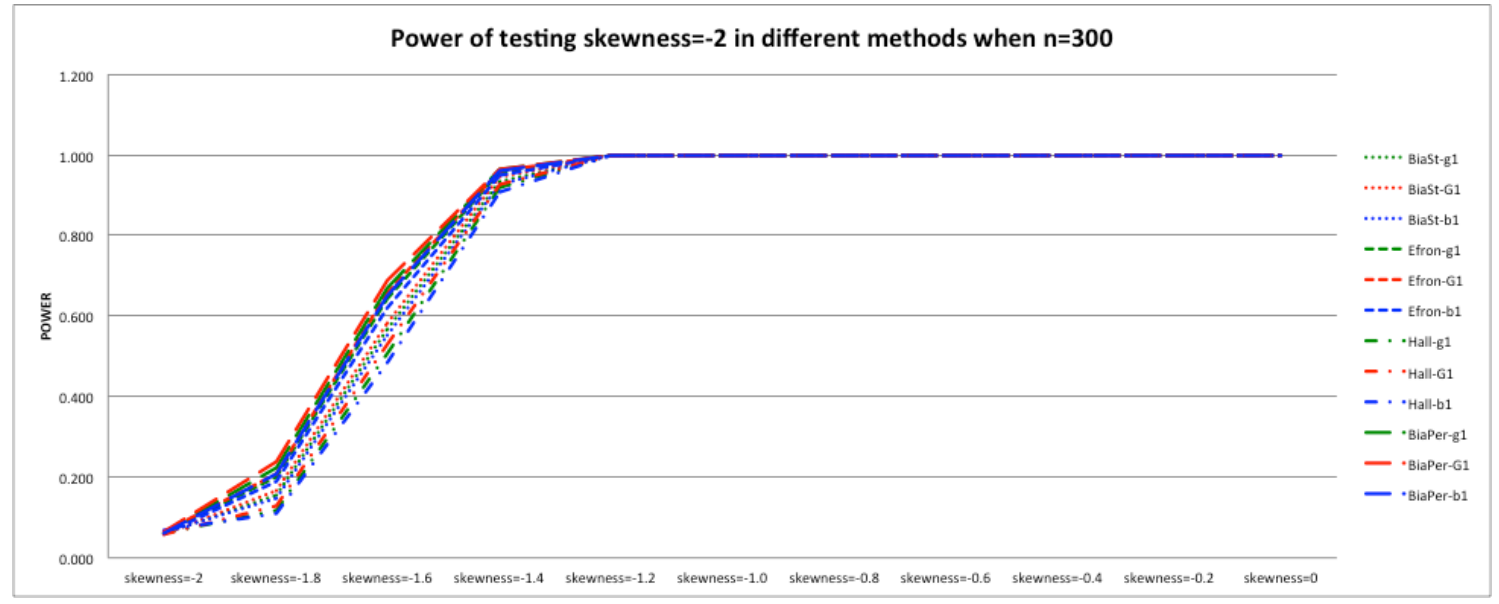

Figure 3.1.31 Power of testing skewness of Beta $(1,0.15470)$ in different methods when $n=300$ 
Since Efron's Percentile Method was employed through all kinds of sample size from 10 to 300 , we could conclude that higher sample size can make higher power under same alternative hypothesis. However the performance of different test statistics based on those proposed estimators vary greatly with changes of sample size. And we may conclude that for a large sample size with Efron's Percentile Method, the test statistics based on estimator $G_{1}$ performs best whereas the test statistics based on estimator $b_{1}$ performs worst, but if sample size is greater than 300 , no obvious differences among those test statistics can be observed.

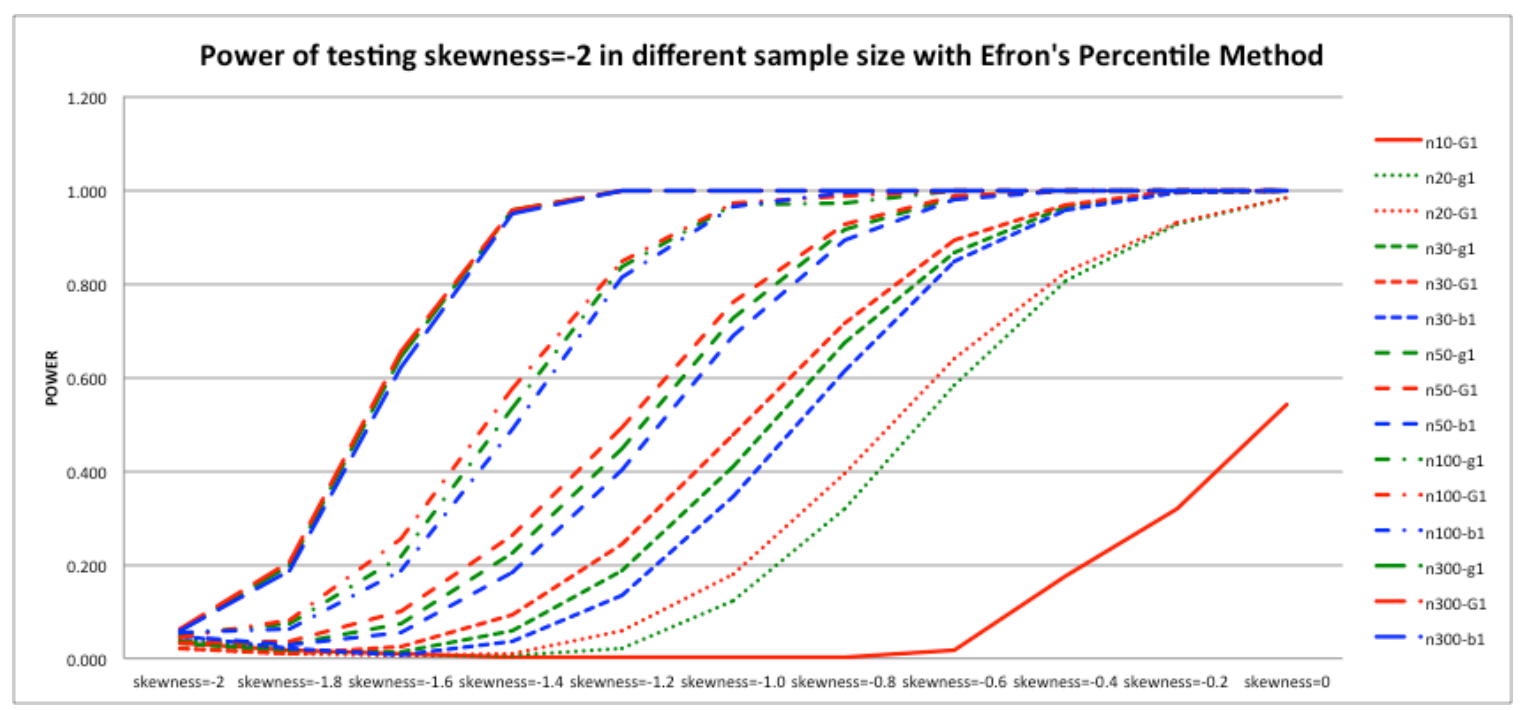

Figure 3.1.32 Power of testing skewness of Beta $(1,0.15470)$ in different sample size with Efron's Percentile Method 


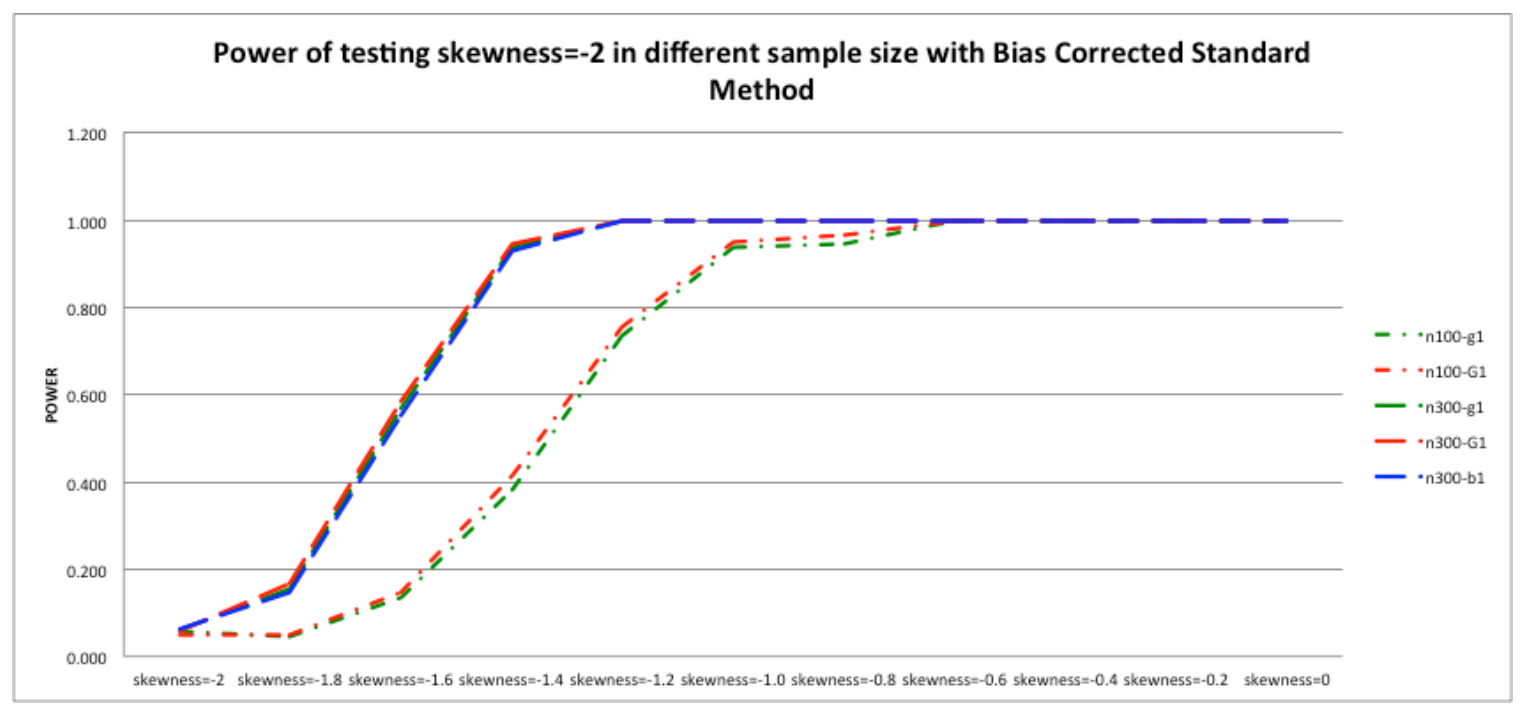

Figure 3.1.33 Power of testing skewness of Beta $(1,0.15470)$ in different sample size with Bias Corrected Percentile Method

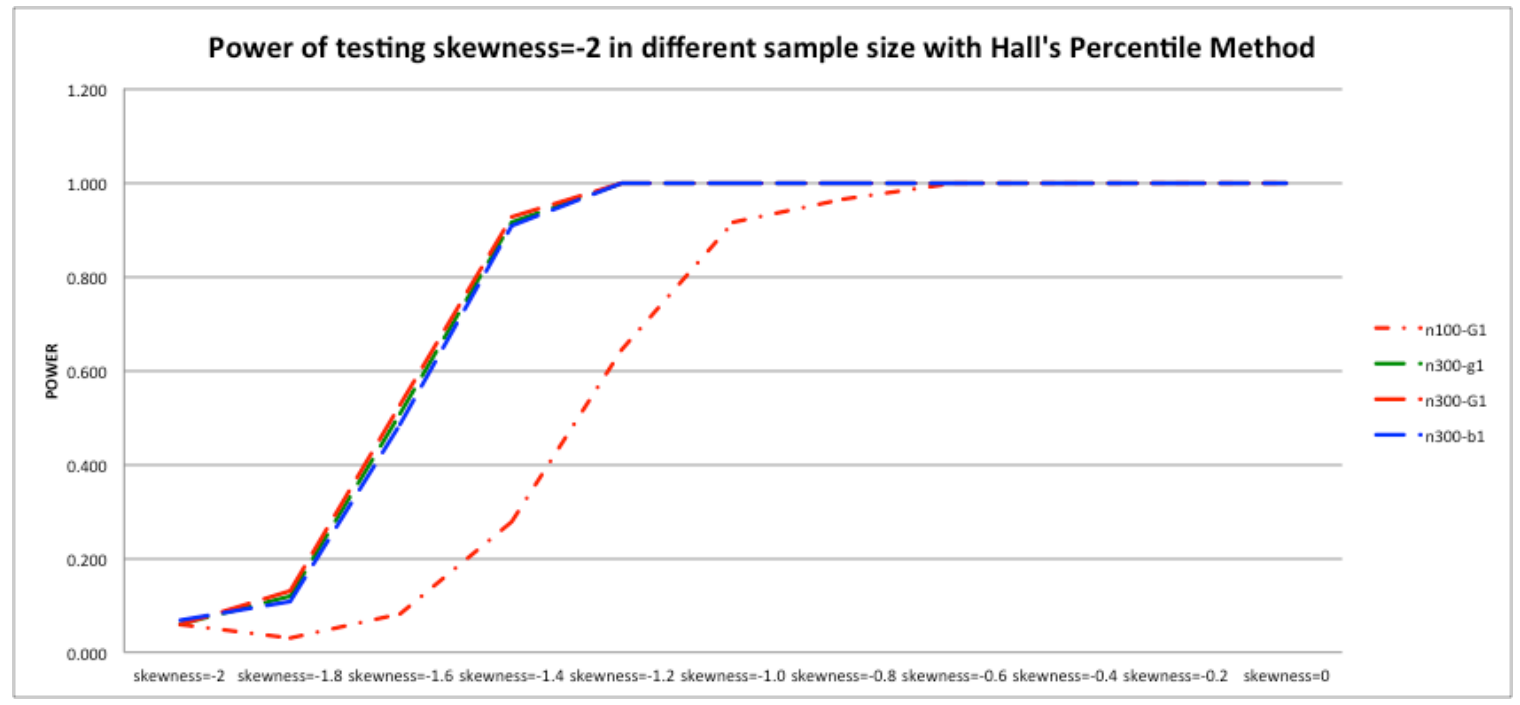

Figure 3.1.34 Power of testing skewness of Beta $(1,0.15470)$ in different sample size with Hall's Percentile Method 


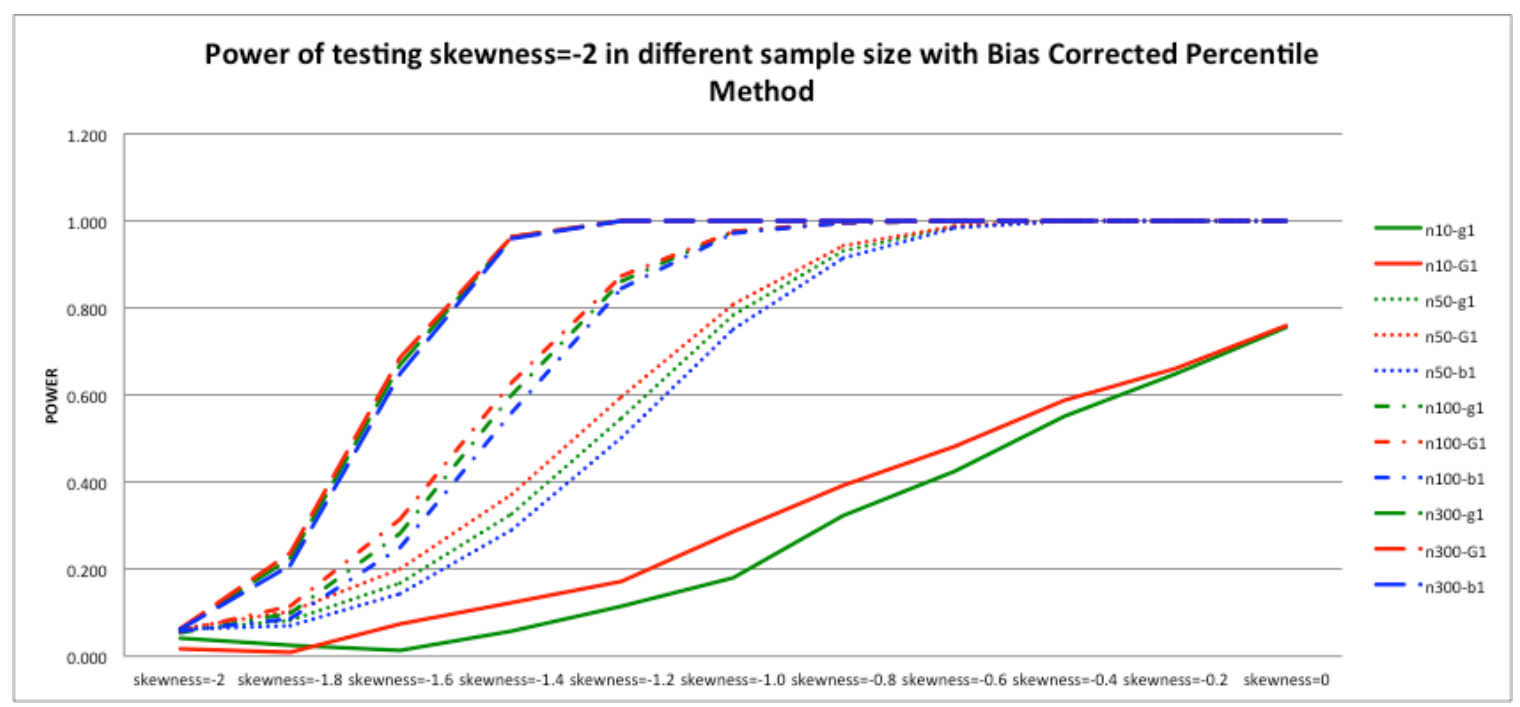

Figure 3.1.35 Power of testing skewness of Beta $(1,0.15470)$ in different sample size with Bias Corrected Percentile Method

\subsection{Simulation Study for Kurtosis}

\subsubsection{Simulation Technique}

Since a theoretical comparison among the proposed test statistics is not possible, a simulation study has been conducted to compare the performance of the test statistics in the sense of attaining the nominal size and empirical power. Even the proposed test statistics are mainly developed for testing data from a normal (or symmetric) population, we will try to see the performance of this tests when the data are other than normal, say long tailed distribution. The flow chart of our simulation study are (not limited) given below and the probability density function of each distribution are located thereafter:

(4) Sample size, $n=10,20,30,50,100$ and 300.

(5) 3000 simulation replications are used for each case, 1000 bootstrap samples for each simulation replication. 
(6) The normal and non-normal distributions are generated as following:

d) Normal distribution with mean 0 and SD 1

e) Beta distribution with shape parameter 2 and scale parameter 5

f) Uniform distribution with shape parameters 0 and scale parameters 1 .

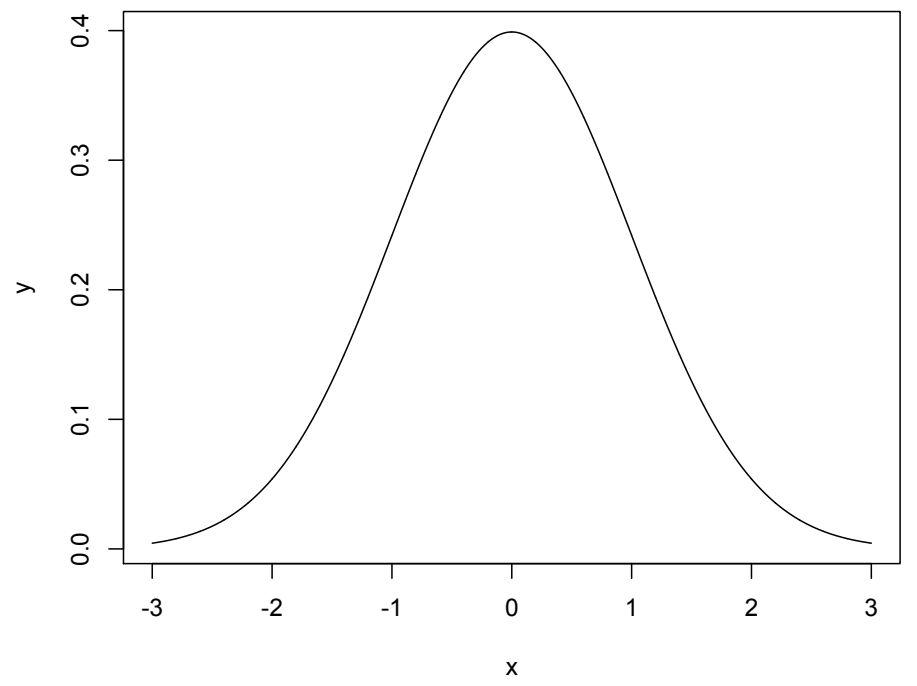

Figure 3.2.1.1 Probability density function of $N(0,1)$ distribution 


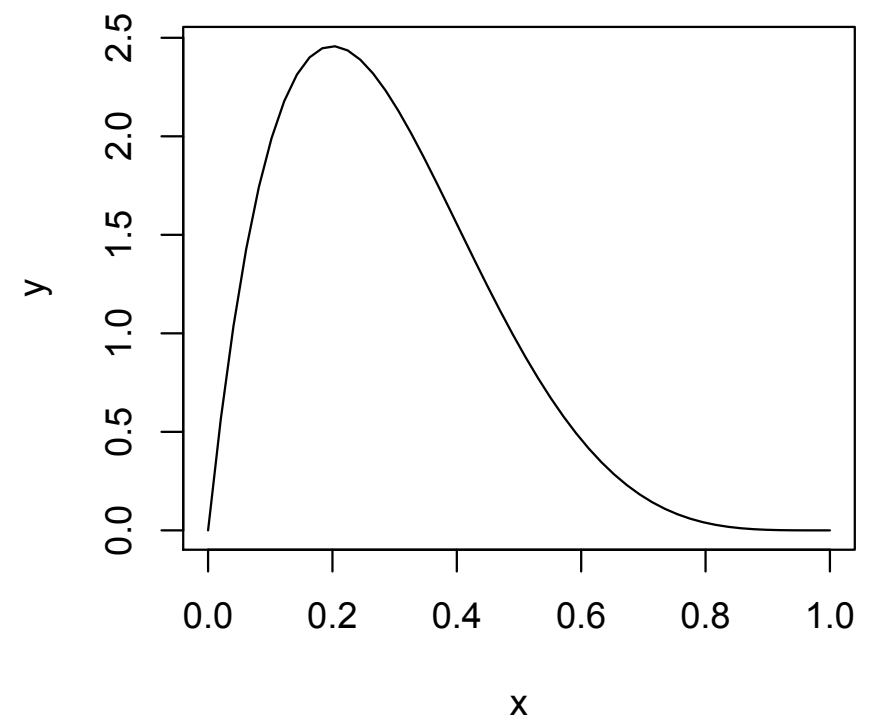

Figure 3.2.1.2 Probability density function of Beta $(2,5)$ distribution

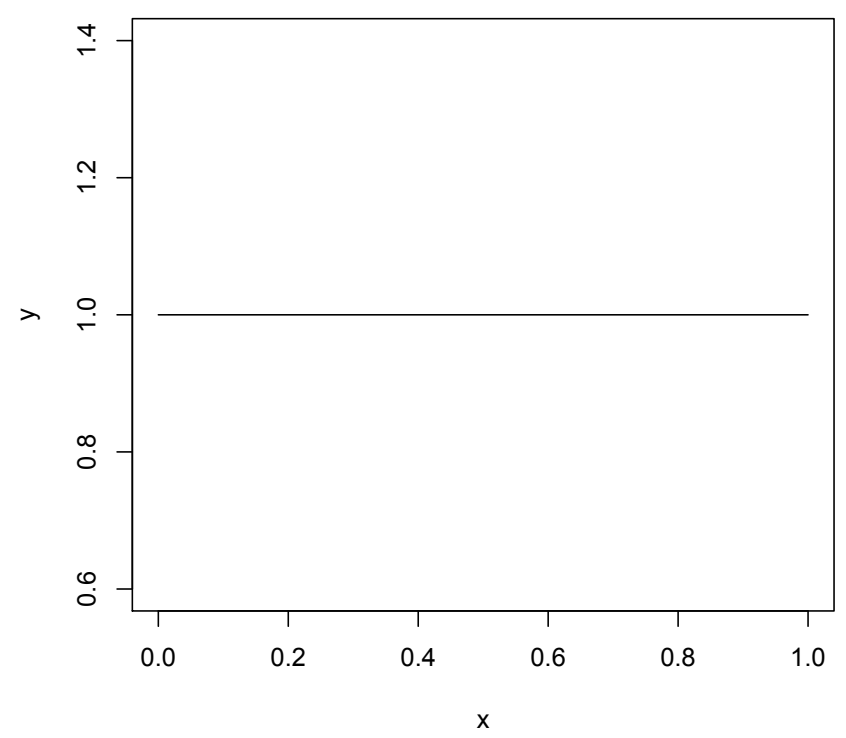

Figure 3.2.1.3 Probability density function of Uniform $(0,1)$ distribution 


\subsubsection{Performance for Normal distribution}

As we defined before, the test statistic is based on excess kurtosis, which is kurtosis minus 3, and for later discussion all about excess kurtosis refers to kurtosis.

Normal distribution is a prominent mesokurtic distribution, which has zero excess kurtosis. Under this assumption and at alpha $=0.05$ level of significance, we are expecting to get the power $=0.05$ from the simulation data. Figure 3.2.1 shows the empirical size of the test when we are testing the kurtosis equals to 0 . It is obvious to see that the classical method performing the best among all methods in order to attain nominal size 0.05 for different sample size. It should be mentioned that the test statistic from Efron's $G_{1}$ estimator performs perfectly when $n=30$, otherwise the bootstrap methods cannot provide any good results than classical method.

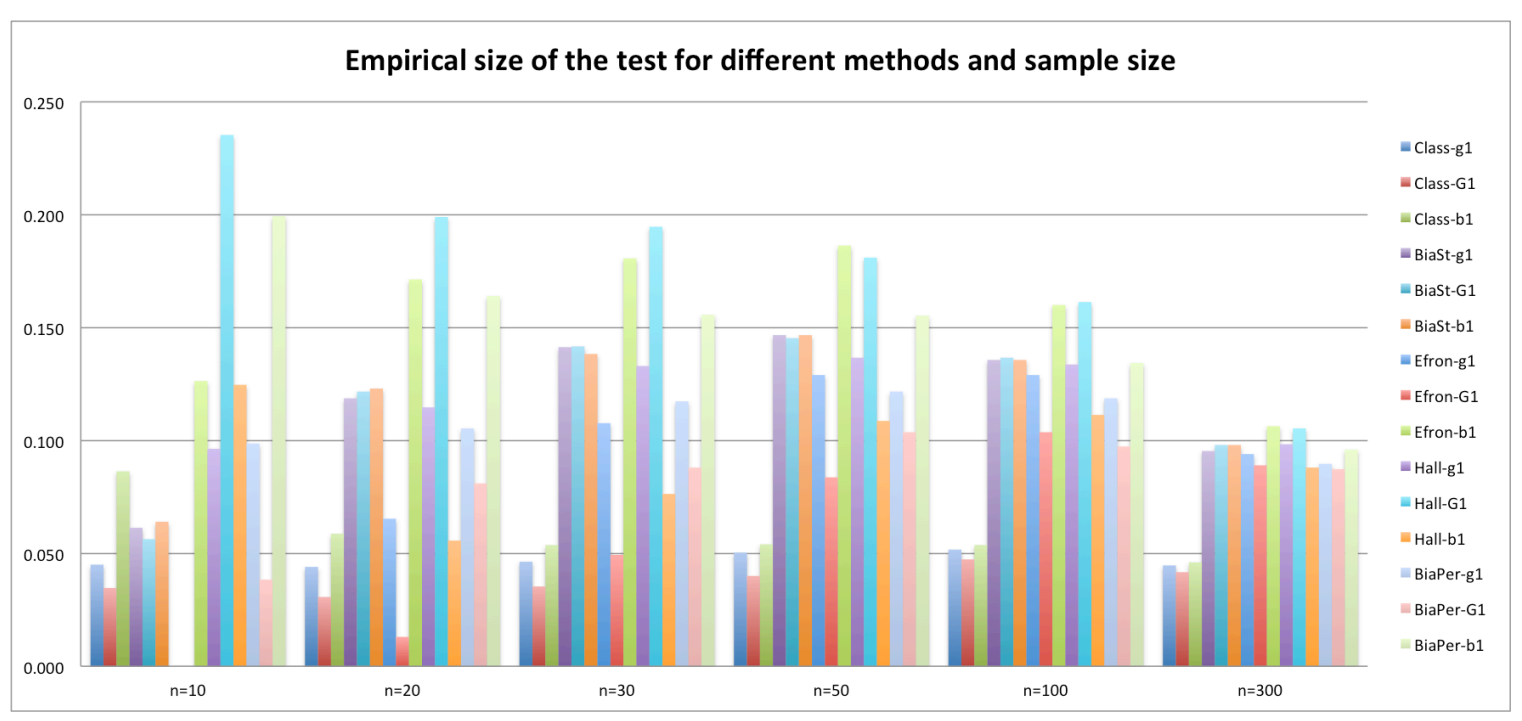

Figure 3.2.1 Empirical size of testing kurtosis $=0$ for different methods and sample size 
Figure 3.2.2 to 3.2.7 are discussing the empirical power against different hypothesized values for all proposed test statistics with different sample sizes: $\mathrm{n}=10,20$, 30, 50, 100 and 300. The $\mathrm{X}$-axis represents different hypothesized values and $\mathrm{Y}$-axis stands for empirical power and we are expecting the empirical power close to 1 with increasing the hypothesized value from 0 to a large value. From these 6 figures, the empirical power appears to reach 1 when kurtosis equals to 3 or above.

It is not difficult to find from Figures 3.2.2 to 3.2.7 that for small sample size, say 10, with moderate departure from null hypothesis the power of the tests differs among the test statistics. Among all sample sizes near the null hypothesis, the power of the test does not vary greatly. Overall, the power approaches 1 when the alternative hypothesis is testing for kurtosis $=3$ except when sample size is 10 .

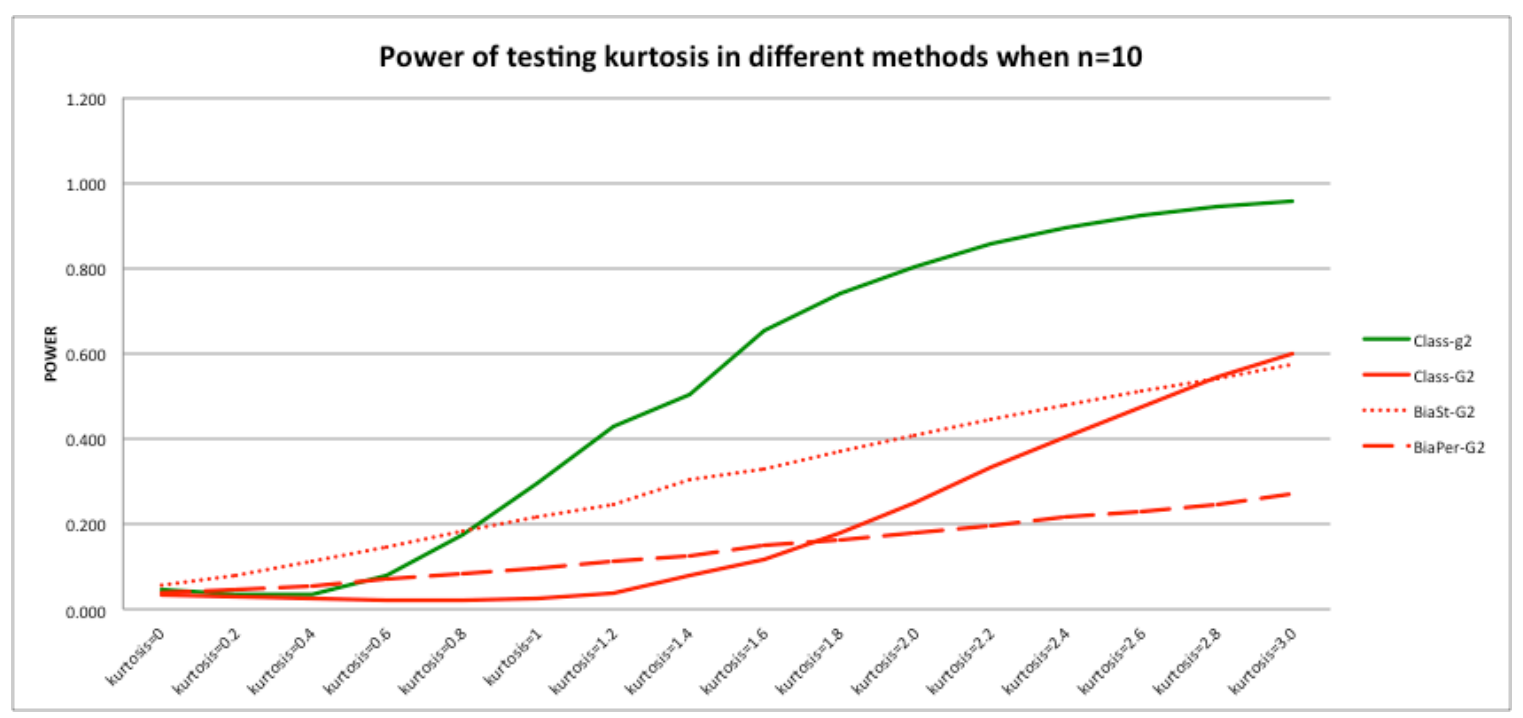

Figure 3.2.2 Power of testing kurtosis of $\mathrm{N}(0,1)$ in different methods when $\mathrm{n}=10$ 


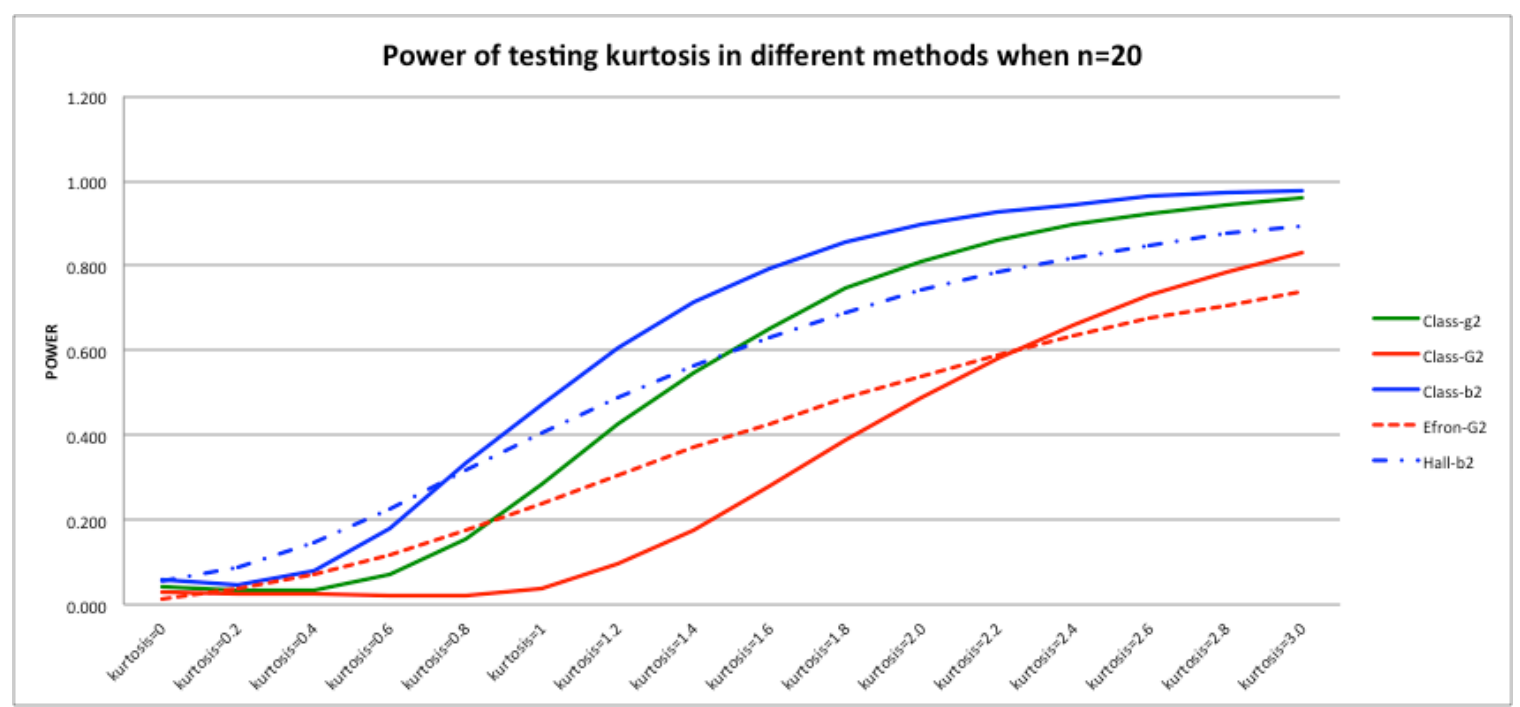

Figure 3.2.3 Power of testing kurtosis of $\mathrm{N}(0,1)$ in different methods when $\mathrm{n}=20$

From Figure 3.2.4 and 3.2.5, only test statistics from classical methods and Efron's $G_{1}$ show acceptable results. With changing the alternative hypothesis, three estimators of the classical method are getting closer to each other and apparently away from Efron's Percentile Method. The power goes up moderately to 1 when kurtosis $=3$ and 2.6 respectively for $\mathrm{n}=30$ and 50 .

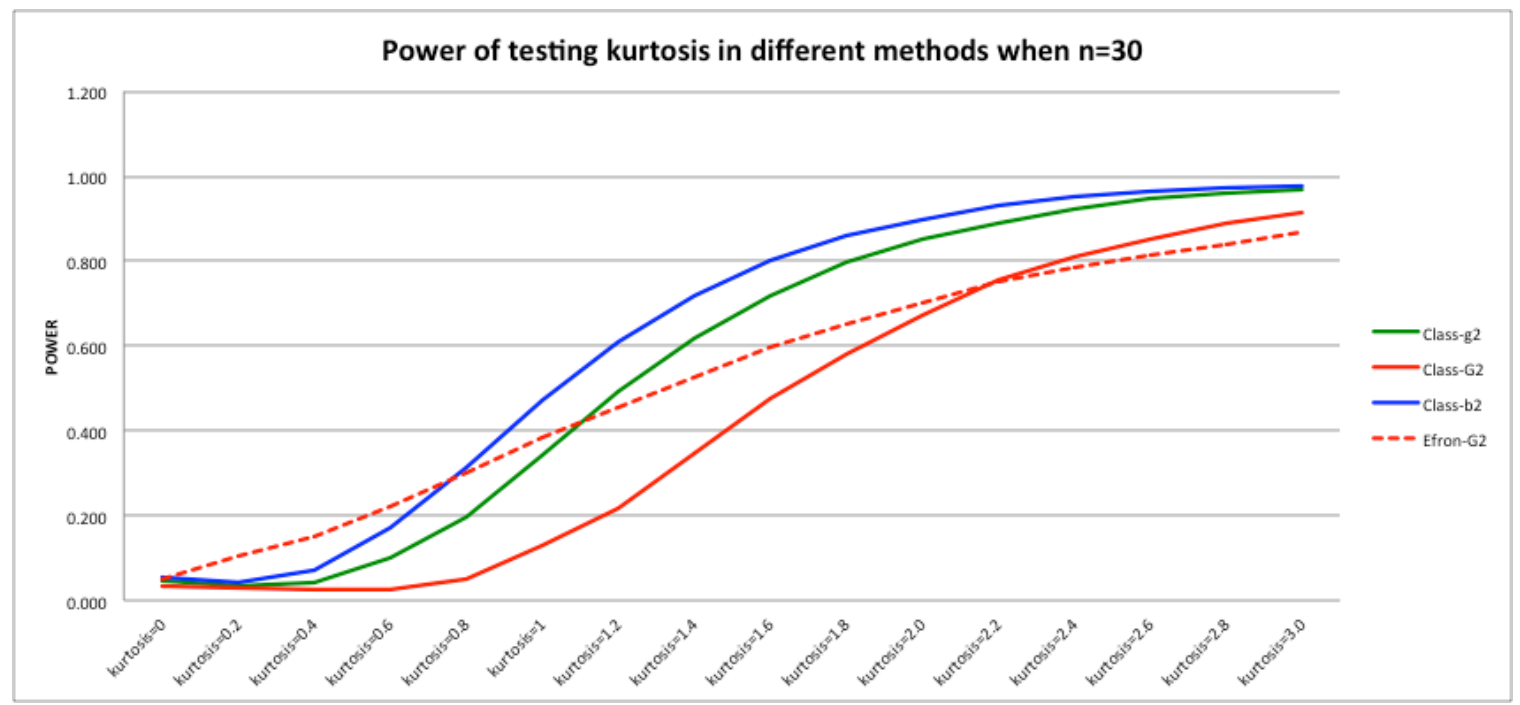

Figure 3.2.4 Power of testing kurtosis of $\mathrm{N}(0,1)$ in different methods when $\mathrm{n}=30$ 


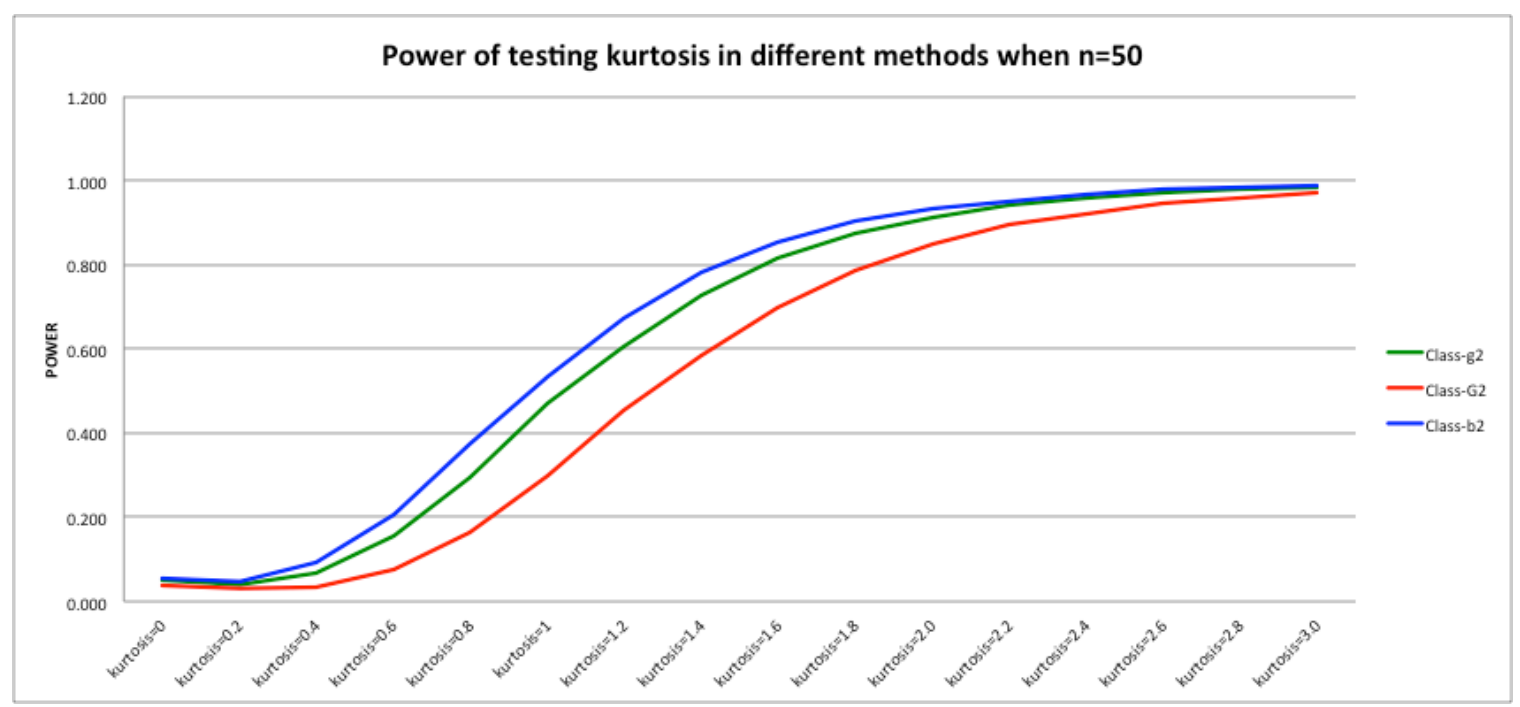

Figure 3.2.5 Power of testing kurtosis of $\mathrm{N}(0,1)$ in different methods when $\mathrm{n}=50$

When we consider the larger sample size, even though the bootstrap method is more powerful than classical method, bootstrap methods are still not useful when data are coming from a normal population as they cannot make the nominal size 0.05 of testing kurtosis $=0$. Thus classical method is employed as the most appropriate method for testing the power.

When sample size is 100 , the power increases sharply to 0.9 for classical methods when kurtosis $=1.4$ and it goes up steadily to 1 from that point on. When the sample size goes up to 300 , the power rises significantly from 0.05 to 0.8 when the kurtosis shifts from 0 to 0.8 and thereafter it increases gradually until 1 when kurtosis $=1.2$. Thus it may be concluded that with increase of the moderate departure from null value, the difference among three proposed estimators are not significant, especially when $n=300$, three test statistics are getting almost same. 


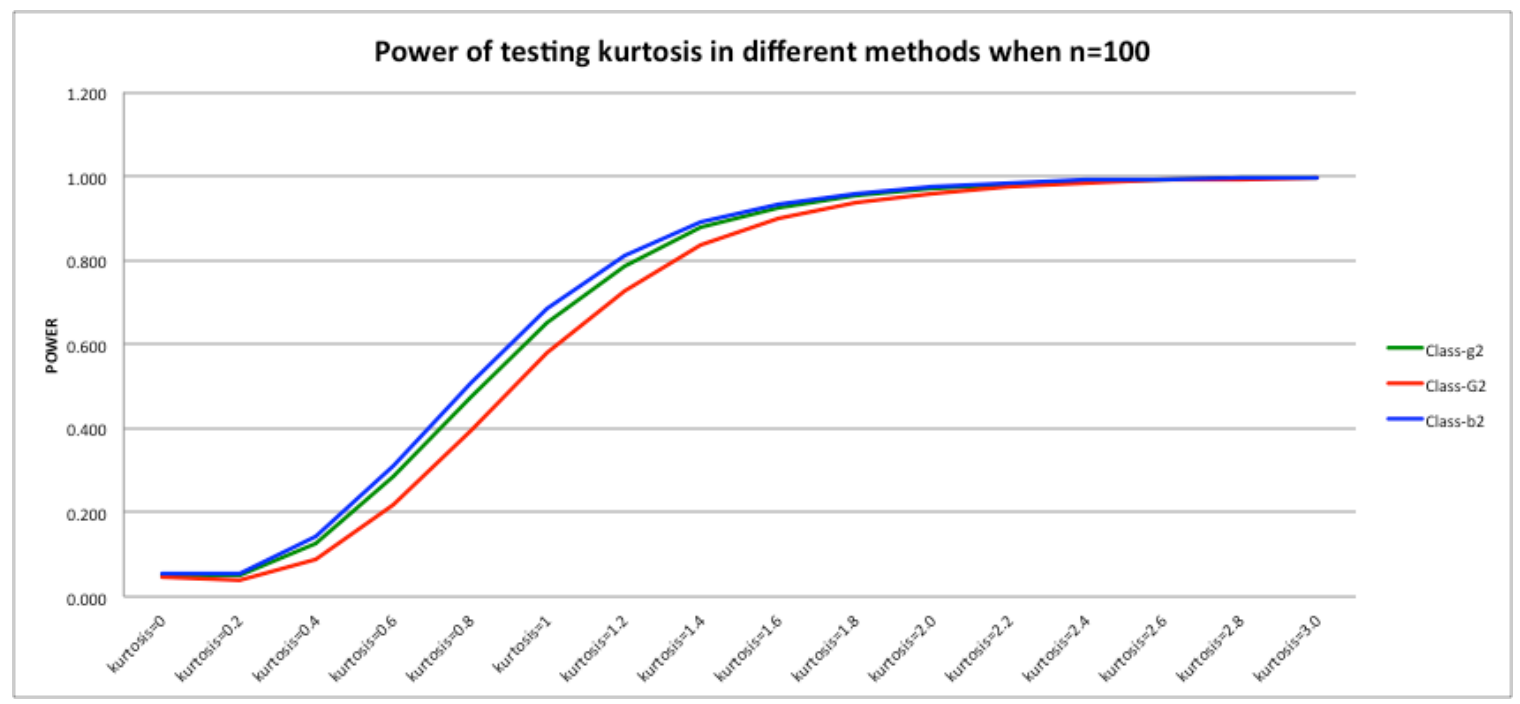

Figure 3.2.6 Power of testing kurtosis of $N(0,1)$ in different methods when $n=100$

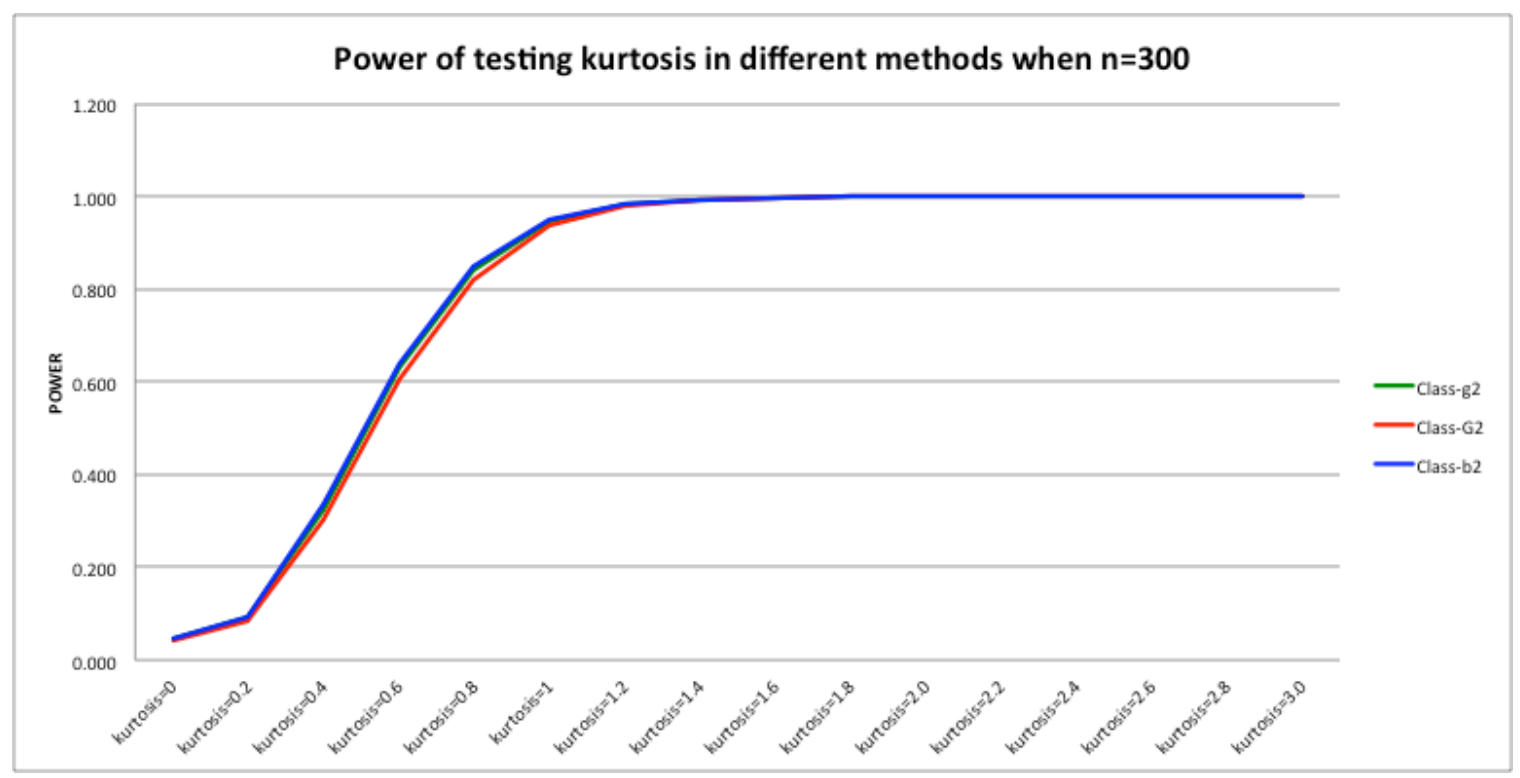

Figure 3.2.7 Power of testing kurtosis of $N(0,1)$ in different methods when $n=300$

Since only classical method works for testing kurtosis $=0$ when distribution is normal, we are discussing the trend from Figure 3.2.8. However, we are not able to confirm the relationship between sample size and test statistics when the sample size is 100 and under. However, we could conclude that if the sample size is large enough, the power is almost 
same for all test statistics based on those proposed estimators and if the sample size is small enough, the test statistic of $G_{1}$ performs least power among those three test statistics.

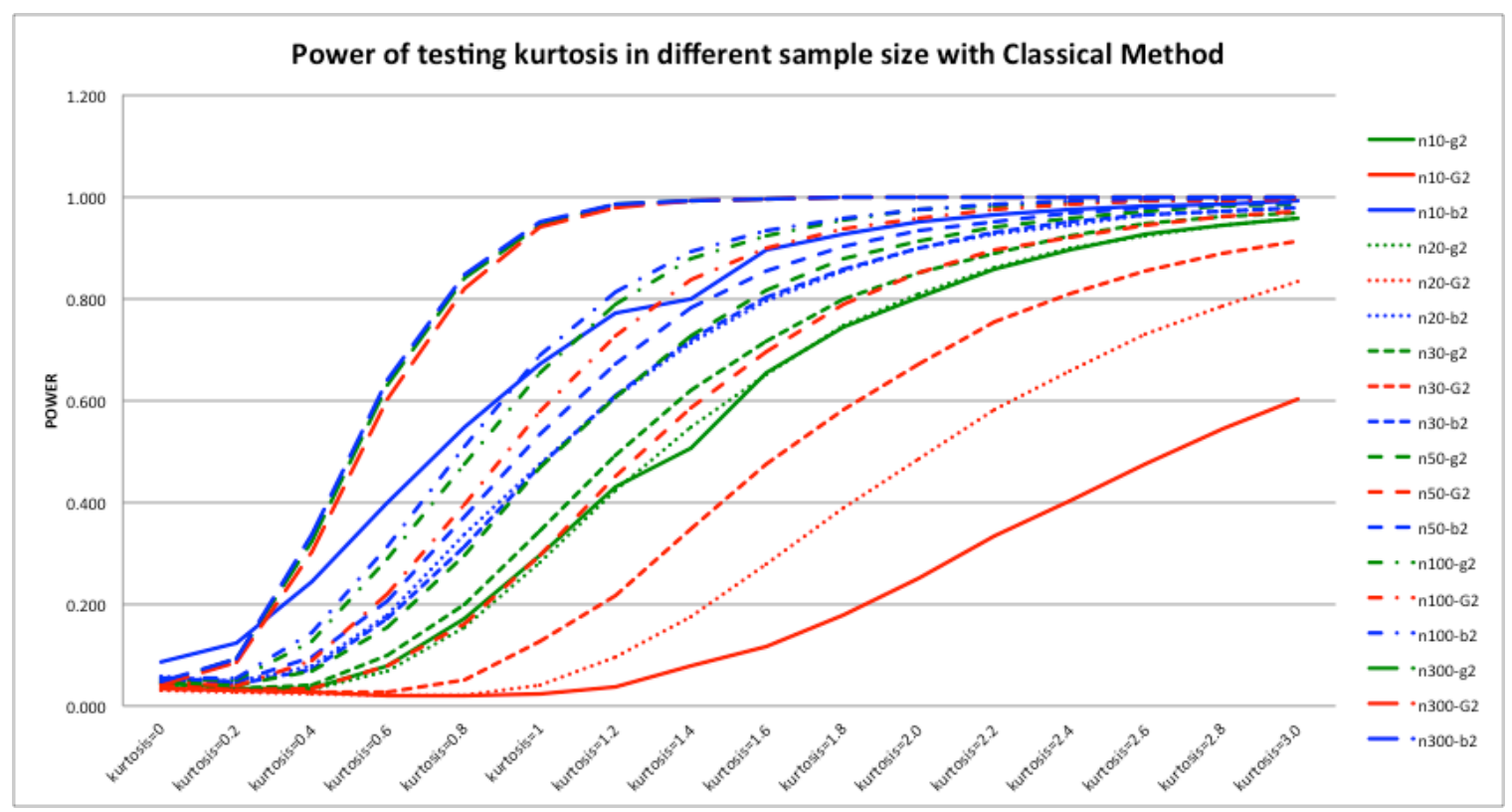

Figure 3.2.8 Power of testing kurtosis of $\mathrm{N}(0,1)$ in different sample size with Classical Method

\subsubsection{Performance for Beta distribution}

We employ Beta $(2,5)$ in this section to test performance of test statistics based on those three proposed estimators for the kurtosis. Without normality assumption and at alpha $=0.05$ level of significance, we are still expecting to get the power $=0.05$ from the simulation data. Figure 3.2.9 shows the empirical size of the test when we are testing the kurtosis equals to -0.12 for Beta $(2,5)$. It is obvious to see that the classical method performing the best among all methods in order to attain nominal size 0.05 for different sample size. It should be mentioned that the test statistic from Efron's $G_{2}$ performs 
perfectly when $n=30$ and Bias Corrected Percentile Method is approaching to 0.05 with increasing the sample size, otherwise the other bootstrap methods cannot provide any good results than classical method.

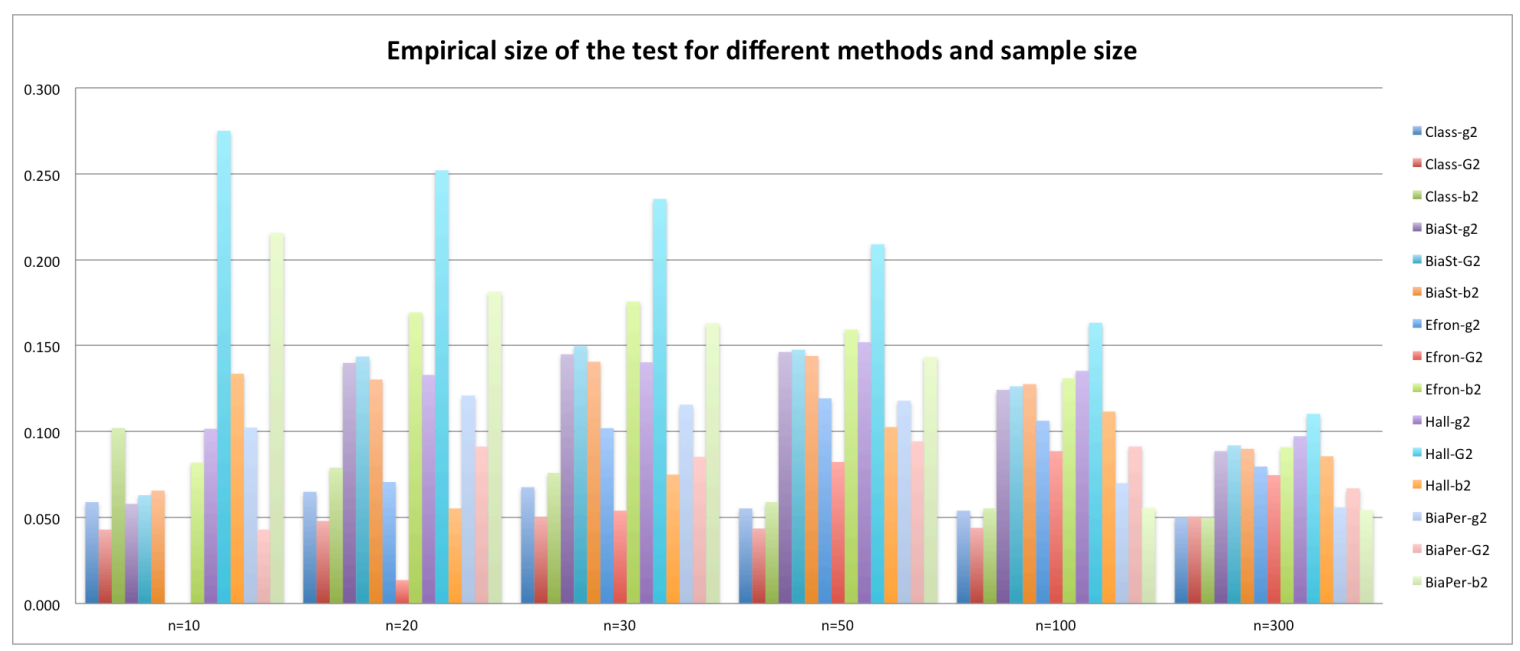

Figure 3.2.9 Empirical size of testing kurtosis=-0.12 for different methods and sample size

When sample is small, say 10, Figure 3.2.10 provides the measures which can get nominal size 0.05 while testing kurtosis $=-0.12$. And we are expecting the power increase gradually to 1 but $G_{2}$ from Bias Corrected Percentile Method does not show rise to 1. As the increase is slow, $g_{2}$ from Classical Method is approaching to 1 at testing kurtosis $=-0.12$. Similar to the results when sample size is 10, Figure 3.2.11 shows slow increase to 1 for both test statistics and under same condition the test statistics based on estimator $b_{2}$ performs better. Following Figure 3.2.12, $G_{2}$ from Classical Method and Efron's Percentile Method are selected as good performance. The Efron's Percentile Method provides higher power than Classical method while after testing kurtosis equals 1 the Classical Methods tends to perform better instead. 


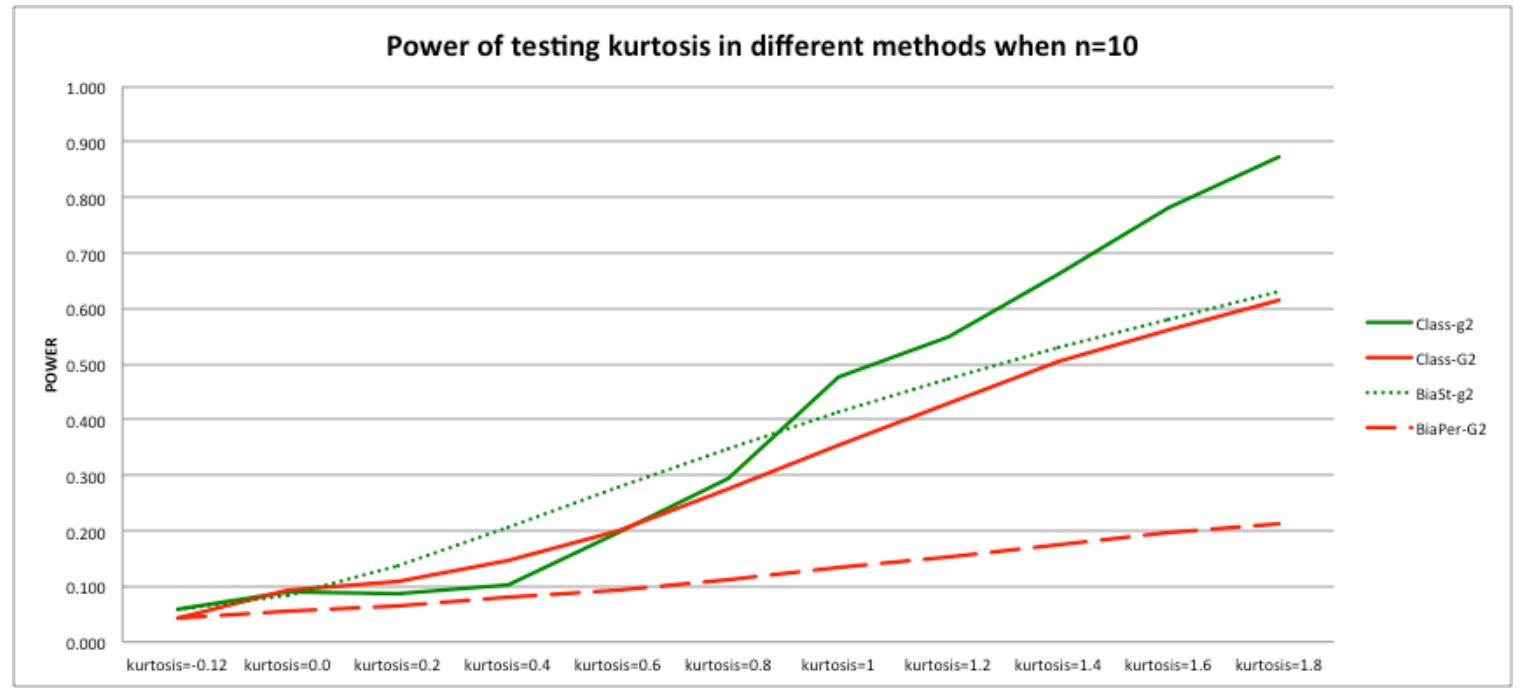

Figure 3.2.10 Power of testing kurtosis of Beta $(2,5)$ in different methods when $n=10$

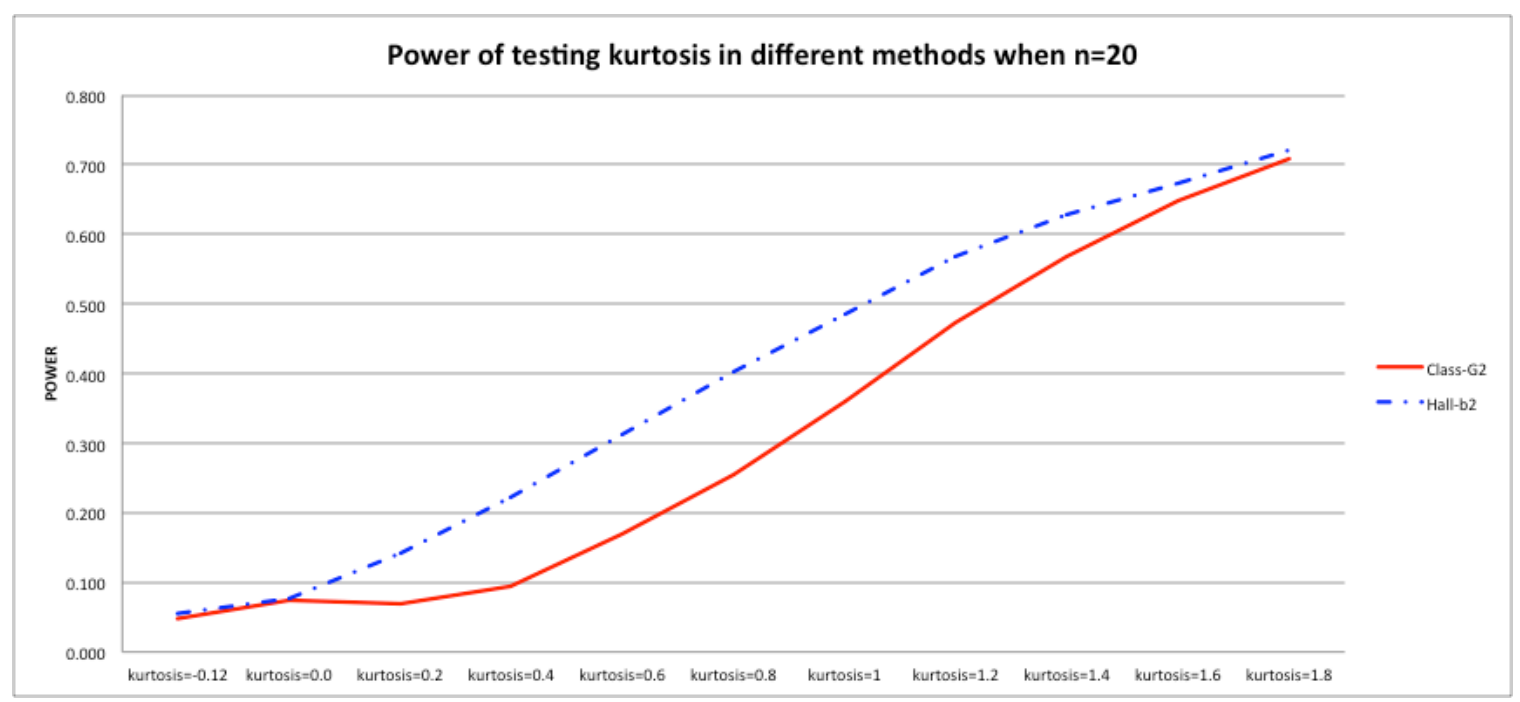

Figure 3.2.11 Power of testing kurtosis of Beta $(2,5)$ in different methods when $n=20$ 


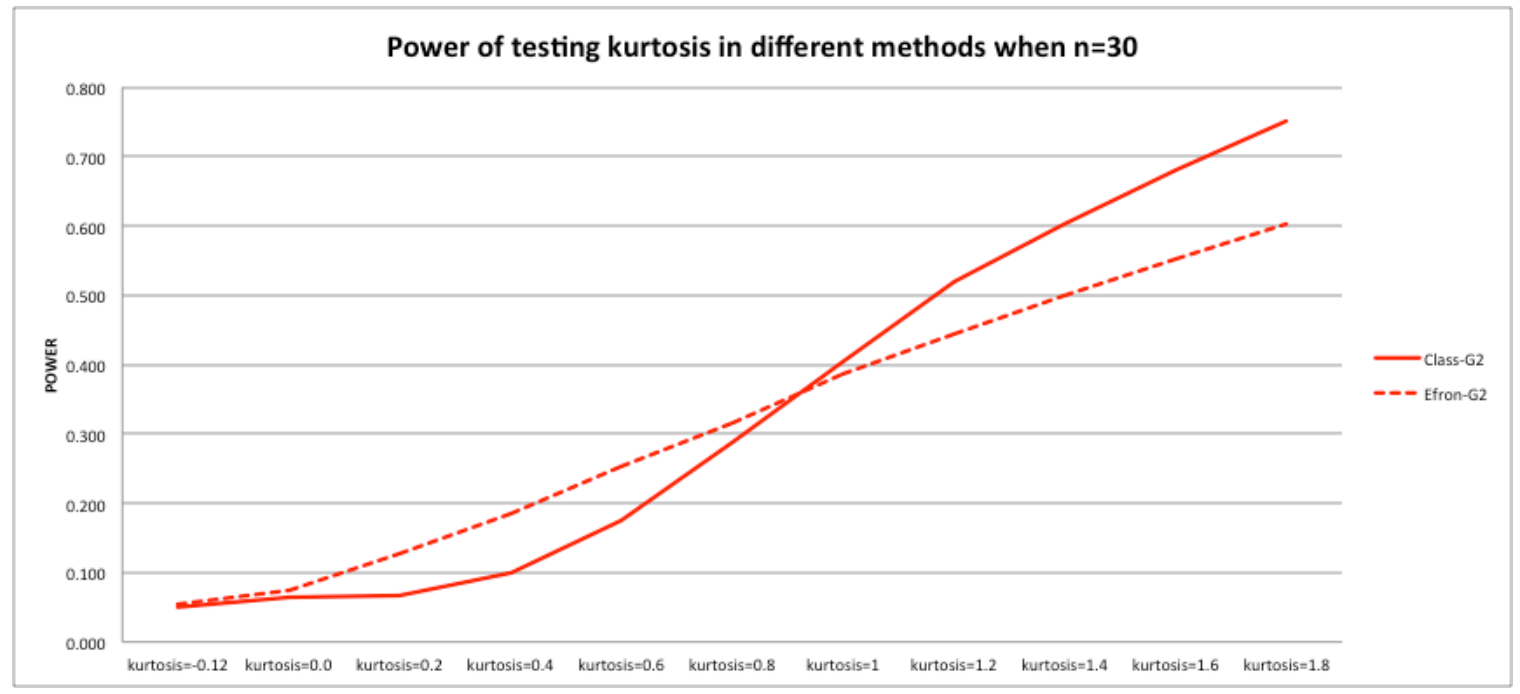

Figure 3.2.12 Power of testing kurtosis of Beta $(2,5)$ in different methods when $n=30$

When the sample size is large, the changes of power do not vary among three test statistics greatly from samples size equal to 50 . The power of the test increase gradually to 1 at testing kurtosis $=1.8$ or above. However for sample size 300 , the power rises rapidly when we are testing kurtosis $=1.2$. It also should be mentioned that, we include the test statistics based on the estimators from Bias Corrected Percentile Method when $\mathrm{n}=100$ and 300 , but this bootstrap method show lower power than Classical Method. Thus we may conclude that both Classical Method and Bias Corrected Percentile Method are working for this distribution but the latter method only presents good results when the sample size is large. However, Classical Method is appropriate for all sample size and more accurate for large sample size. 


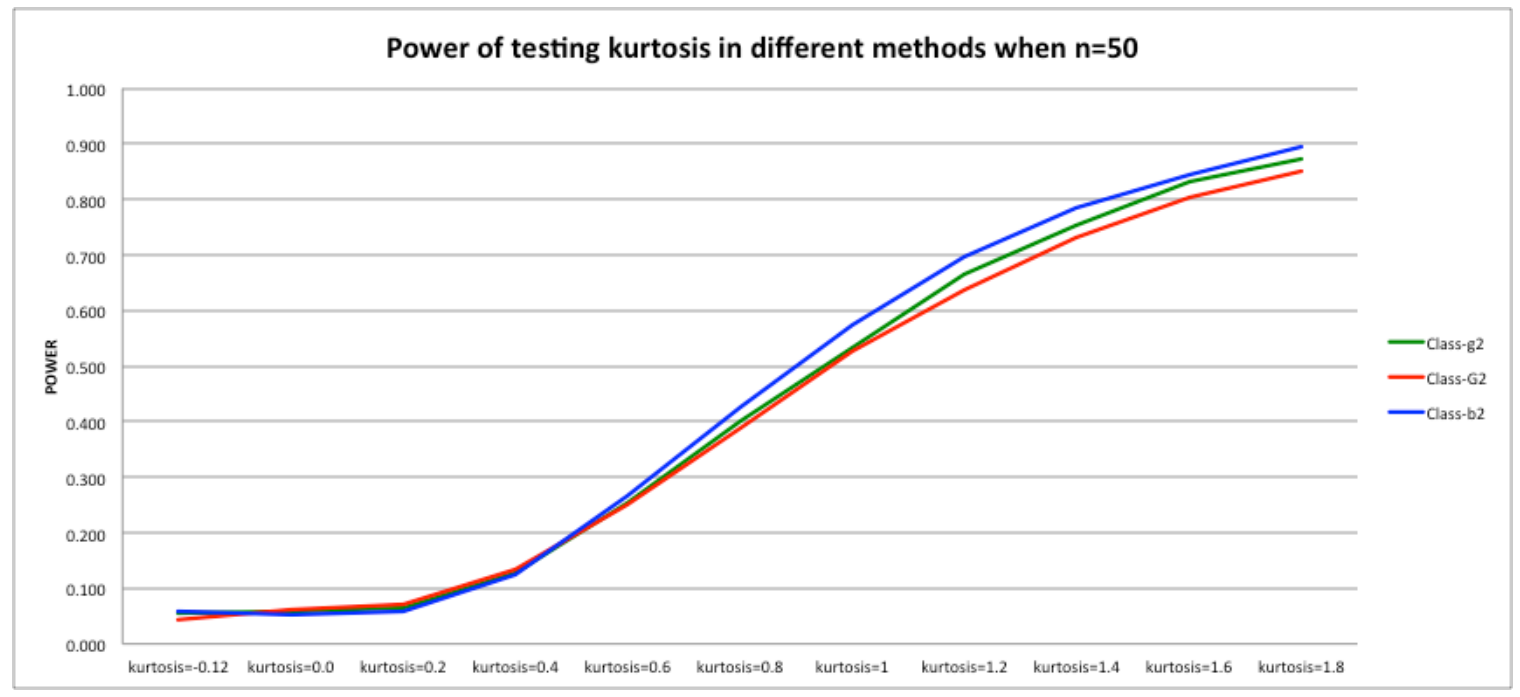

Figure 3.2.13 Power of testing kurtosis of Beta $(2,5)$ in different methods when $n=50$

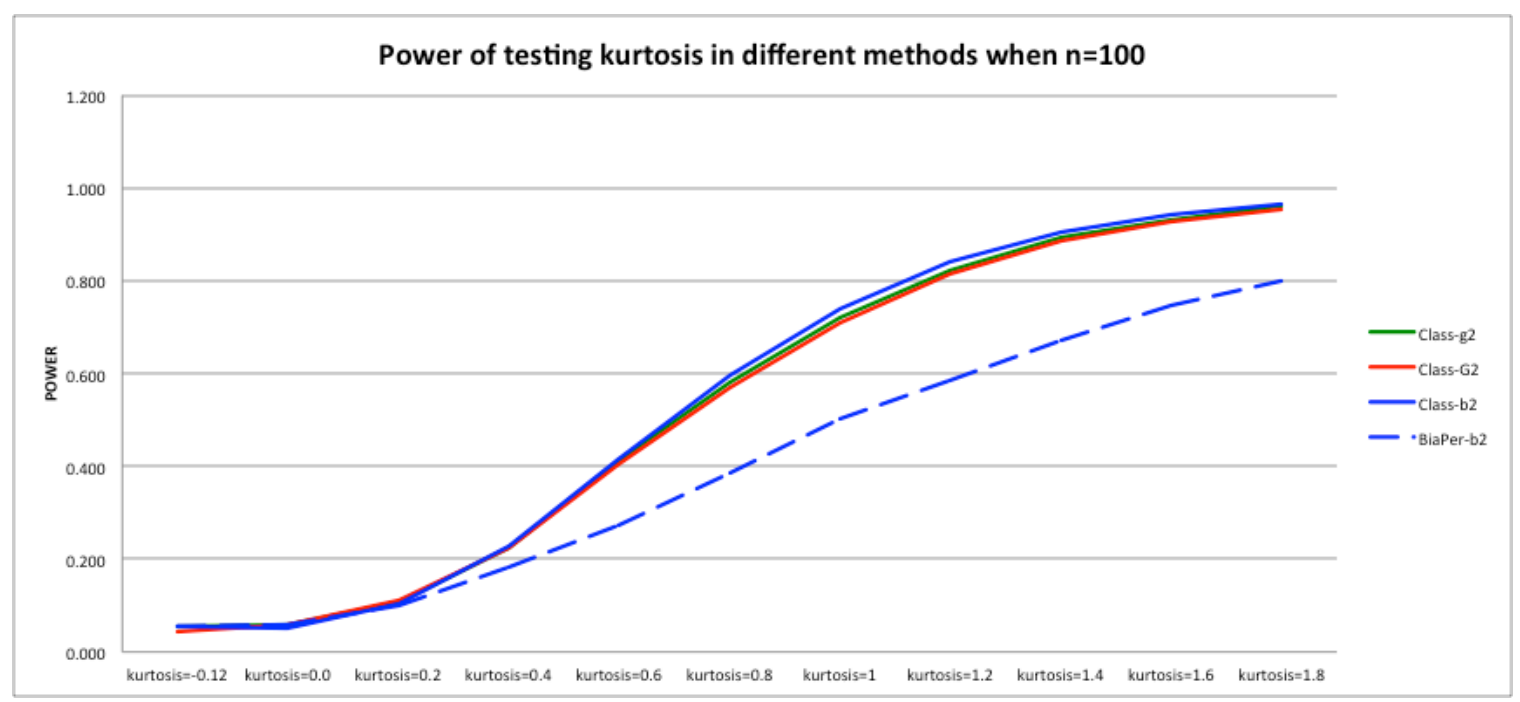

Figure 3.2.14 Power of testing kurtosis of Beta $(2,5)$ in different methods when $n=100$ 


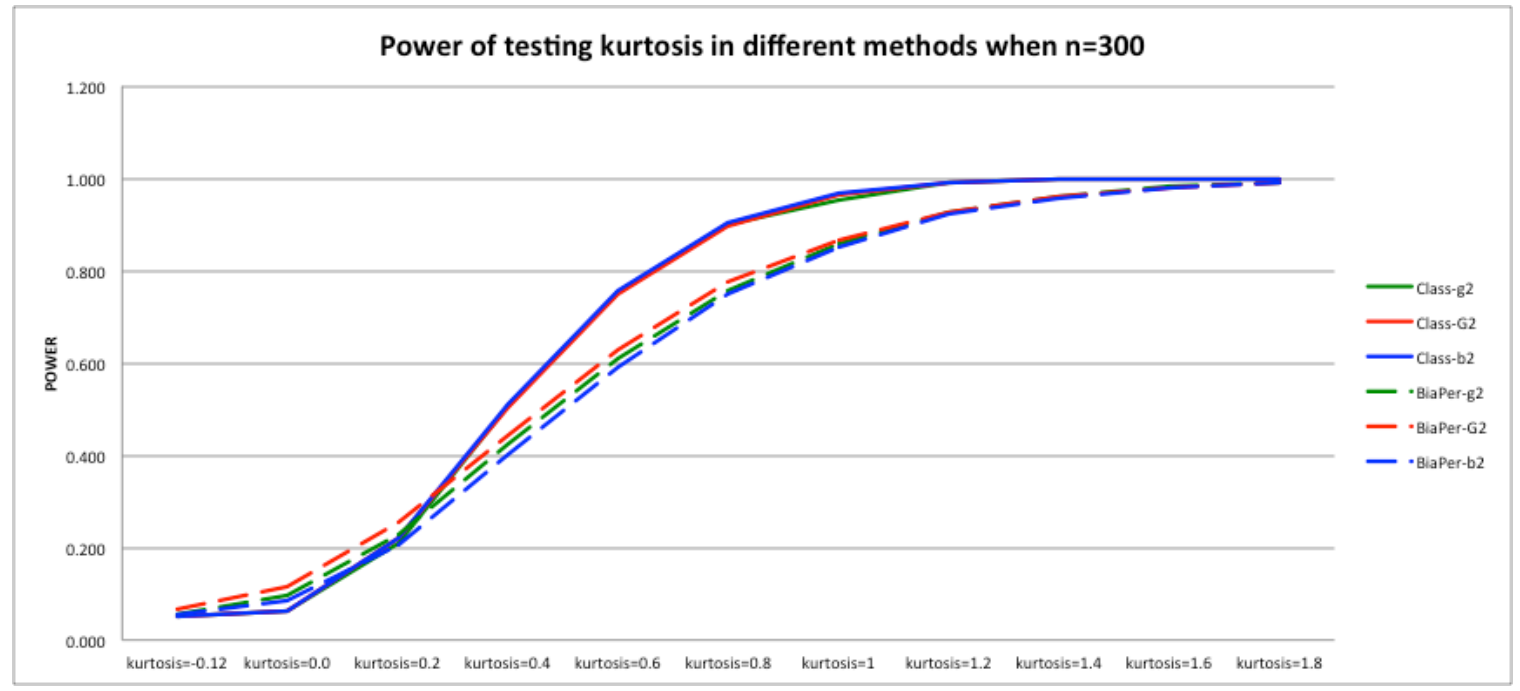

Figure 3.2.15 Power of testing kurtosis of Beta $(2,5)$ in different methods when $n=300$

As we discussed above, the classical method is more appropriate than bootstrap methods in testing kurtosis of Beta $(2,5)$. Figure 3.2.16 shows the changes about the power in different sample size for three proposed estimators and it appears that large sample size are more sensitive about increase to 1 and under same testing value, large sample size could provide higher power. For sample size other than 100 and 300, it is difficult to identify which test statistic performs well. 


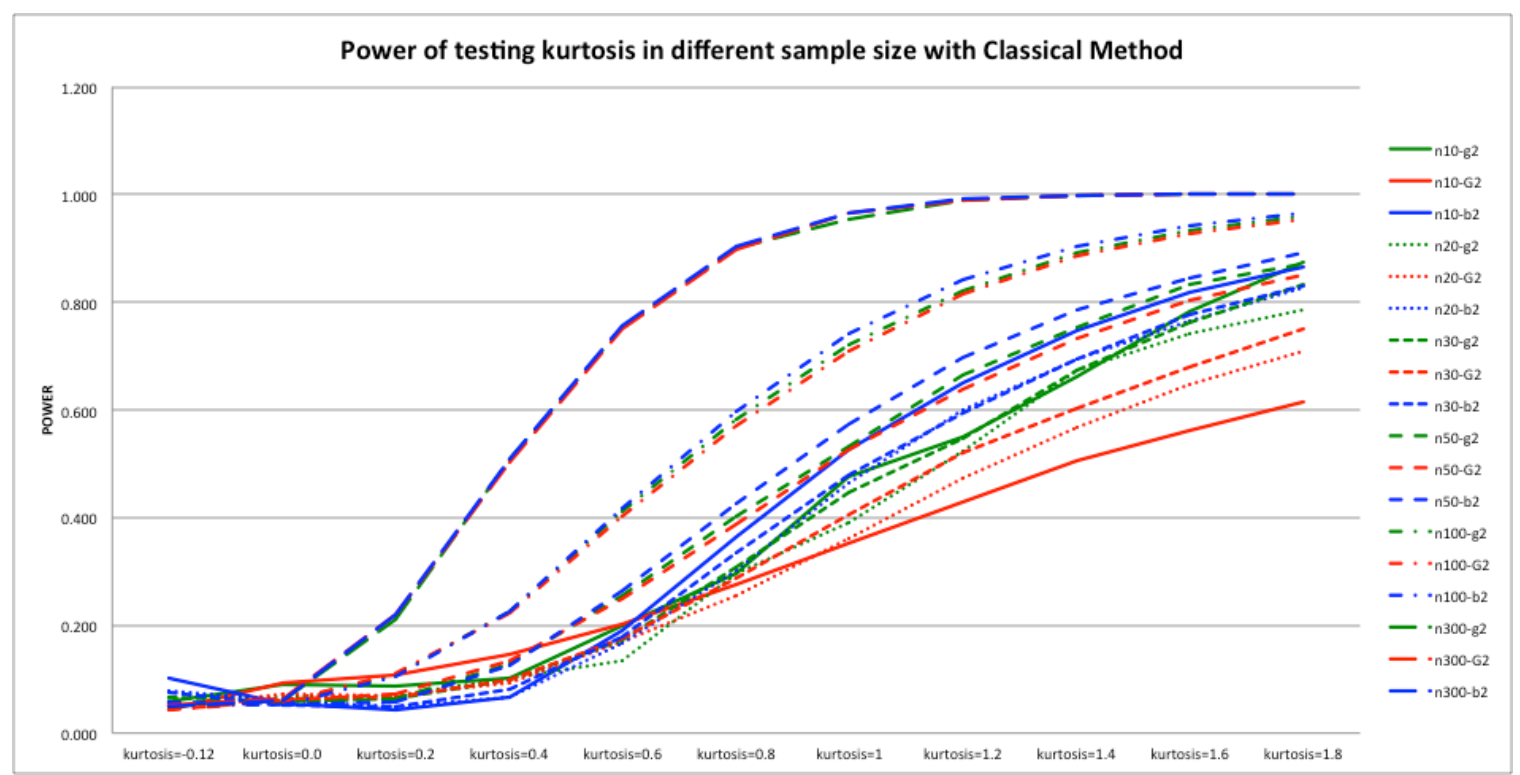

Figure 3.2.16 Power of testing kurtosis of Beta $(2,5)$ in different sample size with Classical Method

\subsubsection{Performance for Uniform distribution}

Uniform distribution is a typical type of platykurtic distribution, which has a negative excess kurtosis value and thinner tails. Without normality assumption, we are still expecting nominal size 0.05 from the simulation data. We employed continuous uniform distribution Uniform $(0,1)$ and the excess kurtosis is -1.2 for any parameter. Figure 3.2.17 shows the empirical size of the test when we are testing the kurtosis equals to -1.2. It is apparent that the classical method does not perform well at any sample sizes in the sense of attaining nominal size 0.05. The results from Bias Corrected Percentile Method do not vary greatly for different sample size and keep stable around 0.05. It also should be mentioned that when the sample size is large, say 100 or above, all bootstrap methods are performing well except b1 from Hall's Percentile Method. The test statistic 
based on estimator b1 from Hall's Percentile Method is significant for all sample sizes, even though the nominal size decrease nearly to 0.05 , the result is about 0.1 . For Bias Corrected Standard Method, Efron's Percentile Method, Hall's Percentile Method, the empirical nominal size is far less than 0.05 when sample size is less than 50 . However, they attained nominal size 0.05 when sample size is large, that is 100 and 300 . In this case bootstrap methods can provide better results than the classical method, despite the limit of sample size.

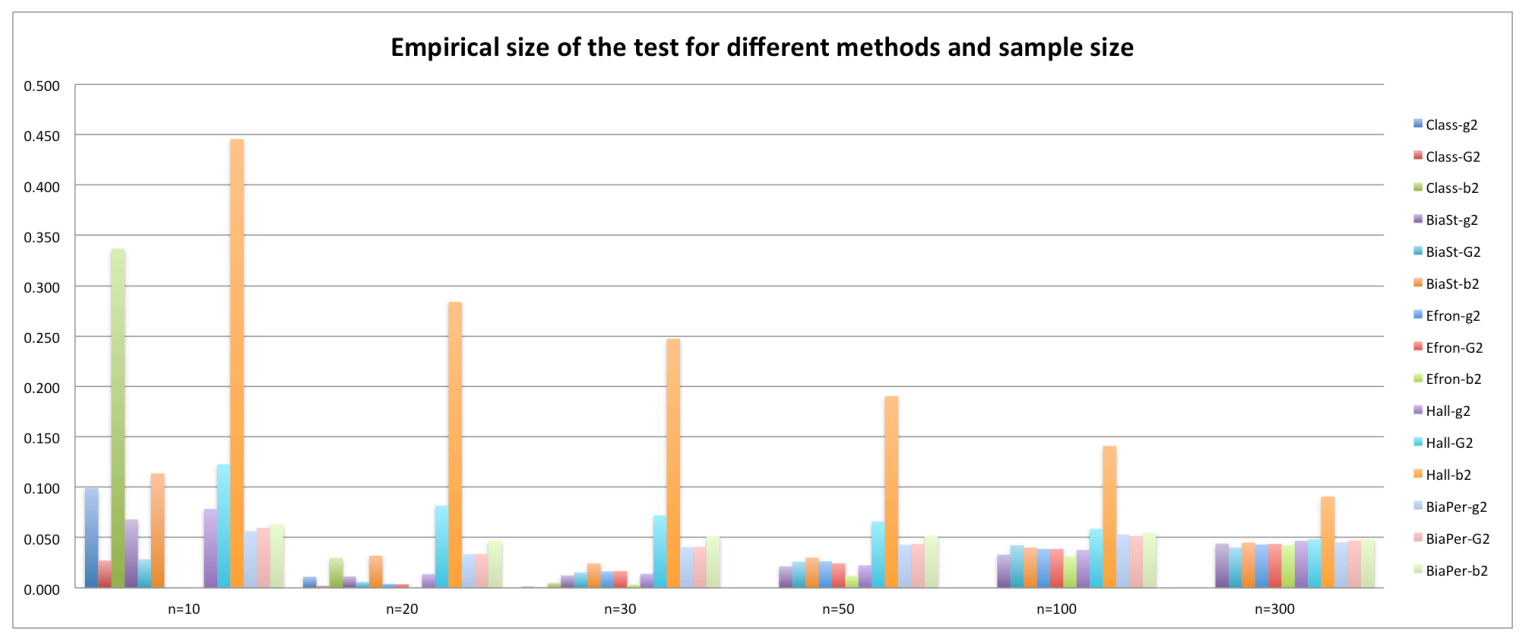

Figure 3.2.17 Empirical size of testing kurtosis=-1.2 for different methods and sample size

Figure 3.2.18 to 3.2 .23 are discussing the empirical power against different hypothesized values for all proposed test statistics with different sample size: $n=10,20$, 30, 50, 100 and 300. The $\mathrm{X}$-axis represents different hypothesized values and Y-axis stands for empirical power. We deleted the test statistics that are not performing good and the empirical power approaches close to 1 with increasing the hypothesized value from -1.2 to a large value. From these 4 figures, it appears that the empirical powers are close 
to 1 when kurtosis equals to 1.8 or above except for small sample size 10 . When we are doing the simulation with small sample size, the power of the test statistic based on estimator $G_{2}$ from classical method decreases with increasing the departure to null hypothesized value. After the sample size goes up to 20, we include testing kurtosis parameter based on $b_{2}$ from classical method and Bias Corrected Standard Method besides Bias Corrected Percentile Method. However, these two methods both show a decrease when we increase the hypothesized value which is not reasonable. Moreover, we can see that for Bias Corrected Percentile Method, the power of the tests do not vary greatly for near the null hypothesized value or for high kurtosis.

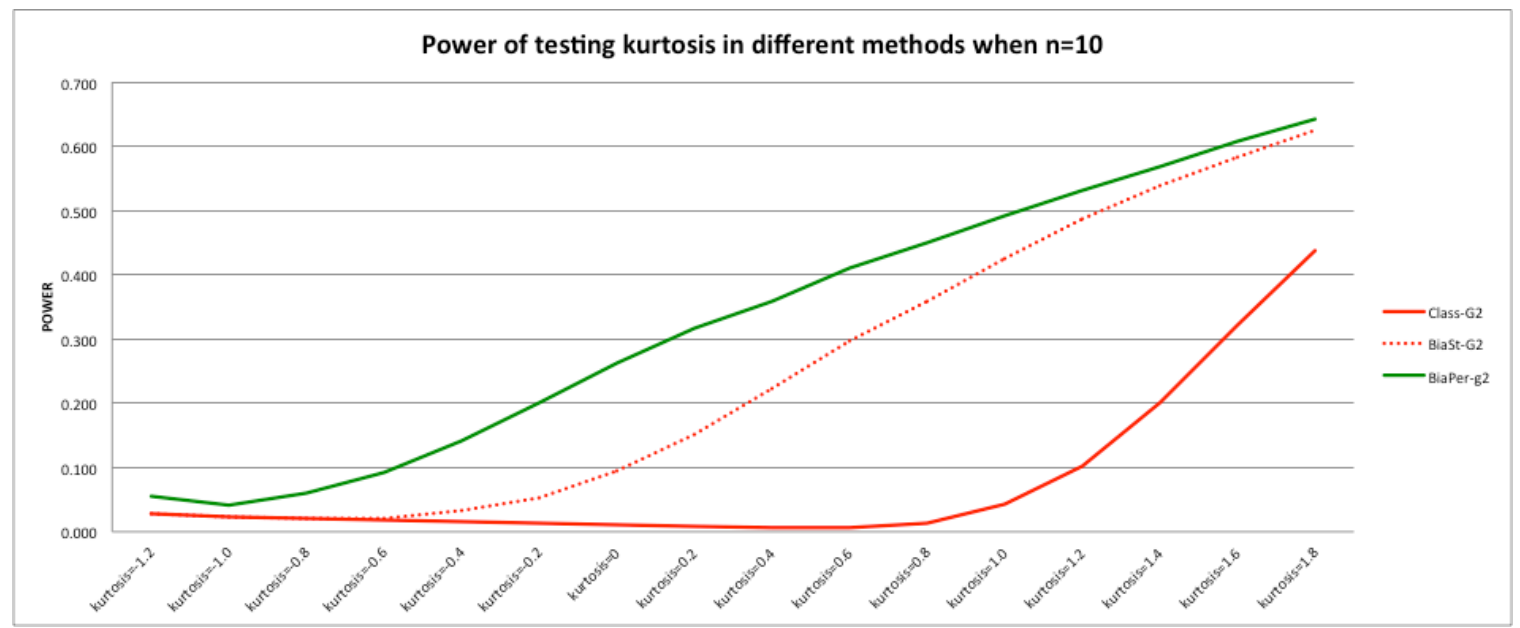

Figure 3.2.18 Power of testing kurtosis of Uniform $(0,1)$ in different methods when $n=10$ 


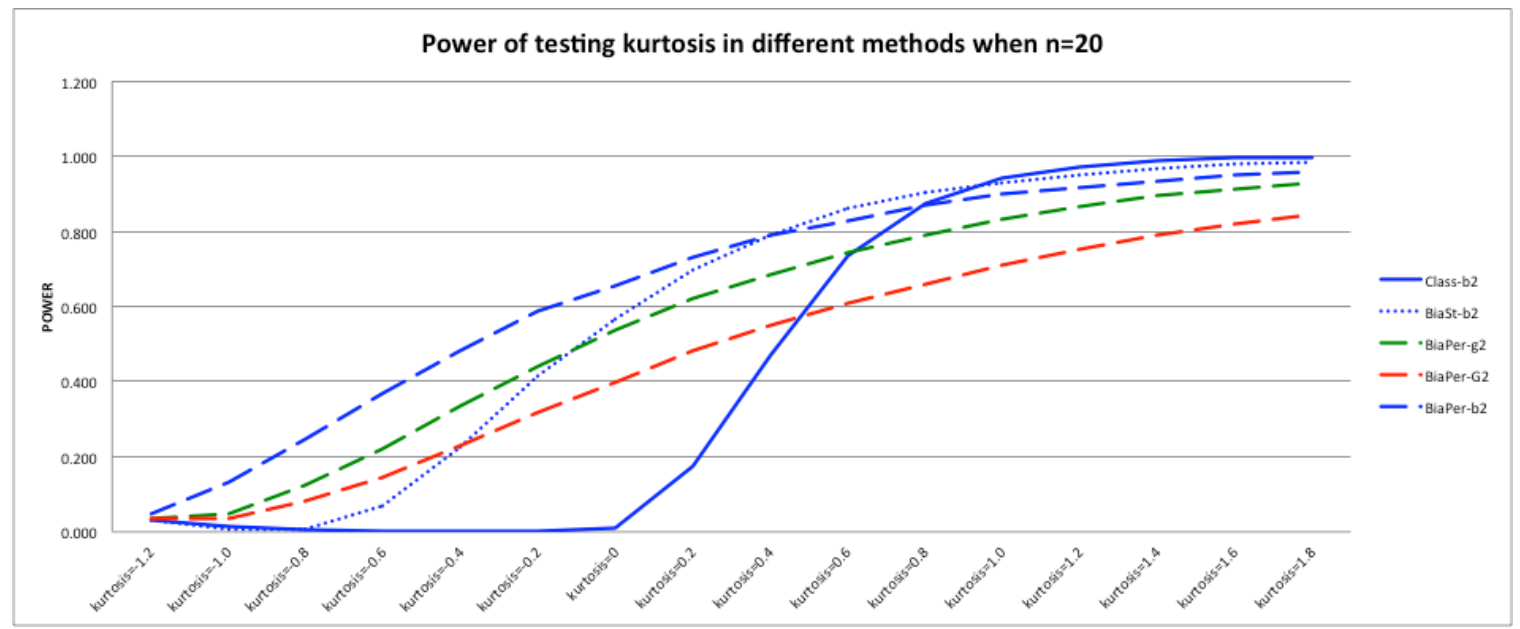

Figure 3.2.19 Power of testing kurtosis of Uniform $(0,1)$ in different methods when $n=20$

For sample size 30 and 50, only Bias Corrected Percentile Method shows acceptable results. The power rises slightly to 1 when kurtosis $=1.2$ and 0.2 respectively for $n=30$ and 50. When we consider the larger sample size, say 100 and 300, all bootstrap methods are performing good except the test statistic based on estimator $b_{2}$ from Hall's Percentile Method. The power of the tests increase rapidly to 1 when testing the kurtosis $=0.4$ and 0.8 for $n=100$ and 300 respectively. However, it is noted that since the classical method do not work, the proposed bootstrap methods are useful when data are not coming from a normal population especially when sample size is large and Bias Corrected Percentile Method is the most appropriate method in both small and large sample size. 


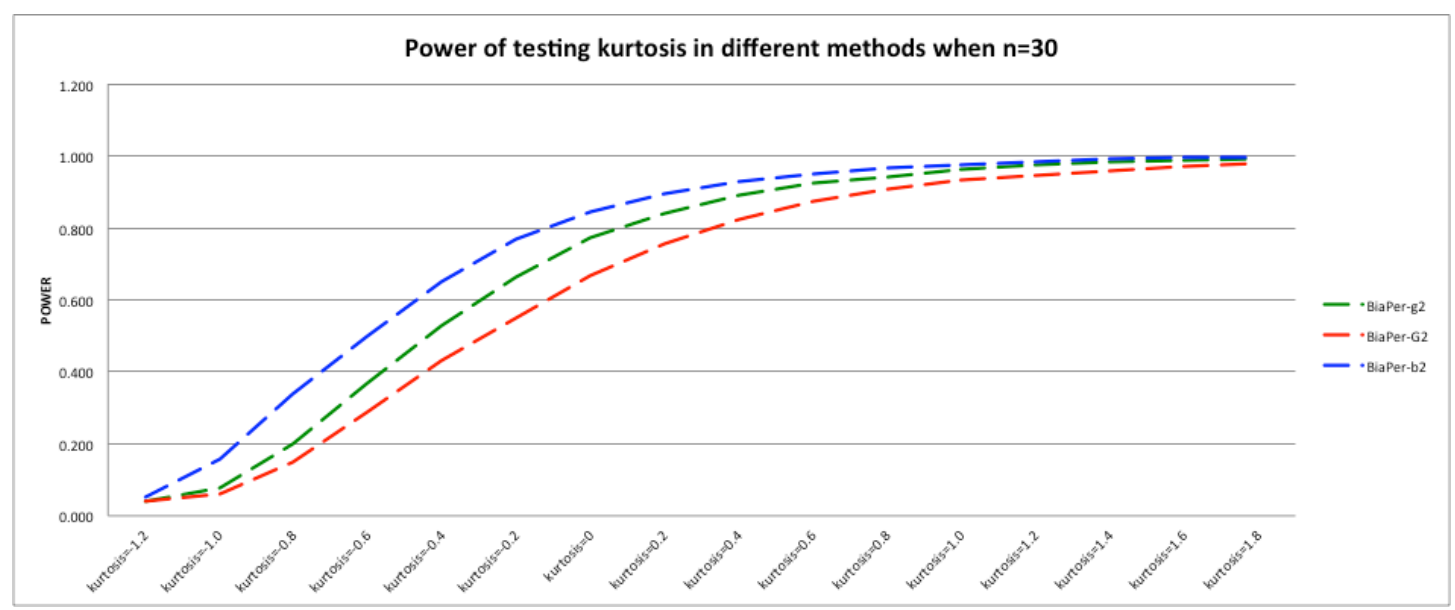

Figure 3.2.20 Power of testing kurtosis of Uniform $(0,1)$ in different methods when $n=30$

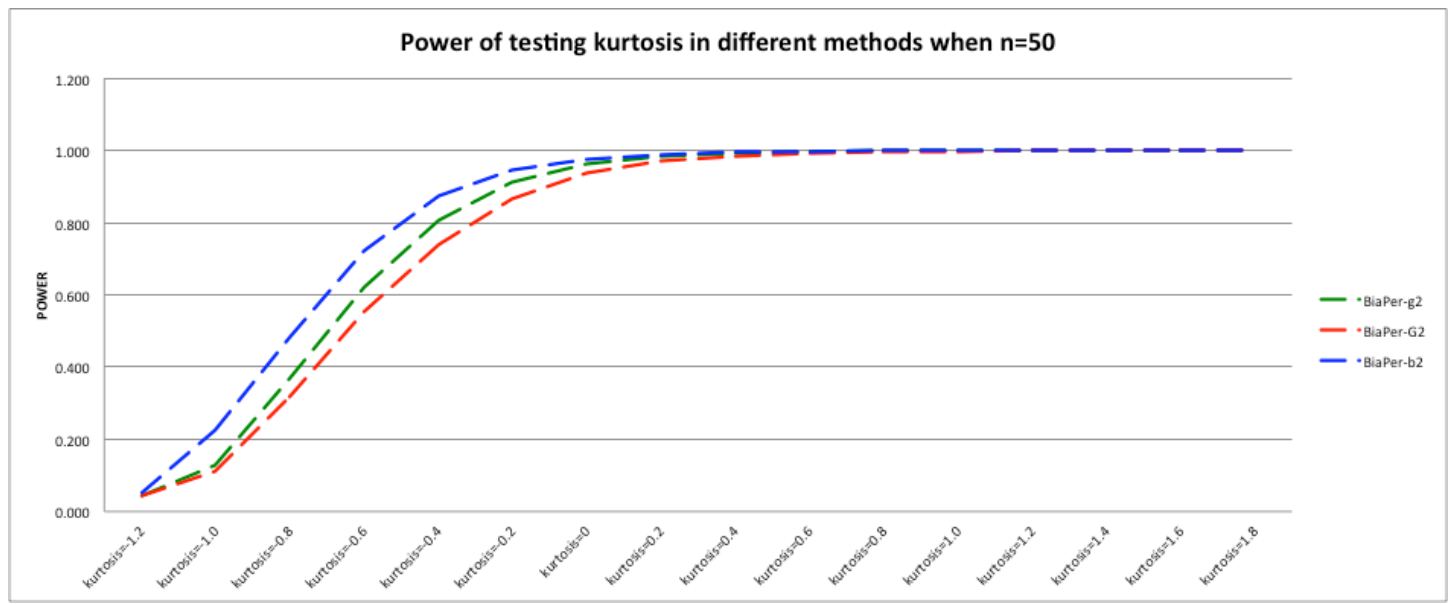

Figure 3.2.21 Power of testing kurtosis of Uniform $(0,1)$ in different methods when $n=50$

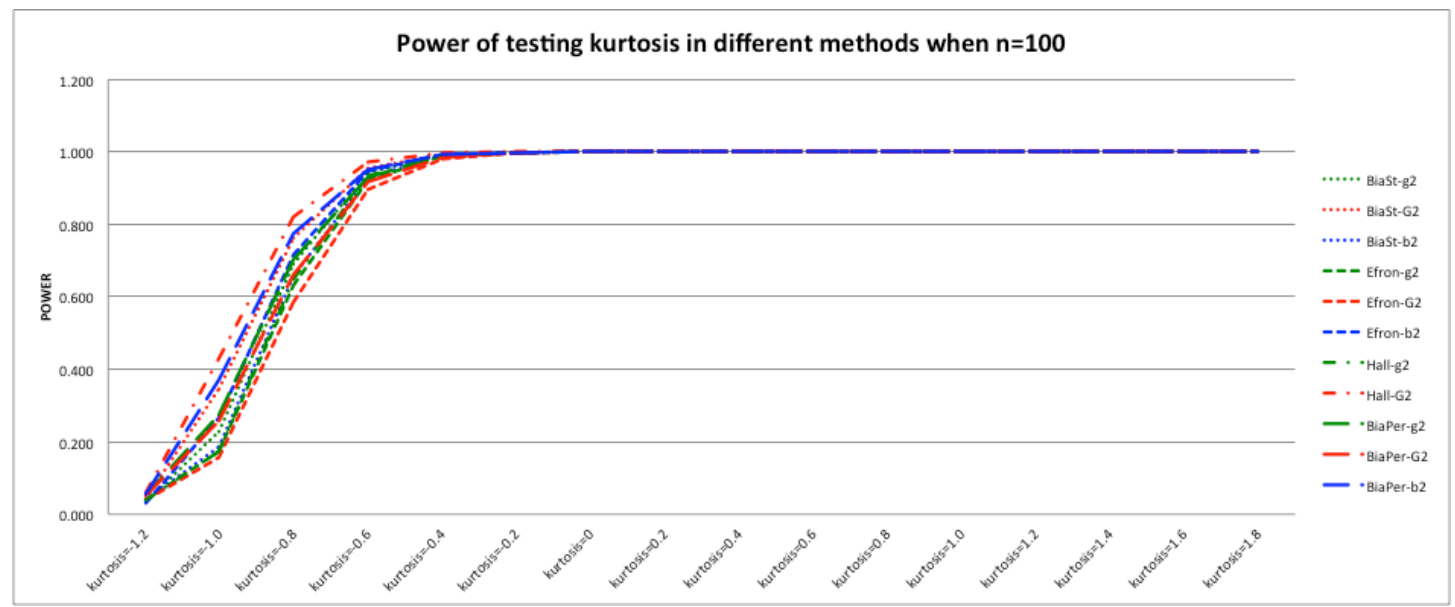

Figure 3.2.22 Power of testing kurtosis of Uniform $(0,1)$ in different methods when $n=100$ 


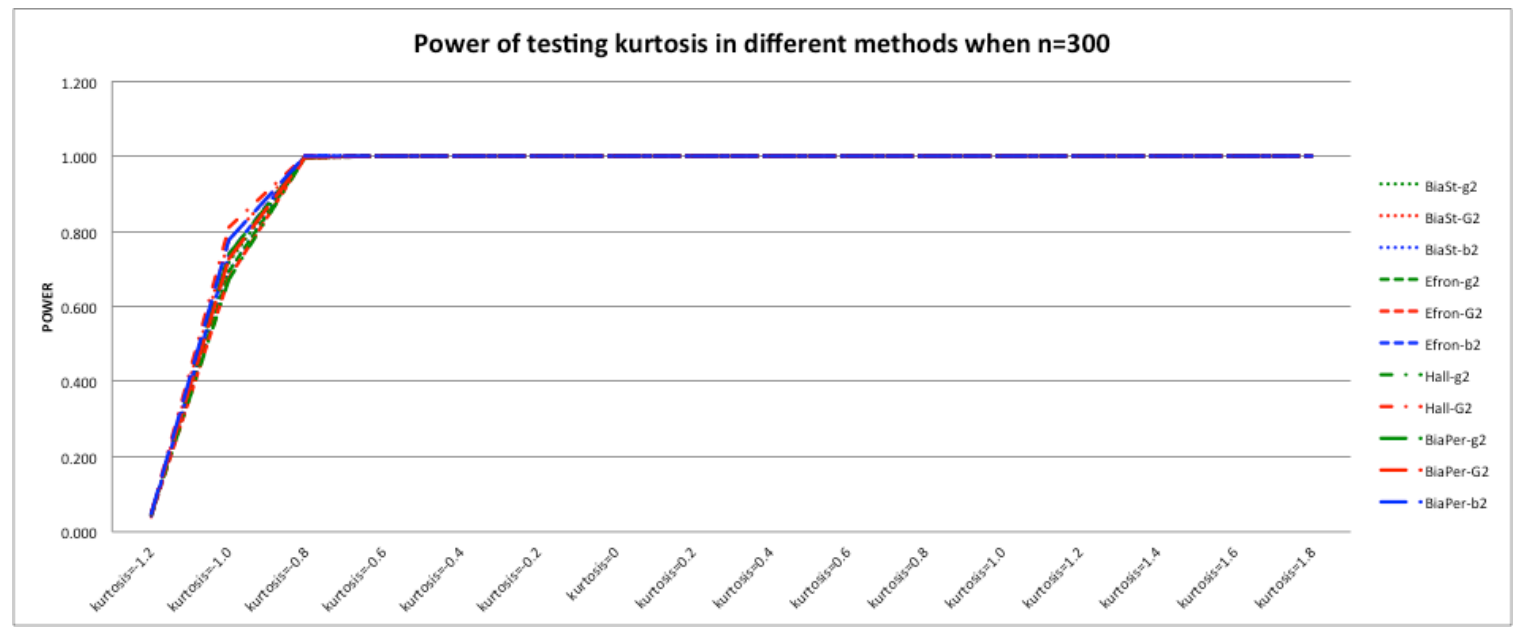

Figure 3.2.23 Power of testing kurtosis of Uniform $(0,1)$ in different methods when $n=300$

As Bias Corrected Percentile Method is viewed as the most appropriate method for testing kurtosis in uniform distribution, Figure 3.2.24 is discussing the changes of the power under same methods but different sample sizes. It is obvious that under same hypothesized value, the large sample size provide higher power. And the test statistic based on estimator $G_{2}$ provides lower power while that based on $b_{2}$ supports higher power under same testing hypothesized value and sample size.

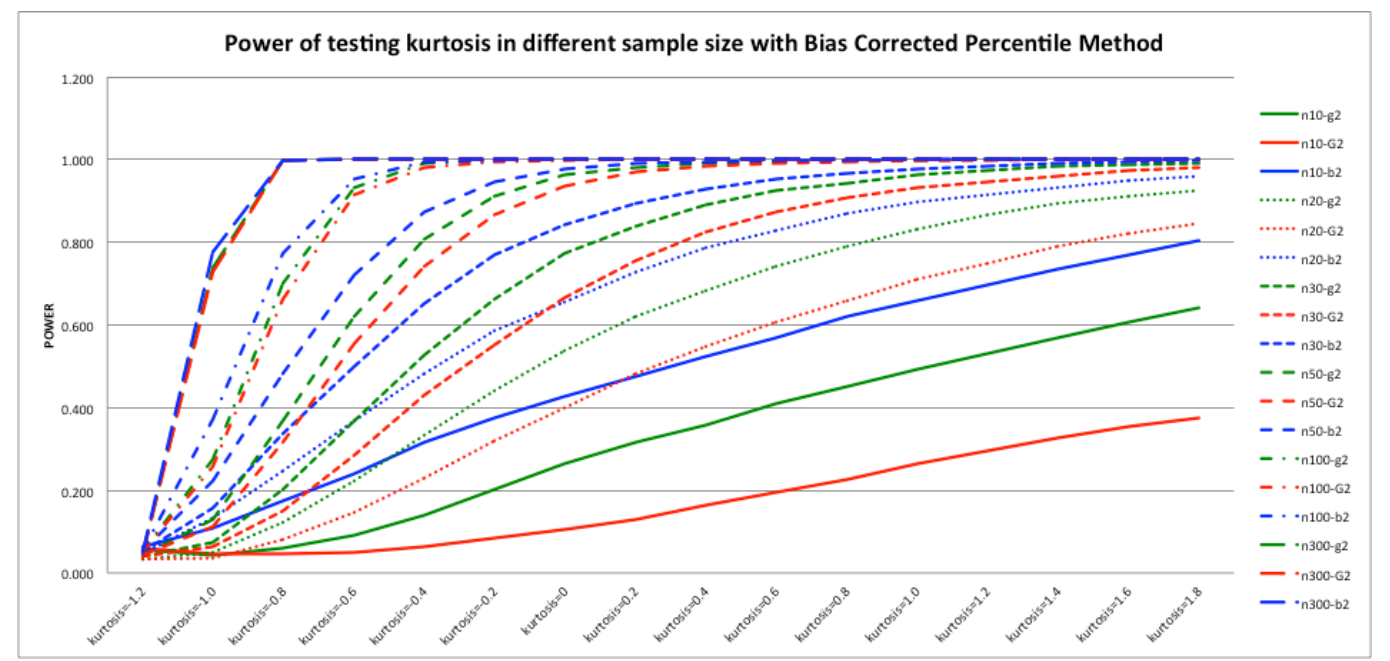

Figure 3.2.24 Power of testing kurtosis of Uniform $(0,1)$ in different sample size with Bias Corrected Percentile Method 


\section{CHAPTER IV}

APPLICATIONS

In this chapter we will discuss four examples to illustrate the performance of the test statistics based on the three estimators. In the following two sections we consider normal and non-normal distribution data for testing the skewness and kurtosis respectively.

\subsection{Examples for skewness}

We got a dataset in regards to 48 SIDS (Sudden Infant Death Syndrome) cases observed in King County, Washington during the years 1974 and 1975 (Belle at el., 2004). However, we used only one variable, birth weights (in grams) of these 48 cases in our study. Using this data the results of test statistics for testing the skewness for various alternative hypothesis are presented in Table 4.1.1. Before testing the hypothesis, we would like to confirm that whether the data follow normal distribution or not. The Q-Q plot of the data is presented in Figure 4.1.1, which supported the assumption of normality. Moreover we have performed the Shapiro test (test statistic, $W=0.9832$, $p$-value $=0.7168$ ), which also confirmed that the data follow normal distribution. We can easily find from Table 4.1.1, the classical method could correctly reject the null hypothesis when we departed the skewness from hypothesized value, say skewness $=0.7$. From that on, the classical method performs very well, however, the Bias Corrected Standard methods shows unusual results which even reject the hypothesis when hypothesized value is close to null hypothesis. The Efron's Percentile method could make good decision at same 
point of classical method does, and other bootstrap method shows positive function when the distance keep increasing.

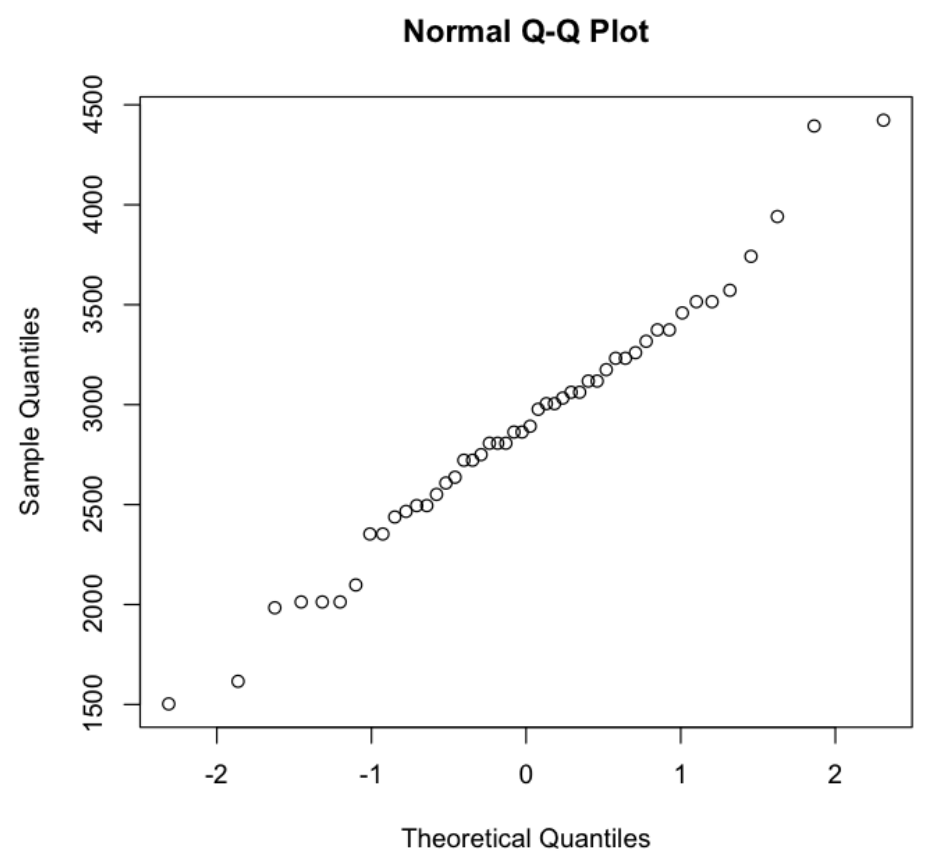

Figure 4.1.1 Normal Q-Q plot for SIDS data in Example 1

Table 4.1.1 Testing skewness for $\mathrm{n}=48$ normal distribution data

\begin{tabular}{|c|c|c|c|c|c|c|c|c|c|}
\hline & & & $\mathrm{sk}=0$ & $\mathrm{sk}=0.15$ & sk $=0.4$ & $\mathrm{sk}=0.6$ & sk $=0.7$ & $\mathrm{sk}=0.8$ & sk $=1.0$ \\
\hline Method & Estimator & Point Estimate & \multicolumn{7}{|c|}{ P-Value } \\
\hline \multirow{3}{*}{ Classical } & g1 & 0.135 & 0.657 & 0.482 & 0.212 & 0.081 & 0.044 & 0.023 & 0.005 \\
\hline & G1 & 0.139 & 0.657 & 0.487 & 0.224 & 0.090 & 0.051 & 0.027 & 0.006 \\
\hline & b1 & 0.131 & 0.657 & 0.476 & 0.201 & 0.072 & 0.038 & 0.019 & 0.003 \\
\hline \multirow{4}{*}{$\begin{array}{c}\text { Bias } \\
\text { Corrected } \\
\text { standard } \\
\end{array}$} & $\mathrm{g} 1$ & 0.135 & 0.000 & 0.000 & 0.000 & 0.000 & 0.000 & 0.000 & 0.000 \\
\hline & G1 & 0.139 & 0.000 & 0.000 & 0.000 & 0.000 & 0.000 & 0.000 & 0.000 \\
\hline & $\mathrm{b} 1$ & 0.131 & 0.000 & 0.000 & 0.000 & 0.000 & 0.000 & 0.000 & 0.000 \\
\hline & & CI & \multicolumn{7}{|c|}{ Decision } \\
\hline \multirow{3}{*}{$\begin{array}{c}\text { Efron's } \\
\text { percentile } \\
\text { bootstrap }\end{array}$} & g1 & $(-0.631,0.676)$ & $\mathrm{A}$ & $\mathrm{A}$ & $\mathrm{A}$ & $\mathrm{A}$ & $\mathrm{R}$ & $R$ & $\mathrm{R}$ \\
\hline & G1 & $(-0.586,0.726)$ & $\mathrm{A}$ & $\mathrm{A}$ & $\mathrm{A}$ & $\mathrm{A}$ & $\mathrm{A}$ & $\mathrm{R}$ & $\mathrm{R}$ \\
\hline & $\mathrm{b} 1$ & $(-0.595,0.648)$ & $\mathrm{A}$ & $\mathrm{A}$ & $\mathrm{A}$ & $\mathrm{A}$ & $R$ & $R$ & $\mathrm{R}$ \\
\hline \multirow{3}{*}{\begin{tabular}{|c|} 
Hall's \\
Percentile \\
bootstrap
\end{tabular}} & g1 & $(-0.445,0.879)$ & $\mathrm{A}$ & $\mathrm{A}$ & $\mathrm{A}$ & $\mathrm{A}$ & $\mathrm{A}$ & $\mathrm{A}$ & $\mathrm{R}$ \\
\hline & G1 & $(-0.444,0.878)$ & $\mathrm{A}$ & $\mathrm{A}$ & $\mathrm{A}$ & $\mathrm{A}$ & $\mathrm{A}$ & $\mathrm{A}$ & $\mathrm{R}$ \\
\hline & b1 & $(-0.424,0.869)$ & $\mathrm{A}$ & $\mathrm{A}$ & $\mathrm{A}$ & $\mathrm{A}$ & $\mathrm{A}$ & $\mathrm{A}$ & $\mathrm{R}$ \\
\hline \multirow{3}{*}{\begin{tabular}{|c|} 
Bias $^{-}$ \\
corrected \\
\cline { 2 - 3 } percentile
\end{tabular}} & g1 & $(-0.517,0.724)$ & $\mathrm{R}$ & $\mathrm{A}$ & $\mathrm{A}$ & $\mathrm{A}$ & $\mathrm{A}$ & $\mathrm{R}$ & $\mathrm{R}$ \\
\hline & G1 & $(-0.539,0.727)$ & $\mathrm{R}$ & $\mathrm{A}$ & $\mathrm{A}$ & $\mathrm{A}$ & $\mathrm{A}$ & $\mathrm{R}$ & $\mathrm{R}$ \\
\hline & b1 & $(-0.574,0.728)$ & $\mathrm{R}$ & $\mathrm{A}$ & $\mathrm{A}$ & $\mathrm{A}$ & $\mathrm{A}$ & $R$ & $\mathrm{R}$ \\
\hline
\end{tabular}

Another example, which is used to test the skewness, is also related to SIDS. We obtain a dataset consists of 78 cases of SIDS occurring in King County between 1976 and 
1977 (Morris et al, 1993). Then they recorded the age at deaths (in Days) of 78 cases of SIDS and finally classify them into 11 different age intervals. For each age interval, the number of deaths was recorded and eventually the number of deaths is employed in this example study. The Q-Q plot of the data is presented in Figure 4.1.2, which didn't support the assumption of normality. Moreover we have performed the Shapiro test (test statistic, $\mathrm{W}=0.82135$, $\mathrm{p}$-value $=0.0329$ ), which cannot support normality assumption as well. By using classical method, the results of testing the statistics based on $g_{1}$ and $b_{1}$ could reject the null hypothesis when testing skewness $=2.0$ while Bias Corrected Standard method does not perform correctly in this test. For bootstrap method, only when the testing hypothesized value is large enough, say skewness $=1.9$ and above, the results from the test statistics based on estimator $b_{1}$ from Efron's Percentile and Hall's Percentile method can provide a good solution to make a correct decision, otherwise the other methods can not. 


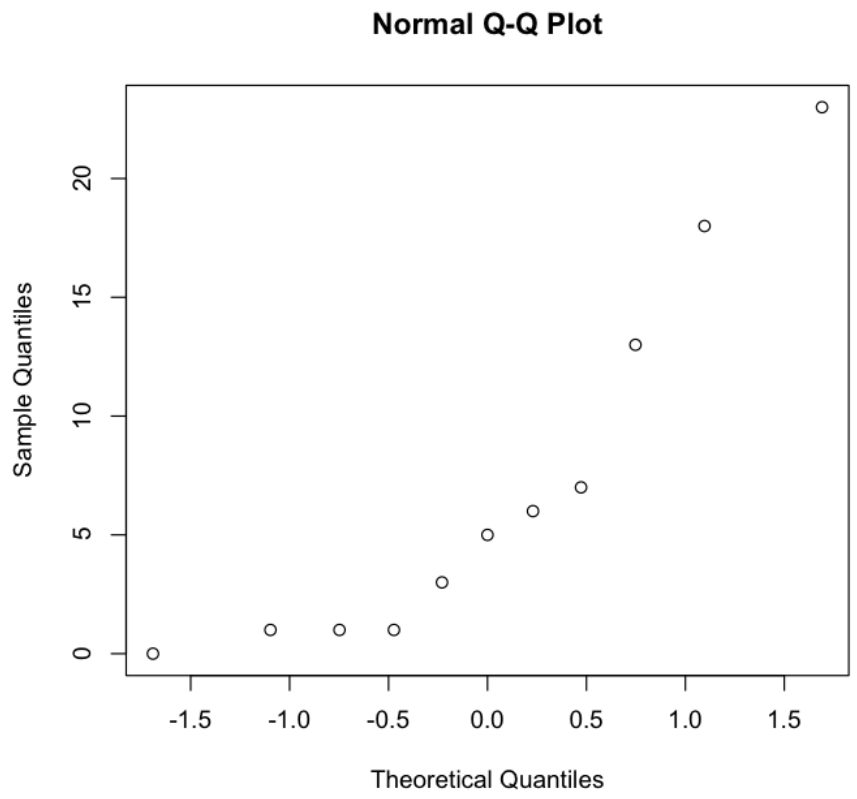

Figure 4.1.2 Normal Q-Q plot for number of death in Example 2

Table 4.1.2 Testing skewness for $\mathrm{n}=11$ non-normal distribution data

\begin{tabular}{|c|c|c|c|c|c|c|c|c|}
\hline & & & $\mathrm{sk}=0$ & $\mathrm{sk}=0.5$ & $\mathrm{sk}=1$ & $\mathrm{sk}=1.5$ & $\mathrm{sk}=1.9$ & $\mathrm{sk}=2.0$ \\
\hline Method & Estimator & Point Estimate & \multicolumn{6}{|c|}{ P-Value } \\
\hline \multirow{3}{*}{ Classical } & g1 & 1.020 & 0.964 & 0.821 & 0.514 & 0.199 & 0.060 & 0.042 \\
\hline & G1 & 1.189 & 0.964 & 0.851 & 0.612 & 0.319 & 0.141 & 0.110 \\
\hline & b1 & 0.884 & 0.964 & 0.783 & 0.407 & 0.105 & 0.019 & 0.012 \\
\hline \multirow{4}{*}{$\begin{array}{c}\text { Bias } \\
\text { Corrected } \\
\text { standard } \\
\end{array}$} & g1 & 1.020 & 0.256 & 0.235 & 0.216 & 0.197 & 0.183 & 0.180 \\
\hline & G1 & 1.189 & 0.270 & 0.249 & 0.229 & 0.209 & 0.195 & 0.191 \\
\hline & b1 & 0.884 & 0.244 & 0.224 & 0.205 & 0.187 & 0.191 & 0.170 \\
\hline & & $\mathrm{CI}$ & \multicolumn{6}{|c|}{ Decision } \\
\hline \multirow{3}{*}{\begin{tabular}{|c|} 
Efron's \\
percentile \\
bootstrap
\end{tabular}} & g1 & $(-0.131,2.202)$ & $\mathrm{A}$ & $\mathrm{A}$ & $\bar{A}$ & $\bar{A}$ & $\mathrm{~A}$ & $\mathrm{~A}$ \\
\hline & G1 & $(-0.065,2.504)$ & $\mathrm{A}$ & $\mathrm{A}$ & $\bar{A}$ & $\bar{A}$ & $\mathrm{~A}$ & $\mathrm{~A}$ \\
\hline & b1 & $(-0.043,1.887)$ & $\mathrm{A}$ & $\mathrm{A}$ & $\mathrm{A}$ & $\mathrm{A}$ & $\mathrm{R}$ & $\mathrm{R}$ \\
\hline \multirow{3}{*}{$\begin{array}{c}\text { Hall's } \\
\text { Percentile } \\
\text { bootstrap }\end{array}$} & g1 & $(-0.189,2.078)$ & $\mathrm{A}$ & $\mathrm{A}$ & $\mathrm{A}$ & $\mathrm{A}$ & A & $\mathrm{A}$ \\
\hline & G1 & $(-0.210,2.558)$ & $\mathrm{A}$ & $\mathrm{A}$ & $\mathrm{A}$ & $\mathrm{A}$ & A & $\mathrm{A}$ \\
\hline & b1 & $(-0.142,1.833)$ & $\mathrm{A}$ & $\mathrm{A}$ & $\mathrm{A}$ & $\mathrm{A}$ & $\mathrm{R}$ & $\mathrm{R}$ \\
\hline \multirow{3}{*}{$\begin{array}{c}\text { Bias }^{-} \\
\text {corrected } \\
\text { percentile }\end{array}$} & g1 & $(0.185,2.370)$ & $\mathrm{R}$ & $\mathrm{A}$ & $\mathrm{A}$ & $\mathrm{A}$ & $\mathrm{A}$ & $\mathrm{A}$ \\
\hline & G1 & $(0.179,2.674)$ & $\mathrm{R}$ & $\mathrm{A}$ & $\mathrm{A}$ & A & $\mathrm{A}$ & $\mathrm{A}$ \\
\hline & b1 & $(0.114,2.036)$ & $\mathrm{R}$ & $\mathrm{A}$ & $\mathrm{A}$ & $\mathrm{A}$ & $\mathrm{A}$ & $\mathrm{A}$ \\
\hline
\end{tabular}

\subsection{Examples for kurtosis}

We acquire a small dataset from the paper by Robertson et al (1976), which discusses the level of plasma prostaglandin E (iPGE) in patients with cancer with and without hypercalcemia. The dataset consists of 21 objects and 2 variables, which are, 
mean plasma iPGE and mean Serum Calcium. In this example study we only consider the variable mean plasma iPGE with hypercalcemia, which consists of 11 objects. The Q-Q plot of the data is depicted in Figure 4.2.1, which supported the assumption of normality. Moreover, the Shapiro test (test statistic, $\mathrm{W}=0.8432$, $\mathrm{p}$-value $=0.132$ ) also supported normality assumption. Using this dataset the results of the test statistics for testing various alternative hypothesis are displayed in Table 4.2.1. Table 4.2.1 shows that both classical and Bias Corrected Standard method provide good solution of testing the alternative hypothesis when we departed the skewness from null hypothesized value. The test statistic based on estimator $g_{1}$ from Bias Corrected Standard method could correctly reject null hypothesis when alternative hypothesis is: kurtosis $=1.5$ with $p$-value equals to 0.045 while all other methods cannot make a decision of rejecting. When departed from the null hypothesis to test kurtosis=2.0, classical, Bias Corrected Standard and Hall's Percentile method show good performance of rejecting the null hypothesis while Efron's Percentile and Bias Corrected Percentile method only could reject the null hypothesis when testing kurtosis $=3$ or above. Overall, the classical and Bias Corrected Standard performs better when the sample size is small and distribution follows normality assumption. 


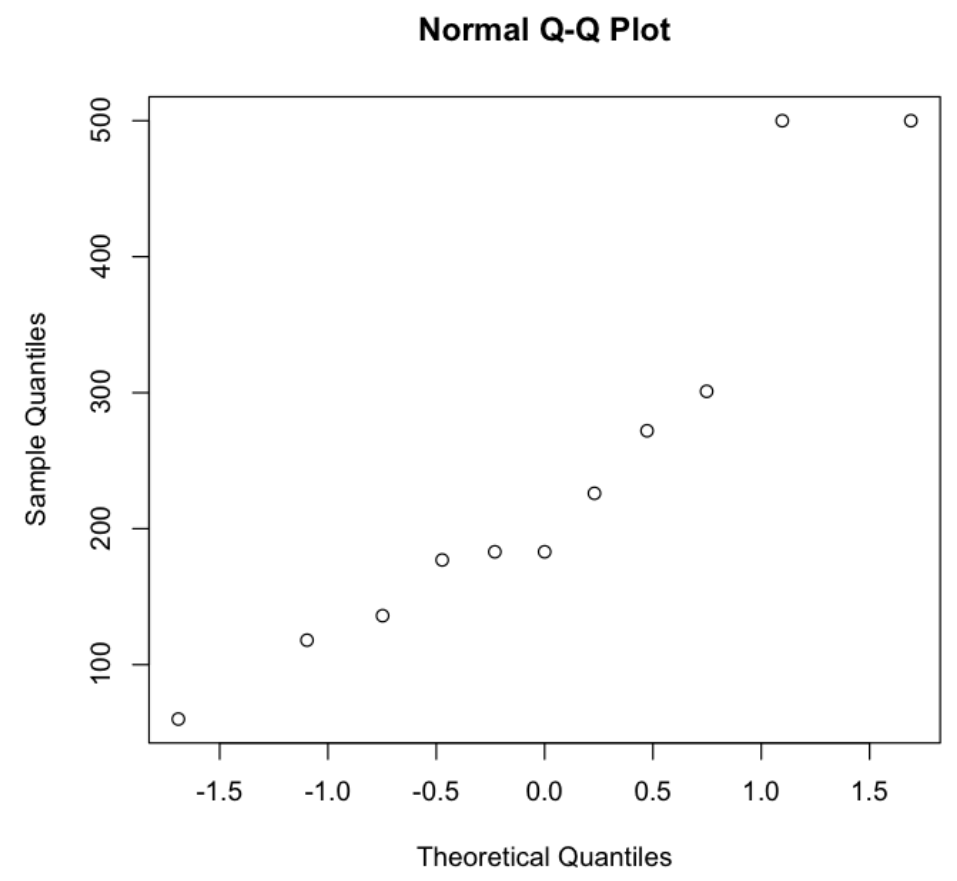

Figure 4.2.1 Normal Q-Q plot for plasma data in Example 3

Table 4.2.1 Testing kurtosis for $\mathrm{n}=11$ normal distribution data

\begin{tabular}{|c|c|c|c|c|c|c|c|c|}
\hline & & & kur $=1$ & kur $=1.5$ & kur $=2$ & kur $=3$ & kur $=4$ & kur $=7$ \\
\hline Method & Estimator & Point Estimate & \multicolumn{6}{|c|}{ P-Value } \\
\hline \multirow{3}{*}{ Classical } & g1 & -0.365 & 0.130 & 0.038 & 0.008 & 0.000 & 0.000 & 0.000 \\
\hline & G1 & 0.225 & 0.261 & 0.145 & 0.071 & 0.011 & 0.001 & 0.000 \\
\hline & b1 & -0.823 & 0.231 & 0.125 & 0.059 & 0.008 & 0.001 & 0.000 \\
\hline \multirow{4}{*}{$\begin{array}{c}\text { Bias } \\
\text { Corrected } \\
\text { standard } \\
\end{array}$} & g1 & -0.365 & 0.128 & 0.045 & 0.010 & 0.000 & 0.000 & 0.000 \\
\hline & G1 & 0.225 & 0.253 & 0.098 & 0.048 & 0.001 & 0.001 & 0.000 \\
\hline & $\mathrm{b} 1$ & -0.823 & 0.221 & 0.102 & 0.047 & 0.008 & 0.001 & 0.000 \\
\hline & & $\mathrm{CI}$ & \multicolumn{6}{|c|}{ Decision } \\
\hline \multirow{3}{*}{$\begin{array}{c}\text { Efron's } \\
\text { percentile } \\
\text { bootstrap }\end{array}$} & $\mathrm{g} 1$ & \begin{tabular}{|l|}
$(-1.682,2.920)$ \\
\end{tabular} & $\mathrm{A}$ & $\mathrm{A}$ & $\mathrm{A}$ & $\mathrm{R}$ & $\mathrm{R}$ & $\mathrm{R}$ \\
\hline & G1 & \begin{tabular}{|l|}
$(-1.930,6.371)$ \\
\end{tabular} & $\mathrm{A}$ & $\mathrm{A}$ & $\mathrm{A}$ & $\mathrm{A}$ & $\mathrm{A}$ & $\mathrm{R}$ \\
\hline & b1 & $(-1.898,2.080)$ & A & A & A & $\mathrm{R}$ & $\mathrm{R}$ & $\mathrm{R}$ \\
\hline \multirow{3}{*}{$\begin{array}{c}\text { Hall's } \\
\text { Percentile } \\
\text { bootstrap }\end{array}$} & g1 & \begin{tabular}{|l|}
$(-2.788,1.955)$ \\
\end{tabular} & $\mathrm{A}$ & $\mathrm{A}$ & $\mathrm{R}$ & $\mathrm{R}$ & $\mathrm{R}$ & $\mathrm{R}$ \\
\hline & G1 & $(-5.547,2.494)$ & $\mathrm{A}$ & $\mathrm{A}$ & $\mathrm{A}$ & $\mathrm{R}$ & $\bar{R}$ & $\bar{R}$ \\
\hline & b1 & \begin{tabular}{|l|}
$(-1.627,2.182)$ \\
\end{tabular} & $\mathrm{A}$ & $\bar{A}$ & $\bar{A}$ & $\bar{R}$ & $\mathrm{R}$ & $\mathrm{R}$ \\
\hline \multirow{3}{*}{$\begin{array}{c}\text { Bias }^{-} \\
\text {corrected } \\
\text { percentile }\end{array}$} & g1 & \begin{tabular}{|l|}
$(-1.660,3.257)$ \\
\end{tabular} & $\mathrm{A}$ & $\mathrm{A}$ & $\mathrm{A}$ & $\mathrm{A}$ & $\mathrm{R}$ & $\mathrm{R}$ \\
\hline & G1 & \begin{tabular}{|l|}
$(-1.954,6.831)$ \\
\end{tabular} & $\mathrm{A}$ & $\mathrm{A}$ & A & $\mathrm{A}$ & $\mathrm{A}$ & $\mathrm{R}$ \\
\hline & b1 & $(-1.895,2.290)$ & $\mathrm{A}$ & $\mathrm{A}$ & $\mathrm{A}$ & $\mathrm{R}$ & $\bar{R}$ & $\mathrm{R}$ \\
\hline
\end{tabular}

Besides normal distribution, a non-normal distribution example study has been conducted in this section. We obtain the dataset, which are courtesy of Dr John Schorling, Depoartment of Medicine, University of Virginia School of Medicine. The dataset 
consists of 403 subjects and 19 variables from 1046 subjects who were studied to understand the popularity of obesity, diabetes and other cardiovascular risk factors in central Virginia for African Americans. However, we only consider one, total cholesterol from this dataset. The Normal Q-Q plot is depicted in Figure 4.2.2, which didn't support normality assumption. Moreover we performed the Shapiro test (test statistic, $\mathrm{W}=0.95987$, $\mathrm{p}$-value $=0$ ), which also supported the normality assumption. Table 4.2.2 shows a slow decrease about the p-value from about 1 to below 0.05 against with increase of the distance from null hypothesized value. Overall, these results do not reply quickly with the changes of alternative hypothesized value. For classical and Bias Corrected Standard method, we reject the null hypothesis when testing kurtosis $=5.0$ which is far from null hypothesized value. Besides, the other bootstrap methods provide a wide confidence interval, which sometimes cannot reject the null hypothesis when it is false such as testing kurtosis $=1.0,3.0$, or 4.0 and for other testing values there is at least one method can correctly reject the null hypothesis. 


\section{Normal Q-Q Plot}

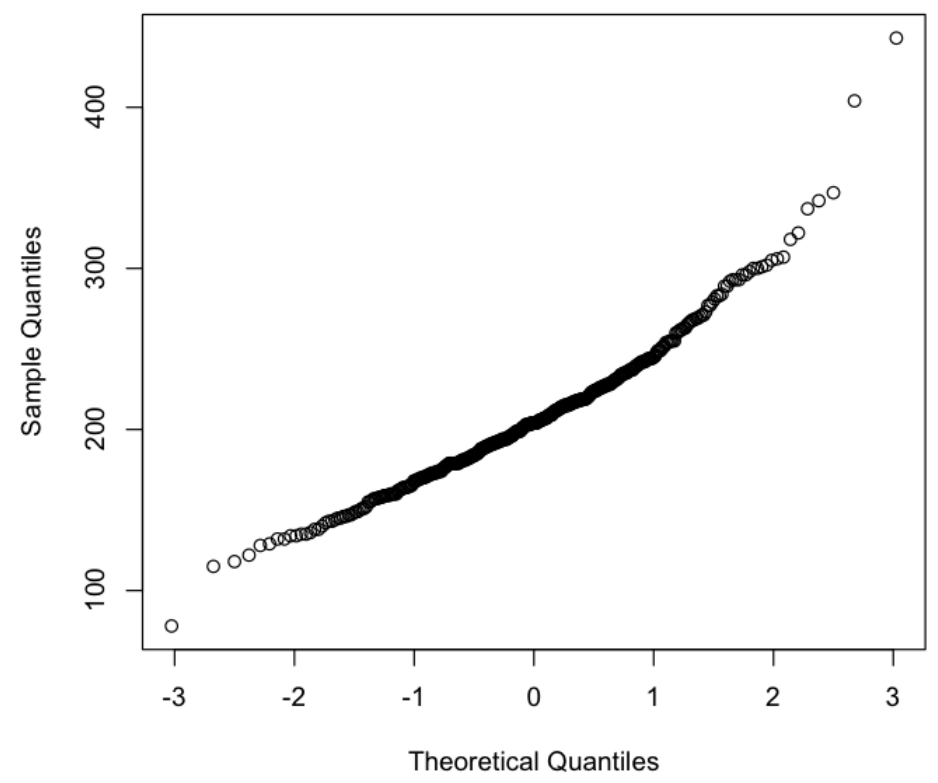

Figure 4.2.2 Normal Q-Q plot for cholesterol data in Example 4

Table 4.2.2 Testing kurtosis for $\mathrm{n}=403$ non-normal distribution data

\begin{tabular}{|c|c|c|c|c|c|c|c|c|c|}
\hline & & & kur $=0.2$ & kur $=0.3$ & kur $=1.0$ & kur $=3.0$ & kur $=4.0$ & kur $=5.0$ & kur $=6.0$ \\
\hline Method & Estimator & Point Estimate & \multicolumn{7}{|c|}{ P-Value } \\
\hline \multirow{3}{*}{ Classical } & $\mathrm{g} 1$ & 2.561 & 0.987 & 0.903 & 0.794 & 0.493 & 0.124 & 0.042 & 0.013 \\
\hline & G1 & 2.608 & 0.998 & 0.943 & 0.652 & 0.349 & 0.207 & 0.039 & 0.009 \\
\hline & b1 & 2.533 & 0.976 & 0.921 & 0.698 & 0.448 & 0.135 & 0.043 & 0.007 \\
\hline \multirow{4}{*}{$\begin{array}{c}\text { Bias } \\
\text { Corrected } \\
\text { standard } \\
\end{array}$} & g1 & 2.561 & 0.965 & 0.913 & 0.733 & 0.398 & 0.090 & 0.044 & 0.012 \\
\hline & G1 & 2.608 & 0.988 & 0.911 & 0.696 & 0.487 & 0.108 & 0.038 & 0.013 \\
\hline & b1 & 2.533 & 0.946 & 0.921 & 0.702 & 0.378 & 0.089 & 0.042 & 0.011 \\
\hline & & $\mathrm{CI}$ & \multicolumn{7}{|c|}{ Decision } \\
\hline \multirow{3}{*}{\begin{tabular}{|c|} 
Efron's \\
percentile \\
bootstrap
\end{tabular}} & $\mathrm{g} 1$ & $(0.164,4.710)$ & $\mathrm{A}$ & $\mathrm{A}$ & $\mathrm{A}$ & $\mathrm{A}$ & $\mathrm{A}$ & $\mathrm{R}$ & $\mathrm{R}$ \\
\hline & G1 & $(0.203,5.065)$ & $\mathrm{R}$ & $\mathrm{A}$ & $\mathrm{A}$ & $\mathrm{A}$ & $\mathrm{A}$ & $\mathrm{A}$ & $\mathrm{R}$ \\
\hline & $\mathrm{b} 1$ & $(0.183,4.795)$ & $\mathrm{A}$ & $\mathrm{A}$ & $\mathrm{A}$ & $\mathrm{A}$ & $\mathrm{A}$ & $\mathrm{R}$ & $\mathrm{R}$ \\
\hline \multirow{3}{*}{$\begin{array}{c}\text { Hall's } \\
\text { Percentile } \\
\text { bootstrap }\end{array}$} & g1 & $(0.194,4.895)$ & $\mathrm{A}$ & $\mathrm{A}$ & $\mathrm{A}$ & $\mathrm{A}$ & $\mathrm{A}$ & $\mathrm{R}$ & $\mathrm{R}$ \\
\hline & G1 & $(0.321,5.085)$ & $\mathrm{R}$ & $\mathrm{R}$ & $\mathrm{A}$ & $\mathrm{A}$ & $\mathrm{A}$ & $\mathrm{A}$ & $\mathrm{R}$ \\
\hline & b1 & $(0.337,4.975)$ & $\mathrm{R}$ & $\mathrm{R}$ & $\mathrm{A}$ & $\mathrm{A}$ & $\mathrm{A}$ & $\mathrm{R}$ & $\mathrm{R}$ \\
\hline \multirow{3}{*}{\begin{tabular}{|c|} 
Bias $^{-}$ \\
corrected \\
percentile
\end{tabular}} & $\mathrm{g} 1$ & $(0.346,5.314)$ & $\mathrm{R}$ & $\mathrm{R}$ & $\mathrm{A}$ & $\mathrm{A}$ & $\mathrm{A}$ & $\mathrm{A}$ & $\mathrm{R}$ \\
\hline & G1 & $(0.340,5.273)$ & $\mathrm{R}$ & $\mathrm{R}$ & $\mathrm{A}$ & $\mathrm{A}$ & $\mathrm{A}$ & $\mathrm{A}$ & $\mathrm{R}$ \\
\hline & b1 & $(0.235,5.119)$ & $\mathrm{R}$ & $\mathrm{A}$ & $\mathrm{A}$ & $\mathrm{A}$ & $\mathrm{A}$ & $\mathrm{A}$ & $\mathrm{R}$ \\
\hline
\end{tabular}




\section{CHAPTER V \\ CONCLUSIONS}

This thesis proposed several test statistics for testing the skewness and kurtosis parameters of a distribution, not limited to normal distribution. Since a theoretical comparison is not possible, a simulation study has been conducted to compare the performance of the test statistics.

We have compared both parametric method (Classical method with normality assumption) and non-parametric methods (bootstrap in Bias Corrected Standard Method, Efron's Percentile Method, Hall's Percentile Method and Bias Corrected Percentile Method) in the hypothesis testing of skewness, where the data are generated from normal, gamma and beta distributions. Table 5.1 illustrates the performance of the tests and our simulation results indicate that the power of the tests differs significantly across sample sizes, the choice of alternative hypotheses and methods we chose. When the data are generated from normal distribution, both classical method and Efron's Percentile Method can attain a nominal size 0.05 while other bootstrap methods cannot provide good results in this situation. However, for skewed distribution, say beta distribution, bootstrap methods show higher power with increasing the sample size whereas the classical method only performs well in small sample size. The results in Bias Percentile Method are approaching to other bootstrap methods, which is obviously away from classical method. Moreover, for testing different hypotheses among all distributions, larger sample size 
always provide with higher empirical power.

\begin{tabular}{|c|c|c|c|c|c|c|c|}
\hline & & \multicolumn{4}{|c|}{ Performance of Hypothesis Test of Skewness } & \multirow[b]{2}{*}{$n=100$} & \multirow[b]{2}{*}{$n=300$} \\
\hline Distribution & Method & $n=10$ & $n=20$ & $n=30$ & $n=50$ & & \\
\hline \multirow[t]{5}{*}{$\mathrm{N}(0,1)$} & Classical & Good & Good & Good & Good & Good & Good \\
\hline & Bias Corrected Standard Bootstrap & Weak & Weak & Weak & Weak & Weak & Fair \\
\hline & Efron's Percentile Bootstrap & Good & Good & Good & Good & Fair & Good \\
\hline & Hall's Percentile Bootstrap & Weak & Weak & Weak & Weak & Weak & Fair \\
\hline & Bias Corrected Percentile Bootstrap & Weak & Weak & Weak & Weak & Weak & Fair \\
\hline \multirow[t]{5}{*}{ Gamma $(4,1)$} & Classical & Weak & Weak & Weak & Weak & Weak & Weak \\
\hline & Bias Corrected Standard Bootstrap & Weak & Weak & Weak & Weak & Weak & Weak \\
\hline & Efron's Percentile Bootstrap & Weak & Weak & Weak & Weak & Weak & Weak \\
\hline & Hall's Percentile Bootstrap & Weak & Weak & Weak & Weak & Weak & Weak \\
\hline & Bias Corrected Percentile Bootstrap & Weak & Weak & Weak & Weak & Weak & Weak \\
\hline \multirow[t]{5}{*}{ Gamma $(7.5,1)$} & Classical & Weak & Fair & Fair & Fair & Fair & Weak \\
\hline & Bias Corrected Standard Bootstrap & Weak & Weak & Weak & Weak & Weak & Weak \\
\hline & Efron's Percentile Bootstrap & Fair & Weak & Weak & Weak & Weak & Weak \\
\hline & Hall's Percentile Bootstrap & Weak & Weak & Weak & Weak & Weak & Weak \\
\hline & Bias Corrected Percentile Bootstrap & Weak & Weak & Weak & Weak & Weak & Weak \\
\hline \multirow[t]{5}{*}{ Gamma $(10,1)$} & Classical & Fair & Fair & Fair & Fair & Fair & Weak \\
\hline & Bias Corrected Standard Bootstrap & Weak & Weak & Weak & Weak & Weak & Weak \\
\hline & Efron's Percentile Bootstrap & Weak & Weak & Weak & Weak & Weak & Weak \\
\hline & Hall's Percentile Bootstrap & Good & Weak & Weak & Weak & Weak & Weak \\
\hline & Bias Corrected Percentile Bootstrap & Weak & Weak & Weak & Weak & Weak & Weak \\
\hline \multirow[t]{5}{*}{ Beta $(1,0.35181)$} & Classical & Good & Good & Good & Good & Good & Good \\
\hline & Bias Corrected Standard Bootstrap & Fair & Good & Good & Good & Good & Good \\
\hline & Efron's Percentile Bootstrap & Good & Good & Good & Good & Good & Good \\
\hline & Hall's Percentile Bootstrap & Weak & Good & Good & Good & Good & Good \\
\hline & Bias Corrected Percentile Bootstrap & Good & Good & Good & Good & Good & Good \\
\hline \multirow[t]{5}{*}{ Beta $(1,0.15470)$} & Classical & Fair & Weak & Weak & Weak & Weak & Weak \\
\hline & Bias Corrected Standard Bootstrap & Weak & Weak & Fair & Fair & Good & Good \\
\hline & Efron's Percentile Bootstrap & Fair & Good & Good & Good & Good & Good \\
\hline & Hall's Percentile Bootstrap & Weak & Weak & Weak & Fair & Good & Good \\
\hline & Bias Corrected Percentile Bootstrap & Good & Fair & Fair & Good & Good & Good \\
\hline
\end{tabular}

Table 5.1 Performance of hypothesis test of skewness

Kurtosis parameter has also been tested based the methods mentioned above,

however, the data are generated from normal, beta and uniform distributions due to

different shape parameters. Table 5.2 shows the performance of hypothesis test of kurtosis. Only classical method performs well when the data are generated from normal distribution throughout all sample sizes in the simulation, whereas the bootstrap methods are not useful in this case. Similarly, the results from beta distribution show that the Bias Corrected Percentile Method can obtain a nominal size 0.05 for a large sample size besides classical method. Bootstrap methods can provide better solution than classical method for testing kurtosis parameter especially when the data are from uniform 
distribution.

\begin{tabular}{|c|c|c|c|c|c|c|c|}
\hline & & \multicolumn{4}{|c|}{ Performance of Hypothesis Test of Kurtosis } & \multirow[b]{2}{*}{$n=100$} & \multirow[b]{2}{*}{$n=300$} \\
\hline Distribution & Method & $n=10$ & $\mathrm{n}=20$ & $\mathrm{n}=30$ & $n=50$ & & \\
\hline \multirow[t]{5}{*}{$\mathrm{N}(0,1)$} & Classical & Good & Good & Good & Good & Good & Good \\
\hline & Bias Corrected Standard Bootstrap & Good & Weak & Weak & Weak & Weak & Fair \\
\hline & Efron's Percentile Bootstrap & Fair & Fair & Fair & Fair & Weak & Weak \\
\hline & Hall's Percentile Bootstrap & Weak & Fair & Weak & Weak & Weak & Weak \\
\hline & Bias Corrected Percentile Bootstrap & Fair & Weak & Weak & Weak & Weak & Fair \\
\hline \multirow[t]{5}{*}{ Beta $(2,5)$} & Classical & Fair & Good & Good & Good & Good & Good \\
\hline & Bias Corrected Standard Bootstrap & Good & Weak & Weak & Weak & Weak & Fair \\
\hline & Efron's Percentile Bootstrap & Good & Fair & Fair & Fair & Fair & Fair \\
\hline & Hall's Percentile Bootstrap & Weak & Fair & Weak & Weak & Weak & Fair \\
\hline & Bias Corrected Percentile Bootstrap & Weak & Weak & Weak & Weak & Fair & Good \\
\hline \multirow[t]{5}{*}{ Uniform $(0,1)$} & Classical & Fair & Good & Good & Weak & Weak & Weak \\
\hline & Bias Corrected Standard Bootstrap & Fair & Good & Good & Good & Good & Good \\
\hline & Efron's Percentile Bootstrap & Weak & Good & Good & Good & Good & Good \\
\hline & Hall's Percentile Bootstrap & Fair & Fair & Fair & Fair & Fair & Fair \\
\hline & Bias Corrected Percentile Bootstrap & Good & Good & Good & Good & Good & Good \\
\hline
\end{tabular}

Table 5.2 Performance of hypothesis test of kurtosis

A limitation of this study is that the test statistics used in this thesis are based on the assumption of normal distribution. However, the results suggested that these statistics can be used for some non-normal distributions too. It is noted that the performance of gamma distribution needs further investigation since the bootstrap methods cannot work for the data coming from this distribution. We would suggest continuing to explore the test of skewness of gamma distribution and some other distributions with specific kurtosis features. 


\section{LIST OF REFERENCES}

Ankarali, H., \& ANKARALI, S. (2009). A bootstrap confidence interval for skewness and kurtosis and properties of t-test in small samples from normal distribution. Balkan Medical Journal, 2009(4).

Balanda, K. P., \& MacGillivray, H. L. (1988). Kurtosis: a critical review. The American Statistician, 42(2), 111-119.

Cramér, H. (1946). A contribution to the theory of statistical estimation. Scandinavian Actuarial Journal, 1946(1), 85-94.

DiCiccio, T. J., \& Romano, J. P. (1988). A review of bootstrap confidence intervals. Journal of the Royal Statistical Society. Series B (Methodological), 338-354.

Efron, B. (1987). Better bootstrap confidence intervals. Journal of the American statistical Association, 82(397), 171-185.

Efron, B. (1992). Bootstrap methods: another look at the jackknife. In Breakthroughs in Statistics (pp. 569-593). Springer New York.

Fisher, R. A. (1930). Moments and product moments of sampling distributions. Proceedings of the London Mathematical Society, 2(1), 199-238.

Groeneveld, R. A., \& Meeden, G. (1984). Measuring skewness and kurtosis. The Statistician, 391-399.

Hall, P. (2013). The bootstrap and Edgeworth expansion. Springer Science \& Business Media. 
Joanes, D. N., \& Gill, C. A. (1998). Comparing measures of sample skewness and kurtosis. Journal of the Royal Statistical Society: Series D (The Statistician), 47(1), 183-189.

Morris, J. C., Edland, S., Clark, C., Galasko, D., Koss, E., Mohs, R., ... \& Heyman, A. (1993). The Consortium to Establish a Registry for Alzheimer's Disease (CERAD) Part IV. Rates of cognitive change in the longitudinal assessment of probable Alzheimer's disease. Neurology, 43(12), 2457-2457.

Pearson, K. (1894). Mathematical Contributions to the Theory of Evolution. II. Skew Variation in Homogeneous Material. Proceedings of the Royal Society of London, 57(340-346), 257-260.

Robertson, S. E., \& Jones, K. S. (1976). Relevance weighting of search terms. Journal of the American Society for Information science, 27(3), 129-146.

Sergio Perez-Meloand, \& Kibria, B. M. G. (2016). Comparison of Some Confidence Intervals for Estimating the Skewness Parameter of a Distribution. Thailand Statistician, 14(1), 93-115.

Van Belle, G., Fisher, L. D., Heagerty, P. J., \& Lumley, T. (2004). Biostatistics: a methodology for the health sciences (Vol. 519). John Wiley \& Sons. 


\section{APPENDIX A}

Table A1: Power for $\mathrm{N}(0,1)$ with skewness $=0$ against with other value for different sample sizes

\begin{tabular}{|c|c|c|c|c|c|c|c|c|c|c|c|c|}
\hline & & $=10$ & & & & & & & & & & \\
\hline Method & ist & $1=0$ & $=0.2$ & $=0.4$ & $1=0.6$ & $=0.8$ & $1=1.0$ & $1=1.2$ & $1=1.4$ & $1=1.6$ & $1=1.8$ & $1=2.0$ \\
\hline \multirow{3}{*}{ Classical } & 81 & 060 & 069 & .110 & .179 & .275 & .399 & .543 & 0.688 & 0.802 & 0.881 & 0.930 \\
\hline & G1 & .060 & 0.066 & 0.092 & 0.143 & 0.214 & 0.298 & 0.410 & 0.525 & 0.658 & 0.758 & 0.842 \\
\hline & b1 & .060 & 0.073 & 0.129 & 0.228 & 0.360 & 0.518 & 0.693 & 0.820 & 0.901 & 0.951 & 0.977 \\
\hline \multirow{3}{*}{$\begin{array}{c}\text { Bias } \\
\text { Corrected } \\
\text { standard }\end{array}$} & $\mathrm{g} 1$ & .105 & 0.126 & 0.174 & 0.256 & 0.359 & 0.473 & 0.596 & 0.694 & 0.774 & 0.843 & 0.884 \\
\hline & G1 & 0.105 & 0.115 & 0.158 & 0.211 & 0.294 & 0.382 & 0.482 & 0.584 & 0.675 & 0.745 & 0.809 \\
\hline & b1 & .102 & 0.130 & 0.198 & 0.303 & 0.433 & 0.580 & 0.698 & 0.792 & 0.854 & 0.901 & $\overline{0.932}$ \\
\hline \multirow{3}{*}{$\begin{array}{c}\text { Efron's } \\
\text { percentile } \\
\text { bootstrap } \\
\end{array}$} & g1 & 0.001 & 0.008 & 0.043 & 0.137 & 0.266 & 0.414 & 0.588 & 0.728 & 0.829 & 0.905 & 0.951 \\
\hline & G1 & .000 & 0.008 & 0.028 & 0.087 & 0.177 & 0.301 & 0.429 & 0.572 & 0.695 & 0.795 & 0.861 \\
\hline & b1 & 0.002 & 0.012 & 0.067 & 0.198 & 0.372 & 0.565 & \begin{tabular}{|l|}
0.729 \\
\end{tabular} & 0.843 & 0.923 & 0.969 & 0.993 \\
\hline \multirow{3}{*}{$\begin{array}{c}\text { Hall's } \\
\text { Percentile } \\
\text { bootstrap }\end{array}$} & g1 & 0.116 & 0.128 & 0.177 & 0.247 & 0.349 & 0.469 & 0.591 & 0.692 & 0.775 & .837 & .874 \\
\hline & G1 & 0.123 & 0.129 & 0.160 & 0.210 & 0.283 & 0.375 & 0.474 & 0.579 & 0.676 & 0.745 & 0.805 \\
\hline & $\mathrm{b} 1$ & 0.122 & 0.136 & 0.200 & 0.297 & 0.431 & 0.575 & 0.698 & 0.790 & 0.851 & 0.890 & 0.924 \\
\hline \multirow{4}{*}{$\begin{array}{c}\text { Bias } \\
\text { Corrected } \\
\text { percentile } \\
\end{array}$} & $\mathrm{g} 1$ & .106 & 0.126 & 0.180 & 0.255 & 0.354 & 0.458 & 0.565 & 0.664 & 0.742 & .810 & 0.870 \\
\hline & G1 & 0.105 & 0.118 & 0.158 & 0.218 & 0.290 & 0.375 & 0.465 & 0.554 & 0.639 & 0.716 & 0.778 \\
\hline & b1 & 0.105 & .128 & 0.203 & 01 & 0.420 & 48 & 0.666 & .760 & 836 & 00 & .952 \\
\hline & & $\mathrm{n}=20$ & & & & & & & & & & \\
\hline & Est & $\gamma 1=0$ & $=0.2$ & $\gamma 1=0.4$ & $1=0.6$ & $1=0.8$ & $=1.0$ & $\gamma 1=1.2$ & $\gamma 1=1.4$ & $\gamma 1=1.6$ & $1=1.8$ & $\gamma 1=2.0$ \\
\hline \multirow{3}{*}{ Classical } & g1 & 0.055 & 0.067 & 0.123 & 0.229 & 0.384 & 0.578 & 0.731 & 0.858 & 0.921 & 0.965 & 0.987 \\
\hline & G1 & 0.055 & 0.065 & 0.111 & 0.198 & 0.333 & 0.500 & 0.663 & 0.798 & 0.886 & 0.936 & 0.970 \\
\hline & b1 & 0.055 & 0.071 & 0.136 & 0.266 & 0.442 & 641 & 0.799 & 0.895 & 0.950 & .983 & 0.994 \\
\hline \multirow{3}{*}{$\begin{array}{c}\text { Bias } \\
\text { Corrected } \\
\text { standard } \\
\end{array}$} & g1 & 0.110 & 0.140 & 0.231 & 0.390 & 0.551 & 0.686 & 0.791 & 0.862 & 0.910 & 0.938 & 0.959 \\
\hline & G1 & .114 & 0.133 & 0.215 & 0.355 & 0.504 & 0.641 & 0.753 & 0.824 & 80 & 0.918 & 943 \\
\hline & b1 & 0.114 & 0.142 & 0.257 & 0.431 & 0.597 & 0.730 & 0.830 & 0.890 & 0.929 & 0.955 & 0.973 \\
\hline \multirow{3}{*}{$\begin{array}{l}\text { Efron's } \\
\text { percentile } \\
\text { bootstrap }\end{array}$} & g1 & 0.030 & 0.062 & 0.161 & 0.328 & 0.524 & 0.702 & 0.830 & 0.901 & 0.947 & 0.976 & 0.990 \\
\hline & G1 & 0.032 & 0.057 & 0.139 & 0.282 & 0.465 & 0.635 & 0.777 & 0.865 & 0.923 & 0.960 & 0.980 \\
\hline & b1 & 0.031 & 0.068 & 0.183 & 0.373 & 0.587 & 0.757 & 0.865 & 0.930 & 0.971 & 0.987 & $\overline{0.996}$ \\
\hline \multirow{3}{*}{$\begin{array}{c}\text { Hall's } \\
\text { Percentile } \\
\text { bootstrap }\end{array}$} & g1 & 0.120 & 0.146 & 0.240 & 0.395 & 0.555 & 88 & 0.791 & 0.855 & 0.905 & .933 & 0.954 \\
\hline & G1 & 0.118 & 0.142 & 0.221 & 0.357 & 0.513 & 0.638 & 0.750 & 0.826 & 0.881 & 0.915 & 0.939 \\
\hline & b1 & 0.124 & 0.147 & 0.266 & 0.437 & 0.598 & 0.735 & 0.825 & 0.886 & 0.924 & 0.948 & 0.967 \\
\hline \multirow{4}{*}{$\begin{array}{c}\text { Bias } \\
\text { Corrected } \\
\text { percentile }\end{array}$} & g1 & 0.108 & 0.132 & 0.233 & 0.373 & 0.533 & 0.678 & 0.785 & 0.864 & 0.907 & 0.943 & 0.967 \\
\hline & G1 & 0.111 & 0.128 & 0.207 & 0.336 & 0.487 & 0.627 & 0.740 & 0.827 & 0.881 & 0.921 & 0.951 \\
\hline & $\mathrm{b} 1$ & 0.110 & 39 & 0.248 & 0.416 & 0.581 & 0.725 & 0.831 & 0.889 & 0.931 & 0.963 & 0.981 \\
\hline & & $\mathrm{n}=30$ & & & & & & & & & & \\
\hline $\bar{d}$ & Est & $\gamma 1=0$ & $\gamma 1=0.2$ & $1=0.4$ & $1=0.6$ & $1=0.8$ & $1=1.0$ & $\gamma 1=1.2$ & $\gamma 1=1.4$ & $\gamma 1=1.6$ & $1=1.8$ & $\gamma 1=2.0$ \\
\hline \multirow{3}{*}{ Classical } & g1 & 0.032 & 0.050 & 0.128 & 0.291 & 0.506 & 0.726 & 0.884 & 0.957 & 0.986 & 0.996 & 0.998 \\
\hline & G1 & 0.032 & 0.048 & 0.118 & 0.260 & 0.460 & 0.676 & 0.844 & 0.940 & 0.977 & 0.992 & 0.998 \\
\hline & b1 & 0.032 & 0.053 & 0.143 & 0.322 & 0.555 & 0.770 & 0.914 & 0.971 & 0.991 & 0.998 & 0.999 \\
\hline \multirow{3}{*}{$\begin{array}{c}\text { Bias } \\
\text { Corrected } \\
\text { standard }\end{array}$} & g1 & 0.103 & 0.166 & 0.328 & 0.529 & 0.712 & 0.832 & 0.914 & 0.954 & 0.974 & 0.987 & 0.992 \\
\hline & G1 & 0.099 & 0.160 & 0.307 & 0.497 & 0.680 & 0.814 & 0.893 & 0.942 & 0.967 & 0.981 & 0.989 \\
\hline & b1 & 0.103 & 0.173 & 0.342 & 0.564 & 0.743 & 0.859 & 0.930 & 0.963 & 0.978 & 0.989 & 0.994 \\
\hline \multirow{3}{*}{$\begin{array}{c}\text { Efron's } \\
\text { percentile } \\
\text { bootstrap }\end{array}$} & g1 & 0.045 & 0 . & 0.273 & 0.504 & 0.731 & 0.878 & 0.952 & 0.982 & 0.993 & 0.999 & 0.999 \\
\hline & G1 & 0.046 & 0.096 & 0.253 & 0.469 & 0.691 & 0.850 & 0.934 & 0.975 & 0.991 & 0.997 & 0.999 \\
\hline & $\mathrm{b} 1$ & 0.051 & 0.109 & 0.297 & 0.544 & 0.767 & 0.903 & 0.968 & 0.987 & 0.995 & 0.999 & 0.999 \\
\hline \multirow{3}{*}{$\begin{array}{c}\text { Hall's } \\
\text { Percentile } \\
\text { bootstrap } \\
\end{array}$} & g1 & 0.111 & 0.172 & 0.337 & 0.542 & 0.714 & 0.838 & 0.908 & 0.950 & 0.971 & 0.985 & 0.994 \\
\hline & G1 & 0.112 & 0.169 & 0.319 & 0.508 & 0.678 & 0.812 & 0.890 & 0.937 & 0.965 & 0.978 & 0.989 \\
\hline & b1 & 0.110 & 0.178 & 0.354 & 0.572 & 0.742 & 0.857 & 0.925 & 0.957 & 0.979 & 0.990 & 0.994 \\
\hline \multirow{3}{*}{$\begin{array}{c}\text { Bias } \\
\text { Corrected } \\
\text { percentile }\end{array}$} & g1 & 0.091 & 0.151 & 0.306 & 0.516 & 0.711 & 0.848 & 0.924 & 0.971 & 0.983 & 0.993 & 0.997 \\
\hline & G1 & 0.090 & 0.150 & 0.289 & 0.486 & 0.673 & 0.815 & 0.906 & 0.958 & 0.979 & 0.990 & 0.996 \\
\hline & b1 & 0.091 & 0.158 & 0.333 & 0.546 & 0.743 & 0.876 & 0.942 & 0.977 & 0.990 & 0.995 & 0.999 \\
\hline
\end{tabular}


Table A1 (Continued)

\begin{tabular}{|c|c|c|c|c|c|c|c|c|c|c|c|c|}
\hline & & $n=50$ & & & & & & & & & & \\
\hline Method & Est & $\gamma 1=0$ & $=0.2$ & $1=0.4$ & $1=0.6$ & $=0.8$ & $=1.0$ & $\gamma 1=1.2$ & $\gamma 1=1.4$ & $1=1.6$ & $1=1.8$ & $1=2.0$ \\
\hline \multirow{3}{*}{ Classical } & g1 & 034 & .075 & 0.203 & 0.442 & 0.707 & 0.887 & 0.968 & 0.992 & 0.998 & 0.999 & 1.000 \\
\hline & G1 & 034 & .073 & 0.193 & 0.419 & 0.680 & 0.868 & 0.960 & 0.989 & 0.997 & 0.999 & 1.000 \\
\hline & b1 & 034 & .078 & 0.215 & 0.467 & 0.734 & 0.900 & 0.976 & 0.995 & 0.999 & .999 & 1.000 \\
\hline \multirow{3}{*}{$\begin{array}{c}\text { Bias } \\
\text { Corrected } \\
\text { standard } \\
\end{array}$} & $\mathrm{g} 1$ & .100 & 0.182 & 0.392 & 0.630 & 0.807 & 0.910 & 0.960 & 0.982 & 0.990 & 0.995 & 0.998 \\
\hline & G1 & .102 & 0.182 & 0.376 & 0.614 & 0.788 & 0.896 & 0.952 & 0.981 & 0.989 & 0.995 & 998 \\
\hline & $\overline{b 1}$ & 104 & 0.190 & 0.406 & 0.656 & 0.823 & 0.920 & 0.966 & 0.985 & 0.993 & 0.996 & 0.998 \\
\hline \multirow{3}{*}{$\begin{array}{c}\text { Efron's } \\
\text { percentile } \\
\text { bootstrap }\end{array}$} & $\mathrm{g} 1$ & 059 & 0.140 & 0.367 & 0.638 & 0.837 & 0.941 & 0.981 & 0.996 & 0.999 & 1.000 & 1.000 \\
\hline & G1 & .058 & 0.137 & 0.349 & 0.613 & 0.820 & 0.930 & 0.975 & 0.992 & 0.998 & 0.999 & 1.000 \\
\hline & b1 & 0.058 & 0.145 & 0.385 & 0.663 & 0.855 & 0.949 & 0.985 & 0.996 & 0.999 & 1.000 & 1.000 \\
\hline \multirow{3}{*}{$\begin{array}{c}\text { Hall's } \\
\text { Percentile } \\
\text { bootstrap }\end{array}$} & g1 & 114 & 0.197 & 0.399 & 0.635 & 0.804 & 0.904 & 0.960 & 0.984 & 0.990 & 0.996 & 0.998 \\
\hline & G1 & 0.109 & 0.189 & 0.385 & 0.617 & 0.792 & 0.893 & 0.955 & 0.980 & 0.990 & 0.994 & 0.997 \\
\hline & b1 & 111 & 0.203 & 0.418 & 0.652 & 0.821 & 18 & 0.966 & 0.986 & 0.992 & .996 & .999 \\
\hline \multirow{4}{*}{$\begin{array}{c}\text { Bias } \\
\text { Corrected } \\
\text { percentile } \\
\end{array}$} & $\mathrm{g} 1$ & 0.093 & 0.173 & 0.381 & 0.636 & 0.815 & 0.924 & 0.973 & 0.991 & 0.997 & 0.999 & 1.000 \\
\hline & G1 & 0.091 & 0.170 & 0.371 & 0.611 & 0.798 & 0.914 & 0.967 & 0.988 & 0.996 & 0.999 & 0.999 \\
\hline & b1 & 0.093 & .181 & 0.392 & 7 & .833 & .931 & 0.978 & 992 & 97 & .999 & 000 \\
\hline & & $n=100$ & & & & & & & & & & \\
\hline & Est & $1=0$ & .2 & 0.4 & 0.6 & $=0.8$ & $=1.0$ & $=1.2$ & $=1.4$ & $=1.6$ & $=1.8$ & $1=2.0$ \\
\hline \multirow{3}{*}{ Classical } & $\mathrm{g} 1$ & 0.048 & 0.123 & 0.379 & 0.733 & 0.923 & 0.988 & 0.998 & 0.999 & 1.000 & 1.000 & 1.000 \\
\hline & G1 & 0.048 & 0.121 & 0.371 & 0.717 & 0.917 & 0.987 & 0.998 & 0.999 & 1.000 & 1.000 & 1.000 \\
\hline & b1 & 0.048 & 0.125 & 0.391 & 0.746 & 0.929 & 0.989 & 0.998 & 0.999 & 1.000 & 1.000 & 1.000 \\
\hline \multirow{3}{*}{$\begin{array}{c}\text { Bias } \\
\text { Corrected } \\
\text { standard } \\
\end{array}$} & g1 & 0.096 & 0.215 & 0.529 & 0.803 & 0.928 & 0.978 & 0.993 & 0.997 & 0.998 & 0.999 & 0.999 \\
\hline & G1 & 0.096 & 0.210 & 0.514 & 0.796 & 0.924 & 975 & 0.992 & 0.997 & 0.998 & .999 & 0.999 \\
\hline & $\mathrm{b1}$ & 0.097 & 0.223 & 0.536 & 0.808 & 0.930 & 0.978 & 0.995 & 0.998 & 0.998 & 0.999 & 1.000 \\
\hline \multirow{3}{*}{$\begin{array}{l}\text { Efron's } \\
\text { percentile } \\
\text { bootstrap }\end{array}$} & $\mathrm{g} 1$ & & & & & & & & & & & 0 \\
\hline & G1 & 0.069 & 0.191 & 0.512 & 0.811 & 0.939 & 0.986 & 0.996 & 0.998 & 0.999 & 1.000 & 1.000 \\
\hline & b1 & 0.067 & 0.195 & 0.534 & 0.830 & 0.946 & 0.988 & 0.997 & 0.999 & 0.999 & 1.000 & 1.000 \\
\hline \multirow{3}{*}{$\begin{array}{c}\text { Hall's } \\
\text { Percentile } \\
\text { bootstrap }\end{array}$} & g1 & 0.100 & 0.226 & 0.533 & 0.806 & 0.928 & 0.976 & 0.993 & 0.997 & 0.999 & 0.999 & 1.000 \\
\hline & G1 & 0.102 & 0.220 & 0.524 & 0.794 & 0.924 & 0.973 & 0.992 & 0.997 & 0.998 & 0.999 & 1.000 \\
\hline & b1 & 0.098 & 0.223 & 0.544 & 0.813 & 0.932 & 0.977 & 0.994 & 0.998 & 0.999 & 0.999 & 1.000 \\
\hline \multirow{4}{*}{$\begin{array}{c}\text { Bias } \\
\text { Corrected } \\
\text { percentile }\end{array}$} & $\mathrm{g} 1$ & 0.090 & 0.217 & 0.530 & 0.807 & 0.931 & 0.982 & 0.996 & 0.998 & 0.999 & 1.000 & 1.000 \\
\hline & G1 & 0.092 & 0.210 & 0.518 & 0.798 & 0.927 & 0.980 & 0.995 & 0.998 & 0.999 & 1.000 & 1.000 \\
\hline & b1 & 0.092 & 0.218 & 0.536 & .815 & 936 & .984 & 0.996 & 0.998 & 0.999 & 1.000 & 1.000 \\
\hline & & $n=300$ & & & & & & & & & & \\
\hline $\bar{d}$ & Est & $\gamma 1=0$ & $\gamma 1=0.2$ & $\gamma 1=0.4$ & $1=0.6$ & $\gamma 1=0.8$ & $\gamma 1=1.0$ & $\gamma 1=1.2$ & $\gamma 1=1.4$ & $\gamma 1=1.6$ & $\gamma 1=1.8$ & $\gamma 1=2.0$ \\
\hline \multirow{3}{*}{ Classical } & g1 & 0.044 & 0.296 & 0.821 & 0.994 & 1.000 & 1.000 & 1.000 & 1.000 & 1.000 & 1.000 & 1.000 \\
\hline & G1 & 0.044 & 0.292 & 0.819 & 0.993 & 1.000 & 1.000 & 1.000 & 1.000 & 1.000 & 1.000 & 1.000 \\
\hline & b1 & 0.044 & 0.298 & 0.825 & 0.994 & 1.000 & 1.000 & 1.000 & 1.000 & 1.000 & 1.000 & 1.000 \\
\hline \multirow{3}{*}{$\begin{array}{c}\text { Bias } \\
\text { Corrected } \\
\text { standard }\end{array}$} & $\mathrm{g} 1$ & 0.064 & 0.365 & 0.843 & 0.989 & 0.999 & 1.000 & 1.000 & 1.000 & 1.000 & 1.000 & 1.000 \\
\hline & G1 & 0.064 & 0.362 & 0.837 & 0.989 & 0.999 & 1.000 & 1.000 & 1.000 & 1.000 & 1.000 & 1.000 \\
\hline & $\mathrm{b} 1$ & 0.066 & 0.362 & 0.842 & 0.989 & 0.999 & 1.000 & 1.000 & 1.000 & 1.000 & 1.000 & 1.000 \\
\hline \multirow{3}{*}{$\begin{array}{l}\text { Efron's } \\
\text { percentile } \\
\text { bootstrap }\end{array}$} & $\mathrm{g} 1$ & 0.060 & 0.366 & 0.850 & 0.991 & 0.999 & 1.000 & 1.000 & 1.000 & 1.000 & 1.000 & 1.000 \\
\hline & G1 & 0.059 & 0.363 & 0.844 & 0.990 & 0.999 & 1.000 & 1.000 & 1.000 & 1.000 & 1.000 & 1.000 \\
\hline & $\mathrm{b} 1$ & 0.059 & 0.367 & 0.854 & 0.991 & 0.999 & 1.000 & 1.000 & 1.000 & 1.000 & 1.000 & 1.000 \\
\hline \multirow{3}{*}{$\begin{array}{c}\text { Hall's } \\
\text { Percentile } \\
\text { bootstrap }\end{array}$} & $\mathrm{g} 1$ & 0.065 & 0.369 & 0.844 & 0.990 & 0.999 & 1.000 & 1.000 & 1.000 & 1.000 & 1.000 & 1.000 \\
\hline & G1 & 0.067 & 0.366 & 0.842 & 0.990 & 0.999 & 1.000 & 1.000 & 1.000 & 1.000 & 1.000 & 1.000 \\
\hline & $\overline{b 1}$ & 0.068 & 0.368 & 0.846 & 0.990 & 0.999 & 1.000 & 1.000 & 1.000 & 1.000 & 1.000 & 1.000 \\
\hline \multirow{3}{*}{$\begin{array}{c}\text { Bias } \\
\text { Corrected } \\
\text { percentile }\end{array}$} & g1 & 0.065 & 0.375 & 0.839 & 0.989 & 0.999 & 1.000 & 1.000 & 1.000 & 1.000 & 1.000 & 1.000 \\
\hline & G1 & 0.064 & 0.369 & 0.841 & 0.988 & 0.999 & 1.000 & 1.000 & 1.000 & 1.000 & 1.000 & 1.000 \\
\hline & b1 & 0.065 & 0.372 & 0.843 & 0.987 & 0.999 & 1.000 & 1.000 & 1.000 & 1.000 & 1.000 & 1.000 \\
\hline
\end{tabular}


Table A2: Power for Gamma $(4,1)$ with skewness=1 against with other value for different sample size

\begin{tabular}{|c|c|c|c|c|c|c|c|c|c|c|c|c|}
\hline & & & & & & & & & & & & \\
\hline $\mathrm{d}$ & st & $=1.0$ & $=1.2$ & $=1.4$ & $=1.0$ & $=1.8$ & $=2.0$ & $=2.2$ & $1=2.4$ & $1=2.6$ & $1=2.8$ & $1=3.0$ \\
\hline \multirow{3}{*}{ Classical } & 1 & 137 & 236 & .355 & .497 & .628 & .741 & .823 & 0.901 & 0.941 & 0.968 & .984 \\
\hline & G1 & .096 & 142 & 0.227 & 0.325 & 0.437 & .552 & 0.664 & 0.752 & 0.822 & .884 & .931 \\
\hline & b1 & .223 & .360 & 0.530 & 0.671 & 0.790 & 0.879 & 0.938 & 0.968 & 0.987 & 0.997 & .999 \\
\hline \multirow{3}{*}{$\begin{array}{c}\text { Bias Corrected } \\
\text { standard } \\
\text { bootstrap }\end{array}$} & g1 & 204 & .293 & 0.390 & 0.493 & 0.587 & .663 & 0.730 & 0.779 & 0.829 & .868 & .898 \\
\hline & G1 & 0.155 & .211 & 0.288 & 0.365 & 0.455 & 0.536 & 0.613 & 0.671 & 0.722 & 0.767 & .810 \\
\hline & b1 & 0.278 & .392 & 0.517 & 0.620 & 0.702 & .767 & 0.823 & 0.870 & 0.904 & .925 & .944 \\
\hline \multirow{3}{*}{$\begin{array}{c}\text { Efron's } \\
\text { percentile } \\
\text { bootstrap }\end{array}$} & g1 & .186 & .302 & 0.446 & 0.585 & 0.701 & 0.810 & 0.907 & 0.973 & 0.999 & 1.000 & 1.000 \\
\hline & G1 & 0.110 & 0.190 & 0.292 & 0.405 & 0.531 & 0.637 & 0.730 & 0.824 & 0.903 & 0.961 & 0.996 \\
\hline & b1 & 0.285 & 0.447 & 0.608 & 0.749 & 0.864 & 0.958 & 0.998 & 1.000 & 1.000 & 1.000 & 1.000 \\
\hline \multirow{3}{*}{$\begin{array}{l}\text { Hall's } \\
\text { Percentile } \\
\text { bootstrap }\end{array}$} & g1 & .217 & .310 & 0.407 & 0.499 & 0.590 & 0.660 & 0.720 & 0.769 & 0.815 & .854 & .886 \\
\hline & G1 & 0.174 & 0.224 & 0.302 & 0.377 & 0.467 & 0.541 & \begin{tabular}{|l|}
0.614 \\
\end{tabular} & 0.669 & 0.720 & 0.760 & .801 \\
\hline & $\mathrm{b} 1$ & .296 & 417 & 0.519 & 0.619 & 0.692 & 755 & 0.809 & 0.857 & 0.894 & .916 & .938 \\
\hline \multirow{3}{*}{$\begin{array}{c}\text { Bias-corrected } \\
\text { percentile } \\
\text { bootstrap }\end{array}$} & g1 & .188 & 0.261 & 0.351 & 0.445 & 0.541 & 0.631 & 0.736 & 0.843 & 0.970 & 1.000 & 1.000 \\
\hline & G1 & 138 & 191 & 0.256 & 0.325 & 0.403 & 0.485 & 0.562 & 0.646 & .723 & .819 & 0.924 \\
\hline & $\mathrm{b} 1$ & 0.255 & 0.359 & 0.472 & 0.575 & 0.681 & 0.809 & 0.960 & 1.000 & 1.000 & 1.000 & 1.000 \\
\hline & & $=20$ & & & & & & & & & & \\
\hline & st & $1=1.0$ & $=1.2$ & $1=1.4$ & $1=1.6$ & $1=1.8$ & $1=2.0$ & $\gamma 1=2.2$ & $\gamma 1=2.4$ & $\gamma 1=2.6$ & $1=2.8$ & $1=3.0$ \\
\hline \multirow{3}{*}{ assical } & $8+$ & 116 & .214 & 0.351 & 0.510 & .664 & .778 & 0.865 & 0.917 & 0.954 & .973 & .985 \\
\hline & G1 & 0.095 & 0.160 & 0.276 & 0.409 & 0.563 & 0.696 & 0.797 & 0.869 & 0.917 & 0.952 & 0.971 \\
\hline & $\mathrm{b1}$ & .146 & 0.279 & 0.437 & 0.6 & 0.753 & 0.853 & 0.913 & 0.952 & .974 & .986 & .994 \\
\hline \multirow{3}{*}{$\begin{array}{l}\text { Bias Corrected } \\
\text { standard } \\
\text { bootstrap }\end{array}$} & g1 & 230 & .321 & 0.433 & 0.545 & 0.637 & 0.714 & 0.776 & 0.823 & 0.865 & .894 & .917 \\
\hline & G1 & 183 & 0.272 & .369 & & & & & & .000 & & .892 \\
\hline & $\mathrm{b} 1$ & 261 & 0.375 & 0.496 & 0.606 & .694 & .763 & 0.816 & 0.862 & 0.898 & .919 & .938 \\
\hline \multirow{3}{*}{$\begin{array}{c}\text { Efron's } \\
\text { percentile } \\
\text { bootstrap }\end{array}$} & g1 & 0.228 & 0.355 & 0.500 & 0.641 & 0.748 & 0.836 & 0.897 & 0.939 & 0.962 & 0.979 & 0.992 \\
\hline & G1 & .176 & 0.298 & 0.426 & 0.554 & 0.678 & 0.770 & 0.843 & 0.901 & 0.938 & 0.960 & 0.979 \\
\hline & b1 & 276 & 426 & 0.577 & 10 & .815 & 85 & .934 & ). 961 & .982 & .993 & .998 \\
\hline \multirow{3}{*}{$\begin{array}{l}\text { Hall's } \\
\text { Percentile } \\
\text { bootstrap }\end{array}$} & $\overline{\mathrm{g} 1}$ & 246 & 0.340 & 0.449 & 0.557 & 0.639 & 0.714 & 0.772 & 0.822 & 0.859 & 0.891 & 0.917 \\
\hline & G1 & 211 & .293 & 396 & .499 & ). 589 & .659 & 0.722 & 0.775 & 0.818 & ). 858 & .887 \\
\hline & b1 & 286 & .395 & .514 & 612 & 695 & .762 & 0.813 & 0.860 & 0.894 & 0.917 & 0.936 \\
\hline \multirow{3}{*}{$\begin{array}{c}\text { Bias-corrected } \\
\text { percentile } \\
\text { bootstrap }\end{array}$} & gl & .203 & 0.299 & 0.412 & 0.523 & 0.626 & 0.705 & 0.773 & 0.832 & 0.877 & 0.916 & 0.945 \\
\hline & G1 & 171 & 254 & 0.347 & .455 & 0555 & 39 & 0.719 & .778 & 0.837 & .876 & 0.908 \\
\hline & b1 & .239 & 352 & 475 & 0.587 & 0.685 & 0.763 & 0.827 & 0.880 & 0.916 & 0.949 & 0.972 \\
\hline & & $=30$ & & & & & & & & & & \\
\hline & Est & $\gamma 1=1.0$ & $1=1.2$ & $1=1.4$ & $1=1.0$ & $1=1.8$ & $1=2.0$ & $\gamma 1=2.2$ & $\gamma 1=2.4$ & $\gamma 1=2.6$ & $\gamma 1=2.8$ & $\gamma 1=3.0$ \\
\hline \multirow{3}{*}{ Classica } & g1 & 0.141 & 0.239 & 0.404 & 0.579 & 0.728 & .832 & 0.899 & 0.937 & 0.962 & 0.981 & 0.989 \\
\hline & G1 & 0.121 & 0.204 & 0.332 & 0.505 & 0.665 & 0.781 & 0.861 & 0.916 & 0.946 & 0.968 & 0.984 \\
\hline & b1 & 163 & 0.284 & 0.465 & 0.646 & 0.779 & 68 & .921 & 0.955 & 0.974 & .987 & .995 \\
\hline \multirow{3}{*}{$\begin{array}{c}\text { Bias Corrected } \\
\text { standard } \\
\text { bootstrap }\end{array}$} & g1 & 0.226 & 0.340 & 0.469 & 0.592 & 0.688 & 0.758 & 0.808 & 0.851 & 0.881 & 0.908 & 0.927 \\
\hline & G1 & 0.204 & 0.301 & 0.425 & 0.545 & 0.646 & 0.724 & 0.783 & 0.826 & 0.862 & 0.888 & 0.914 \\
\hline & b1 & 0.245 & 0.383 & 0.513 & 0.639 & 0.718 & 0.784 & 0.836 & 0.868 & 0.897 & 0.924 & 0.943 \\
\hline \multirow{3}{*}{$\begin{array}{l}\text { Efron's } \\
\text { percentile } \\
\text { bootstrap }\end{array}$} & g1 & 0.236 & 0.395 & 0.555 & 0.692 & 0.789 & 0.864 & 0.914 & 0.941 & 0.964 & 0.982 & 0.989 \\
\hline & G1 & 0.204 & 0.340 & 0.499 & 0.637 & 0.751 & 0.830 & 0.890 & 0.924 & 0.951 & 0.971 & 0.984 \\
\hline & b1 & 0.275 & 0.439 & 0.604 & 0.739 & 0.826 & 0.892 & 0.929 & 0.955 & 0.978 & 0.987 & 0.995 \\
\hline \multirow{3}{*}{$\begin{array}{c}\text { Hall's } \\
\text { Percentile } \\
\text { bootstrap }\end{array}$} & g1 & 0.252 & 0.365 & 0.490 & 0.602 & 0.687 & 0.750 & 0.808 & 0.844 & 0.877 & 0.906 & 0.929 \\
\hline & G1 & 0.228 & 0.323 & 0.445 & 0.553 & 0.652 & 0.724 & 0.776 & 0.825 & 0.857 & 0.888 & 0.913 \\
\hline & b1 & 0.275 & 0.402 & 0.525 & 0.640 & 0.720 & 0.785 & 0.830 & 0.864 & 0.897 & 0.923 & 0.940 \\
\hline \multirow{3}{*}{$\begin{array}{l}\text { Bias-corrected } \\
\text { percentile } \\
\text { bootstrap }\end{array}$} & g1 & 0.209 & 0.324 & 0.458 & 0.588 & 0.698 & 0.776 & 0.836 & 0.882 & 0.916 & 0.934 & 0.951 \\
\hline & G1 & 0.188 & 0.284 & 0.419 & 0.547 & 0.650 & 0.739 & 0.801 & 0.856 & 0.892 & 0.919 & 0.939 \\
\hline & b1 & 0.235 & 0.364 & 0.506 & 0.635 & 0.740 & 0.807 & 0.865 & 0.905 & 0.930 & 0.948 & 0.967 \\
\hline
\end{tabular}


Table A2 (Continued)

\begin{tabular}{|c|c|c|c|c|c|c|c|c|c|c|c|c|}
\hline & & & & & & & & & & & & \\
\hline thod & st & $=1.0$ & $=1.2$ & $=1.4$ & $=1.6$ & $=1.8$ & $=2.0$ & $1=2.2$ & $1=2.4$ & $1=2.6$ & $1=2.8$ & $1=3.0$ \\
\hline \multirow{3}{*}{ Classical } & 1 & 145 & 274 & .452 & .645 & .780 & .874 & .931 & .964 & .978 & 0.987 & 0.993 \\
\hline & G1 & 133 & 244 & 0.415 & 0.600 & 0.747 & 855 & 919 & 0.954 & .974 & 0.985 & .992 \\
\hline & b1 & 160 & .305 & 0.497 & 0.686 & 0.815 & 0.899 & 0.944 & 0.969 & 0.983 & 0.991 & 0.995 \\
\hline \multirow{3}{*}{$\begin{array}{l}\text { Bias Corrected } \\
\text { standard } \\
\text { bootstrap }\end{array}$} & g1 & 216 & 345 & 0.478 & 0.604 & 0.701 & .782 & .833 & 0.872 & 0.906 & .928 & .944 \\
\hline & G1 & .204 & .321 & 0.445 & 0.571 & 0.678 & 0.760 & 0.817 & 0.862 & 0.894 & 0.917 & .939 \\
\hline & $\overline{b 1}$ & 236 & 367 & 0.503 & 0.631 & 0.725 & .797 & 0.852 & 0.888 & 0.913 & 0.938 & .951 \\
\hline \multirow{3}{*}{$\begin{array}{c}\text { Efron's } \\
\text { percentile } \\
\text { bootstrap }\end{array}$} & g1 & 223 & .392 & 0.561 & 0.704 & 0.812 & 0.881 & 0.927 & 0.959 & 0.974 & .985 & .990 \\
\hline & G1 & 198 & .359 & 0.527 & 0.671 & 0.785 & 865 & 0.914 & 0.950 & 0.968 & 0.981 & .990 \\
\hline & b1 & 250 & 0.420 & 0.593 & 0.735 & 0.833 & 0.896 & 0.940 & 0.965 & 0.979 & 0.989 & .993 \\
\hline \multirow{3}{*}{$\begin{array}{c}\text { Hall's } \\
\text { Percentile } \\
\text { bootstrap }\end{array}$} & g1 & 253 & .364 & 0.483 & 0.608 & 0.701 & .779 & 0.831 & 0.870 & 0.903 & .930 & .943 \\
\hline & G1 & 0.236 & 0.346 & 0.458 & 0.580 & 0.680 & 0.755 & 0.812 & 0.855 & 0.891 & .920 & 939 \\
\hline & b1 & 267 & 388 & 0.509 & 0.637 & 0.727 & 795 & 0.848 & 0.885 & .914 & 0.936 & .951 \\
\hline \multirow{4}{*}{$\begin{array}{l}\text { Bias-corrected } \\
\text { percentile } \\
\text { bootstrap }\end{array}$} & g1 & 203 & 0.331 & 0.483 & 0.619 & 0.738 & 0.825 & 0.884 & 0.925 & 0.953 & 0.970 & .980 \\
\hline & G1 & 186 & 312 & 0.452 & 0.593 & 0.714 & 804 & .868 & .911 & .939 & .962 & .974 \\
\hline & $\mathrm{b1}$ & 0.217 & 362 & 0.518 & 0.656 & 0.763 & 0.846 & 0.899 & 0.937 & 0.963 & 0.974 & 0.983 \\
\hline & & $=100$ & & & & & & & & & & \\
\hline & st & $\gamma 1=1.0$ & $=1.2$ & $1=1.4$ & $1=1.6$ & $=1.8$ & $=2.0$ & $\gamma 1=2.2$ & $\gamma 1=2.4$ & $\gamma 1=2.6$ & $1=2.8$ & $1=3.0$ \\
\hline \multirow{3}{*}{ Classical } & $\mathrm{g} 1$ & 150 & 331 & 0.576 & 0.775 & .899 & 953 & 0.981 & .992 & 0.996 & .999 & .999 \\
\hline & G1 & 144 & 0.307 & 0.547 & 0.759 & 0.885 & 0.946 & 0.976 & 0.992 & 0.995 & 0.998 & 0.999 \\
\hline & b1 & 161 & 353 & 0.603 & 0.794 & 0.908 & 08 & .983 & .993 & .996 & .999 & .999 \\
\hline \multirow{3}{*}{$\begin{array}{l}\text { Bias Corrected } \\
\text { standard } \\
\text { bootstrap }\end{array}$} & g1 & 177 & 353 & 0.530 & 0.677 & 0.791 & .859 & 0.903 & 0.933 & 0.952 & 0.969 & .979 \\
\hline & G1 & 167 & 334 & .516 & & . & 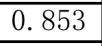 & .896 & .950 & & .966 & 976 \\
\hline & $\overline{b 1}$ & 189 & 366 & .547 & 695 & .800 & 67 & 0.911 & .936 & .958 & 0.973 & .979 \\
\hline \multirow{3}{*}{$\begin{array}{l}\text { Efron's } \\
\text { percentile } \\
\text { bootstrap }\end{array}$} & g1 & & & & 0.772 & 0.870 & & & & 90 & .994 & .997 \\
\hline & G1 & 180 & 0.387 & 0.588 & 0.750 & 0.859 & 0.916 & 0.955 & 0.977 & 0.986 & 0.994 & 0.996 \\
\hline & $\mathrm{b} 1$ & 210 & 428 & 630 & 8 & .879 & 30 & 0.965 & .982 & 0.990 & .994 & .998 \\
\hline \multirow{3}{*}{$\begin{array}{l}\text { Hall's } \\
\text { Percentile } \\
\text { bootstrap }\end{array}$} & g1 & 203 & 0.362 & 0.531 & 0.683 & 0.789 & 0.859 & 0.906 & 0.935 & 0.956 & 0.972 & 0.981 \\
\hline & G1 & 13 & 347 & .514 & . & .775 & .851 & 9 & .931 & & & \\
\hline & b1 & 209 & 382 & .556 & 699 & .802 & 867 & .909 & 39 & 60 & .974 & .982 \\
\hline \multirow{4}{*}{$\begin{array}{c}\text { Bias-corrected } \\
\text { percentile } \\
\text { bootstrap }\end{array}$} & g1 & 8 & & & & & & 22 & 0 & 44 & 92 & \\
\hline & G1 & 157 & 334 & 0.530 & 22 & 0.822 & 92 & 0.936 & .966 & .981 & 0.990 & 0.995 \\
\hline & b1 & 183 & 370 & 566 & 31 & .845 & 910 & 0.949 & 0.973 & 0.98 & 0.992 & .996 \\
\hline & & $=300$ & & & & & & & & & & \\
\hline & Est & $\gamma 1=1.0$ & $1=1.2$ & $1=1.4$ & $1=1.6$ & $1-1.8$ & $1=2.0$ & $\gamma 1=2.2$ & $\gamma 1=2.4$ & $\gamma_{1}-2.0$ & $\gamma 1=2.8$ & $y 1=3.0$ \\
\hline \multirow{3}{*}{ issical } & g1 & 0.203 & .478 & 0.797 & 0.936 & 0.979 & .994 & 0.998 & 1.000 & 1.000 & 1.000 & 1.000 \\
\hline & G1 & 0.199 & 0.467 & 0.789 & 0.933 & 0.977 & 0.993 & 0.998 & 1.000 & 1.000 & 1.000 & 1.000 \\
\hline & b1 & 208 & 0.490 & 806 & 0.939 & 0.979 & 994 & 0.999 & 1.000 & 1.000 & 1.000 & .000 \\
\hline \multirow{3}{*}{$\begin{array}{c}\text { Bias Corrected } \\
\text { standard } \\
\text { bootstrap }\end{array}$} & g1 & 0.142 & 0.376 & 0.641 & 0.808 & 0.900 & 0.944 & 0.968 & 0.983 & 0.990 & 0.993 & 0.996 \\
\hline & G1 & 137 & 0.369 & 631 & 0.805 & 0.896 & 941 & 0.966 & 0.982 & 0.989 & 0.992 & .996 \\
\hline & b1 & 0.148 & 0.384 & 0.651 & 0.813 & 0.901 & 0.944 & 0.969 & 0.982 & 0.990 & 0.992 & 0.996 \\
\hline \multirow{3}{*}{$\begin{array}{c}\text { Efron's } \\
\text { percentile } \\
\text { bootstrap }\end{array}$} & $\mathrm{g} 1$ & 0.147 & 0.422 & 0.696 & 0.856 & 0.925 & 0.964 & 0.983 & 0.991 & 0.995 & 0.998 & 0.999 \\
\hline & G1 & 0.142 & 0.411 & 0.687 & 0.847 & 0.922 & 0.962 & 0.983 & 0.991 & 0.995 & 0.997 & 0.999 \\
\hline & b1 & 0.157 & 0.430 & 0.703 & 0.855 & 0.927 & 0.965 & 0.984 & 0.992 & 0.996 & 0.997 & 0.999 \\
\hline \multirow{3}{*}{$\begin{array}{l}\text { Ha11's } \\
\text { Percentile } \\
\text { bootstrap }\end{array}$} & g1 & 0.152 & 0.380 & 0.654 & 0.817 & 0.903 & 0.950 & 0.973 & 0.985 & 0.990 & 0.995 & 0.998 \\
\hline & G1 & 0.149 & 0.369 & 0.643 & 0.815 & 0.899 & 0.947 & 0.971 & 0.985 & 0.990 & 0.995 & 0.997 \\
\hline & b1 & 0.155 & 0.387 & 0.660 & 0.824 & 0.907 & 0.951 & 0.975 & 0.985 & 0.991 & 0.996 & 0.998 \\
\hline \multirow{3}{*}{$\begin{array}{c}\text { Bias-corrected } \\
\text { percentile } \\
\text { bootstrap }\end{array}$} & g1 & 0.133 & 0.369 & 0.650 & 0.823 & 0.909 & 0.953 & 0.979 & 0.989 & 0.993 & 0.997 & 0.998 \\
\hline & G1 & 0.130 & 0.362 & 0.639 & 0.818 & 0.907 & 0.951 & 0.976 & 0.989 & 0.993 & 0.997 & 0.999 \\
\hline & b1 & 0.136 & 0.380 & 0.659 & 0.825 & 0.910 & 0.954 & 0.978 & 0.989 & 0.993 & 0.997 & 0.999 \\
\hline
\end{tabular}


Table A3: Power for Gamma $(7.5,1)$ with skewness $=0.73$ against with other value for different sample size

\begin{tabular}{|c|c|c|c|c|c|c|c|c|c|c|c|c|}
\hline & & $=10$ & & & & & & & & & & \\
\hline Method & Est & $1=0.73$ & $=1.0$ & $=1.2$ & $1=1.4$ & $1=1.6$ & $1=1.8$ & $1=2.0$ & $1=2.2$ & $1=2.4$ & $1=2.6$ & $1=2.8$ \\
\hline \multirow{3}{*}{ Classical } & 1 & 0.090 & .182 & .312 & .450 & .578 & .703 & 0.803 & 0.873 & 0.921 & 0.954 & 0.977 \\
\hline & G1 & 0.071 & 0.122 & 0.191 & 0.296 & 0.416 & 0.529 & 0.641 & 0.730 & 0.814 & 0.871 & 0.913 \\
\hline & b1 & 0.127 & 0.290 & 0.454 & 0.609 & 0.738 & 0.847 & 0.910 & 0.951 & 0.978 & 0.993 & 0.998 \\
\hline \multirow{3}{*}{$\begin{array}{c}\text { Bias } \\
\text { Corrected } \\
\text { standard }\end{array}$} & g1 & .151 & .264 & 0.367 & 0.476 & 0.575 & 0.656 & 0.725 & 0.785 & 0.831 & 0.865 & 0.893 \\
\hline & G1 & 0.132 & 0.194 & 0.269 & 0.356 & 0.447 & 0.532 & 0.612 & 0.676 & 0.732 & 0.785 & 0.826 \\
\hline & b1 & 0.194 & 0.355 & 0.478 & 0.593 & 0.686 & 0.759 & 0.823 & 0.861 & 0.895 & 0.916 & 0.937 \\
\hline \multirow{3}{*}{$\begin{array}{c}\text { Efron's } \\
\text { percentile } \\
\text { bootstrap }\end{array}$} & g1 & 0.092 & 0.237 & 0.384 & 0.518 & 0.653 & 0.765 & 0.863 & 0.935 & 0.980 & 0.999 & 1.000 \\
\hline & G1 & 0.054 & 0.141 & 0.243 & 0.368 & 0.487 & 0.599 & 0.695 & 0.784 & 0.866 & 0.931 & 0.975 \\
\hline & b1 & 0.146 & 0.368 & 0.526 & 0.673 & 0.797 & 0.904 & 0.969 & 0.998 & 1.000 & 1.000 & 1.000 \\
\hline \multirow{3}{*}{$\begin{array}{c}\text { Hall's } \\
\text { Percentile } \\
\text { bootstrap }\end{array}$} & g1 & 0.164 & 0.272 & 0.379 & 0.481 & 0.579 & 0.658 & 0.721 & 0.781 & 0.819 & .853 & .882 \\
\hline & G1 & 0.144 & 0.199 & 0.276 & 0.370 & 0.457 & 0.541 & 0.618 & 0.677 & 0.727 & 0.779 & 0.813 \\
\hline & b1 & 0.203 & 0.367 & 0.483 & 0.596 & 0.684 & 0.754 & 0.810 & 0.849 & 0.881 & 0.912 & 0.930 \\
\hline \multirow{4}{*}{$\begin{array}{c}\text { Bias } \\
\text { Corrected } \\
\text { percentile } \\
\end{array}$} & g1 & 0.141 & 0.249 & 0.340 & 0.442 & 0.535 & 617 & 0.700 & 0.785 & 0.884 & 0.985 & 1.000 \\
\hline & G1 & 0.115 & 0.174 & 0.248 & 0.333 & 0.416 & 0.497 & 0.570 & 0.644 & 0.706 & 0.785 & 0.863 \\
\hline & b1 & 0.182 & 0.331 & 0.447 & 42 & 0.642 & 48 & .854 & 0.972 & 1.000 & 1.000 & 1.000 \\
\hline & & $\mathrm{n}=20$ & & & & & & & & & & \\
\hline & Est & $\gamma 1=0.73$ & $\gamma 1=1.0$ & $\gamma 1=1.2$ & $1=1.4$ & $1=1.6$ & $=1.8$ & $\gamma 1=2.0$ & $\gamma 1=2.2$ & $y=2.4$ & $\gamma 1=2.6$ & $\gamma 1=2.8$ \\
\hline \multirow{3}{*}{ Classical } & g1 & 0.082 & 0.188 & 0.337 & 0.495 & 0.662 & 0.783 & 0.870 & 0.929 & 0.962 & 0.979 & 0.987 \\
\hline & G1 & 0.076 & 0.151 & 0.264 & 0.409 & 0.568 & 0.704 & 0.803 & 0.882 & 0.931 & 0.962 & 0.976 \\
\hline & b1 & 0.096 & 0.246 & 0.413 & 0.595 & 0.742 & 846 & 0.918 & .959 & 0.977 & .988 & .993 \\
\hline \multirow{3}{*}{$\begin{array}{c}\text { Bias } \\
\text { Corrected } \\
\text { standard } \\
\end{array}$} & g1 & 0.178 & 0.319 & 0.446 & 0.564 & 0.667 & 0.743 & 0.803 & 0.845 & 0.882 & 0.911 & 0.932 \\
\hline & G1 & 0.157 & 0.277 & 386 & 0.500 & 0.611 & .694 & .759 & 0.810 & 0.847 & .878 & 0.911 \\
\hline & $\mathrm{b} 1$ & 0.202 & 0.368 & 0.503 & 0.623 & 0.722 & 0.787 & 0.834 & 0.876 & 0.910 & 0.933 & 0.948 \\
\hline \multirow{3}{*}{$\begin{array}{l}\text { Efron's } \\
\text { percentile } \\
\text { bootstrap }\end{array}$} & $\mathrm{g} 1$ & 0.153 & 0.340 & 0.497 & 0.650 & 0.762 & 0.846 & 0.911 & 0.948 & 0.968 & 0.983 & 0.992 \\
\hline & G1 & 0.125 & 0.284 & 0.419 & 0.572 & 0.698 & 0.789 & 0.864 & 0.921 & 0.950 & 0.970 & 0.982 \\
\hline & b1 & 0.190 & 0.397 & 0.576 & 0.720 & 0.815 & 0.898 & 0.944 & 0.965 & 0.983 & 0.992 & 0.996 \\
\hline \multirow{3}{*}{$\begin{array}{c}\text { Hall's } \\
\text { Percentile } \\
\text { bootstrap }\end{array}$} & g1 & 91 & 0.336 & 0.459 & 0.569 & 0.669 & 0.741 & 0.794 & 0.837 & 0.875 & .908 & 0.929 \\
\hline & G1 & 0.172 & 0.292 & 0.401 & 0.506 & 0.614 & 0.695 & 0.755 & 0.804 & 0.841 & 0.876 & 0.904 \\
\hline & b1 & 0.220 & 0.383 & 0.515 & 0.634 & 0.718 & 0.780 & 0.830 & 0.873 & 0.908 & 0.930 & 0.947 \\
\hline \multirow{4}{*}{$\begin{array}{c}\text { Bias } \\
\text { Corrected } \\
\text { percentile }\end{array}$} & g1 & 0.167 & 0.311 & 0.423 & 0.548 & 0.661 & 0.744 & 0.810 & 0.863 & 0.905 & 0.933 & 0.956 \\
\hline & G1 & 0.144 & 0.263 & 0.366 & 0.478 & 0.595 & 0.686 & 0.764 & 0.818 & 0.867 & 0.904 & 0.931 \\
\hline & b1 & 0.195 & 0.351 & 0.489 & 0.614 & 0.719 & 0.796 & 0.849 & 0.898 & 0.931 & 0.956 & 0.973 \\
\hline & & $n=30$ & & & & & & & & & & \\
\hline $\bar{d}$ & Est & $\gamma 1=0.73$ & $\gamma 1=1.0$ & $1=1.2$ & $1=1.4$ & $1=1.6$ & $1=1.8$ & $\gamma 1=2.0$ & $\gamma 1=2.2$ & $\gamma 1=2.4$ & $\gamma 1=2.6$ & $\gamma 1=2.8$ \\
\hline \multirow{3}{*}{ Classical } & g1 & 0.082 & 0.219 & 0.408 & 0.624 & 0.781 & 0.882 & 0.937 & 0.968 & 0.984 & $\begin{array}{l}0.992 \\
\end{array}$ & 0.997 \\
\hline & G1 & 0.072 & 0.187 & 0.344 & 0.550 & 0.725 & 0.843 & 0.913 & 0.954 & 0.976 & 0.988 & 0.993 \\
\hline & b1 & 0.095 & 0.259 & 0.475 & 0.691 & 0.831 & 0.910 & 0.957 & 0.978 & 0.989 & 0.996 & 0.999 \\
\hline \multirow{3}{*}{$\begin{array}{c}\text { Bias } \\
\text { Corrected } \\
\text { standard }\end{array}$} & g1 & 0.224 & 0.412 & 0.554 & 0.682 & 0.773 & 0.837 & 0.880 & 0.911 & 0.932 & 0.950 & 0.966 \\
\hline & G1 & 0.205 & 0.369 & 0.515 & 0.641 & 0.743 & 0.810 & 0.862 & 0.895 & 0.919 & 0.938 & 0.955 \\
\hline & b1 & 0.240 & 0.452 & 0.603 & 0.721 & 0.803 & 0.859 & 0.896 & 0.921 & 0.945 & 0.961 & 0.971 \\
\hline \multirow{3}{*}{$\begin{array}{l}\text { Efron's } \\
\text { percentile } \\
\text { bootstrap }\end{array}$} & $\mathrm{g} 1$ & 0.216 & 0.461 & 0.655 & 0.782 & 0.871 & 0.925 & 0.962 & 0.978 & 0.989 & 0.995 & 0.998 \\
\hline & G1 & 0.194 & 0.414 & 0.598 & 0.740 & 0.842 & 0.903 & 0.943 & 0.969 & 0.982 & 0.990 & 0.995 \\
\hline & b1 & 0.255 & 0.517 & 0.699 & 0.825 & 0.895 & 0.942 & 0.970 & 0.985 & 0.992 & 0.997 & 1.000 \\
\hline \multirow{3}{*}{$\begin{array}{c}\text { Hall's } \\
\text { Percentile } \\
\text { bootstrap }\end{array}$} & g1 & 0.238 & 0.422 & 0.561 & 0.683 & 0.766 & 0.830 & 0.874 & 0.908 & 0.930 & 0.950 & 0.965 \\
\hline & G1 & 0.222 & 0.384 & 0.524 & 0.643 & 0.732 & 0.808 & 0.854 & 0.889 & 0.917 & 0.937 & 0.956 \\
\hline & b1 & 0.255 & 0.465 & 0.603 & 0.717 & 0.798 & 0.851 & 0.891 & 0.921 & 0.943 & 0.960 & 0.970 \\
\hline \multirow{3}{*}{$\begin{array}{c}\text { Bias } \\
\text { Corrected } \\
\text { percentile }\end{array}$} & g1 & 0.212 & 0.403 & 0.568 & 0.704 & 0.802 & 0.864 & 0.915 & 0.945 & 0.965 & 0.976 & 0.986 \\
\hline & G1 & 0.193 & 0.364 & 0.516 & 0.661 & 0.764 & 0.841 & 0.892 & 0.925 & 0.951 & 0.969 & 0.980 \\
\hline & b1 & 0.234 & 0.446 & 0.615 & 0.743 & 0.828 & 0.891 & 0.928 & 0.959 & 0.974 & 0.983 & 0.991 \\
\hline
\end{tabular}


Table A3 (Continued)

\begin{tabular}{|c|c|c|c|c|c|c|c|c|c|c|c|c|}
\hline & & $n=50$ & & & & & & & & & & \\
\hline Method & Est & $\gamma 1=0.73$ & $=1.0$ & $1=1.2$ & $1=1.4$ & $=1.6$ & $=1.8$ & $\gamma 1=2.0$ & $1=2.2$ & $\gamma 1=2.4$ & $1=2.6$ & $1=2.8$ \\
\hline \multirow{3}{*}{ Classical } & g1 & 0.081 & 0.276 & 0.518 & 0.720 & 0.855 & 0.936 & 0.975 & 0.988 & 0.994 & 0.997 & 0.999 \\
\hline & G1 & 0.075 & 0.246 & 0.476 & 0.682 & 0.832 & 0.917 & 0.967 & 0.985 & 0.992 & 0.996 & 0.999 \\
\hline & b1 & .093 & 0.316 & 0.559 & 0.759 & 0.880 & 0.950 & .980 & 0.990 & 0.996 & .998 & .999 \\
\hline \multirow{3}{*}{$\begin{array}{c}\text { Bias } \\
\text { Corrected } \\
\text { standard } \\
\end{array}$} & g1 & 0.197 & 0.428 & 0.594 & 0.733 & 0.808 & 0.874 & 0.912 & 0.942 & 0.961 & 0.973 & 0.979 \\
\hline & G1 & 0.184 & 0.402 & 0.566 & 0.699 & 0.794 & 0.856 & 0.897 & 0.932 & 0.954 & 0.968 & 976 \\
\hline & $\overline{b 1}$ & .212 & 0.450 & 0.624 & 0.745 & 0.823 & 0.881 & 0.922 & 0.950 & 0.965 & 0.977 & 0.983 \\
\hline \multirow{3}{*}{$\begin{array}{l}\text { Efron's } \\
\text { percentile } \\
\text { bootstrap }\end{array}$} & $\mathrm{g} 1$ & 0.207 & 0.483 & 0.678 & 0.811 & 0.896 & 0.946 & 0.976 & 0.987 & 0.993 & 0.997 & 0.999 \\
\hline & G1 & 0.188 & 0.456 & 0.646 & 0.786 & 0.878 & 0.938 & 0.970 & 0.982 & 0.991 & 0.996 & 0.998 \\
\hline & b1 & 0.224 & 0.516 & 0.707 & 0.835 & 0.914 & 0.957 & 0.980 & 0.989 & 0.995 & 0.998 & 0.999 \\
\hline \multirow{3}{*}{$\begin{array}{c}\text { Hall's } \\
\text { Percentile } \\
\text { bootstrap }\end{array}$} & g1 & 0.217 & 0.437 & 0.601 & 0.724 & 0.806 & 0.863 & 0.907 & 0.940 & 0.961 & 0.971 & 0.978 \\
\hline & G1 & 0.203 & 0.413 & 0.567 & 0.695 & 0.789 & 0.852 & 0.894 & 0.929 & 0.954 & 0.969 & 0.976 \\
\hline & b1 & 0.229 & 0.461 & 0.627 & 0.746 & 0.820 & 877 & 0.917 & 0.946 & .964 & .975 & 984 \\
\hline \multirow{4}{*}{$\begin{array}{c}\text { Bias } \\
\text { Corrected } \\
\text { percentile } \\
\end{array}$} & $\mathrm{g} 1$ & 0.192 & 0.432 & 0.613 & 0.752 & 0.848 & 0.915 & 0.956 & 0.978 & 0.987 & 0.992 & 0.995 \\
\hline & G1 & 0.175 & 0.406 & 0.580 & 0.726 & 0.833 & 0.898 & 0.943 & 0.971 & 0.984 & 0.991 & 0.994 \\
\hline & b1 & 0.206 & 0.456 & 0.647 & 80 & .868 & .927 & 0.961 & .981 & 89 & .992 & .997 \\
\hline & & $n=100$ & & & & & & & & & & \\
\hline Method & Est & $\gamma 1=0.73$ & .0 & .2 & .4 & 1.6 & $=1.8$ & $=2.0$ & $=2.2$ & $=2.4$ & $1=2.6$ & $=2.8$ \\
\hline \multirow{3}{*}{ Classical } & $\mathrm{g} 1$ & 0.097 & 0.353 & 0.648 & 0.848 & 0.944 & 0.979 & 0.991 & 0.997 & 0.998 & 0.999 & 1.000 \\
\hline & G1 & 0.093 & 0.325 & 0.623 & 0.830 & 0.935 & 0.975 & 0.990 & 0.996 & 0.998 & 0.999 & 1.000 \\
\hline & b1 & \begin{tabular}{l|l}
0.099 \\
\end{tabular} & 0.374 & 0.668 & 0.859 & 0.949 & 0.983 & 0.992 & 0.998 & 0.999 & 0.999 & 1.000 \\
\hline \multirow{3}{*}{$\begin{array}{c}\text { Bias } \\
\text { Corrected } \\
\text { standard } \\
\end{array}$} & g1 & 0.153 & 0.421 & 0.624 & 0.765 & 0.868 & 0.923 & 0.954 & 0.971 & 0.980 & 0.986 & 0.989 \\
\hline & G1 & 0.145 & 0.400 & 0.609 & 0.758 & 0.857 & 918 & 0.951 & 0.969 & 0.978 & .984 & .990 \\
\hline & $\mathrm{b1}$ & 0.162 & 0.440 & 0.637 & 0.778 & 0.879 & 0.930 & 0.957 & 0.971 & 0.982 & 0.987 & 0.991 \\
\hline \multirow{3}{*}{$\begin{array}{c}\text { Efron's } \\
\text { percentile } \\
\text { bootstrap }\end{array}$} & $\mathrm{g} 1$ & & & & & & & & & & & 99 \\
\hline & G1 & 0.148 & 0.461 & 0.684 & 0.836 & 0.924 & 0.964 & 0.980 & 0.991 & 0.995 & 0.998 & 0.999 \\
\hline & b1 & 0.168 & 0.501 & 0.716 & 0.860 & 0.936 & 0.968 & 0.985 & 0.991 & 0.996 & 0.998 & 0.999 \\
\hline \multirow{3}{*}{$\begin{array}{c}\text { Hall's } \\
\text { Percentile } \\
\text { bootstrap }\end{array}$} & g1 & 0.172 & 0.428 & 0.627 & 0.767 & 0.866 & 0.924 & 0.953 & 0.971 & 0.981 & 0.987 & 0.991 \\
\hline & G1 & 0.164 & 0.410 & 0.611 & 0.755 & 0.856 & 0.919 & 0.949 & 0.969 & 0.980 & 0.986 & 0.991 \\
\hline & b1 & 175 & 0.444 & 0.641 & 0.776 & 0.879 & 930 & 0.957 & 0.972 & 0.982 & 0.989 & .992 \\
\hline \multirow{4}{*}{$\begin{array}{c}\text { Bias } \\
\text { Corrected } \\
\text { percentile }\end{array}$} & $\mathrm{g} 1$ & 0.140 & 0.431 & 0.648 & 0.804 & 0.908 & 0.951 & 0.977 & 0.988 & 0.993 & 0.997 & 0.999 \\
\hline & G1 & 0.134 & 0.411 & 0.633 & 0.786 & 0.900 & 0.951 & 0.973 & 0.988 & 0.992 & 0.996 & .998 \\
\hline & b1 & 0.155 & 0.442 & 0.662 & .815 & .912 & .957 & 0.978 & 0.990 & 0.995 & 0.998 & .999 \\
\hline & & $\mathrm{n}=300$ & & & & & & & & & & \\
\hline $\bar{d}$ & Est & $\gamma 1=0.73$ & $\gamma 1=1.0$ & $1=1.2$ & $1=1.4$ & $1=1.6$ & $\gamma 1=1.8$ & $\gamma 1=2.0$ & $\gamma 1=2.2$ & $\gamma 1=2.4$ & $\gamma 1=2.6$ & $\gamma 1=2.8$ \\
\hline \multirow{3}{*}{ Classical } & g1 & 0.133 & 0.597 & 0.894 & 0.982 & 0.996 & 0.999 & 1.000 & 1.000 & 1.000 & 1.000 & 1.000 \\
\hline & G1 & 0.132 & 0.586 & 0.889 & 0.981 & 0.995 & 0.999 & 1.000 & 1.000 & 1.000 & 1.000 & 1.000 \\
\hline & b1 & 0.136 & 0.606 & 0.898 & 0.982 & 0.996 & 0.999 & 1.000 & 1.000 & 1.000 & 1.000 & 1.000 \\
\hline \multirow{3}{*}{$\begin{array}{c}\text { Bias } \\
\text { Corrected } \\
\text { standard }\end{array}$} & $\mathrm{g} 1$ & 0.128 & 0.532 & 0.789 & 0.915 & 0.964 & 0.986 & 0.992 & 0.996 & 0.998 & 0.999 & .999 \\
\hline & G1 & 0.123 & 0.524 & 0.791 & 0.909 & 0.961 & 0.983 & 0.992 & 0.996 & 0.998 & 0.999 & 0.999 \\
\hline & $\mathrm{b} 1$ & 0.132 & 0.538 & 0.798 & 0.917 & 0.964 & 0.985 & 0.992 & 0.996 & 0.998 & 0.999 & 0.999 \\
\hline \multirow{3}{*}{$\begin{array}{l}\text { Efron's } \\
\text { percentile } \\
\text { bootstrap }\end{array}$} & $\mathrm{g} 1$ & 0.134 & 0.573 & 0.831 & 0.935 & 0.978 & 0.991 & 0.996 & 0.998 & 0.999 & 1.000 & 1.000 \\
\hline & G1 & 0.128 & 0.571 & 0.828 & 0.933 & 0.978 & 0.990 & 0.996 & 0.998 & 0.999 & 1.000 & 1.000 \\
\hline & $\mathrm{b} 1$ & 0.138 & 0.585 & 0.837 & 0.936 & 0.979 & 0.992 & 0.996 & 0.999 & 0.999 & 1.000 & 1.000 \\
\hline \multirow{3}{*}{\begin{tabular}{|c|} 
Hall's \\
Percentile \\
bootstrap \\
\end{tabular}} & g1 & 0.133 & 0.541 & 0.803 & 0.916 & 0.970 & 0.989 & 0.993 & 0.997 & 0.999 & 0.999 & 1.000 \\
\hline & G1 & 0.130 & 0.535 & 0.795 & 0.917 & 0.968 & 0.989 & 0.993 & 0.997 & 0.999 & 0.999 & 1.000 \\
\hline & $\overline{b 1}$ & 0.138 & 0.550 & 0.808 & 0.922 & 0.971 & 0.989 & 0.993 & 0.997 & 0.999 & 1.000 & 1.000 \\
\hline \multirow{3}{*}{$\begin{array}{c}\text { Bias } \\
\text { Corrected } \\
\text { percentile }\end{array}$} & g1 & 0.123 & 0.532 & 0.797 & 0.917 & 0.968 & 0.988 & 0.995 & 0.998 & 0.999 & 0.999 & 1.000 \\
\hline & G1 & 0.119 & 0.524 & 0.790 & 0.916 & 0.968 & 0.987 & 0.994 & 0.998 & 0.999 & 0.999 & 1.000 \\
\hline & b1 & 0.125 & 0.541 & 0.803 & 0.920 & 0.971 & 0.988 & 0.995 & 0.998 & 0.999 & 1.000 & 1.000 \\
\hline
\end{tabular}


Table A4: Power for Gamma(10,1) with skewness $=0.63$ against with other value for different sample size

\begin{tabular}{|c|c|c|c|c|c|c|c|c|c|c|c|c|}
\hline & & $=10$ & & & & & & & & & & \\
\hline Method & Est & $1=0.63$ & $=0.8$ & $=1.0$ & $1=1.2$ & $1=1.4$ & $1=1.6$ & $1=1.8$ & $1=2.0$ & $1=2.2$ & $1=2.4$ & $1=2.6$ \\
\hline \multirow{3}{*}{ Classical } & 91 & 0.083 & .127 & .215 & .342 & .476 & .610 & .739 & 0.836 & 0.894 & 0.937 & 0.967 \\
\hline & G1 & 0.068 & 0.091 & 0.144 & 0.219 & 0.330 & 0.446 & 0.555 & 0.676 & 0.766 & 0.844 & 0.892 \\
\hline & $\mathrm{b} 1$ & 0.106 & 0.184 & 0.323 & 0.480 & 0.640 & 0.779 & 0.869 & 0.927 & 0.963 & .981 & $\overline{0.992}$ \\
\hline \multirow{3}{*}{$\begin{array}{c}\text { Bias } \\
\text { Corrected } \\
\text { standard }\end{array}$} & g1 & 0.145 & 0.200 & 0.293 & 0.401 & 0.500 & 0.602 & 0.689 & 0.755 & 0.812 & 0.853 & 0.888 \\
\hline & G1 & 0.122 & 0.158 & 0.219 & 0.302 & 0.392 & 0.479 & \begin{tabular}{|l|}
0.561 \\
\end{tabular} & 0.643 & 0.709 & 0.765 & 0.807 \\
\hline & b1 & 0.176 & 0.259 & 0.383 & 0.509 & 0.623 & 0.714 & 0.784 & 0.844 & 0.884 & 0.915 & 0.936 \\
\hline \multirow{3}{*}{$\begin{array}{c}\text { Efron's } \\
\text { percentile } \\
\text { bootstrap }\end{array}$} & g1 & 0.069 & 0.140 & 0.259 & 0.397 & 0.553 & 0.682 & 0.794 & 0.877 & 0.943 & 0.986 & 1.000 \\
\hline & G1 & 0.043 & 0.085 & 0.162 & 0.267 & 0.387 & 0.517 & 0.634 & 0.738 & 0.819 & 0.889 & 0.942 \\
\hline & $\mathrm{b} 1$ & 0.109 & 0.223 & 0.380 & 0.557 & 0.705 & 0.825 & 0.913 & 0.978 & 0.999 & 1.000 & 1.000 \\
\hline \multirow{3}{*}{$\begin{array}{c}\text { Hall's } \\
\text { Percentile } \\
\text { bootstrap }\end{array}$} & g1 & 0.156 & 0.208 & 0.297 & 0.410 & 0.509 & 0.610 & 0.685 & 0.751 & 0.795 & .840 & .874 \\
\hline & G1 & 0.132 & 0.170 & 0.219 & 0.305 & 0.400 & 0.486 & 0.569 & 0.647 & 0.706 & 0.754 & 0.797 \\
\hline & $\mathrm{b} 1$ & 0.189 & 0.263 & 0.400 & 0.512 & 0.628 & 0.711 & 0.776 & 0.827 & 0.873 & 0.906 & 0.928 \\
\hline \multirow{4}{*}{$\begin{array}{c}\text { Bias } \\
\text { Corrected } \\
\text { percentile } \\
\end{array}$} & g1 & 0.141 & 0.186 & 0.278 & 0.369 & 0.471 & 558 & 0.649 & 0.736 & 0.824 & .904 & 0.979 \\
\hline & G1 & 0.126 & 0.155 & 0.202 & 0.283 & 0.361 & 0.450 & 0.524 & 0.595 & 0.671 & 0.747 & 0.813 \\
\hline & b1 & 0.169 & 0.246 & 0361 & 74 & 0.576 & 77 & 0.780 & 0.877 & .972 & 1.000 & 1.000 \\
\hline & & $\mathrm{n}=20$ & & & & & & & & & & \\
\hline & Est & $\gamma 1=0.63$ & $\gamma 1=0.8$ & $\gamma 1=1.0$ & $1=1.2$ & $\gamma 1=1.4$ & $=1.6$ & $\gamma 1=1.8$ & $\gamma 1=2.0$ & $y=2.2$ & $\gamma 1=2.4$ & $\gamma 1=2.6$ \\
\hline \multirow{3}{*}{ Classical } & g1 & 0.072 & 0.117 & 0.223 & 0.358 & 0.538 & 0.701 & 0.822 & 0.893 & 0.937 & 0.966 & 0.983 \\
\hline & G1 & 0.066 & 0.096 & 0.174 & 0.290 & 0.441 & 0.603 & 0.742 & 0.843 & 0.905 & 0.940 & 0.966 \\
\hline & $\mathrm{b} 1$ & 0.081 & 0.141 & 0.273 & 0 & 0.633 & .780 & 0.877 & 0.932 & 0.964 & .982 & .991 \\
\hline \multirow{3}{*}{$\begin{array}{c}\text { Bias } \\
\text { Corrected } \\
\text { standard } \\
\end{array}$} & g1 & 0.158 & 0.233 & 0.355 & 0.481 & 0.603 & 0.697 & 0.774 & 0.827 & 0.868 & 0.900 & 0.923 \\
\hline & G1 & 0.142 & 0.209 & 0.307 & 0.424 & 0.536 & .644 & 0.728 & 0.791 & 0.838 & .873 & .899 \\
\hline & $\mathrm{b} 1$ & 0.179 & 0.272 & 0.407 & 0.539 & 0.662 & 0.755 & 0.814 & 0.862 & 0.897 & 0.922 & 0.940 \\
\hline \multirow{3}{*}{$\begin{array}{l}\text { Efron's } \\
\text { percentile } \\
\text { bootstrap }\end{array}$} & g1 & 0.121 & 0.219 & 0.369 & 0.536 & 0.684 & 0.791 & 0.873 & 0.921 & 0.955 & 0.975 & 0.987 \\
\hline & G1 & 0.100 & 0.183 & 0.309 & 0.462 & 0.610 & 0.729 & 0.819 & 0.888 & 0.930 & 0.958 & 0.974 \\
\hline & b1 & 0.149 & 0.264 & 0.440 & 0.611 & 0.752 & 0.850 & 0.911 & 0.950 & 0.972 & 0.987 & 0.994 \\
\hline \multirow{3}{*}{$\begin{array}{c}\text { Hall's } \\
\text { Percentile } \\
\text { bootstrap }\end{array}$} & g1 & 0.170 & 0.251 & 0.361 & 88 & 0.601 & 0.705 & 0.776 & 0.826 & 0.867 & .896 & .917 \\
\hline & G1 & 0.156 & 0.223 & 0.322 & 0.433 & 0.545 & 0.644 & 0.731 & 0.785 & 0.832 & 0.869 & 0.897 \\
\hline & $\mathrm{b} 1$ & 0.191 & 0.285 & 0.415 & 0.546 & 0.659 & 0.755 & 0.814 & 0.857 & 0.891 & 0.917 & 0.939 \\
\hline \multirow{4}{*}{$\begin{array}{c}\text { Bias } \\
\text { Corrected } \\
\text { percentile }\end{array}$} & g1 & 0.146 & 0.223 & 0.340 & 0.467 & 0.593 & 0.691 & 0.777 & 0.838 & 0.886 & 0.922 & 0.950 \\
\hline & G1 & 0.129 & 0.188 & 0.294 & 0.404 & 0.524 & 0.634 & 0.726 & 0.791 & 0.850 & 0.893 & 0.922 \\
\hline & $\mathrm{b} 1$ & 0.165 & 0.260 & 0.384 & 0.524 & 0.651 & 0.748 & 0.823 & 0.883 & 0.919 & 0.948 & 0.966 \\
\hline & & $n=30$ & & & & & & & & & & \\
\hline $\bar{M}$ & Est & $\gamma 1=0.63$ & $\gamma 1=0.8$ & $1=1.0$ & $1=1.2$ & $1=1.4$ & $1=1.6$ & $\gamma 1=1.8$ & $\gamma 1=2.0$ & $\gamma 1=2.2$ & $\gamma 1=2.4$ & $\gamma 1=2.6$ \\
\hline \multirow{3}{*}{ Classical } & g1 & 0.081 & 0.133 & 0.260 & 0.455 & 0.637 & 0.774 & \begin{tabular}{|l|}
0.877 \\
\end{tabular} & 0.934 & 0.966 & 0.983 & 0.991 \\
\hline & G1 & 0.075 & 0.117 & 0.224 & 0.390 & 0.575 & 0.724 & 0.843 & 0.909 & 0.951 & 0.974 & 0.985 \\
\hline & $\mathrm{b} 1$ & 0.086 & 0.154 & 0.304 & 0.516 & 0.691 & 0.831 & 0.908 & 0.954 & 0.977 & 0.988 & 0.995 \\
\hline \multirow{3}{*}{$\begin{array}{c}\text { Bias } \\
\text { Corrected } \\
\text { standard }\end{array}$} & g1 & 0.168 & 0.255 & 0.398 & 0.543 & 0.666 & 0.752 & 0.822 & 0.867 & 0.906 & 0.929 & 0.947 \\
\hline & G1 & 0.151 & 0.229 & 0.363 & 0.500 & 0.626 & 0.717 & 0.795 & 0.847 & 0.888 & 0.917 & 0.936 \\
\hline & $\mathrm{b} 1$ & 0.179 & 0.286 & 0.433 & 0.585 & 0.702 & 0.785 & 0.847 & 0.889 & 0.920 & 0.941 & 0.956 \\
\hline \multirow{3}{*}{$\begin{array}{l}\text { Efron's } \\
\text { percentile } \\
\text { bootstrap }\end{array}$} & $\mathrm{g} 1$ & 0.139 & 0.269 & 0.444 & 0.622 & 0.751 & 0.845 & 0.907 & 0.951 & 0.971 & 0.985 & 0.993 \\
\hline & G1 & 0.122 & 0.230 & 0.399 & 0.566 & 0.705 & 0.807 & 0.883 & 0.929 & 0.962 & 0.978 & 0.988 \\
\hline & $\mathrm{b} 1$ & 0.161 & 0.306 & 0.491 & 0.668 & 0.786 & 0.877 & 0.929 & 0.963 & 0.981 & 0.992 & 0.995 \\
\hline \multirow{3}{*}{$\begin{array}{c}\text { Hall's } \\
\text { Percentile } \\
\text { bootstrap }\end{array}$} & g1 & 0.182 & 0.269 & 0.408 & 0.544 & 0.667 & 0.752 & 0.814 & 0.867 & 0.897 & 0.925 & 0.944 \\
\hline & G1 & 0.169 & 0.252 & 0.374 & 0.510 & 0.628 & 0.717 & 0.791 & 0.842 & 0.883 & 0.910 & 0.932 \\
\hline & b1 & 0.197 & 0.296 & 0.447 & 0.586 & 0.697 & 0.784 & 0.840 & 0.883 & 0.914 & 0.938 & 0.958 \\
\hline \multirow{3}{*}{$\begin{array}{c}\text { Bias } \\
\text { Corrected } \\
\text { percentile }\end{array}$} & g1 & 0.154 & 0.248 & 0.394 & 0.549 & 0.674 & 0.773 & 0.850 & 0.901 & 0.935 & 0.961 & 0.973 \\
\hline & G1 & 0.145 & 0.221 & 0.362 & 0.502 & 0.633 & 0.735 & 0.813 & 0.879 & 0.917 & 0.948 & 0.966 \\
\hline & b1 & 0.171 & 0.278 & 0.434 & 0.595 & 0.715 & 0.808 & 0.875 & 0.916 & 0.951 & 0.971 & 0.980 \\
\hline
\end{tabular}


Table A4 (Continued)

\begin{tabular}{|c|c|c|c|c|c|c|c|c|c|c|c|c|}
\hline & & $n=50$ & & & & & & & & & & \\
\hline Method & ist & $\gamma 1=0.63$ & $\gamma 1=0.8$ & $1=1.0$ & $=1.2$ & $1=1.4$ & $=1.6$ & $\gamma 1=1.8$ & $1=2.0$ & $\gamma 1=2.2$ & $1=2.4$ & $1=2.6$ \\
\hline \multirow{3}{*}{ Classical } & g1 & 0.075 & 0.147 & .329 & 0.561 & 0.758 & .881 & 0.946 & 0.981 & 0.991 & 0.997 & 0.999 \\
\hline & G1 & 074 & 0.131 & 0.301 & 0.516 & 0.724 & 0.858 & 0.935 & 0.976 & 0.989 & 0.995 & 0.998 \\
\hline & b1 & 076 & 0.164 & 0.363 & 0.602 & 0.790 & 0.907 & .961 & 0.986 & 0.994 & .998 & 0.999 \\
\hline \multirow{3}{*}{$\begin{array}{c}\text { Bias } \\
\text { Corrected } \\
\text { standard } \\
\end{array}$} & g1 & 0.151 & 0.270 & 0.442 & 0.607 & 0.729 & 0.819 & 0.883 & 0.919 & 0.949 & 0.966 & 0.979 \\
\hline & G1 & 0.144 & 0.251 & 0.416 & 0.582 & 0.710 & 0.801 & 0.869 & 0.910 & 0.939 & 0.959 & .974 \\
\hline & b1 & 0.159 & 0.287 & 0.475 & 0.632 & 0.756 & 0.837 & 0.894 & 0.928 & 0.954 & 0.971 & 0.983 \\
\hline \multirow{3}{*}{$\begin{array}{l}\text { Efron's } \\
\text { percentile } \\
\text { bootstrap }\end{array}$} & $\mathrm{g} 1$ & 0.146 & 0.291 & 0.501 & 0.691 & 0.821 & 0.906 & 0.950 & 0.980 & 0.991 & 0.996 & 0.998 \\
\hline & G1 & \begin{tabular}{l|l}
0.130 \\
\end{tabular} & 0.266 & 0.467 & 0.661 & 0.798 & 0.889 & 0.944 & 0.973 & 0.987 & 0.994 & $\overline{0.997}$ \\
\hline & b1 & \begin{tabular}{l|l}
0.160 \\
\end{tabular} & 0.313 & 0.536 & 0.716 & 0.844 & 0.922 & 0.959 & 0.984 & 0.992 & 0.997 & 0.999 \\
\hline \multirow{3}{*}{$\begin{array}{c}\text { Hall's } \\
\text { Percentile } \\
\text { bootstrap }\end{array}$} & g1 & 0.170 & 0.285 & 0.448 & 0.604 & 0.728 & 0.815 & 0.876 & 0.916 & 0.945 & 0.966 & 0.980 \\
\hline & G1 & 0.162 & 0.264 & 0.421 & 0.579 & 0.707 & 0.795 & 0.860 & 0.908 & 0.935 & 0.959 & 0.974 \\
\hline & b1 & 0.181 & 0.296 & 0.476 & 0.627 & 0.750 & 831 & .891 & .926 & .952 & .973 & .984 \\
\hline \multirow{4}{*}{$\begin{array}{c}\text { Bias } \\
\text { Corrected } \\
\text { percentile } \\
\end{array}$} & $\mathrm{g} 1$ & \begin{tabular}{l|l|}
0.142 \\
\end{tabular} & 0.267 & 0.446 & 0.625 & 0.764 & 0.862 & 0.924 & 0.959 & 0.982 & 0.990 & 0.996 \\
\hline & G1 & 0.135 & 0.244 & 0.420 & 0.596 & 0.735 & 0.846 & 0.910 & 0.949 & 0.977 & 0.988 & 0.993 \\
\hline & b1 & 0.154 & 0.286 & 0.477 & 357 & 0.790 & 882 & 0.937 & 969 & 84 & .992 & $\overline{.996}$ \\
\hline & & $n=100$ & & & & & & & & & & \\
\hline & Est & $\gamma 1=0.63$ & 8 & 1.0 & .2 & 1.4 & 1.6 & $=1.8$ & $=2.0$ & $=2.2$ & $=2.4$ & $1=2.6$ \\
\hline \multirow{3}{*}{ Classical } & $\mathrm{g} 1$ & 0.092 & 0.189 & 0.464 & 0.728 & 0.886 & 0.959 & 0.986 & 0.995 & 0.999 & 0.999 & 1.000 \\
\hline & G1 & 0.090 & 0.178 & 0.437 & 0.707 & 0.876 & 0.954 & 0.984 & 0.995 & 0.998 & 0.999 & 1.000 \\
\hline & b1 & \begin{tabular}{l|l|}
0.094 \\
\end{tabular} & 0.205 & 0.486 & 0.747 & 0.897 & 0.964 & 0.989 & 0.996 & 0.999 & 0.999 & 1.000 \\
\hline \multirow{3}{*}{$\begin{array}{c}\text { Bias } \\
\text { Corrected } \\
\text { standard }\end{array}$} & $\mathrm{g} 1$ & 0.129 & 0.281 & 0.503 & 0.692 & 0.814 & 0.885 & 0.937 & 0.959 & 0.977 & 0.987 & 0.991 \\
\hline & G1 & 0.130 & 0.264 & 0.485 & 0.677 & 0.807 & 883 & 0.931 & 0.958 & 0.975 & .986 & .990 \\
\hline & b1 & 0.134 & 0.293 & 0.518 & 0.703 & 0.828 & 0.893 & 0.943 & 0.962 & 0.979 & 0.988 & 0.992 \\
\hline \multirow{3}{*}{$\begin{array}{l}\text { Efron's } \\
\text { percentile } \\
\text { bootstrap }\end{array}$} & g1 & & & & & & & & & & & $\overline{99}$ \\
\hline & G1 & 0.125 & 0.293 & 0.545 & 0.744 & 0.870 & 0.933 & 0.969 & 0.988 & 0.993 & 0.997 & 0.999 \\
\hline & b1 & 0.138 & 0.325 & 0.580 & 0.778 & 0.882 & 0.946 & 0.977 & 0.990 & 0.995 & 0.998 & 1.000 \\
\hline \multirow{3}{*}{$\begin{array}{c}\text { Hall's } \\
\text { Percentile } \\
\text { bootstrap }\end{array}$} & g1 & 0.148 & 0.288 & 0.506 & 0.693 & 0.816 & 0.885 & 0.937 & 0.961 & 0.980 & 0.988 & 0.993 \\
\hline & G1 & 0.146 & 0.277 & 0.486 & 0.675 & 0.809 & 0.879 & 0.933 & 0.958 & 0.977 & 0.987 & 0.992 \\
\hline & b1 & 0.153 & 0.295 & 0.523 & 0.705 & 0.825 & 0.891 & 0.943 & 0.966 & 0.982 & 0.989 & 0.993 \\
\hline \multirow{4}{*}{$\begin{array}{c}\text { Bias } \\
\text { Corrected } \\
\text { percentile }\end{array}$} & g1 & 0.127 & 0.275 & 0.510 & 0.717 & 0.845 & 0.919 & 0.961 & 0.983 & 0.991 & 0.996 & 0.998 \\
\hline & G1 & 0.117 & 0.264 & 0.500 & 0.699 & 0.840 & 0.911 & 0.959 & 0.981 & 0.991 & 0.996 & 0.998 \\
\hline & b1 & 0.127 & 0.297 & 0.534 & 731 & 0.856 & .926 & 0.964 & 0.985 & 0.992 & 0.997 & 0.999 \\
\hline & & $\mathrm{n}=300$ & & & & & & & & & & \\
\hline $\bar{d}$ & ist & $\gamma 1=0.63$ & $\gamma 1=0.8$ & $1=1.0$ & $1=1.2$ & $\gamma 1=1.4$ & $\gamma 1=1.6$ & $\gamma 1=1.8$ & $\gamma 1=2.0$ & $\gamma 1=2.2$ & $\gamma 1=2.4$ & $\gamma 1=2.6$ \\
\hline \multirow{3}{*}{ Classical } & g1 & 0.108 & 0.329 & 0.768 & 0.950 & 0.991 & 0.999 & 1.000 & 1.000 & 1.000 & 1.000 & 1.000 \\
\hline & G1 & 0.108 & 0.320 & 0.759 & 0.947 & 0.990 & 0.999 & 1.000 & 1.000 & 1.000 & 1.000 & 1.000 \\
\hline & b1 & 0.110 & 0.338 & 0.776 & 0.952 & 0.992 & 0.999 & 1.000 & 1.000 & 1.000 & 1.000 & 1.000 \\
\hline \multirow{3}{*}{$\begin{array}{c}\text { Bias } \\
\text { Corrected } \\
\text { standard }\end{array}$} & $\mathrm{g} 1$ & 0.106 & 0.328 & 0.677 & 0.868 & 0.949 & 0.979 & 0.990 & 0.995 & 0.997 & 0.999 & 0.999 \\
\hline & G1 & 0.103 & 0.318 & 0.671 & 0.864 & 0.947 & 0.978 & 0.989 & 0.994 & 0.997 & 0.999 & 0.999 \\
\hline & b1 & 0.107 & 0.338 & 0.680 & 0.870 & 0.951 & 0.979 & 0.991 & 0.994 & 0.997 & 0.999 & 0.999 \\
\hline \multirow{3}{*}{$\begin{array}{l}\text { Efron's } \\
\text { percentile } \\
\text { bootstrap }\end{array}$} & $\mathrm{g} 1$ & 0.105 & 0.365 & 0.718 & 0.895 & 0.963 & 0.987 & 0.994 & 0.997 & 0.999 & 0.999 & 1.000 \\
\hline & G1 & 0.101 & 0.353 & 0.711 & 0.893 & 0.961 & 0.985 & 0.993 & 0.998 & 0.999 & 0.999 & 1.000 \\
\hline & b1 & 0.109 & 0.373 & 0.726 & 0.899 & 0.966 & 0.987 & 0.994 & 0.998 & 0.999 & 1.000 & 1.000 \\
\hline \multirow{3}{*}{$\begin{array}{c}\text { Hall's } \\
\text { Percentile } \\
\text { bootstrap }\end{array}$} & g1 & 0.106 & 0.340 & 0.686 & 0.877 & 0.953 & 0.981 & 0.993 & 0.996 & 0.999 & 0.999 & 1.000 \\
\hline & G1 & 0.108 & 0.328 & 0.674 & 0.874 & 0.951 & 0.981 & 0.993 & 0.996 & 0.998 & 0.999 & 1.000 \\
\hline & b1 & 0.110 & 0.347 & 0.690 & 0.880 & 0.957 & 0.982 & 0.994 & 0.996 & 0.998 & 0.999 & 1.000 \\
\hline \multirow{3}{*}{$\begin{array}{c}\text { Bias } \\
\text { Corrected } \\
\text { percentile }\end{array}$} & g1 & 0.101 & 0.327 & 0.675 & 0.870 & 0.952 & 0.981 & 0.992 & 0.996 & 0.998 & 0.999 & 1.000 \\
\hline & G1 & 0.097 & 0.319 & 0.673 & 0.865 & 0.950 & 0.981 & 0.992 & 0.996 & 0.998 & 0.999 & 1.000 \\
\hline & b1 & 0.105 & 0.334 & 0.683 & 0.876 & 0.954 & 0.983 & 0.992 & 0.997 & 0.999 & 0.999 & 1.000 \\
\hline
\end{tabular}


Table A5: Power for Beta $(1,0.35181)$ with skewness=-1 against with other value for different sample size

\begin{tabular}{|c|c|c|c|c|c|c|c|c|c|c|c|c|}
\hline & & $=10$ & & & & & & & & & & \\
\hline Method & Est & $1=-1.0$ & $\gamma 1=-0.8$ & $1=-0.6$ & $=-0.4$ & $\gamma 1=-0.2$ & $\gamma 1=0$ & $1=0.2$ & $1=0.4$ & $1=0.6$ & $1=0.8$ & $1=1.0$ \\
\hline \multirow{3}{*}{ Classical } & 91 & 0.046 & 0.049 & 0.070 & 0.117 & 0.191 & .294 & .429 & 0.575 & 0.716 & 0.833 & 0.917 \\
\hline & G1 & .048 & 0.060 & 0.089 & 0.135 & 0.210 & .294 & 0.406 & 0.529 & 0.647 & 0.762 & 0.851 \\
\hline & b1 & 0.067 & 0.046 & 0.057 & 0.098 & 0.177 & .294 & 0.452 & 0.622 & 0.778 & .896 & 0.961 \\
\hline \multirow{3}{*}{$\begin{array}{c}\text { Bias } \\
\text { Corrected } \\
\text { standard }\end{array}$} & g1 & 0.083 & .100 & 0.120 & 0.162 & 0.223 & .315 & 0.447 & 0.578 & 0.709 & 0.833 & 0.909 \\
\hline & G1 & 0.091 & 0.107 & 0.140 & 0.181 & 0.229 & 0.314 & 0.429 & 0.533 & 0.643 & 0.754 & 0.862 \\
\hline & b1 & 0.108 & 0.084 & 0.107 & 0.147 & 0.211 & .315 & 0.466 & 0.620 & 0.778 & 0.893 & 0.959 \\
\hline \multirow{3}{*}{$\begin{array}{l}\text { Efron's } \\
\text { percentile } \\
\text { bootstrap } \\
\end{array}$} & g1 & 0.039 & 0.012 & 0.003 & 0.003 & 0.020 & 0.112 & 0.313 & 0.535 & 0.715 & 0.841 & 0.918 \\
\hline & G1 & 0.015 & 0.005 & 0.001 & 0.006 & 0.033 & .113 & 0.280 & 0.463 & 0.642 & 0.761 & 0.864 \\
\hline & $\mathrm{b} 1$ & 0.075 & 0.026 & 0.006 & 0.002 & 0.018 & 0.118 & 0.349 & 0.613 & 0.783 & 0.900 & 0.957 \\
\hline \multirow{3}{*}{$\begin{array}{c}\text { Hall's } \\
\text { Percentile } \\
\text { bootstrap }\end{array}$} & g1 & 0.101 & 0.111 & 0.136 & 0.172 & 0.231 & .310 & 0.403 & 0.506 & 0.627 & .752 & .853 \\
\hline & G1 & 0.109 & 0.125 & 0.148 & 0.186 & 0.243 & .309 & 0.389 & 0.475 & 0.563 & 0.669 & 0.779 \\
\hline & b1 & 0.123 & 0.100 & 0.123 & 0.156 & 0.222 & .311 & 0.418 & 0.547 & 0.689 & 0.833 & 0.925 \\
\hline \multirow{4}{*}{$\begin{array}{c}\text { Bias } \\
\text { Corrected } \\
\text { percentile } \\
\end{array}$} & g1 & 0.051 & 0.072 & 0.117 & 86 & 0.270 & .380 & 0.534 & 0.677 & 0.797 & .882 & 0.935 \\
\hline & G1 & 0.061 & 0.104 & 0.151 & 0.211 & 0.287 & 0.380 & 0.510 & 0.633 & 0.750 & 0.830 & 0.896 \\
\hline & b1 & 0.063 & 0.055 & 0.094 & 61 & 0.255 & .377 & 0.556 & 0.724 & 0.850 & 923 & .964 \\
\hline & & $\mathrm{n}=20$ & & & & & & & & & & \\
\hline & Est & $\gamma 1=-1.0$ & $\gamma 1=-0.8$ & $\gamma 1=-0.6$ & $1=-0.4$ & $\gamma 1=-0.2$ & $y \mathrm{l}=0$ & $\gamma 1=0.2$ & $\gamma 1=0.4$ & $\gamma 1=0.6$ & $\gamma 1=0.8$ & $\gamma 1=1.0$ \\
\hline \multirow{3}{*}{ Classical } & g1 & 0.032 & 0.049 & 0.088 & 0.171 & 0.313 & .514 & 0.716 & 0.865 & 0.957 & 0.987 & 0.998 \\
\hline & G1 & 0.034 & 0.059 & 0.107 & 0.191 & 0.324 & 0.514 & 0.701 & 0.846 & 0.942 & 0.983 & 0.996 \\
\hline & $\mathrm{b} 1$ & 0.030 & 0.038 & 0.077 & 57 & 02 & 514 & 0.730 & .881 & 0.967 & .991 & .999 \\
\hline \multirow{3}{*}{$\begin{array}{c}\text { Bias } \\
\text { Corrected } \\
\text { standard } \\
\end{array}$} & g1 & 0.043 & 0.047 & 0.084 & 0.173 & 0.351 & 0.574 & 0.802 & 0.938 & 0.985 & 0.999 & 1.000 \\
\hline & G1 & 0.040 & 0.055 & 0.099 & 93 & 0.368 & .578 & .785 & 0.923 & 0.979 & 95 & 1.000 \\
\hline & $\mathrm{b} 1$ & 0.059 & 0.042 & 0.070 & 57 & 0.336 & .571 & 0.814 & 0.948 & 0.991 & 0.999 & 1.000 \\
\hline \multirow{3}{*}{$\begin{array}{l}\text { Efron's } \\
\text { percentile } \\
\text { bootstrap }\end{array}$} & g1 & 0.030 & 0.013 & 0.044 & 0.169 & 0.395 & 0.660 & 0.853 & 0.953 & 0.987 & 0.997 & 1.000 \\
\hline & G1 & 0.021 & 0.017 & 0.062 & 0.198 & 0.418 & 0.663 & 0.845 & 0.944 & 0.982 & 0.995 & 0.999 \\
\hline & b1 & 0.044 & 0.017 & 0.032 & 0.143 & 0.379 & 0.662 & 0.865 & 0.963 & 0.989 & 0.999 & 1.000 \\
\hline \multirow{3}{*}{$\begin{array}{c}\text { Hall's } \\
\text { Percentile } \\
\text { bootstrap }\end{array}$} & g1 & 0.047 & 0.037 & 58 & 14 & 0.240 & 439 & 0.702 & 0.897 & 0.980 & .997 & 1.000 \\
\hline & G1 & 0.040 & 0.041 & 0.066 & 30 & 0.253 & 0.443 & 0.675 & 0.876 & 0.973 & 0.994 & 1.000 \\
\hline & $\mathrm{b} 1$ & 0.068 & 0.038 & 0.051 & 00 & 0.224 & .442 & 0.714 & 0.920 & 0.990 & 1.000 & 1.000 \\
\hline \multirow{4}{*}{$\begin{array}{c}\text { Bias } \\
\text { Corrected } \\
\text { percentile }\end{array}$} & g1 & 0.046 & 0.074 & 0.151 & 306 & 0.528 & 0.740 & 0.888 & 0.963 & 0.990 & 0.998 & 1.000 \\
\hline & G1 & 0.051 & 0.092 & 0.179 & 0.338 & 0.548 & 0.747 & 0.885 & 0.956 & 0.987 & 0.997 & 1.000 \\
\hline & $\mathrm{b} 1$ & 0.049 & 60 & 0.128 & 75 & 0.509 & .742 & 0.898 & 0.971 & 0.992 & 0.999 & 1.000 \\
\hline & & $=30$ & & & & & & & & & & \\
\hline & Est & $\gamma 1=-1.0$ & $\gamma 1=-0.8$ & $\gamma 1=-0.6$ & $=-0.4$ & $\gamma 1=-0.2$ & $\gamma 1=0$ & $\gamma 1=0.2$ & $\gamma 1=0.4$ & $\gamma \mathrm{I}=0.6$ & $\gamma 1=0.8$ & $\gamma 1=1.0$ \\
\hline \multirow{3}{*}{ Classical } & g1 & 0.028 & 0.060 & 0.135 & 0.262 & 0.474 & 0.709 & \begin{tabular}{|l|}
0.883 \\
\end{tabular} & 0.969 & 0.996 & 0.999 & 1.000 \\
\hline & G1 & 0.034 & 0.072 & 0.144 & 0.284 & 0.485 & 0.709 & 0.876 & 0.964 & 0.995 & 0.999 & 1.000 \\
\hline & $\mathrm{b} 1$ & 0.026 & 0.050 & 0.118 & 0.245 & 0.459 & 0.709 & 0.890 & 0.976 & 0.997 & 0.999 & 1.000 \\
\hline \multirow{3}{*}{$\begin{array}{c}\text { Bias } \\
\text { Corrected } \\
\text { standard }\end{array}$} & g1 & 0.042 & 0.052 & 0.128 & 0.307 & 0.579 & 0.846 & 0.963 & 0.997 & 1.000 & 1.000 & 1.000 \\
\hline & G1 & 0.038 & 0.060 & 0.153 & 0.333 & 0.595 & 0.835 & 0.960 & 0.995 & 0.999 & 1.000 & 1.000 \\
\hline & $\mathrm{b} 1$ & 0.057 & 0.044 & 0.114 & 0.282 & 0.569 & 0.841 & 0.969 & 0.997 & 1.000 & 1.000 & 1.000 \\
\hline \multirow{3}{*}{$\begin{array}{l}\text { Efron's } \\
\text { percentile } \\
\text { bootstrap }\end{array}$} & $\mathrm{g} 1$ & 0.034 & 0.044 & 0.150 & 0.381 & 0.659 & 0.877 & 0.971 & 0.996 & 1.000 & 1.000 & 1.000 \\
\hline & G1 & 0.023 & 0.056 & \begin{tabular}{|l|}
0.178 \\
\end{tabular} & 0.410 & 0.679 & 0.877 & 0.968 & 0.996 & 0.999 & 1.000 & 1.000 \\
\hline & b1 & 0.040 & 0.038 & 0.128 & 0.358 & 0.649 & 0.881 & 0.975 & 0.997 & 0.999 & 1.000 & 1.000 \\
\hline \multirow{3}{*}{$\begin{array}{c}\text { Hall's } \\
\text { Percentile } \\
\text { bootstrap }\end{array}$} & g1 & 0.048 & 0.032 & \begin{tabular}{|l}
0.075 \\
\end{tabular} & 0.209 & 0.469 & 0.774 & 0.952 & 0.995 & 1.000 & 1.000 & 1.000 \\
\hline & G1 & 0.036 & 0.035 & 0.088 & 0.229 & 0.480 & 0.773 & 0.943 & 0.994 & 0.999 & 1.000 & 1.000 \\
\hline & b1 & 0.063 & 0.028 & 0.066 & 0.192 & 0.448 & 0.775 & 0.955 & 0.996 & 1.000 & 1.000 & 1.000 \\
\hline \multirow{3}{*}{$\begin{array}{c}\text { Bias } \\
\text { Corrected } \\
\text { percentile }\end{array}$} & g1 & 0.052 & 0.103 & 0.235 & 0.474 & 0.724 & 0.905 & 0.978 & 0.997 & 0.999 & 1.000 & 1.000 \\
\hline & G1 & 0.060 & 0.122 & 0.263 & 0.495 & 0.739 & 0.901 & 0.978 & 0.996 & 0.999 & 1.000 & 1.000 \\
\hline & b1 & 0.056 & 0.083 & 0.212 & 0.439 & 0.710 & 0.903 & 0.980 & 0.997 & 1.000 & 1.000 & 1.000 \\
\hline
\end{tabular}


Table A5 (Continued)

\begin{tabular}{|c|c|c|c|c|c|c|c|c|c|c|c|c|}
\hline & & $n=50$ & & & & & & & & & & \\
\hline Mothed & st & $1=-1.0$ & $\gamma 1=-0.8$ & $\gamma 1=-0.6$ & $=-0.4$ & $\gamma 1=-0.2$ & $\gamma 1=0$ & $1=0.2$ & $\gamma 1=0.4$ & $\gamma 1=0.6$ & $1=0.8$ & $1=1.0$ \\
\hline \multirow{3}{*}{ Classical } & g1 & 0.025 & 0.059 & 0.171 & 0.415 & 0.694 & .903 & .986 & 1.000 & 1.000 & 1.000 & 1.000 \\
\hline & G1 & .025 & 0.068 & 0.189 & 0.432 & 0.702 & 0.903 & 0.985 & 1.000 & 1.000 & 1.000 & 1.000 \\
\hline & b1 & 024 & .048 & 0.156 & 0.398 & 0.688 & .903 & .987 & 1.000 & 1.000 & 1.000 & 1.000 \\
\hline \multirow{3}{*}{$\begin{array}{c}\text { Bias } \\
\text { Corrected } \\
\text { standard } \\
\end{array}$} & g1 & 0.051 & 0.066 & 0.232 & 0.561 & 0.849 & 0.979 & 0.999 & 1.000 & 1.000 & 1.000 & 1.000 \\
\hline & G1 & 0.045 & 0.074 & 0.268 & 0.584 & 0.855 & .978 & 0.999 & 1.000 & 1.000 & 1.000 & 1.000 \\
\hline & b1 & 0.059 & 0.056 & 0.217 & 0.536 & 0.849 & .978 & 0.999 & 1.000 & 1.000 & 1.000 & 1.000 \\
\hline \multirow{3}{*}{$\begin{array}{l}\text { Efron's } \\
\text { percentile } \\
\text { bootstrap }\end{array}$} & g1 & 0.050 & 0.091 & 0.303 & 0.624 & 0.882 & 0.981 & 1.000 & 1.000 & 1.000 & 1.000 & 1.000 \\
\hline & G1 & \begin{tabular}{|l|}
0.048 \\
\end{tabular} & 0.102 & 0.331 & 0.638 & 0.884 & 0.983 & 0.999 & 1.000 & 1.000 & 1.000 & 1.000 \\
\hline & b1 & 0.055 & 0.075 & 0.271 & 0.602 & 0.872 & 0.983 & 0.999 & 1.000 & 1.000 & 1.000 & 1.000 \\
\hline \multirow{3}{*}{$\begin{array}{c}\text { Hall's } \\
\text { Percentile } \\
\text { bootstrap }\end{array}$} & g1 & 0.050 & 0.041 & 0.166 & 0.482 & 0.801 & .974 & 0.999 & 1.000 & 1.000 & 1.000 & 1.000 \\
\hline & G1 & 0.043 & 0.046 & 0.184 & 0.515 & 0.819 & 0.973 & 0.999 & 1.000 & 1.000 & 1.000 & 1.000 \\
\hline & b1 & 0.060 & 0.039 & 0.142 & 0.468 & 0.798 & 974 & 0.999 & 1.000 & 1.000 & 1.000 & 1.000 \\
\hline \multirow{4}{*}{$\begin{array}{c}\text { Bias } \\
\text { Corrected } \\
\text { percentile } \\
\end{array}$} & $\mathrm{g} 1$ & 0.057 & 0.123 & 0.363 & 0.667 & 0.899 & 0.986 & 1.000 & 1.000 & 1.000 & 1.000 & 1.000 \\
\hline & G1 & 0.057 & 0.141 & 0.384 & 0.686 & 0.907 & 0.985 & 0.999 & 1.000 & 1.000 & 1.000 & 1.000 \\
\hline & b1 & 0.055 & 0.107 & 332 & 52 & 0.895 & 986 & 0.999 & 1.000 & 1.000 & 1.000 & 1.000 \\
\hline & & $n=100$ & & & & & & & & & & \\
\hline & $\mathrm{st}$ & -1.0 & $=-0.8$ & $=-0.6$ & $=-0.4$ & $\gamma 1=-0.2$ & $=0$ & $=0.2$ & $\gamma 1=0.4$ & $=0.6$ & $1=0.8$ & $1=1.0$ \\
\hline \multirow{3}{*}{ Classical } & $\mathrm{g} 1$ & 0.016 & 0.096 & 0.353 & 0.748 & 0.969 & 0.997 & 1.000 & 1.000 & 1.000 & 1.000 & 1.000 \\
\hline & G1 & 0.017 & 0.103 & 0.372 & 0.758 & 0.971 & 0.997 & 1.000 & 1.000 & 1.000 & 1.000 & 1.000 \\
\hline & b1 & \begin{tabular}{|l|}
0.015 \\
\end{tabular} & 0.087 & 0.333 & 0.738 & 0.968 & 0.997 & 1.000 & 1.000 & 1.000 & 1.000 & 1.000 \\
\hline \multirow{3}{*}{$\begin{array}{c}\text { Bias } \\
\text { Corrected } \\
\text { standard }\end{array}$} & $\mathrm{g} 1$ & 0.042 & 0.147 & 0.528 & 0.900 & 0.995 & 1.000 & 1.000 & 1.000 & 1.000 & 1.000 & 1.000 \\
\hline & G1 & 0.042 & 0.163 & 0.551 & 910 & 0.995 & .000 & 1.000 & 1.000 & 1.000 & 1.000 & 1.000 \\
\hline & b1 & 0.047 & 0.133 & 0.507 & 0.901 & 0.994 & .000 & 1.000 & 1.000 & 1.000 & 1.000 & 1.000 \\
\hline \multirow{3}{*}{$\begin{array}{l}\text { Efron's } \\
\text { percentile } \\
\text { bootstrap }\end{array}$} & g1 & & & & 0. & & 1.000 & 1.000 & 1.000 & & & 00 \\
\hline & G1 & 0.047 & 0.195 & 0.598 & 0.928 & 0.995 & 1.000 & 1.000 & 1.000 & 1.000 & 1.000 & 1.000 \\
\hline & b1 & 0.045 & 0.162 & 0.558 & 0.915 & 0.995 & .000 & 1.000 & 1.000 & 1.000 & 1.000 & 1.000 \\
\hline \multirow{3}{*}{$\begin{array}{c}\text { Hall's } \\
\text { Percentile } \\
\text { bootstrap }\end{array}$} & g1 & 042 & 0.115 & 0.479 & 0.885 & 0.993 & 1.000 & 1.000 & 1.000 & 1.000 & 1.000 & 1.000 \\
\hline & G1 & 0.038 & 0.125 & 0.497 & 0.890 & 0.994 & 1.000 & 1.000 & 1.000 & 1.000 & 1.000 & 1.000 \\
\hline & b1 & 046 & 0.106 & 0.454 & 0.876 & 0.992 & 1.000 & 1.000 & 1.000 & 1.000 & 1.000 & 1.000 \\
\hline \multirow{4}{*}{$\begin{array}{c}\text { Bias } \\
\text { Corrected } \\
\text { percentile }\end{array}$} & g1 & 0.055 & 0.210 & 0.613 & 30 & 0.996 & 1.000 & 1.000 & 1.000 & 1.000 & 1.000 & 1.000 \\
\hline & G1 & 0.056 & 0.225 & 0.631 & 0.936 & 0.996 & 1.000 & 1.000 & 1.000 & 1.000 & 1.000 & 1.000 \\
\hline & b1 & 0.051 & & 0.589 & .927 & 0996 & .000 & 1.000 & 1.000 & 1.000 & 1.000 & 1.000 \\
\hline & & $n=300$ & & & & & & & & & & \\
\hline $\bar{d}$ & ist & $\gamma 1=-1.0$ & $\gamma 1=-0.8$ & $1=-0.6$ & $1=-0.4$ & $\gamma 1=-0.2$ & $\gamma 1=0$ & $\gamma 1=0.2$ & $\gamma 1=0.4$ & $\gamma 1=0.6$ & $\gamma 1=0.8$ & $\gamma 1=1.0$ \\
\hline \multirow{3}{*}{ Classical } & g1 & 0.015 & 0.244 & 0.876 & 1.000 & 1.000 & 1.000 & 1.000 & 1.000 & 1.000 & 1.000 & 1.000 \\
\hline & G1 & 0.016 & 0.256 & 0.883 & 1.000 & 1.000 & 1.000 & 1.000 & 1.000 & 1.000 & 1.000 & 1.000 \\
\hline & b1 & 0.016 & 0.233 & 0.870 & 0.999 & 1.000 & 1.000 & 1.000 & 1.000 & 1.000 & 1.000 & 1.000 \\
\hline \multirow{3}{*}{$\begin{array}{c}\text { Bias } \\
\text { Corrected } \\
\text { standard }\end{array}$} & $\mathrm{g} 1$ & 0.052 & 0.428 & 0.962 & 1.000 & 1.000 & 1.000 & 1.000 & 1.000 & 1.000 & 1.000 & 1.000 \\
\hline & G1 & 0.052 & 0.443 & 0.966 & 1.000 & 1.000 & 1.000 & 1.000 & 1.000 & 1.000 & 1.000 & 1.000 \\
\hline & b1 & 0.054 & 0.404 & 0.960 & 1.000 & 1.000 & 1.000 & 1.000 & 1.000 & 1.000 & 1.000 & 1.000 \\
\hline \multirow{3}{*}{$\begin{array}{l}\text { Efron's } \\
\text { percentile } \\
\text { bootstrap }\end{array}$} & g1 & 0.052 & 0.450 & 0.970 & 1.000 & 1.000 & 1.000 & 1.000 & 1.000 & 1.000 & 1.000 & 1.000 \\
\hline & G1 & 0.051 & 0.468 & 0.971 & 1.000 & 1.000 & 1.000 & 1.000 & 1.000 & 1.000 & 1.000 & 1.000 \\
\hline & b1 & 0.051 & 0.430 & 0.965 & 1.000 & & 1.000 & 1.000 & 1.000 & 1.000 & 1.000 & 1.000 \\
\hline \multirow{3}{*}{$\begin{array}{c}\text { Hall's } \\
\text { Percentile } \\
\text { bootstrap }\end{array}$} & g1 & 0.053 & 0.395 & 0.957 & 1.000 & 1.000 & 1.000 & 1.000 & 1.000 & 1.000 & 1.000 & 1.000 \\
\hline & G1 & 0.050 & 0.411 & 0.963 & 1.000 & 1.000 & 1.000 & 1.000 & 1.000 & 1.000 & 1.000 & 1.000 \\
\hline & b1 & 0.051 & 0.381 & 0.955 & 1.000 & 1.000 & 1.000 & 1.000 & 1.000 & 1.000 & 1.000 & 1.000 \\
\hline \multirow{3}{*}{$\begin{array}{c}\text { Bias } \\
\text { Corrected } \\
\text { percentile }\end{array}$} & g1 & 0.052 & 0.474 & 0.971 & 1.000 & 1.000 & 1.000 & 1.000 & 1.000 & 1.000 & 1.000 & 1.000 \\
\hline & G1 & 0.051 & 0.489 & 0.974 & 1.000 & 1.000 & 1.000 & 1.000 & 1.000 & 1.000 & 1.000 & 1.000 \\
\hline & b1 & 0.051 & 0.457 & 0.970 & 1.000 & 1.000 & 1.000 & 1.000 & 1.000 & 1.000 & 1.000 & 1.000 \\
\hline
\end{tabular}


Table A6: Power for Beta $(1,0.15470)$ with skewness=-2 against with other value for different sample size

\begin{tabular}{|c|c|c|c|c|c|c|c|c|c|c|c|c|}
\hline & & $n=10$ & & & & & & & & & & \\
\hline Method & Est & $1=-2.0$ & $\gamma 1=-1.8$ & $\gamma 1=-1.6$ & $=-1.4$ & $\gamma 1=-1.2$ & $\gamma 1=-1.0$ & $\gamma 1=-0.8$ & $\gamma 1=-0.6$ & $\gamma 1=-0.4$ & $\gamma 1=-0.2$ & $\gamma 1=0$ \\
\hline \multirow{3}{*}{ Classical } & $\bar{g} 1$ & 0.137 & 0.074 & 0.035 & 0.080 & 0.146 & 0.214 & 0.286 & 0.374 & 0.473 & 0.618 & 0.729 \\
\hline & G1 & .048 & 0.034 & 0.097 & 0.152 & 0.209 & 0.272 & .341 & .414 & .530 & 0.635 & .729 \\
\hline & b1 & 0.307 & 0.196 & 0.092 & 0.039 & 0.079 & 0.154 & 0.235 & 0.329 & 0.431 & 0.596 & 0.729 \\
\hline \multirow{3}{*}{$\begin{array}{c}\text { Bias } \\
\text { Corrected } \\
\text { standard }\end{array}$} & g1 & 0.097 & 0.108 & 0.152 & 0.194 & 0.246 & 0.295 & 0.344 & 0.406 & 0.463 & 0.531 & .632 \\
\hline & G1 & 0.135 & 0.172 & 0.206 & 0.247 & 0.293 & 0.338 & 0.382 & 0.433 & 0.485 & 0.542 & 0.630 \\
\hline & $\mathrm{b} 1$ & 0.202 & 0.127 & 0.095 & 0.148 & 0.197 & 0.253 & 0.310 & 0.379 & 0.449 & 0.515 & .630 \\
\hline \multirow{3}{*}{$\begin{array}{c}\text { Efron's } \\
\text { percentile } \\
\text { bootstrap } \\
\end{array}$} & g1 & 0.076 & 0.046 & 0.025 & 0.010 & 0.003 & 0.001 & 0.000 & 0.008 & 0.092 & 0.284 & 0.539 \\
\hline & G1 & 0.033 & 0.016 & 0.008 & 0.003 & 0.001 & 0.001 & 0.004 & 0.017 & 0.175 & 0.320 & 0.542 \\
\hline & $\mathrm{b} 1$ & 0.171 & 0.098 & 0.055 & 0.028 & 0.012 & 0.002 & 0.001 & 0.003 & 0.023 & 0.266 & .550 \\
\hline \multirow{3}{*}{$\begin{array}{c}\text { Hall's } \\
\text { Percentile } \\
\text { bootstrap } \\
\end{array}$} & g1 & 0.279 & 0.263 & 0.260 & 0.273 & 0.307 & 0.348 & 0.396 & 0.445 & 0.506 & 0.596 & 0.671 \\
\hline & G1 & 0.258 & 0.269 & 0.282 & 0.313 & 0.346 & 82 & 0.427 & 0.469 & .537 & 0.607 & .671 \\
\hline & b1 & 0.352 & 0.302 & 0.266 & 0.260 & 0.273 & 0.313 & 0.362 & 0.419 & 0.482 & 0.582 & 0.670 \\
\hline \multirow{4}{*}{$\begin{array}{c}\text { Bias- }^{-} \\
\text {corrected } \\
\text { percentile }\end{array}$} & g1 & 0.041 & 0.025 & 0.013 & 0.058 & 0.114 & 0.179 & 0.324 & 0.427 & 0.553 & 0.651 & 0.755 \\
\hline & G1 & 0.017 & 0.009 & 0.073 & 0.123 & 0.174 & 0.286 & 0.394 & 0.480 & .588 & 0.660 & 0.758 \\
\hline & b1 & 0.091 & 0.053 & 0.028 & 0.013 & 0.053 & 0.128 & 0.198 & 0.381 & 0.500 & 0.634 & 0.759 \\
\hline & & $=20$ & & & & & & & & & & \\
\hline Method & Est & $1=-2.0$ & $\gamma 1=-1.8$ & $\gamma 1=-1.6$ & $=-1.4$ & $\gamma 1=-1.2$ & $\gamma 1=-1.0$ & $\gamma 1=-0.8$ & $\gamma 1=-0.6$ & $\gamma 1=-0.4$ & $\gamma 1=-0.2$ & $\gamma 1=0$ \\
\hline \multirow{3}{*}{ Classical } & g1 & 0.150 & 0.123 & 0.154 & 0.216 & 0.299 & 0.399 & 0.536 & 0.674 & 0.807 & 0.900 & .961 \\
\hline & G1 & 0.124 & 0.146 & 0.189 & 0.261 & 0.335 & 0.451 & 0.576 & 0.704 & 0.824 & 0.906 & 0.961 \\
\hline & $\mathrm{b} 1$ & 0.200 & 0.137 & 0.130 & 0.178 & 0.260 & 0.353 & 0.495 & 0.642 & 0.785 & 0.893 & 0.961 \\
\hline \multirow{3}{*}{$\begin{array}{c}\text { Bias } \\
\text { Corrected } \\
\text { standard }\end{array}$} & g1 & 0.127 & 0.114 & 0.120 & 0.148 & 0.192 & 0.246 & 0.345 & 0.469 & 0.606 & 0.757 & .884 \\
\hline & G1 & 0.118 & 0.118 & 0.138 & 0.166 & 0.213 & 0.274 & 0.382 & 0.489 & 0.623 & 0.766 & 0.884 \\
\hline & b1 & 161 & 0.124 & 114 & 32 & 0.167 & 0.219 & 0.309 & 0.432 & .581 & .736 & 882 \\
\hline \multirow{3}{*}{$\begin{array}{c}\text { Efron's } \\
\text { percentile } \\
\text { bootstrap }\end{array}$} & $\mathrm{g} 1$ & 0.042 & 0.017 & 0.007 & 0.005 & 0.023 & 0.123 & 0.318 & 0.582 & 0.805 & 0.925 & 0.982 \\
\hline & G1 & 0.021 & 0.010 & 0.005 & 0.010 & 0.059 & 0.179 & 0.396 & 0.639 & 0.825 & 0.932 & 0.984 \\
\hline & $\mathrm{b} 1$ & 0.075 & 0.034 & 0.014 & 0.004 & 0.011 & 0.072 & 0.244 & 0.515 & 0.771 & 0.917 & 0.984 \\
\hline \multirow{3}{*}{$\begin{array}{c}\text { Hall's } \\
\text { Percentile } \\
\text { bootstrap }\end{array}$} & g1 & 0.181 & 0.139 & 0.122 & 0.140 & 0.170 & 0.220 & 0.284 & 0.354 & 0.455 & 0.580 & 0.725 \\
\hline & G1 & 0.148 & 0.119 & 0.131 & 0.151 & 0.191 & 0.247 & 0.303 & 0.372 & 0.468 & .594 & 0.721 \\
\hline & $\mathrm{b} 1$ & 0.228 & 0.164 & 0.126 & 0.130 & 0.152 & 0.200 & 0.266 & 0.337 & 0.437 & 0.565 & 0.718 \\
\hline \multirow{4}{*}{$\begin{array}{c}\text { Bias }^{-} \\
\text {corrected } \\
\text { percentile }\end{array}$} & g1 & 0.058 & 0.082 & 0.125 & 0.177 & 0.244 & 0.381 & 0.542 & 0.721 & 0.862 & 0.951 & 0.988 \\
\hline & G1 & 0.077 & 0.112 & 0.157 & 0.211 & 0.299 & 0.446 & 0.597 & 0.758 & 0.877 & 0.954 & 0.989 \\
\hline & b1 & 0.060 & 0.061 & 0.099 & 0.147 & 0.204 & 0.315 & 0.491 & 0.683 & 0.841 & 0.944 & 0.988 \\
\hline & & $n=30$ & & & & & & & & & & \\
\hline (110u & Est & $\gamma 1=-2.0$ & $\gamma 1=-1.8$ & $\gamma 1=-1.6$ & $\gamma 1=-1.4$ & $\gamma 1=-1.2$ & $\gamma 1=-1.0$ & $\gamma 1=-0.8$ & $\gamma 1=-0.6$ & $\gamma 1=-0.4$ & $\gamma 1=-0.2$ & $\gamma 1=0$ \\
\hline \multirow{3}{*}{ Classical } & g1 & 0.146 & 0.147 & 0.203 & 0.296 & 0.427 & 0.575 & 0.728 & 0.861 & 0.943 & 0.983 & 0.998 \\
\hline & G1 & 0.141 & 0.169 & 0.237 & 0.334 & 0.472 & 0.616 & 0.763 & 0.877 & 0.948 & 0.984 & 0.998 \\
\hline & b1 & 0.164 & 0.141 & 0.174 & 0.254 & 0.382 & 0.537 & 0.698 & 0.843 & 0.935 & 0.983 & 0.998 \\
\hline \multirow{3}{*}{$\begin{array}{c}\text { Bias } \\
\text { Corrected } \\
\text { standard } \\
\end{array}$} & $\mathrm{g} 1$ & 0.090 & 0.076 & 0.079 & 0.117 & 0.194 & 0.300 & 0.446 & 0.647 & 0.829 & 0.957 & 0.994 \\
\hline & G1 & 0.081 & 0.078 & 0.093 & 0.139 & 0.228 & 0.332 & 0.481 & 0.671 & 0.848 & 0.959 & 0.995 \\
\hline & $\mathrm{b} 1$ & 0.110 & 0.078 & 0.075 & 0.100 & 0.168 & 0.277 & 0.414 & 0.617 & 0.815 & 0.950 & 0.997 \\
\hline \multirow{3}{*}{$\begin{array}{c}\text { Efron's } \\
\text { percentile } \\
\text { bootstrap }\end{array}$} & $\mathrm{g} 1$ & 0.032 & 0.013 & 0.016 & 0.060 & 0.188 & 0.411 & 0.672 & 0.868 & 0.964 & 0.996 & 1.000 \\
\hline & G1 & 0.020 & 0.008 & 0.024 & 0.093 & 0.243 & 0.479 & 0.716 & 0.895 & 0.970 & 0.997 & 1.000 \\
\hline & $\mathrm{b} 1$ & 0.048 & 0.020 & 0.007 & 0.037 & 0.135 & 0.345 & 0.615 & 0.846 & 0.958 & 0.996 & 1.000 \\
\hline \multirow{3}{*}{$\begin{array}{c}\text { Hall's } \\
\text { Percentile } \\
\text { bootstrap }\end{array}$} & g1 & 0.112 & 0.079 & 0.070 & 0.085 & 0.123 & 0.190 & 0.285 & 0.429 & 0.632 & 0.835 & 0.955 \\
\hline & G1 & 0.095 & 0.073 & 0.073 & 0.098 & 0.142 & 0.207 & 0.308 & 0.456 & 0.652 & 0.836 & 0.956 \\
\hline & $\mathrm{b} 1$ & 0.144 & 0.095 & 0.073 & 0.078 & 0.106 & 0.163 & 0.262 & 0.402 & 0.614 & 0.822 & 0.951 \\
\hline \multirow{3}{*}{$\begin{array}{c}\text { Bias }- \\
\text { corrected } \\
\text { percentile }\end{array}$} & g1 & 0.070 & 0.081 & 0.126 & 0.226 & 0.369 & 0.569 & 0.763 & 0.909 & 0.976 & 0.996 & 1.000 \\
\hline & G1 & 0.067 & 0.093 & 0.162 & 0.267 & 0.433 & 0.623 & 0.801 & 0.925 & 0.978 & 0.998 & 1.000 \\
\hline & b1 & 0.071 & 0.070 & 0.099 & 0.184 & 0.321 & 0.516 & 0.728 & 0.892 & 0.971 & 0.997 & 1.000 \\
\hline
\end{tabular}


Table A6 (Continued)

\begin{tabular}{|c|c|c|c|c|c|c|c|c|c|c|c|c|}
\hline & & $n=50$ & & & & & & & & & & \\
\hline Sthol & st & $1=-2.0$ & $\gamma 1=-1.8$ & $\gamma 1=-1.6$ & $\gamma 1=-1.4$ & $\gamma 1=-1.2$ & $\gamma 1=-1.0$ & $\gamma 1=-0.8$ & $\gamma 1=-0.6$ & $\gamma 1=-0.4$ & $\gamma 1=-0.2$ & $\gamma 1=0$ \\
\hline \multirow{3}{*}{ Classical } & g1 & 0.147 & 0.167 & 0.257 & 0.391 & 0.576 & 0.762 & 0.901 & 0.968 & 0.995 & 1.000 & 1.000 \\
\hline & G1 & .144 & 0.183 & 0.286 & 0.430 & 0.617 & 0.784 & 0.913 & 0.973 & .995 & 1.000 & 1.000 \\
\hline & $\mathrm{b} 1$ & 162 & 155 & 0.231 & 0.360 & 0.536 & 0.743 & .884 & 0.965 & .994 & 1.000 & 1.000 \\
\hline \multirow{3}{*}{$\begin{array}{c}\text { Bias } \\
\text { Corrected } \\
\text { standard } \\
\end{array}$} & g1 & 0.067 & 0.048 & 0.070 & 0.144 & 0.273 & 0.509 & 0.765 & 0.944 & 0.994 & 1.000 & 1.000 \\
\hline & G1 & 0.061 & 0.053 & 0.084 & 0.162 & 0.314 & 0.547 & 0.802 & 0.952 & .997 & 1.000 & 1.000 \\
\hline & b1 & .078 & 0.049 & 0.061 & 0.112 & 0.242 & 0.477 & 0.734 & 0.935 & 0.995 & 1.000 & 1.000 \\
\hline \multirow{3}{*}{$\begin{array}{c}\text { Efron's } \\
\text { percentile } \\
\text { bootstrap }\end{array}$} & g1 & 0.037 & 0.030 & \begin{tabular}{|l|}
0.076 \\
\end{tabular} & 0.224 & 0.448 & 0.726 & 0.917 & 0.983 & 0.999 & 1.000 & 1.000 \\
\hline & G1 & \begin{tabular}{|l|}
0.033 \\
\end{tabular} & 0.038 & 0.101 & 0.262 & 0.493 & 0.762 & 0.926 & 0.987 & 0.999 & 1.000 & 1.000 \\
\hline & b1 & 0.047 & 0.029 & \begin{tabular}{l|l}
0.056 \\
\end{tabular} & 0.183 & 0.401 & 0.689 & 0.895 & 0.980 & 0.999 & 1.000 & 1.000 \\
\hline \multirow{3}{*}{$\begin{array}{c}\text { Hall's } \\
\text { Percentile } \\
\text { bootstrap }\end{array}$} & g1 & 0.085 & 0.045 & 0.036 & 0.068 & 0.150 & 0.315 & 0.589 & 0.864 & 0.980 & 1.000 & 1.000 \\
\hline & G1 & 0.066 & 0.038 & 0.045 & 0.081 & 0.177 & 0.348 & 0.628 & 0.879 & 0.987 & 0.999 & 0.999 \\
\hline & b1 & 0.112 & 0.052 & 0.036 & 0.056 & 0.128 & 0.277 & 0.551 & 0.832 & 0.978 & 0.999 & .000 \\
\hline \multirow{4}{*}{$\begin{array}{c}\text { Bias }^{-} \\
\text {corrected } \\
\text { percentile } \\
\end{array}$} & $\mathrm{g} 1$ & 0.060 & 0.083 & 0.169 & 0.329 & 0.547 & 0.783 & 0.932 & 0.989 & 1.000 & 1.000 & 1.000 \\
\hline & G1 & 0.063 & 0.103 & 0.201 & 0.370 & 0.599 & 0.810 & 0.943 & 0.990 & 1.000 & 1.000 & 1.000 \\
\hline & b1 & 0.062 & 0.070 & 142 & 39 & 0.504 & 750 & 916 & 86 & 99 & 1.000 & .000 \\
\hline & & $n=100$ & & & & & & & & & & \\
\hline & st & $\gamma 1=-2.0$ & $=-1.8$ & $=-1.6$ & $=-1.4$ & $\gamma 1=-1.2$ & $\gamma 1=-1.0$ & $\gamma 1=-0.8$ & $\gamma 1=-0.6$ & $\gamma 1=-0.4$ & $\gamma 1=-0.2$ & $\gamma 1=0$ \\
\hline \multirow{3}{*}{ Classical } & $\mathrm{g} 1$ & 0.133 & 0.183 & 0.387 & 0.650 & 0.859 & 0.965 & 0.978 & 1.000 & 1.000 & 1.000 & 1.000 \\
\hline & G1 & 0.134 & 0.204 & 0.414 & 0.678 & 0.870 & 0.970 & 0.988 & 1.000 & 1.000 & 1.000 & 1.000 \\
\hline & b1 & \begin{tabular}{|l|}
0.142 \\
\end{tabular} & 0.173 & 0.357 & 0.624 & 0.845 & 0.960 & 0.965 & 1.000 & 1.000 & 1.000 & 1.000 \\
\hline \multirow{3}{*}{$\begin{array}{c}\text { Bias } \\
\text { Corrected } \\
\text { standard } \\
\end{array}$} & $\mathrm{g} 1$ & 0.057 & 0.045 & \begin{tabular}{|l|}
0.133 \\
\end{tabular} & 0.383 & 0.733 & 0.938 & 0.944 & 1.000 & 1.000 & 1.000 & 1.000 \\
\hline & G1 & 0.048 & 0.048 & 0.148 & 14 & 0.753 & 951 & 965 & 1.000 & 000 & 1.000 & 1.000 \\
\hline & b1 & 0.066 & 0.042 & 0.114 & 0.349 & 0.703 & 0.931 & 0.954 & 1.000 & 1.000 & 1.000 & 1.000 \\
\hline \multirow{3}{*}{$\begin{array}{l}\text { Efron's } \\
\text { percentile } \\
\text { bootstrap }\end{array}$} & g1 & & & & & & 0.5 & 3 & & & & 00 \\
\hline & G1 & 0.045 & 0.083 & 0.254 & 0.575 & 0.849 & 0.973 & 0.988 & 1.000 & 1.000 & 1.000 & 1.000 \\
\hline & b1 & 0.054 & 0.065 & 0.187 & 0.489 & 0.812 & 0.964 & 0.993 & 1.000 & .000 & 1.000 & 1.000 \\
\hline \multirow{3}{*}{$\begin{array}{c}\text { Hall's } \\
\text { Percentile } \\
\text { bootstrap }\end{array}$} & g1 & 0.065 & 0.031 & 0.066 & 0.238 & 0.609 & 0.902 & 0.997 & 1.000 & 1.000 & 1.000 & 1.000 \\
\hline & G1 & 0.059 & 0.030 & 0.083 & 0.279 & 0.643 & 0.916 & 0.965 & 1.000 & 1.000 & 1.000 & 1.000 \\
\hline & b1 & 077 & 0.034 & 0.059 & 0.218 & 0.579 & 0.886 & 0.976 & 1.000 & 1.000 & 1.000 & 1.000 \\
\hline \multirow{4}{*}{$\begin{array}{c}\text { Bias }^{-} \\
\text {corrected } \\
\text { percentile }\end{array}$} & g1 & 0.053 & 0.098 & 0.281 & 99 & 0.861 & 0.976 & 0.998 & 1.000 & 1.000 & 1.000 & 1.000 \\
\hline & G1 & 0.056 & 0.115 & 0.316 & 0.630 & 0.875 & 0.976 & 0.995 & 1.000 & 1.000 & 1.000 & 1.000 \\
\hline & b1 & 0.057 & 0,088 & 251 & 560 & 0.845 & & 0.996 & 1.000 & 1.000 & 1.000 & 1.000 \\
\hline & & $n=300$ & & & & & & & & & & \\
\hline $\bar{y}$ & Est & $\gamma 1=-2.0$ & $\gamma 1=-1.8$ & $1=-1.6$ & $=-1.4$ & $\gamma 1=-1.2$ & $\gamma 1=-1.0$ & $\gamma 1=-0.8$ & $\gamma 1=-0.6$ & $\gamma 1=-0.4$ & $\gamma 1=-0.2$ & $\gamma 1=0$ \\
\hline \multirow{3}{*}{ Classical } & g1 & 0.154 & 0.335 & 0.739 & 0.966 & 1.000 & 1.000 & 1.000 & 1.000 & 1.000 & 1.000 & 1.000 \\
\hline & G1 & 0.152 & 0.348 & 0.754 & 0.969 & 1.000 & 1.000 & 1.000 & 1.000 & 1.000 & 1.000 & 1.000 \\
\hline & b1 & 0.152 & 0.317 & 0.724 & 0.965 & 1.000 & 1.000 & 1.000 & 1.000 & 1.000 & 1.000 & 1.000 \\
\hline \multirow{3}{*}{$\begin{array}{c}\text { Bias } \\
\text { Corrected } \\
\text { standard }\end{array}$} & $\mathrm{g} 1$ & 0.060 & 0.154 & 0.567 & 0.935 & 1.000 & 1.000 & 1.000 & 1.000 & 1.000 & 1.000 & 1.000 \\
\hline & G1 & 0.058 & 0.166 & 0.583 & 0.944 & 0.999 & 1.000 & 1.000 & 1.000 & 1.000 & 1.000 & 1.000 \\
\hline & b1 & 0.063 & 0.148 & 0.551 & 0.927 & 0.999 & 1.000 & 1.000 & 1.000 & 1.000 & 1.000 & 1.000 \\
\hline \multirow{3}{*}{$\begin{array}{l}\text { Efron's } \\
\text { percentile } \\
\text { bootstrap }\end{array}$} & g1 & 0.059 & 0.200 & 0.642 & 0.957 & 1.000 & 1.000 & 1.000 & 1.000 & 1.000 & 1.000 & 1.000 \\
\hline & G1 & 0.063 & 0.208 & 0.657 & 0.959 & 1.000 & 1.000 & 1.000 & 1.000 & 1.000 & 1.000 & 1.000 \\
\hline & b1 & 0.059 & 0.189 & 0.622 & 0.951 & 1.000 & 1.000 & 1.000 & 1.000 & 1.000 & 1.000 & 1.000 \\
\hline \multirow{3}{*}{$\begin{array}{c}\text { Hall's } \\
\text { Percentile } \\
\text { bootstrap }\end{array}$} & g1 & 0.060 & 0.119 & 0.508 & 0.917 & 0.999 & 1.000 & 1.000 & 1.000 & 1.000 & 1.000 & 1.000 \\
\hline & G1 & 0.058 & 0.129 & 0.528 & 0.926 & 0.999 & 1.000 & 1.000 & 1.000 & 1.000 & 1.000 & 1.000 \\
\hline & b1 & 0.068 & 0.109 & 0.485 & 0.909 & 0.999 & 1.000 & 1.000 & 1.000 & 1.000 & 1.000 & 1.000 \\
\hline \multirow{3}{*}{$\begin{array}{c}\text { Bias }^{-} \\
\text {corrected } \\
\text { percentile }\end{array}$} & g1 & 0.063 & 0.225 & 0.669 & 0.964 & 1.000 & 1.000 & 1.000 & 1.000 & 1.000 & 1.000 & 1.000 \\
\hline & G1 & 0.063 & 0.238 & 0.687 & 0.964 & 1.000 & 1.000 & 1.000 & 1.000 & 1.000 & 1.000 & 1.000 \\
\hline & b1 & 0.061 & 0.210 & 0.649 & 0.959 & 1.000 & 1.000 & 1.000 & 1.000 & 1.000 & 1.000 & 1.000 \\
\hline
\end{tabular}


Table A7: Power for $\mathrm{N}(0,1)$ with kurtosis $=0$ against with other value for different sample size

\begin{tabular}{|c|c|c|c|c|c|c|c|c|c|c|c|c|c|c|c|c|c|}
\hline & & & & & & & & & & & & & & & & & \\
\hline & & & & & & 8 & 1.0 & 2 & & & & 2.0 & 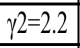 & & & .0. & \\
\hline \multirow{3}{*}{ Classical } & & & & 035 & 078 & & 27 & & & & & 03 & & & 25 & 44 & \\
\hline & G1 & 35 & 030 & 025 & 022 & 200 & 023 & 38 & 79 & 18 & 179 & 251 & 332 & 404 & 474 & 543 & 0 \\
\hline & b1 & 886 & 124 & 244 & 399 & 549 & 671 & 773 & 99 & 894 & 928 & 950 & 964 & 973 & 981 & 986 & \\
\hline \multirow{3}{*}{$\begin{array}{c}\text { Bias } \\
\text { Corrected } \\
\text { standard }\end{array}$} & & 61 & 098 & 160 & 219 & 289 & .357 & 25 & & 554 & 605 & 50 & 97 & 728 & 765 & 801 & 827 \\
\hline & G1 & 056 & 79 & 13 & 47 & 82 & 17 & 47 & 04 & 27 & 9 & 07 & 443 & 79 & 12 & 42 & \\
\hline & $b 1$ & 064 & 112 & 187 & 269 & 358 & 439 & 519 & 577 & 644 & 699 & 743 & 782 & 824 & 853 & 880 & 00 \\
\hline \multirow{3}{*}{$\begin{array}{c}\text { Efron's } \\
\text { percentile } \\
\text { bootstrap }\end{array}$} & $\overline{g 1}$ & 00 & 002 & 28 & & 171 & 264 & 57 & & 19 & 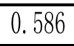 & 655 & 714 & 761 & 805 & 843 & 885 \\
\hline & $\mathrm{Gl}$ & 000 & 000 & 000 & 000 & 000 & 0.000 & 000 & 058 & .016 & .048 & 085 & 132 & 183 & 234 & 287 & - \\
\hline & b1 & 126 & 243 & & & 554 & 000 & 11 & 800 & 82 & .872 & 99 & 37 & 57 & 978 & 987 & t \\
\hline \multirow{3}{*}{$\begin{array}{c}\text { Hall's } \\
\text { Percentile } \\
\text { bootstrap } \\
\end{array}$} & $\mathrm{g} 1$ & 96 & & & & 23 & 389 & & & & & 80 & 26 & 62 & 92 & 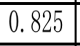 & \\
\hline & G1 & 235 & 272 & 310 & 351 & 388 & 0.430 & 467 & 502 & .540 & 568 & 598 & 628 & 654 & 684 & 711 & 100 \\
\hline & b1 & 125 & 886 & 78 & 01 & 153 & 228 & & & & & 621 & . & & 778 & 818 & \\
\hline \multirow{4}{*}{$\begin{array}{c}\text { Bias } \\
\text { Corrected } \\
\text { percentile }\end{array}$} & $\mathrm{g} 1$ & 099 & 124 & 152 & 184 & 214 & 0.242 & 282 & 02 & 50 & 91 & 428 & 466 & 06 & 47 & 35 & Us \\
\hline & G1 & 038 & 046 & 054 & 070 & 084 & 0.098 & 114 & 23 & .149 & 0.163 & 179 & 197 & 215 & 229 & 46 & 210 \\
\hline & $b 1$ & 199 & 242 & & & 372 & 421 & & & & & & 720 & & & & \\
\hline & & & & & & & & & & & & & & & & & \\
\hline & & $=0$ & & & & $=0.8$ & $2=1.0$ & 1.2 & & & & 2.0 & 2.2 & 2.4 & 2.0 & $=2.8$ & J.0 \\
\hline \multirow{3}{*}{ Classical } & 0. & & & & & & & & & & & & & & & & \\
\hline & $\mathrm{Gl}$ & 031 & 0.026 & 024 & 021 & .022 & 0.040 & 0.098 & 175 & 0.280 & 0.389 & .487 & 0.582 & 0.659 & .732 & .784 & 83 \\
\hline & b1 & 59 & 46 & & & 336 & 0.474 & 06 & & 795 & & 97 & 26 & t5 & 05 & 72 & \\
\hline \multirow{3}{*}{$\begin{array}{c}\text { Bias } \\
\text { Corrected } \\
\text { standard }\end{array}$} & gl & 9 & 0.171 & 249 & 23 & 0.397 & 50 & 24 & 32 & 29 & 0.681 & 27 & & 96 & 84 & 47 & \\
\hline & G1 & 122 & 160 & 212 & 270 & 324 & 0.380 & 134 & 488 & .530 & 0.574 & 614 & 655 & 0.691 & .721 & 752 & 777 \\
\hline & b1 & 23 & & & & & & & & & & & & & & & \\
\hline \multirow{3}{*}{\begin{tabular}{|c|} 
Efron's \\
percentile \\
bootstrap
\end{tabular}} & $\mathrm{g} 1$ & 665 & 126 & 209 & 290 & 374 & 0.447 & .521 & 592 & 6 & 0.65 & 744 & 0.784 & 0.814 & .842 & 873 & 89 \\
\hline & $\mathrm{Gl}$ & 13 & 039 & 073 & 117 & 175 & 0.238 & 305 & 371 & 427 & 0.487 & 537 & .591 & .637 & 675 & 08 & 740 \\
\hline & $\mathrm{bl}$ & & & & & & & & & & & & & & & & \\
\hline \multirow{3}{*}{\begin{tabular}{|c|} 
Hall's \\
Percentile \\
bootstrap
\end{tabular}} & $\mathrm{g} 1$ & 115 & 171 & 252 & 332 & 409 & 0.48 & 560 & 15 & 0.6 & $\overline{0.7}$ & 0.764 & .7 & 0.829 & .855 & .877 & 89 \\
\hline & G1 & 199 & 271 & 328 & 393 & 450 & 0.506 & 558 & 604 & 651 & 0.689 & 726 & 760 & 0.783 & 809 & 832 & $853^{3}$ \\
\hline & b1 & 56 & 0.089 & 48 & 226 & 318 & 0.4 & 1 & & .02 & .0 & 2 & 0.783 & 0.81 & & 5 & 89 \\
\hline \multirow{4}{*}{\begin{tabular}{|c|} 
Bias \\
Corrected \\
percentile
\end{tabular}} & $\mathrm{g} 1$ & 05 & 32 & 183 & 234 & 289 & 0.3 & 34 & 6 & 473 & 0.507 & 53 & 592 & 0.623 & 656 & 80 & .712 \\
\hline & G1 & 81 & & & & & & & & & 360 & 390 & 450 & & & & 553 \\
\hline & b1 & 164 & 213 & 275 & 020 & 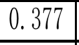 & & & & & & 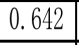 & & & & & 070 \\
\hline & & & & & & & & & & & & & & & & & \\
\hline & l & & $=0.2$ & $=0.4$ & 6 & $=0.8$ & $\gamma 2=1.0$ & .2 & .4 & .0 & $\frac{10}{0}$ & $=2.0$ & 2 & -2.4 & -2.0 & -2.0 & 0.0 \\
\hline \multirow{3}{*}{ Classical } & 81 & 6 & 001 & 41 & 099 & 198 & 0.344 & 493 & 619 & 718 & $\overline{7 c}$ & 851 & 890 & .923 & .946 & 960 & 968 \\
\hline & G1 & 035 & 0.030 & 026 & 026 & 051 & 0.129 & 0.217 & 348 & 477 & 0.581 & 671 & 755 & 0.810 & 853 & 0.887 & 914 \\
\hline & $b 1$ & 4 & 042 & 013 & 171 & 312 & 0.473 & .610 & 18 & .801 & .8 & 897 & 0.930 & .951 & .966 & 0.973 & .97 \\
\hline \multirow{3}{*}{\begin{tabular}{c|} 
Bias \\
Corrected \\
standard \\
\cline { 2 - 3 }
\end{tabular}} & $\mathrm{g} 1$ & & 197 & 278 & 256 & 450 & 0.522 & .591 & 46 & 0.704 & 0.750 & 784 & 812 & 0.837 & 860 & 881 & 898 \\
\hline & $\mathrm{Gl}$ & 42 & 0 & 257 & 327 & 400 & 0.466 & 0.527 & 584 & 35 & 0.683 & 0.722 & 759 & 0.791 & 0.812 & 833 & \\
\hline & b1 & 100 & 201 & 291 & 390 & 471 & 0.550 & 616 & 011 & .228 & 0.1 & 801 & 0.8 & 851 & 0.879 & 896 & .91 \\
\hline \multirow{3}{*}{\begin{tabular}{|c|} 
Efron's \\
percentile \\
bootstrap \\
\end{tabular}} & $\mathrm{g} 1$ & 108 & .174 & 259 & 362 & 0.455 & 0.531 & 316 & 680 & 0.735 & 0.779 & 813 & 0.842 & 0.874 & 896 & 917 & .929 \\
\hline & G1 & 049 & 0.103 & 0.152 & 223 & 0.302 & 0.383 & 0.455 & 525 & .595 & 0.652 & 0.701 & 0.750 & 0.786 & 0.815 & 0.839 & 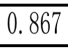 \\
\hline & $\mathrm{b1}$ & 81 & .279 & 383 & 476 & 0.00 & 0.64 & 0.707 & 764 & 0.801 & $\pi$ & 67 & 0.891 & 0.914 & .931 & 941 & .952 \\
\hline \multirow{3}{*}{\begin{tabular}{|c|} 
Hall's \\
Percentile \\
bootstrap \\
\end{tabular}} & $\mathrm{g} 1$ & 33 & 0.197 & 282 & 380 & 0.467 & 0.542 & 5 & 672 & 0.732 & 0.772 & 0.805 & 0.837 & 0.863 & 0.883 & 0.899 & .011 \\
\hline & G1 & 195 & 0.265 & 0.348 & 0.424 & 0.492 & 0.560 & 0.613 & 0.664 & 0.716 & 0.757 & 0.785 & 0.810 & 0.838 & 0.860 & 0.879 & 0.89 \\
\hline & $b 1$ & 076 & 0.137 & 0.200 & 0.299 & 0.401 & 0.491 & 0.576 & 0.641 & 0.705 & 407 & 0.796 & 0.826 & 0.857 & .883 & 0.900 & 0.91 \\
\hline \multirow{3}{*}{\begin{tabular}{|c|} 
Bias \\
Corrected \\
percentile
\end{tabular}} & $\mathrm{g} 1$ & 117 & 0.157 & 0.210 & 0.276 & 0.341 & 0.403 & 0.465 & 0.523 & 0.571 & 0.624 & 0.668 & 0.702 & 0.737 & 0.765 & 794 & 0.817 \\
\hline & $\mathrm{Gl}$ & 088 & 0.110 & 0.145 & 0.184 & 0.232 & 0.290 & 0.344 & 0.399 & 0.452 & 0.500 & 0.549 & 0.592 & 0.631 & 0.664 & 0.698 & 0.731 \\
\hline & b1 & 156 & .217 & 285 & 357 & 423 & 0.491 & .547 & 0.599 & 651 & .697 & 0.734 & 0.765 & 0.790 & .814 & 0.835 & 0.857 \\
\hline
\end{tabular}


Table A7 (Continued)

\begin{tabular}{|c|c|c|c|c|c|c|c|c|c|c|c|c|c|c|c|c|c|}
\hline & & $n=50$ & & & & & & & & & & & & & & & \\
\hline Method & Est & $\gamma_{2}=0$ & $=0.2$ & $\gamma 2=0.4$ & $\gamma 2=0.6$ & $\gamma 2=0.8$ & $=1.0$ & $\gamma 2=1.2$ & $\gamma 2=1.4$ & $\gamma 2=1.6$ & $\gamma 2=1.8$ & $\gamma 2=2.0$ & $\gamma 2=2.2$ & $\gamma 2=2.4$ & $\gamma 2=2.6$ & $\gamma 2=2.8$ & $\gamma 2=3.0$ \\
\hline \multirow{3}{*}{ Classical } & $\mathrm{g} 1$ & 0.050 & 0.040 & 0.067 & 0.155 & 0.296 & 0.469 & 0.606 & 0.727 & \begin{tabular}{|l|}
0.816 \\
\end{tabular} & \begin{tabular}{|l|}
0.877 \\
\end{tabular} & 0.911 & 0.941 & 0.958 & 0.972 & 0.980 & 0.985 \\
\hline & G1 & 0.040 & 0.031 & 0.033 & 0.078 & 0.162 & 0.297 & 0.452 & 0.585 & 0.696 & \begin{tabular}{|l|}
0.788 \\
\end{tabular} & 0.850 & 0.896 & 0.921 & 0.944 & 0.960 & 0.971 \\
\hline & b1 & 0.054 & 0.047 & 0.094 & 0.205 & 0.373 & 0.534 & 0.671 & 0.780 & 0.852 & \begin{tabular}{|l|}
0.904 \\
\end{tabular} & 0.932 & 0.952 & 0.967 & 0.979 & 0.984 & 0.990 \\
\hline \multirow{3}{*}{$\begin{array}{c}\text { Bias } \\
\text { Corrected } \\
\text { standard }\end{array}$} & $\mathrm{g} 1$ & 0.147 & 0.225 & 0.324 & 0.426 & 0.512 & 0.595 & 0.662 & \begin{tabular}{|l|}
0.724 \\
\end{tabular} & \begin{tabular}{|l|}
0.780 \\
\end{tabular} & \begin{tabular}{|l|}
0.822 \\
\end{tabular} & 0.851 & 0.882 & 0.901 & 0.918 & 0.928 & 0.938 \\
\hline & G1 & 0.145 & 0.216 & 0.302 & 0.396 & 0.481 & 0.554 & 0.629 & \begin{tabular}{|l|}
0.686 \\
\end{tabular} & \begin{tabular}{|l|}
0.739 \\
\end{tabular} & \begin{tabular}{|l|}
0.783 \\
\end{tabular} & 0.823 & 0.851 & 0.877 & 0.897 & 0.911 & 0.924 \\
\hline & b1 & 0.147 & 0.226 & 0.332 & 0.433 & 0.523 & 0.611 & 0.679 & 0.739 & \begin{tabular}{|l|}
0.794 \\
\end{tabular} & \begin{tabular}{|l|}
0.833 \\
\end{tabular} & 0.869 & 0.890 & 0.909 & 0.924 & 0.935 & 0.944 \\
\hline \multirow{3}{*}{$\begin{array}{c}\text { Efron's } \\
\text { percentile } \\
\text { bootstrap }\end{array}$} & $\mathrm{g} 1$ & 0.129 & 0.223 & 0.333 & 0.443 & 0.538 & 0.624 & 0.702 & \begin{tabular}{|l|}
0.767 \\
\end{tabular} & \begin{tabular}{|l|}
0.816 \\
\end{tabular} & \begin{tabular}{|l|}
0.861 \\
\end{tabular} & 0.892 & 0.910 & 0.928 & 0.945 & 0.954 & 0.963 \\
\hline & G1 & 0.084 & 0.155 & 0.244 & 0.347 & 0.439 & 0.533 & 0.610 & 0.686 & 0.746 & \begin{tabular}{|l|}
0.797 \\
\end{tabular} & 0.838 & 0.873 & 0.897 & 0.912 & 0.931 & 0.942 \\
\hline & b1 & 0.186 & 0.292 & 0.412 & 0.514 & 0.607 & 0.693 & 0.760 & 0.816 & 0.860 & 0.890 & 0.911 & 0.929 & 0.945 & 0.957 & 0.966 & 0.974 \\
\hline \multirow{3}{*}{$\begin{array}{c}\text { Hall's } \\
\text { Percentile } \\
\text { bootstrap }\end{array}$} & $\mathrm{g} 1$ & 0.137 & 0.221 & 0.325 & 0.435 & 0.529 & 0.612 & 0.683 & \begin{tabular}{|l|}
0.746 \\
\end{tabular} & \begin{tabular}{|l|}
0.798 \\
\end{tabular} & \begin{tabular}{|l|}
0.838 \\
\end{tabular} & 0.872 & 0.895 & 0.910 & 0.924 & 0.935 & 0.948 \\
\hline & G1 & 0.181 & 0.271 & 0.374 & 0.462 & 0.546 & 0.620 & 0.683 & 0.741 & 0.790 & \begin{tabular}{|l|}
0.827 \\
\end{tabular} & 0.858 & 0.883 & 0.905 & 0.917 & 0.926 & 0.938 \\
\hline & $\mathrm{bl}$ & 0.109 & 0.171 & 0.263 & 0.389 & 0.486 & 0.576 & 0.659 & 0.727 & 0.784 & 0.828 & 0.865 & 0.891 & 0.909 & 0.923 & 0.935 & 0.949 \\
\hline \multirow{4}{*}{$\begin{array}{c}\text { Bias } \\
\text { Corrected } \\
\text { percentile }\end{array}$} & $\mathrm{g} 1$ & 0.122 & 0.184 & 0.260 & 0.349 & 0.436 & 0.509 & 0.577 & \begin{tabular}{|l|}
0.651 \\
\end{tabular} & \begin{tabular}{|l|}
0.701 \\
\end{tabular} & \begin{tabular}{|l|}
0.753 \\
\end{tabular} & 0.797 & 0.830 & 0.858 & 0.881 & 0.902 & 0.918 \\
\hline & $\mathrm{Gl}$ & 0.104 & 0.139 & 0.196 & 0.272 & 0.352 & 0.431 & 0.493 & 0.563 & 0.620 & 0.676 & 0.721 & 0.770 & 0.801 & 0.836 & 0.862 & 0.882 \\
\hline & $\mathrm{bl}$ & 0.155 & 0.236 & 0.321 & 0.415 & 0.491 & 0.569 & 0.636 & 0.696 & 0.749 & \begin{tabular}{|l|}
0.794 \\
\end{tabular} & 0.829 & 0.859 & 0.883 & 0.905 & 0.921 & 0.933 \\
\hline & & $n=100$ & & & & & & & & & & & & & & & \\
\hline od & Est & $\gamma_{2}=0$ & $=0.2$ & $\gamma 2=0.4$ & $\gamma 2=0.6$ & $\gamma 2=0.8$ & $\gamma 2=1.0$ & $\gamma 2=1.2$ & $\gamma 2=1.4$ & $\gamma 2=1.6$ & $\gamma 2=1.8$ & $\gamma 2=2.0$ & $\gamma 2=2.2$ & $\gamma 2=2.4$ & $\gamma_{2}=2.6$ & $\gamma 2=2.8$ & $\gamma 2=3.0$ \\
\hline \multirow{3}{*}{ Classical } & $\mathrm{g} 1$ & 0.052 & 0.050 & 0.127 & 0.287 & 0.477 & 0.653 & 0.788 & 0.878 & 0.923 & 0.954 & 0.973 & 0.981 & 0.988 & 0.993 & 0.996 & 0.997 \\
\hline & G1 & 0.047 & 0.039 & 0.089 & 0.219 & 0.396 & 0.578 & 0.728 & \begin{tabular}{|l|}
0.838 \\
\end{tabular} & \begin{tabular}{|l|}
0.898 \\
\end{tabular} & \begin{tabular}{|l|}
0.937 \\
\end{tabular} & 0.959 & \begin{tabular}{|l|}
0.974 \\
\end{tabular} & \begin{tabular}{|l|}
0.984 \\
\end{tabular} & \begin{tabular}{|l|}
0.990 \\
\end{tabular} & 0.993 & 0.996 \\
\hline & b1 & 0.054 & 0.055 & 0.143 & 0.313 & 0.510 & 0.687 & 0.813 & 0.891 & 0.934 & 0.958 & 0.974 & 0.985 & 0.990 & 0.994 & 0.996 & 0.997 \\
\hline \multirow{3}{*}{$\begin{array}{c}\text { Bias } \\
\text { Corrected } \\
\text { standard }\end{array}$} & $\mathrm{g} 1$ & 0.136 & 0.228 & 0.353 & 0.481 & 0.606 & 0.696 & 0.774 & \begin{tabular}{|l|}
0.827 \\
\end{tabular} & \begin{tabular}{|l|}
0.871 \\
\end{tabular} & \begin{tabular}{|l|}
0.903 \\
\end{tabular} & 0.924 & 0.942 & 0.955 & \begin{tabular}{|l|}
0.964 \\
\end{tabular} & 0.970 & 0.975 \\
\hline & G1 & 0.137 & 0.223 & 0.346 & 0.459 & 0.581 & 0.675 & 0.751 & \begin{tabular}{|l|}
0.813 \\
\end{tabular} & \begin{tabular}{|l|}
0.859 \\
\end{tabular} & \begin{tabular}{|l|}
0.890 \\
\end{tabular} & 0.914 & 0.932 & \begin{tabular}{|l|}
0.948 \\
\end{tabular} & 0.957 & 0.965 & 0.973 \\
\hline & b1 & 0. & 0.234 & 0.359 & 0.493 & 0.611 & 0.705 & 0.785 & 0.838 & 0.874 & 0.908 & 0.928 & 0.945 & 0.958 & 0.966 & 0.972 & 0.976 \\
\hline \multirow{3}{*}{\begin{tabular}{|c|} 
Efron's \\
percentile \\
bootstrap
\end{tabular}} & $\mathrm{g} 1$ & 0.129 & 0.237 & 0.377 & 0.517 & 0.631 & 0.730 & 0.811 & 0.860 & 0.899 & 0.926 & 0.945 & 0.961 & 0.970 & 0.978 & 0.982 & 0.987 \\
\hline & G1 & 0.104 & 0.191 & 0.327 & 0.453 & 0.579 & 0.683 & 0.769 & 0.829 & 0.873 & \begin{tabular}{|l|}
0.907 \\
\end{tabular} & 0.930 & 0.948 & 0.964 & 0.971 & 0.977 & 0.982 \\
\hline & $\mathrm{bl}$ & 0. & 84 & 0. & 63 & 0.678 & 67 & 33 & 80 & 0.913 & 0.936 & 0.954 & 0.966 & 0.975 & 0.981 & 0.985 & 0.990 \\
\hline \multirow{3}{*}{\begin{tabular}{|c|} 
Hall's \\
Percentile \\
bootstrap
\end{tabular}} & $\mathrm{g} 1$ & 0.134 & 0.235 & 0.364 & 0.494 & 0.618 & 0.713 & 0.793 & 0.844 & 0.881 & 0.913 & 0.932 & 0.946 & 0.961 & \begin{tabular}{|c|}
0.969 \\
\end{tabular} & 0.975 & 0.980 \\
\hline & $\mathrm{Gl}$ & 0.161 & 0.265 & 0.394 & 0.517 & 0.629 & 0.719 & 0.792 & 0.843 & 0.880 & \begin{tabular}{|l|}
0.912 \\
\end{tabular} & 0.929 & 0.945 & 0.958 & 0.966 & 0.973 & 0.977 \\
\hline & $\mathrm{bl}$ & 0.111 & 203 & 0.332 & 0.463 & 0.593 & 0.694 & 0.777 & 38 & 0.878 & 0.911 & 0.931 & 0.946 & 0.960 & 0.968 & 0.974 & 0.980 \\
\hline \multirow{4}{*}{\begin{tabular}{|c|} 
Bias \\
Corrected \\
percentile \\
\cline { 2 - 2 }
\end{tabular}} & $\mathrm{gl}$ & 0.119 & 0.199 & 0.312 & 0.425 & 0.550 & 0.644 & 0.732 & 0.795 & 0.846 & 0.885 & 0.911 & 0.932 & 0.948 & 0.961 & 0.971 & 0.976 \\
\hline & G1 & 0.097 & 0.163 & 0.264 & 0.375 & 0.490 & 0.595 & 0.683 & 0.757 & 0.811 & 0.857 & 0.891 & 0.916 & 0.934 & 0.948 & 0.960 & 0.968 \\
\hline & $\mathrm{bl}$ & 0.134 & 0.231 & 0.349 & 0.469 & 0.584 & 0.683 & 0.763 & 0.819 & 0.867 & 0.902 & 0.924 & 0.941 & 0.957 & 0.966 & 0.975 & 0.981 \\
\hline & & $\mathrm{n}=300$ & & & & & & & & & & & & & & & \\
\hline Method & Est & $\gamma 2=0$ & $\gamma_{2}=0.2$ & $\gamma 2=0.4$ & $\gamma 2=0.6$ & $\gamma 2=0.8$ & $\gamma 2=1.0$ & $\gamma 2=1.2$ & $\gamma 2=1.4$ & $\gamma 2=1.6$ & $\gamma 2=1.8$ & $\gamma 2=2.0$ & $\gamma 2=2.2$ & $\gamma_{2}=2.4$ & $\gamma_{2}=2.6$ & $\gamma_{2}=2.8$ & $\gamma 2=3.0$ \\
\hline \multirow{3}{*}{ Classical } & $\mathrm{g} 1$ & 0.045 & 0.091 & 0.325 & 0.631 & 0.840 & 0.945 & 0.984 & 0.993 & 0.995 & \begin{tabular}{|l|}
0.999 \\
\end{tabular} & 1.000 & 1.000 & 1.000 & 1.000 & 1.000 & 1.000 \\
\hline & G1 & 0.042 & 0.085 & 0.303 & 0.604 & 0.821 & 0.939 & 0.980 & 0.992 & 0.995 & 0.999 & 1.000 & 1.000 & 1.000 & 1.000 & 1.000 & 1.000 \\
\hline & b1 & 0.046 & 0.094 & 0.336 & 0.639 & 0.847 & 0.950 & 0.985 & \begin{tabular}{|l|}
0.993 \\
\end{tabular} & \begin{tabular}{|l|}
0.996 \\
\end{tabular} & \begin{tabular}{|l|}
0.999 \\
\end{tabular} & 1.000 & 1.000 & \begin{tabular}{|l|}
1.000 \\
\end{tabular} & \begin{tabular}{|l|}
1.000 \\
\end{tabular} & 1.000 & 1.000 \\
\hline \multirow{3}{*}{$\begin{array}{c}\text { Bias } \\
\text { Corrected } \\
\text { standard }\end{array}$} & g1 & 0.095 & 0.254 & 0.464 & 0.664 & 0.802 & 0.887 & 0.936 & \begin{tabular}{|l|}
0.965 \\
\end{tabular} & \begin{tabular}{|l|}
0.980 \\
\end{tabular} & \begin{tabular}{|l|}
0.989 \\
\end{tabular} & 0.992 & 0.994 & 0.995 & \begin{tabular}{|l|}
0.997 \\
\end{tabular} & 0.998 & 0.999 \\
\hline & G1 & 0.098 & 0.255 & 0.457 & 0.655 & 0.796 & 0.884 & 0.933 & 0.963 & 0.979 & 0.989 & 0.992 & 0.993 & 0.995 & 0.997 & 0.998 & 0.998 \\
\hline & $\mathrm{b1}$ & 0.098 & 0.259 & 0.464 & 0.667 & 0.809 & 0.892 & 0.937 & \begin{tabular}{|l|}
0.965 \\
\end{tabular} & \begin{tabular}{|l|}
0.981 \\
\end{tabular} & \begin{tabular}{|l|}
0.990 \\
\end{tabular} & 0.992 & 0.994 & \begin{tabular}{|l|}
0.995 \\
\end{tabular} & \begin{tabular}{|l|}
0.997 \\
\end{tabular} & 0.998 & 0.999 \\
\hline \multirow{3}{*}{$\begin{array}{c}\text { Efron's } \\
\text { percentile } \\
\text { bootstrap }\end{array}$} & $\mathrm{g} 1$ & 0.094 & 0.269 & 0.485 & 0.684 & 0.823 & 0.902 & 0.942 & 0.968 & 0.986 & 0.991 & 0.992 & 0.994 & 0.997 & 0.998 & 0.998 & 0.999 \\
\hline & G1 & 0.089 & 0.247 & 0.457 & 0.658 & 0.802 & 0.894 & 0.937 & 0.967 & 0.984 & 0.989 & 0.992 & 0.995 & 0.996 & 0.998 & 0.998 & 0.999 \\
\hline & $\mathrm{bl}$ & 0.106 & 0.290 & 0.510 & 0.704 & 0.837 & 0.907 & 0.949 & \begin{tabular}{|l|}
0.973 \\
\end{tabular} & \begin{tabular}{|l|}
0.986 \\
\end{tabular} & \begin{tabular}{|l|}
0.991 \\
\end{tabular} & 0.993 & 0.995 & \begin{tabular}{|l|}
0.997 \\
\end{tabular} & \begin{tabular}{|l|}
0.998 \\
\end{tabular} & 0.998 & 0.999 \\
\hline \multirow{3}{*}{$\begin{array}{c}\text { Hall's } \\
\text { Percentile } \\
\text { bootstrap }\end{array}$} & $\mathrm{g} 1$ & 0.098 & 0.264 & 0.477 & 0.690 & 0.826 & 0.904 & 0.951 & \begin{tabular}{|l|}
0.974 \\
\end{tabular} & \begin{tabular}{|l|}
0.987 \\
\end{tabular} & 0.992 & 0.994 & 0.996 & 0.997 & 0.998 & 0.999 & 1.000 \\
\hline & $\mathrm{Gl}$ & 0.105 & 0.286 & 0.495 & 0.698 & 0.828 & 0.903 & 0.951 & \begin{tabular}{|l|}
0.974 \\
\end{tabular} & 0.986 & 0.991 & 0.993 & 0.996 & \begin{tabular}{|l|}
0.997 \\
\end{tabular} & \begin{tabular}{|l|}
0.998 \\
\end{tabular} & 0.999 & 1.000 \\
\hline & $\mathrm{bl}$ & 0.088 & 0.244 & 0.459 & 0.674 & 0.814 & 0.900 & 0.949 & \begin{tabular}{|l|}
0.974 \\
\end{tabular} & 0.986 & \begin{tabular}{|l|}
0.991 \\
\end{tabular} & 0.994 & 0.996 & 0.997 & 0.998 & 0.999 & 1.000 \\
\hline \multirow{3}{*}{$\begin{array}{c}\text { Bias } \\
\text { Corrected } \\
\text { percentile }\end{array}$} & $\mathrm{g} 1$ & 0.090 & 0.230 & 0.427 & 0.622 & 0.767 & 0.864 & 0.922 & \begin{tabular}{|l|}
0.954 \\
\end{tabular} & \begin{tabular}{|l|}
0.973 \\
\end{tabular} & \begin{tabular}{|l|}
0.988 \\
\end{tabular} & 0.991 & 0.993 & 0.994 & 0.996 & 0.997 & 0.998 \\
\hline & $\mathrm{Gl}$ & 0.087 & 0.197 & 0.392 & 0.592 & 0.748 & 0.852 & 0.913 & 0.948 & 0.969 & 0.985 & 0.990 & 0.993 & 0.994 & 0.996 & 0.997 & 0.998 \\
\hline & $b 1$ & 0.096 & 0.248 & 0.452 & 0.643 & 0.782 & 0.874 & 0.925 & 0.959 & 0.975 & 0.988 & 0.992 & 0.993 & 0.996 & \begin{tabular}{|l|}
0.997 \\
\end{tabular} & 0.998 & 0.999 \\
\hline
\end{tabular}


Table A8: Power for $\operatorname{Beta}(2,5)$ with kurtosis=-0.12 against with other value for different sample size

\begin{tabular}{|c|c|c|c|c|c|c|c|c|c|c|c|c|}
\hline & & & & & & & & & & & & \\
\hline Method & st & $2=-0.12$ & $2=0$ & $=0.2$ & $=0.4$ & $2=0.6$ & $2=0.8$ & $2=1.0$ & $2=1.2$ & $2=1.4$ & $2=1.6$ & $2=1.8$ \\
\hline \multirow{3}{*}{ Classical } & $\mathrm{g} 1$ & \begin{tabular}{l|}
0.059 \\
\end{tabular} & 0.089 & .088 & .103 & 0.198 & 0.296 & .476 & 0.550 & 0.662 & .783 & .874 \\
\hline & G1 & 0.043 & 0.093 & 0.109 & 0.148 & 0.202 & 0.275 & .354 & 0.430 & 0.505 & 0.561 & .615 \\
\hline & b1 & 0.102 & 0.054 & 0.042 & 0.068 & 0.192 & 0.364 & 0.525 & 0.650 & 0.749 & 0.819 & 867 \\
\hline \multirow{3}{*}{$\begin{array}{c}\text { Bias } \\
\text { Corrected } \\
\text { standard }\end{array}$} & $\mathrm{g} 1$ & 058 & 085 & 0.138 & 0.206 & 0.280 & .349 & .414 & 0.473 & 0.530 & .580 & .632 \\
\hline & G1 & 0.063 & 0.084 & 0.112 & 0.145 & 0.187 & 0.229 & 0.271 & 0.307 & 0.347 & 0.387 & 0.424 \\
\hline & b1 & 0.066 & 0.081 & 0.150 & 0.250 & 0.331 & 0.414 & 0.487 & 0.547 & 0.617 & 0.668 & .710 \\
\hline \multirow{3}{*}{$\begin{array}{l}\text { Efron's } \\
\text { percentile } \\
\text { bootstrap } \\
\end{array}$} & g1 & 0.000 & 0.000 & 0.001 & 0.030 & 0.106 & 0.193 & 0.287 & 0.364 & 0.438 & 0.514 & .574 \\
\hline & G1 & 0.000 & 0.000 & 0.000 & 0.000 & 0.000 & 0.000 & 0.000 & 0.001 & 0.004 & 0.019 & 052 \\
\hline & b1 & 0.082 & 0.159 & 0.269 & 0.365 & 0.457 & 0.550 & 0.622 & 0.680 & 0.743 & 0.792 & 0.842 \\
\hline \multirow{3}{*}{$\begin{array}{c}\text { Hall's } \\
\text { Percentile } \\
\text { bootstrap }\end{array}$} & g1 & 0.102 & 0.127 & 0.181 & 0.248 & 0.326 & 0.399 & 0.467 & 0.529 & 0.577 & 0.628 & 0.680 \\
\hline & G1 & 0.275 & 0.304 & 0.350 & 0.389 & 0.428 & 0.465 & 0.504 & 0.535 & 0.562 & 0.590 & 617 \\
\hline & b1 & 0.134 & 0.112 & 0.087 & 0.092 & 0.141 & 0.208 & 0.298 & 0.391 & 0.474 & 0.549 & 0.608 \\
\hline \multirow{4}{*}{$\begin{array}{c}\text { Bias } \\
\text { Corrected } \\
\text { percentile }\end{array}$} & g1 & 0.102 & 0.027 & 0.015 & 0.012 & 0.011 & 0.010 & 0.009 & 0.008 & 0.007 & 0.006 & .007 \\
\hline & G1 & 0.043 & 0.054 & 0.065 & 0.081 & 0.095 & 0.113 & 0.133 & 0.154 & 0.175 & 0.196 & .213 \\
\hline & b1 & 0.216 & 0.119 & 9 & 2 & 0.052 & 0.041 & 0.037 & 0.040 & 0.055 & 0.075 & 0.116 \\
\hline & & $n=20$ & & & & & & & & & & \\
\hline Met & Est & $2=-0.12$ & $=0$ & $\gamma 2=0.2$ & $=0.4$ & $=0.6$ & $=0.8$ & $2=1.0$ & $\gamma 2=1.2$ & $\gamma 2=1.4$ & $2=1.6$ & $2=1.8$ \\
\hline \multirow{3}{*}{ Classical } & $\mathrm{g} 1$ & \begin{tabular}{l|l|}
0.065 \\
\end{tabular} & 068 & 0.070 & 0.102 & 134 & 298 & .392 & 0.523 & 0.673 & .742 & .786 \\
\hline & G1 & 0.048 & 0.074 & 0.069 & 0.094 & 0.169 & 0.255 & 0.361 & 0.472 & 0.568 & 0.648 & 0.708 \\
\hline & b1 & 0.079 & 0.062 & 0.049 & 68 & .166 & .303 & 0.465 & 0.599 & .696 & .767 & .827 \\
\hline \multirow{3}{*}{$\begin{array}{c}\text { Bias } \\
\text { Corrected } \\
\text { standard }\end{array}$} & g1 & 140 & 0.177 & 0.240 & 0.307 & 0.377 & 0.443 & 0.508 & 0.562 & 0.614 & 0.652 & 0.687 \\
\hline & G1 & 0.144 & 0.175 & 0.224 & 0.276 & 0.331 & 0.383 & 0.433 & 0.479 & 0.528 & 0.570 & 0.608 \\
\hline & b1 & 0.130 & 0.175 & 0.248 & 0.332 & 0.400 & 0.468 & 0.535 & 0.596 & 0.644 & 0.684 & .723 \\
\hline \multirow{3}{*}{$\begin{array}{c}\text { Efron's } \\
\text { percentile } \\
\text { bootstrap }\end{array}$} & g1 & 0.071 & 0.095 & 0.165 & 0.242 & 0.309 & 0.378 & 0.450 & 0.514 & 0.566 & 0.618 & 0.665 \\
\hline & G1 & 0.014 & 0.025 & 0.061 & 01 & 0.158 & 215 & 0.270 & 0.325 & .377 & .436 & 485 \\
\hline & b1 & 0.169 & 0.208 & 0.294 & 0.370 & 0.446 & 0.511 & 0.580 & 0.631 & 0.678 & 0.719 & 0.760 \\
\hline \multirow{3}{*}{$\begin{array}{c}\text { Hall's } \\
\text { Percentile } \\
\text { bootstrap }\end{array}$} & g1 & 0.133 & 0.181 & 0.253 & 0.332 & 0.420 & 0.492 & 0.564 & 0.622 & 0.667 & 0.706 & 0.744 \\
\hline & G1 & 0.252 & 0.287 & 0.347 & 0.416 & 0.472 & 0.528 & 0.584 & 0.622 & 0.659 & 0.687 & 0.717 \\
\hline & b1 & 0.055 & 0.078 & 0.142 & 0.223 & 0.312 & 0.404 & 0.485 & 0.569 & 0.629 & 0.674 & 0.721 \\
\hline \multirow{4}{*}{$\begin{array}{c}\text { Bias } \\
\text { Corrected } \\
\text { percentile }\end{array}$} & g1 & 0.121 & 0.046 & 0.030 & 0.021 & 0.018 & 0.023 & 0.044 & 0.070 & 0.103 & 0.142 & 0.187 \\
\hline & G1 & 0.091 & 0.097 & 0.119 & 0.145 & 0.174 & 0.208 & 0.244 & 0.280 & 0.315 & 0.351 & 0.384 \\
\hline & b1 & 0.181 & 0.062 & 0.048 & 43 & 0.045 & 0.064 & 0.088 & 0.116 & 0.153 & 0.188 & .231 \\
\hline & & $n=30$ & & & & & & & & & & \\
\hline 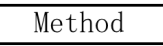 & Est & $2=-0.12$ & $\gamma 2=0$ & $\gamma 2=0.2$ & $2=0.4$ & $z=0.6$ & $2=0.8$ & $\gamma 2=1.0$ & $2=1.2$ & $\gamma 2=1.4$ & $\gamma 2=1.6$ & $y 2=1.8$ \\
\hline \multirow{3}{*}{ Classical } & g1 & 0.068 & 0.059 & 0.064 & 0.098 & 0.173 & 0.309 & 0.446 & 0.548 & 0.675 & 0.763 & 0.834 \\
\hline & G1 & 0.050 & 0.063 & 0.066 & 0.100 & 0.176 & 0.288 & 0.405 & 0.520 & 0.603 & 0.681 & 0.750 \\
\hline & b1 & 0.076 & 0.053 & 0.049 & 0.081 & 0.179 & 0.336 & 0.480 & 0.595 & 0.694 & 0.776 & .830 \\
\hline \multirow{3}{*}{$\begin{array}{c}\text { Bias } \\
\text { Corrected } \\
\text { standard } \\
\end{array}$} & g1 & 0.145 & 0.179 & 0.256 & 0.332 & 0.408 & 0.469 & 0.531 & 0.581 & 0.634 & 0.679 & 0.718 \\
\hline & G1 & 0.150 & 0.181 & 0.246 & 0.302 & 0.364 & 0.426 & 0.479 & 0.530 & 0.572 & 0.621 & 0.660 \\
\hline & b1 & 0.141 & 0.176 & 0.262 & 0.338 & 0.416 & 0.489 & 0.550 & 0.605 & 0.656 & 0.698 & 0.740 \\
\hline \multirow{3}{*}{$\begin{array}{c}\text { Efron's } \\
\text { percentile } \\
\text { bootstrap }\end{array}$} & $\mathrm{g} 1$ & 0.102 & 0.141 & 0.213 & 0.285 & 0.368 & 0.438 & 0.505 & 0.562 & 0.621 & 0.666 & 0.708 \\
\hline & G1 & 0.054 & 0.076 & 0.128 & 0.186 & 0.252 & 0.317 & 0.386 & 0.444 & 0.500 & 0.553 & 0.604 \\
\hline & b1 & 0.176 & 0.220 & 0.296 & 0.380 & 0.456 & 0.523 & 0.588 & 0.641 & 0.687 & 0.735 & 0.778 \\
\hline \multirow{3}{*}{$\begin{array}{c}\text { Hall's } \\
\text { Percentile } \\
\text { bootstrap }\end{array}$} & g1 & 0.140 & 0.187 & 0.268 & 0.356 & 0.430 & 0.509 & 0.574 & 0.630 & 0.680 & 0.725 & 0.763 \\
\hline & G1 & 0.235 & 0.265 & 0.341 & 0.405 & 0.473 & 0.537 & 0.582 & 0.629 & 0.671 & 0.711 & 0.745 \\
\hline & b1 & 0.075 & 0.108 & 0.189 & 0.274 & 0.370 & 0.450 & 0.531 & 0.591 & 0.650 & 0.703 & 0.745 \\
\hline \multirow{3}{*}{$\begin{array}{c}\text { Bias } \\
\text { Corrected } \\
\text { percentile }\end{array}$} & g1 & 0.116 & 0.026 & 0.027 & 0.047 & 0.079 & 0.118 & 0.168 & 0.224 & 0.279 & 0.322 & 0.379 \\
\hline & G1 & 0.085 & 0.099 & 0.133 & 0.172 & 0.216 & 0.264 & 0.305 & 0.362 & 0.403 & 0.440 & 0.480 \\
\hline & b1 & 0.163 & 0.046 & 0.043 & 0.057 & 0.090 & 0.125 & 0.160 & 0.203 & 0.243 & 0.291 & 0.338 \\
\hline
\end{tabular}


Table A8 (Continued)

\begin{tabular}{|c|c|c|c|c|c|c|c|c|c|c|c|c|}
\hline & & $n=50$ & & & & & & & & & & \\
\hline Sthol & ist & $2=-0.12$ & $\gamma 2=0$ & $2=0.2$ & $=0.4$ & $=0.6$ & $=0.8$ & $\gamma 2=1.0$ & $2=1.2$ & $\gamma 2=1.4$ & $2=1.6$ & $2=1.8$ \\
\hline \multirow{3}{*}{ Classical } & g1 & \begin{tabular}{l|l|}
0.055 \\
\end{tabular} & 0.058 & 0.064 & 0.128 & 0.255 & 0.402 & .532 & 0.664 & 0.753 & 0.832 & .873 \\
\hline & G1 & 0.044 & .061 & 0.072 & 0.134 & 0.250 & 0.389 & 0.527 & 0.638 & 0.733 & 0.803 & .850 \\
\hline & $\mathrm{b} 1$ & 059 & .053 & 0.059 & 0.125 & 0.265 & 0.426 & .574 & 0.698 & 0.785 & 0.845 & .894 \\
\hline \multirow{3}{*}{$\begin{array}{c}\text { Bias } \\
\text { Corrected } \\
\text { standard } \\
\end{array}$} & g1 & 0.146 & 0.181 & 0.265 & 0.348 & 0.441 & 0.527 & 0.593 & 0.654 & 0.707 & 0.755 & 0.791 \\
\hline & G1 & 0.148 & 0.178 & 0.254 & 0.332 & 0.419 & 0.494 & 0.562 & 0.623 & 0.671 & 0.719 & 763 \\
\hline & b1 & 0.144 & 0.183 & 0.267 & 0.356 & 0.456 & 0.538 & 0.609 & 0.665 & 0.723 & 0.771 & 0.803 \\
\hline \multirow{3}{*}{$\begin{array}{c}\text { Efron's } \\
\text { percentile } \\
\text { bootstrap }\end{array}$} & $\mathrm{g} 1$ & 0.119 & 0.150 & 0.235 & 0.328 & 0.423 & 0.516 & 0.590 & 0.658 & 0.712 & 0.761 & 0.801 \\
\hline & G1 & 0.082 & 0.105 & 0.178 & 0.255 & 0.333 & 0.423 & 0.507 & 0.576 & 0.639 & 0.693 & 0.741 \\
\hline & b1 & 0.159 & 0.200 & 0.298 & 0.393 & 0.494 & 0.576 & 0.649 & 0.704 & 0.756 & 0.801 & .838 \\
\hline \multirow{3}{*}{$\begin{array}{c}\text { Hall's } \\
\text { Percentile } \\
\text { bootstrap }\end{array}$} & g1 & 0.152 & 0.196 & 0.285 & 0.387 & 0.479 & 0.560 & 0.639 & 0.694 & 0.748 & 0.788 & 0.826 \\
\hline & G1 & 0.209 & 0.248 & 0.333 & 0.426 & 0.504 & 0.577 & 0.642 & 0.697 & 0.743 & 0.781 & 0.816 \\
\hline & b1 & 0.103 & 0.144 & 0.234 & 0.330 & 0.434 & 0.524 & 0.606 & 0.672 & 0.729 & 0.780 & 816 \\
\hline \multirow{4}{*}{$\begin{array}{c}\text { Bias } \\
\text { Corrected } \\
\text { percentile } \\
\end{array}$} & $\mathrm{g} 1$ & \begin{tabular}{|l|}
0.118 \\
\end{tabular} & 0.057 & 0.086 & 0.127 & 0.190 & 0.249 & 0.321 & 0.394 & 0.464 & 0.535 & 0.596 \\
\hline & G1 & 0.094 & 0.114 & 0.155 & 0.210 & 0.272 & 0.339 & 0.402 & 0.469 & 0.531 & 0.586 & 0.631 \\
\hline & b1 & 0.143 & 0.051 & 0.064 & 95 & .140 & 194 & 0.252 & 317 & 37 & .460 & .529 \\
\hline & & $n=100$ & & & & & & & & & & \\
\hline & $\mathrm{st}$ & $2=-1$ & $\gamma 2=0$ & 0.2 & .4 & $=0.6$ & $=0.8$ & $2=1.0$ & $\gamma 2=1.2$ & $=1.4$ & $2=1.6$ & $2=1.8$ \\
\hline \multirow{3}{*}{ Classical } & $\mathrm{g} 1$ & 0.054 & 0.057 & 0.109 & 0.225 & 0.412 & 0.583 & 0.722 & 0.821 & 0.892 & 0.933 & 0.960 \\
\hline & G1 & 0.044 & 0.058 & 0.110 & 0.223 & 0.404 & 0.572 & 0.708 & 0.816 & 0.885 & 0.927 & .955 \\
\hline & b1 & 0.055 & 0.051 & 0.104 & 0.226 & 0.418 & 0.598 & 0.741 & 0.841 & 0.904 & 0.942 & .965 \\
\hline \multirow{3}{*}{$\begin{array}{c}\text { Bias } \\
\text { Corrected } \\
\text { standard } \\
\end{array}$} & $\mathrm{g} 1$ & 0.124 & 0.177 & 0.278 & 0.398 & 0.512 & 0.611 & 0.696 & 0.765 & 0.817 & 0.861 & 0.900 \\
\hline & G1 & 0.126 & 0.174 & 0.267 & 0.384 & 0.504 & 93 & 0.676 & 0.748 & 0.801 & .844 & 883 \\
\hline & b1 & 0.128 & 0.177 & 0.278 & 0.399 & 0.523 & 0.623 & 0.702 & 0.772 & 0.825 & 0.872 & 0.903 \\
\hline \multirow{3}{*}{$\begin{array}{l}\text { Efron's } \\
\text { percentile } \\
\text { bootstrap }\end{array}$} & g1 & & & & & & & & & & & \\
\hline & G1 & 0.089 & 0.133 & 0.228 & 0.337 & 0.460 & 0.570 & 0.653 & 0.738 & 0.799 & 0.853 & 0.893 \\
\hline & b1 & 0.131 & 0.190 & 0.301 & 0.436 & 0.556 & 0.650 & 0.739 & 0.803 & 0.861 & 0.899 & 0.928 \\
\hline \multirow{3}{*}{$\begin{array}{c}\text { Hall's } \\
\text { Percentile } \\
\text { bootstrap }\end{array}$} & g1 & 135 & 0.190 & 0.300 & 0.431 & 0.552 & 0.644 & 0.731 & 0.796 & 0.849 & 0.888 & 0.915 \\
\hline & G1 & 0.163 & 0.220 & 0.334 & 0.461 & 0.565 & 0.652 & 0.735 & 0.798 & 0.845 & 0.884 & 0.913 \\
\hline & b1 & 112 & 0.163 & 0.267 & 0.396 & 0.525 & 0.624 & 0.716 & 0.787 & 0.839 & 0.880 & 0.914 \\
\hline \multirow{4}{*}{$\begin{array}{c}\text { Bias } \\
\text { Corrected } \\
\text { percentile }\end{array}$} & g1 & 0.070 & 0.083 & 0.137 & 0.221 & 0.323 & 0.437 & 0.542 & 0.631 & 0.708 & 0.772 & 0.821 \\
\hline & G1 & 0.091 & 0.113 & 0.186 & 0.276 & 0.374 & 0.485 & 0.572 & 0.648 & 0.723 & 0.783 & 0.828 \\
\hline & b1 & 0.056 & 0.061 & .100 & .182 & 0.272 & & 0.501 & 0.587 & 0.673 & 0.746 & 0.798 \\
\hline & & $n=300$ & & & & & & & & & & \\
\hline Method & Est & $2=-0.12$ & $\gamma 2=0$ & $\gamma 2=0.2$ & $\gamma 2=0.4$ & $\gamma 2=0.6$ & $\gamma 2=0.8$ & $\gamma 2=1.0$ & $\gamma 2=1.2$ & $\gamma 2=1.4$ & $\gamma 2=1.6$ & $\gamma 2=1.8$ \\
\hline \multirow{3}{*}{ Classical } & $\mathrm{g} 1$ & 0.050 & 0.062 & 0.211 & 0.509 & 0.753 & 0.902 & 0.953 & 0.990 & 0.999 & 1.000 & 1.000 \\
\hline & G1 & 0.051 & 0.063 & 0.221 & 0.504 & 0.750 & 0.898 & 0.965 & 0.989 & 0.997 & 1.000 & 1.000 \\
\hline & b1 & 0.050 & 0.061 & 0.220 & 0.510 & 0.757 & 0.904 & 0.967 & 0.991 & 0.998 & 1.000 & 1.000 \\
\hline \multirow{3}{*}{$\begin{array}{c}\text { Bias } \\
\text { Corrected } \\
\text { standard }\end{array}$} & $\mathrm{g} 1$ & 0.089 & 0.159 & 0.340 & 0.537 & 0.712 & 0.833 & 0.913 & 0.956 & 0.975 & 0.989 & 0.995 \\
\hline & G1 & 0.092 & 0.156 & 0.339 & 0.532 & 0.707 & 0.825 & 0.909 & 0.953 & 0.974 & 0.989 & 0.993 \\
\hline & b1 & 0.090 & 0.155 & 0.346 & 0.540 & 0.714 & 0.835 & 0.914 & 0.956 & 0.979 & 0.990 & 0.995 \\
\hline \multirow{3}{*}{$\begin{array}{l}\text { Efron's } \\
\text { percentile } \\
\text { bootstrap }\end{array}$} & g1 & 0.080 & 0.150 & 0.336 & 0.535 & 0.721 & 0.840 & 0.916 & 0.960 & 0.981 & 0.991 & 0.996 \\
\hline & G1 & 0.075 & 0.137 & 0.308 & 0.512 & 0.697 & 0.825 & 0.907 & 0.954 & 0.977 & 0.990 & 0.995 \\
\hline & b1 & 0.091 & 0.163 & 0.355 & 0.559 & 0.736 & 0.850 & 0.927 & 0.961 & 0.983 & 0.993 & 0.996 \\
\hline \multirow{3}{*}{\begin{tabular}{|c|} 
Hall's \\
Percentile \\
bootstrap \\
\end{tabular}} & g1 & 0.097 & 0.172 & 0.367 & 0.573 & 0.741 & 0.855 & 0.927 & 0.961 & 0.982 & 0.991 & 0.995 \\
\hline & G1 & 0.110 & 0.188 & 0.383 & 0.591 & 0.749 & 0.860 & 0.924 & 0.962 & 0.982 & 0.991 & 0.995 \\
\hline & b1 & 0.086 & 0.157 & 0.345 & 0.557 & 0.733 & 0.848 & 0.923 & 0.961 & 0.981 & 0.991 & 0.995 \\
\hline \multirow{3}{*}{$\begin{array}{c}\text { Bias } \\
\text { Corrected } \\
\text { percentile }\end{array}$} & g1 & 0.056 & 0.096 & 0.230 & 0.424 & 0.609 & 0.758 & 0.860 & 0.928 & 0.961 & 0.982 & 0.990 \\
\hline & G1 & 0.067 & 0.116 & 0.254 & 0.445 & 0.629 & 0.775 & 0.867 & 0.929 & 0.963 & 0.981 & 0.991 \\
\hline & b1 & 0.054 & 0.087 & 0.205 & 0.401 & 0.590 & 0.748 & 0.850 & 0.922 & 0.959 & 0.981 & 0.991 \\
\hline
\end{tabular}


Table A9: Power for Uniform $(0,1)$ with kurtosis=-1.2 against with other value for different sample size

\begin{tabular}{|c|c|c|c|c|c|c|c|c|c|c|c|c|c|c|c|c|c|}
\hline & & $n=10$ & & & & & & & & & & & & & & & \\
\hline Method & Est & $\gamma 2=-1.2$ & $\gamma 2=-1.0$ & $\gamma 2=-0.8$ & $\gamma 2=-0.6$ & $\gamma 2=-0.4$ & $\gamma 2=-0.2$ & $\gamma 2=0$ & $\gamma 2=0.2$ & $=0.4$ & $\gamma 2=0.6$ & $\gamma 2=0.8$ & $\gamma 2=1.0$ & $\gamma 2=1.2$ & $\gamma 2=1.4$ & $\gamma 2=1.6$ & $\gamma 2=1.8$ \\
\hline \multirow{3}{*}{ Classical } & $g 1$ & 0.099 & 0.070 & 0.051 & 0.035 & 0.025 & 0.020 & 0.014 & \begin{tabular}{|l|l|}
0.014 \\
\end{tabular} & 0.058 & 0.204 & 0.416 & 0.595 & 0.731 & 0.807 & 0.869 & 0.909 \\
\hline & G1 & 0.027 & 0.024 & 0.021 & 0.019 & 0.015 & 0.013 & 0.011 & 0.007 & 0.006 & 0.007 & 0.013 & 0.043 & 0.102 & 0.202 & 0.322 & 0.437 \\
\hline & b1 & 0.337 & 0.209 & 0.135 & 0.087 & 0.056 & 0.037 & 0.068 & 0.251 & 0.498 & 0.691 & 0.802 & 0.877 & 0.919 & 0.946 & 0.965 & 0.977 \\
\hline \multirow{3}{*}{$\begin{array}{c}\text { Bias } \\
\text { Corrected } \\
\text { standard }\end{array}$} & $\mathrm{g} 1$ & 0.068 & 0.052 & 0.036 & 0.026 & 0.019 & 0.034 & \begin{tabular}{|l|}
0.091 \\
\end{tabular} & 0.211 & 0.332 & 0.440 & 0.541 & \begin{tabular}{|l|}
0.624 \\
\end{tabular} & 0.687 & \begin{tabular}{|l|}
0.737 \\
\end{tabular} & \begin{tabular}{|l|}
0.785 \\
\end{tabular} & 0.818 \\
\hline & G1 & 0.028 & 0.024 & 0.021 & 0.020 & 0.033 & 0.052 & \begin{tabular}{|l|}
0.094 \\
\end{tabular} & 0.151 & 0.223 & \begin{tabular}{|l|}
0.297 \\
\end{tabular} & 0.359 & \begin{tabular}{|l|}
0.425 \\
\end{tabular} & \begin{tabular}{|l|}
0.488 \\
\end{tabular} & 0.539 & \begin{tabular}{|l|}
0.583 \\
\end{tabular} & 0.626 \\
\hline & $\mathrm{b1}$ & 0.114 & 0.073 & 0.045 & 0.032 & 0.023 & 0.025 & 0.085 & 0.238 & 0.381 & 0.512 & 0.613 & 0.696 & 0.759 & 0.805 & 0.839 & 0.874 \\
\hline \multirow{3}{*}{$\begin{array}{c}\text { Efron's } \\
\text { percentile } \\
\text { bootstrap }\end{array}$} & $\mathrm{g} 1$ & 0.000 & 0.000 & 0.000 & 0.000 & 0.000 & 0.000 & 0.000 & 0.004 & 0.041 & 0.153 & 0.279 & 0.399 & 0.486 & 0.567 & 0.629 & 0.689 \\
\hline & G1 & 0.000 & 0.000 & 0.000 & 0.000 & 0.000 & 0.000 & 0.000 & 0.000 & 0.000 & 0.000 & 0.000 & 0.000 & 0.000 & 0.009 & 0.033 & 0.078 \\
\hline & $\mathrm{bl}$ & 0.000 & 0.000 & 0.000 & 0.000 & 0.004 & 0.078 & 0.228 & 0.371 & 0.486 & 0.575 & 0.659 & 0.723 & 0.780 & 0.831 & 0.872 & 0.903 \\
\hline \multirow{3}{*}{\begin{tabular}{|c|} 
Hall's \\
Percentile \\
bootstrap \\
\end{tabular}} & $\mathrm{g} 1$ & 0.078 & 0.057 & 0.042 & 0.036 & 0.048 & 0.103 & \begin{tabular}{|l|}
0.191 \\
\end{tabular} & 0.298 & 0.415 & 0.523 & 0.612 & 0.682 & 0.745 & 0.788 & 0.822 & 0.849 \\
\hline & G1 & \begin{tabular}{|l|}
0.123 \\
\end{tabular} & 0.178 & 0.242 & \begin{tabular}{|l|}
0.303 \\
\end{tabular} & 0.373 & 0.434 & 0.494 & 0.551 & 0.597 & 0.645 & 0.682 & 0.719 & 0.751 & \begin{tabular}{|l|l}
0.778 \\
\end{tabular} & 0.795 & 0.816 \\
\hline & $\mathrm{bl}$ & 0.446 & 0.319 & 0.203 & 0.121 & 0.075 & 0.053 & \begin{tabular}{|l|}
0.037 \\
\end{tabular} & 0.036 & 0.099 & 0.210 & 0.355 & 0.488 & 0.598 & 0.691 & \begin{tabular}{|l|}
0.762 \\
\end{tabular} & 0.806 \\
\hline \multirow{4}{*}{\begin{tabular}{|c|} 
Bias \\
Corrected \\
percentile \\
\end{tabular}} & $\mathrm{g} 1$ & 0.056 & 0.041 & 0.061 & 0.093 & 0.140 & 0.200 & 0.263 & $\mid 0.317$ & 0.358 & 0.410 & 0.450 & 0.492 & 0.531 & 0.568 & 0.607 & 0.643 \\
\hline & G1 & 0.060 & 0.047 & 0.046 & 0.049 & 0.063 & 0.086 & 0.107 & 0.131 & 0.166 & 0.195 & 0.227 & 0.266 & 0.296 & 0.325 & 0.353 & 0.376 \\
\hline & b1 & 0.063 & 0.108 & 0.176 & 0.240 & 0.317 & 0.375 & 0.429 & 0.477 & 0.524 & 0.570 & 0.622 & 0.660 & 0.698 & 0.736 & 0.769 & 0.805 \\
\hline & & $\mathrm{n}=20$ & & & & & & & & & & & & & & & \\
\hline Method & Est & $\gamma 2=-1.2$ & $\gamma 2=-1.0$ & $\gamma 2=-0.8$ & $\gamma 2=-0.6$ & $\gamma 2=-0.4$ & $\gamma 2=-0.2$ & $\gamma 2=0$ & $\gamma 2=0.2$ & $2=0.4$ & $\gamma 2=0.6$ & $\gamma 2=0.8$ & $\gamma 2=1.0$ & $\gamma 2=1.2$ & $\gamma 2=1.4$ & $\gamma 2=1.6$ & $\gamma 2=1.8$ \\
\hline \multirow{3}{*}{ Classical } & $\mathrm{g} 1$ & \begin{tabular}{|l|}
0.011 \\
\end{tabular} & 0.005 & 0.003 & 0.002 & 0.001 & 0.000 & 0.000 & 0.016 & 0.180 & 0.452 & 0.703 & 0.847 & 0.923 & 0.959 & 0.982 & 0.990 \\
\hline & G1 & 0.002 & 0.001 & 0.001 & 0.001 & 0.000 & 0.000 & 0.000 & 0.000 & \begin{tabular}{|l|}
0.001 \\
\end{tabular} & \begin{tabular}{|l|}
0.029 \\
\end{tabular} & \begin{tabular}{|l|}
0.171 \\
\end{tabular} & 0.368 & 0.585 & \begin{tabular}{|l|}
0.747 \\
\end{tabular} & \begin{tabular}{|l|}
0.849 \\
\end{tabular} & 0.912 \\
\hline & $\mathrm{bl}$ & 0.030 & 0.013 & 0.006 & 0.003 & 0.002 & 0.001 & 0.010 & 0.172 & 0.471 & 0.734 & 0.874 & 0.939 & 0.972 & 0.987 & 0.994 & 0.997 \\
\hline \multirow{3}{*}{$\begin{array}{c}\text { Bias } \\
\text { Corrected } \\
\text { standard } \\
\end{array}$} & $\mathrm{g} 1$ & 0.011 & 0.004 & 0.023 & 0.110 & 0.264 & 0.426 & 0.565 & 0.683 & 0.778 & 0.840 & \begin{tabular}{|l|l|}
0.887 \\
\end{tabular} & 0.918 & 0.937 & 0.955 & 0.970 & \begin{tabular}{|l|l}
0.977 \\
\end{tabular} \\
\hline & G1 & 0.006 & \begin{tabular}{|l|}
0.028 \\
\end{tabular} & 0.102 & 0.205 & \begin{tabular}{|l|l}
0.337 \\
\end{tabular} & 0.464 & 0.569 & \begin{tabular}{|l|l|}
0.664 \\
\end{tabular} & \begin{tabular}{|l|l|}
0.734 \\
\end{tabular} & \begin{tabular}{|l|l|}
0.794 \\
\end{tabular} & 0.843 & \begin{tabular}{|l|l|}
0.882 \\
\end{tabular} & \begin{tabular}{|l|}
0.907 \\
\end{tabular} & \begin{tabular}{|l}
0.925 \\
\end{tabular} & 0.940 & \begin{tabular}{|l}
0.955 \\
\end{tabular} \\
\hline & b1 & 0.032 & 0.007 & 0.007 & 0.069 & 0.226 & 0.413 & 0.567 & 0.697 & 0.792 & 0.859 & \begin{tabular}{|l|}
0.902 \\
\end{tabular} & 0.930 & 0.951 & 0.965 & 0.978 & 0.982 \\
\hline \multirow{3}{*}{$\begin{array}{c}\text { Efron's } \\
\text { percentile } \\
\text { bootstrap } \\
\end{array}$} & $\mathrm{g} 1$ & 0.004 & 0.000 & 0.000 & 0.007 & 0.092 & 0.239 & 0.421 & 0.559 & \begin{tabular}{|l|l|}
0.669 \\
\end{tabular} & 0.750 & 0.821 & 0.868 & \begin{tabular}{|l|l|}
0.897 \\
\end{tabular} & 0.926 & \begin{tabular}{|l}
0.942 \\
\end{tabular} & 0.960 \\
\hline & G1 & 0.004 & 0.001 & 0.000 & 0.001 & 0.009 & 0.070 & 0.175 & \begin{tabular}{|l}
0.308 \\
\end{tabular} & \begin{tabular}{|l|l|}
0.438 \\
\end{tabular} & 0.545 & 0.636 & 0.712 & 0.765 & 0.820 & 0.858 & \begin{tabular}{|l|l|}
0.877 \\
\end{tabular} \\
\hline & $b 1$ & 0.001 & 0.000 & 0.013 & 0.136 & 0.315 & 0.488 & 0.631 & \begin{tabular}{|l}
0.731 \\
\end{tabular} & 0.807 & 0.866 & 0.904 & 0.933 & 0.950 & \begin{tabular}{|l|}
0.964 \\
\end{tabular} & 0.973 & 0.980 \\
\hline \multirow{3}{*}{$\begin{array}{c}\text { Hall's } \\
\text { Percentile } \\
\text { bootstrap }\end{array}$} & $\mathrm{g} 1$ & \begin{tabular}{|l|l|}
0.014 \\
\end{tabular} & \begin{tabular}{|l|l|}
0.002 \\
\end{tabular} & \begin{tabular}{|l|l|}
0.019 \\
\end{tabular} & 0.103 & 0.264 & \begin{tabular}{|l|l|}
0.441 \\
\end{tabular} & 0.602 & \begin{tabular}{|l|l|}
0.730 \\
\end{tabular} & 0.815 & 0.878 & 0.916 & 0.941 & \begin{tabular}{|l|l|}
0.960 \\
\end{tabular} & \begin{tabular}{|l|l|}
0.974 \\
\end{tabular} & \begin{tabular}{|l|}
0.982 \\
\end{tabular} & \begin{tabular}{|l|l|}
0.987 \\
\end{tabular} \\
\hline & G1 & 0.082 & 0.196 & \begin{tabular}{|l|}
0.324 \\
\end{tabular} & 0.465 & 0.585 & \begin{tabular}{|l|l}
0.690 \\
\end{tabular} & \begin{tabular}{|l|l}
0.774 \\
\end{tabular} & 0.830 & 0.879 & 0.910 & 0.930 & 0.946 & 0.959 & \begin{tabular}{|l}
0.970 \\
\end{tabular} & 0.978 & 0.984 \\
\hline & $\mathrm{bl}$ & 0.284 & 0.082 & 0.017 & 0.004 & 0.023 & 0.145 & 0.326 & 0.522 & \begin{tabular}{|l|}
0.681 \\
\end{tabular} & \begin{tabular}{|l|}
0.791 \\
\end{tabular} & \begin{tabular}{|l|l|}
0.870 \\
\end{tabular} & 0.915 & \begin{tabular}{|l|}
0.941 \\
\end{tabular} & \begin{tabular}{|l|}
0.961 \\
\end{tabular} & 0.976 & 0.984 \\
\hline \multirow{4}{*}{$\begin{array}{c}\text { Bias } \\
\text { Corrected } \\
\text { percentile } \\
\end{array}$} & $\mathrm{g} 1$ & 0.033 & 0.050 & 0.123 & 0.222 & 0.334 & 0.439 & 0.539 & 0.621 & 0.685 & 0.743 & 0.791 & 0.832 & 0.867 & 0.893 & 0.913 & 0.927 \\
\hline & G1 & \begin{tabular}{|l|l|}
0.034 \\
\end{tabular} & $\begin{array}{ll}0.037 \\
\end{array}$ & $\begin{array}{ll}0.082 \\
\end{array}$ & 0.147 & \begin{tabular}{|l|l|}
0.230 \\
\end{tabular} & 0.320 & 0.398 & \begin{tabular}{|l|l}
0.482 \\
\end{tabular} & 0.549 & 0.607 & 0.659 & 0.711 & 0.750 & \begin{tabular}{|l}
0.790 \\
\end{tabular} & 0.820 & 0.846 \\
\hline & $\mathrm{bl}$ & 0.047 & 0.133 & 0.247 & 0.368 & 0.483 & 0.586 & 0.657 & \begin{tabular}{|l|l|}
0.729 \\
\end{tabular} & 0.788 & 0.828 & 0.869 & 0.898 & 0.915 & 0.933 & 0.949 & 0.959 \\
\hline & & $\mathrm{n}=30$ & & & & & & & & & & & & & & & \\
\hline 100 & Est & $\gamma 2=-1.2$ & $\gamma 2=-1.0$ & $\gamma 2=-0.8$ & $\gamma 2=-0.6$ & $\gamma 2=-0.4$ & $\gamma 2=-0.2$ & $\gamma 2=0$ & $\gamma 2=0.2$ & $\gamma 2=0.4$ & $\gamma 2=0.6$ & $\gamma 2=0.8$ & $\gamma 2=1.0$ & $\gamma 2=1.2$ & $\gamma 2=1.4$ & $\gamma 2=1.6$ & $\gamma 2=1.8$ \\
\hline \multirow{3}{*}{ Classical } & $\mathrm{g} 1$ & 0.001 & 0.001 & 0.001 & 0.000 & 0.000 & 0.000 & 0.010 & 0.155 & 0.492 & 0.766 & 0.916 & 0.967 & 0.988 & 0.996 & 0.999 & 0.999 \\
\hline & G1 & 0.001 & 0.000 & 0.000 & 0.000 & 0.000 & 0.000 & 0.000 & 0.010 & 0.116 & 0.380 & 0.647 & 0.843 & 0.933 & 0.969 & 0.986 & 0.995 \\
\hline & b1 & 0.005 & 0.001 & 0.001 & 0.001 & 0.000 & 0.000 & 0.056 & 0.336 & 0.677 & 0.887 & 0.958 & 0.986 & 0.995 & 0.999 & 0.999 & 1.000 \\
\hline \multirow{3}{*}{\begin{tabular}{|c|} 
Bias \\
Corrected \\
standard \\
\end{tabular}} & $\mathrm{g} 1$ & 0.012 & 0.016 & 0.111 & 0.315 & 0.524 & 0.706 & 0.827 & 0.899 & 0.939 & 0.962 & 0.977 & 0.988 & 0.993 & 0.996 & 0.997 & 0.998 \\
\hline & G1 & 0.015 & 0.080 & 0.235 & 0.419 & 0.591 & 0.733 & 0.822 & 0.888 & 0.928 & 0.953 & 0.968 & 0.978 & 0.988 & 0.993 & 0.995 & 0.997 \\
\hline & $\mathrm{b1}$ & 0.024 & 0.008 & 0.073 & 0.278 & 0.497 & 0.693 & 0.829 & 0.901 & 0.942 & 0.966 & 0.978 & 0.990 & 0.994 & 0.997 & 0.997 & 0.998 \\
\hline \multirow{3}{*}{$\begin{array}{c}\text { Efron's } \\
\text { percentile } \\
\text { bootstrap }\end{array}$} & $\mathrm{g} 1$ & 0.016 & 0.001 & 0.031 & 0.181 & 0.388 & 0.588 & 0.750 & 0.834 & 0.895 & 0.937 & 0.961 & 0.973 & 0.985 & 0.991 & 0.994 & 0.997 \\
\hline & G1 & 0.017 & 0.001 & 0.010 & 0.092 & 0.253 & 0.433 & 0.603 & 0.734 & 0.816 & 0.879 & 0.917 & 0.941 & 0.958 & 0.974 & 0.981 & 0.987 \\
\hline & $\mathrm{bl}$ & 0.003 & 0.014 & 0.136 & 0.355 & 0.580 & 0.743 & 0.848 & 0.905 & 0.942 & 0.963 & 0.980 & 0.987 & 0.991 & 0.994 & 0.998 & 0.998 \\
\hline \multirow{3}{*}{$\begin{array}{c}\text { Hall's } \\
\text { Percentile } \\
\text { bootstrap } \\
\end{array}$} & $\mathrm{g} 1$ & 0.014 & 0.012 & 0.086 & 0.279 & 0.515 & 0.701 & 0.840 & 0.915 & 0.952 & \begin{tabular}{|l|}
0.972 \\
\end{tabular} & 0.983 & \begin{tabular}{|l|}
0.992 \\
\end{tabular} & \begin{tabular}{|l|}
0.996 \\
\end{tabular} & \begin{tabular}{|l|}
0.998 \\
\end{tabular} & 0.999 & 0.999 \\
\hline & G1 & 0.072 & 0.230 & 0.424 & 0.603 & \begin{tabular}{|l}
0.748 \\
\end{tabular} & 0.853 & 0.915 & \begin{tabular}{|l|}
0.947 \\
\end{tabular} & \begin{tabular}{|l|}
0.966 \\
\end{tabular} & \begin{tabular}{|l}
0.978 \\
\end{tabular} & \begin{tabular}{|l|}
0.987 \\
\end{tabular} & 0.993 & 0.996 & \begin{tabular}{|l|}
0.998 \\
\end{tabular} & 0.998 & \begin{tabular}{|l}
0.999 \\
\end{tabular} \\
\hline & b1 & 0.247 & 0.035 & 0.006 & 0.056 & 0.239 & 0.487 & 0.692 & \begin{tabular}{|l}
0.841 \\
\end{tabular} & 0.921 & 0.956 & \begin{tabular}{|l|l|}
0.977 \\
\end{tabular} & 0.986 & 0.994 & \begin{tabular}{|l}
0.997 \\
\end{tabular} & 0.998 & \begin{tabular}{|l|}
0.999 \\
\end{tabular} \\
\hline \multirow{3}{*}{$\begin{array}{c}\text { Bias } \\
\text { Corrected } \\
\text { percentile }\end{array}$} & g1 & 0.040 & 0.076 & 0.200 & \begin{tabular}{|l|l}
0.369 \\
\end{tabular} & 0.528 & 0.661 & 0.772 & \begin{tabular}{|l|l|}
0.840 \\
\end{tabular} & \begin{tabular}{|l|l}
0.890 \\
\end{tabular} & 0.924 & 0.943 & 0.963 & \begin{tabular}{|l|}
0.975 \\
\end{tabular} & \begin{tabular}{|l|}
0.983 \\
\end{tabular} & \begin{tabular}{|l|}
0.989 \\
\end{tabular} & 0.993 \\
\hline & G1 & 0.041 & 0.063 & 0.151 & 0.286 & 0.430 & 0.551 & 0.666 & 0.755 & 0.824 & 0.872 & 0.907 & 0.931 & 0.946 & 0.960 & 0.972 & 0.979 \\
\hline & b1 & 0.051 & 0.159 & 0.337 & 0.499 & 0.652 & 0.770 & 0.843 & 0.895 & 0.930 & 0.951 & 0.966 & 0.976 & 0.985 & 0.992 & 0.996 & 0.997 \\
\hline
\end{tabular}


Table A9 (Continued)

\begin{tabular}{|c|c|c|c|c|c|c|c|c|c|c|c|c|c|c|c|c|c|}
\hline & & $\mathrm{n}=50$ & & & & & & & & & & & & & & & \\
\hline Method & Est & $\gamma 2=-1.2$ & $=-1.0$ & $2=-0.8$ & $\gamma 2=-0.6$ & $\gamma 2=-0.4$ & $\gamma 2=-0.2$ & $\gamma 2=0$ & $\gamma 2=0.2$ & $\gamma 2=0.4$ & $\gamma 2=0.6$ & $\gamma 2=0.8$ & $2=1.0$ & $\gamma 2=1.2$ & $\gamma 2=1.4$ & $\gamma 2=1.6$ & $\gamma 2=1.8$ \\
\hline \multirow{3}{*}{ Classical } & g1 & 0.000 & 0.000 & 0.000 & 0.000 & 0.000 & 0.013 & 0.242 & 0.670 & 0.923 & 0.985 & 0.997 & 1.000 & 1.000 & 1.000 & 1.000 & 1.000 \\
\hline & G1 & 0.000 & 0.000 & 0.000 & 0.000 & 0.000 & 0.002 & 0.080 & 0.427 & 0.779 & 0.945 & 0.986 & 0.997 & 1.000 & 1.000 & 1.000 & 1.000 \\
\hline & b1 & 0.000 & 0.000 & 0.000 & 0.000 & 0.000 & 0.027 & 0.347 & 0.770 & 0.956 & 0.992 & 0.999 & 1.000 & 1.000 & 1.000 & 1.000 & 1.000 \\
\hline \multirow{3}{*}{$\begin{array}{c}\text { Bias } \\
\text { Corrected } \\
\text { standard }\end{array}$} & g1 & 0.021 & 0.072 & 0.321 & 0.616 & 0.836 & 0.940 & 0.976 & 0.992 & 0.996 & 0.999 & 1.000 & 1.000 & 1.000 & 1.000 & 1.000 & 1.000 \\
\hline & G1 & 0.026 & 0.175 & 0.438 & 0.692 & 0.863 & 0.945 & 0.977 & 0.990 & 0.995 & 0.998 & 0.999 & 1.000 & 1.000 & 1.000 & 1.000 & 1.000 \\
\hline & b1 & 0.030 & 0.045 & 0.271 & 0.585 & 0.822 & 0.936 & 0.977 & 0.993 & 0.996 & 0.998 & 1.000 & 1.000 & 1.000 & 1.000 & 1.000 & 1.000 \\
\hline \multirow{3}{*}{\begin{tabular}{|c|} 
Efron's \\
percentile \\
bootstrap \\
\end{tabular}} & g1 & 0.026 & 0.036 & 0.227 & 0.525 & 0.761 & 0.904 & 0.961 & 0.984 & 0.992 & 0.997 & 0.999 & 0.999 & 1.000 & 1.000 & 1.000 & 1.000 \\
\hline & G1 & 0.024 & 0.025 & 0.173 & 0.436 & 0.686 & 0.849 & 0.938 & 0.970 & 0.985 & 0.993 & 0.996 & 0.999 & 0.999 & 1.000 & 1.000 & 1.000 \\
\hline & $\mathrm{bl}$ & 0.012 & 0.085 & 0.363 & 0.650 & 0.850 & 0.943 & 0.978 & 0.991 & 0.996 & 0.998 & 0.999 & 1.000 & 1.000 & 1.000 & 1.000 & 1.000 \\
\hline \multirow{3}{*}{$\begin{array}{c}\text { Hall's } \\
\text { Percentile } \\
\text { bootstrap }\end{array}$} & g1 & 0.022 & 0.044 & 0.267 & 0.579 & 0.826 & 0.942 & 0.981 & 0.993 & 0.997 & 0.999 & 1.000 & 1.000 & 1.000 & 1.000 & 1.000 & 1.000 \\
\hline & G1 & 0.066 & \begin{tabular}{|l|}
0.290 \\
\end{tabular} & 0.571 & 0.803 & 0.926 & 0.972 & 0.989 & 0.995 & 0.998 & 1.000 & 1.000 & 1.000 & 1.000 & 1.000 & 1.000 & 1.000 \\
\hline & b1 & 0.190 & \begin{tabular}{|l|}
0.015 \\
\end{tabular} & 0.073 & 0.348 & 0.665 & 0.879 & 0.962 & 0.987 & 0.994 & 0.998 & 1.000 & 1.000 & 1.000 & 1.000 & 1.000 & 1.000 \\
\hline \multirow{4}{*}{$\begin{array}{c}\text { Bias } \\
\text { Corrected } \\
\text { percentile }\end{array}$} & $\mathrm{g} 1$ & 0.043 & 0.128 & 0.369 & 0.620 & 0.806 & 0.911 & 0.964 & 0.982 & 0.991 & 0.996 & 0.998 & 0.999 & 1.000 & 1.000 & 1.000 & 1.000 \\
\hline & G1 & 0.044 & 0.110 & 0.316 & 0.553 & 0.741 & 0.867 & 0.936 & 0.971 & 0.985 & 0.992 & 0.996 & 0.998 & 0.999 & 1.000 & 1.000 & 1.000 \\
\hline & b1 & 0.052 & 0.224 & 0.484 & 0.721 & 0.873 & 0.946 & 0.977 & 0.989 & 0.995 & 0.997 & 0.999 & 1.000 & 1.000 & 1.000 & 1.000 & 1.000 \\
\hline & & $n=100$ & & & & & & & & & & & & & & & \\
\hline Method & Est & $\gamma 2=-1.2$ & $\gamma 2=-1.0$ & $\gamma 2=-0.8$ & $\gamma 2=-0.6$ & $\gamma 2=-0.4$ & $\gamma 2=-0.2$ & $\gamma 2=0$ & $\gamma 2=0.2$ & $\gamma 2=0.4$ & $\gamma 2=0.6$ & $\gamma 2=0.8$ & $\gamma 2=1.0$ & $\gamma 2=1.2$ & $\gamma 2=1.4$ & $\gamma 2=1.6$ & $\gamma 2=1.8$ \\
\hline \multirow{3}{*}{ Classical } & $\mathrm{g} 1$ & 0.000 & 0.000 & 0.000 & 0.000 & 0.061 & 0.604 & 0.953 & 0.996 & 1.000 & 1.000 & 1.000 & 1.000 & 1.000 & 1.000 & 1.000 & 1.000 \\
\hline & G1 & 0.000 & 0.000 & 0.000 & 0.000 & 0.041 & 0.508 & 0.922 & 0.993 & 0.999 & 1.000 & 1.000 & 1.000 & 1.000 & 1.000 & 1.000 & 1.000 \\
\hline & $\mathrm{bl}$ & 0.000 & 0.000 & 0.000 & 0.000 & 0.072 & 0.648 & 0.961 & 0.998 & 1.000 & 1.000 & 1.000 & 1.000 & 1.000 & 1.000 & 1.000 & 1.000 \\
\hline \multirow{3}{*}{$\begin{array}{c}\text { Bias } \\
\text { Corrected } \\
\text { standard }\end{array}$} & g1 & 0.033 & \begin{tabular}{|l|}
0.230 \\
\end{tabular} & 0.691 & 0.941 & 0.991 & 0.998 & 1.000 & 1.000 & 1.000 & 1.000 & 1.000 & 1.000 & 1.000 & 1.000 & 1.000 & 1.000 \\
\hline & G1 & 0.042 & \begin{tabular}{|l|}
0.345 \\
\end{tabular} & 0.763 & 0.953 & 0.994 & 0.999 & 1.000 & 1.000 & 1.000 & \begin{tabular}{|l|}
1.000 \\
\end{tabular} & 1.000 & 1.000 & 1.000 & 1.000 & 1.000 & 1.000 \\
\hline & $\overline{b 1}$ & 0.040 & \begin{tabular}{|l|}
0.187 \\
\end{tabular} & 0.658 & 0.928 & 0.990 & 0.999 & 1.000 & 1.000 & 1.000 & \begin{tabular}{|l|}
1.000 \\
\end{tabular} & 1.000 & 1.000 & 1.000 & 1.000 & 1.000 & 1.000 \\
\hline \multirow{3}{*}{\begin{tabular}{|c|} 
Efron's \\
percentile \\
bootstrap \\
\end{tabular}} & g1 & 0.039 & 0.175 & 0.630 & 0.920 & 0.987 & 0.998 & 1.000 & 1.000 & 1.000 & 1.000 & 1.000 & 1.000 & 1.000 & 1.000 & 1.000 & 1.000 \\
\hline & G1 & 0.039 & 0.158 & 0.583 & 0.896 & 0.981 & 0.996 & 0.999 & 1.000 & 1.000 & 1.000 & 1.000 & 1.000 & 1.000 & 1.000 & 1.000 & 1.000 \\
\hline & b1 & 0.031 & 0.265 & 0.717 & 0.945 & 0.992 & 0.999 & 1.000 & 1.000 & 1.000 & 1.000 & 1.000 & 1.000 & 1.000 & 1.000 & 1.000 & 1.000 \\
\hline \multirow{3}{*}{$\begin{array}{c}\text { Hall's } \\
\text { Percentile } \\
\text { bootstrap }\end{array}$} & g1 & 0.038 & \begin{tabular}{|l|}
0.175 \\
\end{tabular} & 0.649 & 0.932 & 0.990 & 0.999 & 1.000 & 1.000 & 1.000 & 1.000 & 1.000 & 1.000 & 1.000 & 1.000 & 1.000 & 1.000 \\
\hline & G1 & 0.059 & \begin{tabular}{|l|}
0.431 \\
\end{tabular} & 0.822 & 0.970 & 0.995 & 0.999 & 1.000 & 1.000 & 1.000 & 1.000 & 1.000 & 1.000 & 1.000 & 1.000 & 1.000 & 1.000 \\
\hline & $\mathrm{b} 1$ & 0.141 & \begin{tabular}{|l|}
0.059 \\
\end{tabular} & 0.466 & 0.866 & 0.983 & 0.997 & 1.000 & 1.000 & 1.000 & $\begin{array}{l}1.000 \\
\end{array}$ & 1.000 & 1.000 & 1.000 & 1.000 & 1.000 & 1.000 \\
\hline \multirow{4}{*}{$\begin{array}{c}\text { Bias } \\
\text { Corrected } \\
\text { percentile }\end{array}$} & g1 & 0.053 & \begin{tabular}{|l|}
0.275 \\
\end{tabular} & 0.702 & 0.931 & 0.990 & 0.998 & 1.000 & 1.000 & 1.000 & 1.000 & 1.000 & 1.000 & 1.000 & 1.000 & 1.000 & 1.000 \\
\hline & G1 & 0.051 & 0.256 & 0.662 & 0.916 & 0.982 & 0.996 & 0.999 & 1.000 & 1.000 & 1.000 & 1.000 & 1.000 & 1.000 & 1.000 & 1.000 & 1.000 \\
\hline & $\mathrm{bl}$ & 0.055 & 0.373 & 0.773 & 0.952 & 0.993 & 0.998 & 1.000 & 1.000 & 1.000 & 1.000 & 1.000 & 1.000 & 1. 000 & 1.000 & 1.000 & 1.000 \\
\hline & & $\mathrm{n}=300$ & & & & & & & & & & & & & & & \\
\hline Method & Est & $\gamma 2=-1.2$ & $\gamma 2=-1.0$ & $\gamma 2=-0.8$ & $\gamma 2=-0.6$ & $\gamma 2=-0.4$ & $\gamma 2=-0.2$ & $\gamma 2=0$ & $\gamma 2=0.2$ & $\gamma 2=0.4$ & $\gamma 2=0.6$ & $\gamma 2=0.8$ & $\gamma 2=1.0$ & $\gamma 2=1.2$ & $\gamma 2=1.4$ & $\gamma 2=1.6$ & $\gamma 2=1.8$ \\
\hline \multirow{3}{*}{ Classical } & g1 & 0.000 & 0.000 & 0.004 & 0.696 & 0.999 & 1.000 & 1.000 & 1.000 & 1.000 & 1.000 & 1.000 & 1.000 & 1.000 & 1.000 & 1.000 & 1.000 \\
\hline & G1 & 0.000 & 0.000 & 0.004 & 0.702 & 0.999 & 1.000 & 1.000 & 1.000 & 1.000 & 1.000 & 1.000 & 1.000 & 1.000 & 1.000 & 1.000 & 1.000 \\
\hline & b1 & 0.000 & 0.000 & 0.003 & 0.693 & 0.999 & 1.000 & 1.000 & 1.000 & 1.000 & 1.000 & 1.000 & 1.000 & 1.000 & 1.000 & 1.000 & 1.000 \\
\hline \multirow{3}{*}{$\begin{array}{c}\text { Bias } \\
\text { Corrected } \\
\text { standard }\end{array}$} & g1 & 0.044 & \begin{tabular}{|l|}
0.717 \\
\end{tabular} & 0.998 & 1.000 & 1.000 & 1.000 & 1.000 & 1.000 & 1.000 & 1.000 & 1.000 & 1.000 & 1.000 & 1.000 & 1.000 & 1.000 \\
\hline & G1 & 0.040 & 0.779 & 0.998 & 1.000 & 1.000 & 1.000 & 1.000 & 1.000 & 1.000 & 1.000 & 1.000 & 1.000 & 1.000 & 1.000 & 1.000 & 1.000 \\
\hline & $\overline{b 1}$ & 0.045 & 0.694 & 0.998 & 1.000 & 1.000 & 1.000 & 1.000 & 1.000 & 1.000 & 1.000 & 1.000 & 1.000 & 1.000 & 1.000 & 1.000 & 1.000 \\
\hline \multirow{3}{*}{\begin{tabular}{|c|} 
Efron's \\
percentile \\
bootstrap \\
\end{tabular}} & g1 & 0.043 & 0.691 & 0.997 & 1.000 & 1.000 & 1.000 & 1.000 & 1.000 & 1.000 & 1.000 & 1.000 & 1.000 & 1.000 & 1.000 & 1.000 & 1.000 \\
\hline & G1 & 0.044 & \begin{tabular}{|l|}
0.674 \\
\end{tabular} & 0.997 & 1.000 & 1.000 & 1.000 & 1.000 & 1.000 & 1.000 & 1.000 & 1.000 & 1.000 & 1.000 & 1.000 & 1.000 & 1.000 \\
\hline & $\overline{b 1}$ & 0.042 & 0.740 & 0.998 & 1.000 & 1.000 & 1.000 & 1.000 & 1.000 & 1.000 & 1.000 & 1.000 & 1.000 & 1.000 & 1.000 & 1.000 & 1.000 \\
\hline \multirow{3}{*}{$\begin{array}{c}\text { Hall's } \\
\text { Percentile } \\
\text { bootstrap }\end{array}$} & g1 & 0.047 & 0.673 & 0.997 & 1.000 & 1.000 & 1.000 & 1.000 & 1.000 & 1.000 & 1.000 & 1.000 & 1.000 & 1.000 & 1.000 & 1.000 & 1.000 \\
\hline & G1 & 0.048 & \begin{tabular}{|l|l}
0.809 \\
\end{tabular} & 0.999 & $\begin{array}{l}1.000 \\
\end{array}$ & 1.000 & 1.000 & 1.000 & 1.000 & 1.000 & 1.000 & 1.000 & 1.000 & 1.000 & 1.000 & 1.000 & 1.000 \\
\hline & b1 & 0.091 & 0.536 & 0.994 & 1.000 & 1.000 & 1.000 & 1.000 & 1.000 & 1.000 & 1.000 & 1.000 & 1.000 & 1.000 & 1.000 & 1.000 & 1.000 \\
\hline \multirow{3}{*}{$\begin{array}{c}\text { Bias } \\
\text { Corrected } \\
\text { percentile }\end{array}$} & g1 & 0.045 & 0.740 & 0.998 & 1.000 & 1.000 & 1.000 & 1.000 & 1.000 & 1.000 & 1.000 & 1.000 & 1.000 & 1.000 & 1.000 & 1.000 & 1.000 \\
\hline & $\mathrm{Gl}$ & 0.047 & \begin{tabular}{|l}
0.727 \\
\end{tabular} & 0.997 & 1.000 & 1.000 & 1.000 & 1.000 & 1.000 & 1.000 & 1.000 & 1.000 & 1.000 & 1.000 & 1.000 & 1.000 & 1.000 \\
\hline & b1 & 0.048 & 0.777 & 0.999 & 1.000 & 1.000 & 1.000 & 1.000 & 1.000 & 1.000 & 1.000 & 1.000 & 1.000 & 1.000 & 1.000 & 1.000 & 1.000 \\
\hline
\end{tabular}


Table A10: The abbreviation of test statistics in the figures

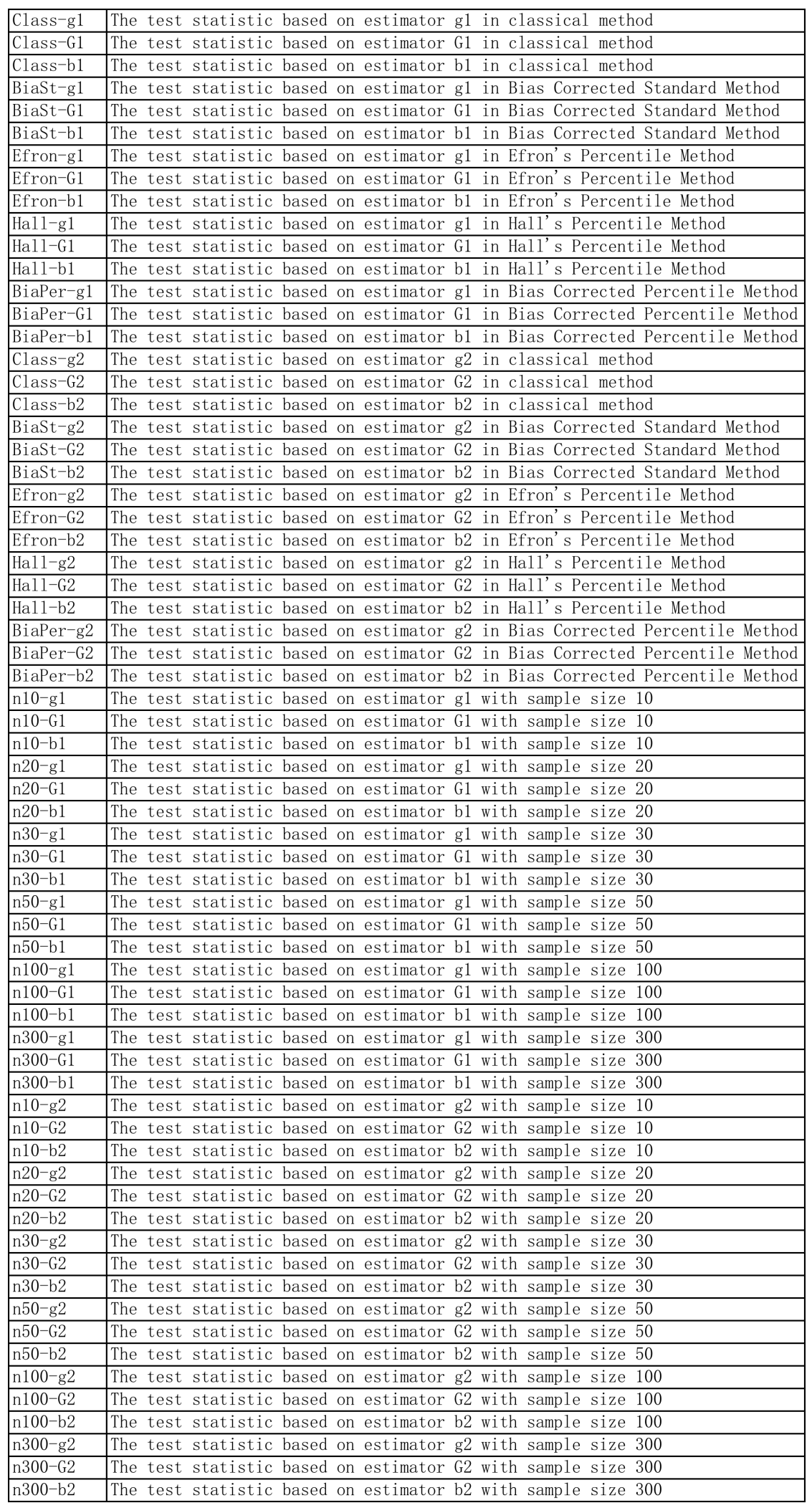

